\author{
UNIVERSIDADE DE SÃO PAULO - USP \\ ESCOLA DE ENGENHARIA DE SÃO CARLOS \\ DEPARTAMENTO DE ENGENHARIA ELÉTRICA E COMPUTAÇÃO \\ PROGRAMA DE PÓS-GRADUAÇÃO EM ENGENHARIA ELÉTRICA
}

Thais Reggina Kempner

Análise da Robustez e da Sensibilidade de Sistemas de

Distribuição para a Alocação Otimizada de Medidores

frente às Variações de Tensão de Curta Duração 

THAIS REGGINA KEMPNER

\section{Análise da Robustez e da Sensibilidade de Sistemas de Distribuição para a Alocação Otimizada de Medidores frente às Variações de Tensão de Curta Duração}

Tese de doutorado apresentada ao Programa de Engenharia Elétrica da Escola de Engenharia de São Carlos, da Universidade de São Paulo, como parte dos requisitos para obtenção do título de Doutor em Ciências.

Área de Concentração: Sistemas Elétricos de Potência

Orientador: Prof. Dr. Mário Oleskovicz

São Carlos

2016 
AUTORIZO A REPRODUÇÃO TOTAL OU PARCIAL DESTE TRABALHO, POR QUALQUER MEIO CONVENCIONAL OU ELETRÔNICO, PARA FINS DE ESTUDO E PESQUISA, DESDE QUE CITADA A FONTE. frente às Variações de Tensão de Curta Duração. / Thais Reggina Kempner; orientador Mário Oleskovicz. São Carlos, 2016.

Tese (Doutorado) - Programa de Pós-Graduação em Engenharia Elétrica e Área de Concentração em Sistemas Elétricos de Potência -- Escola de Engenharia de São Carlos da Universidade de São Paulo, 2016.

1. Sistemas de Distribuição. 2. Método das Posições de Falta. 3. Qualidade da Energia Elétrica. 4. Variações de Tensão de Curta Duração. 5. Alocação Ótima de Medidores de Qualidade da Energia. I. Título. 
Candidata: Engenheira THAIS REGGINA KEMPNER.

Título da tese: "Análise da robustez e da sensibilidade de sistemas de distribuição para a alocação otimizada de medidores frente ás variações de tensão de curta duração".

Data da defesa: 19/05/2016

Comissão Julgadora:

Prof. Dr. Mario Oleskovicz (Orientador)

(Escola de Engenharia de São Carlos/EESC)

Prof. Dr. José Carlos de Melo Vieira Junior

(Escola de Engenharia de São Carlos/EESC)

Prof. Dr. Arnulfo Barroso de Vasconcellos

(Universidade Federal do Mato Grosso/UFMT)

Prof. Titular Nelson Kagan

(Escola Politécnica/EP-USP)

Prof. Titular Geraldo Roberto Martins da Costa

(Escola de Engenharia de São Carlos/EESC)
Resultado:

APROVADA

APROVADA

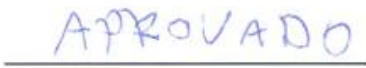

APROVADO

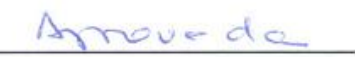

Coordenador do Programa de Pós-Graduação em Engenharia Elétrica:

Prof. Associado Luis Fernando Costa Alberto

Presidente da Comissão de Pós-Graduação:

Prof. Associado Paulo César Lima Segantine 



\section{Agradecimentos}

Ao final de mais uma etapa em minha vida, volto para casa com muitas incertezas, com o futuro ainda indefinido, mas muito satisfeita por ter tido esta experiência tão gratificante que me fez evoluir não somente como pesquisadora, mas também como pessoa.

Apesar das dificuldades e dos percalços vividos aqui em São Carlos, tive a oportunidade de conhecer pessoas incríveis, que marcaram minha vida e me ensinaram muito. Portanto, agradecer a todos não é uma tarefa fácil, pois seis anos se passaram e não quero cometer a injustiça de esquecer alguém que tenha me inspirado, me ajudado ou até mesmo compartilhado bons momentos, essenciais para superar a saudade da família.

Como são muitas pessoas que merecem o meu muito obrigada, sendo o espaço aqui destinado pequeno para expressar toda a minha gratidão, vou citar apenas as pessoas mais próximas que contribuíram com meu crescimento nessa trajetória.

Meu primeiro agradecimento é dedicado à minha família, em especial a minha mãe Marli e aos meus avós, Gema e Gabriel, que sempre torceram muito pelo meu sucesso, propiciando o alicerce necessário para que eu tivesse força o suficiente para não desistir. A vocês eu peço desculpas pela ausência, e agradeço a compreensão, as orações e o amor incondicional.

Agradeço também aos meus amigos da graduação, que compartilharam de momentos decisivos em minha vida e me proporcionaram muitas alegrias. Minha gratidão ao Marcus, ao Rafael, e em especial a Camila, que me incentivou e seguiu comigo nesta caminhada, estando sempre ao meu lado nos momentos que mais precisei.

Dentre tantos dedicados professores que tive a oportunidade de conhecer, agradeço ao Prof. Dr. Arnulfo Barroso de Vasconcelos, pelo estímulo à realização da pós-graduação e pelo incentivo às minhas primeiras publicações, ao Prof. Dr. José Carlos de Melo Vieira Júnior, pela paciência e prontidão em esclarecer eventuais dúvidas sempre que precisei, e especialmente, ao meu orientador Prof. Dr. Mário Oleskovicz, pela confiança, pela dedicação, pelos conselhos, pelas correções e sugestões relevantes feitas durante a orientação, mas, sobretudo pelo exemplo profissional. 
No auxílio à realização deste trabalho agradeço ao meu amigo Athila, pela pronta atuação, sempre disposto a ajudar, principalmente quando tive dificuldades com a programação computacional. Além disso, agradeço os conselhos, as risadas e os bons momentos compartilhados.

Aos meus colegas e amigos do Laboratório de Sistemas de Energia Elétrica (LSEE), minha sincera gratidão pelos momentos de descontração, pela companhia nos cafezinhos e na hora do almoço, e, principalmente, pelo auxílio prestado pelo Monaro, Eduardo, Rui, Ricardo (Vences), Douglas, Fernando e Fabrício.

Sou eternamente grata também aos amigos que fiz aqui em São Carlos, os quais sempre recordarei com muito carinho, pois foram fundamentais para superar a saudade da família. Espero que apesar da distância possamos sempre manter contato, pois vocês foram essenciais não somente nesta fase, mas também para o meu crescimento pessoal. Já sinto saudades de algumas pessoas que já não estão mais em São Carlos, como da minha querida amiga Lu, da Maria Angélica, da Karem, da Aline, da Ana Cecília, do Fabão, do Festa, do Remy, do Julian, do Vinicius, do Rodolpho, do Renan, do Breno, do Paulo (PL), do Igor, do Rafael (perninha), do Klaus, do Lucas e do André. Sei também que sentirei muitas saudades da Raissa, da Thayz, da Joelma, do Rafa, do Spatti, do Samuel, do Marcelo, do Wellington, do Elian, do Fabinho e do Ailton.

E é claro que eu vou sentir uma imensa saudade da Tati, minha amiga irmã que sempre me incentivou e foi essencial para a minha permanência e término do doutorado. Muito obrigada por tudo minha amiga e companheira de todas as horas. Faltam palavras para expressar toda a gratidão e admiração que tenho por você.

Agradeço ainda a Fundação de Amparo à Pesquisa do Estado de São Paulo (FAPESP 2011/22151-5) pelo suporte financeiro concedido para a realização da pesquisa, e à Eletrobrás Distribuição Piauí (PD-0042/2014-ANEEL) pelo suporte complementar disponibilizado em um período específico do trabalho.

Por fim, meus agradecimentos ao LSEE, da Escola de Engenharia de São Carlos (EESC-USP) pela infraestrutura proporcionada, assim como aos funcionários do Departamento de Engenharia Elétrica e de Computação, em especial à Verinha, Jussara, Marisa e Daniel pela atenção e disponibilidade.

Termino esta etapa com a sensação de dever cumprido, e agradeço a todos vocês, que de forma direta ou indireta contribuíram para tornar este objetivo realidade.

Muito obrigada! 
“A tarefa não é tanto ver aquilo que ninguém viu, mas pensar o que ninguém ainda pensou sobre aquilo que todo mundo vê." (Arthur Schopenhauer) 



\section{Resumo}

\section{KEMPNER, T. R. Análise da Robustez e da Sensibilidade de Sistemas de Distribuição}

para a Alocação Otimizada de Medidores frente às Variações de Tensão de Curta Duração. 217 p. Tese de doutorado - Escola de Engenharia de São Carlos, Universidade de São Paulo, São Carlos, 2016.

Como as Variações de Tensão de Curta Duração (VTCDs) estão entre as perturbações mais difíceis de serem monitoradas, uma vez que são ocasionadas por fatores aleatórios e imprevisíveis, a monitoração do Sistema de Distribuição (SD) representa uma providência essencial para a obtenção de informações representativas para a regulamentação de novos indicadores relativos a esses distúrbios. Neste cenário, este trabalho busca garantir a completa observabilidade das VTCDs em SD, quando da incidência de qualquer tipo de curto-circuito, através da alocação ótima de medidores. Para a determinação da magnitude da tensão em cada nó do SD é utilizado o método das posições de falta, denotando assim, a influência e a propagação das VTCDs sobre a rede como um todo. Na sequência, é determinada uma matriz binária resultante que observa os afundamentos de tensão de forma simultânea para todos os tipos de faltas. Posteriormente, é proposta a redução desta matriz para diminuir o esforço computacional em SDs de grande porte. Ainda, é analisada a vulnerabilidade de cada nó do SD para estabelecer a sua posterior ponderação no processo de otimização. Os resultados revelam que a metodologia de alocação apresentada torna o processo de obtenção da solução ótima ágil e direto, pois menos execuções computacionais são necessárias para obter diferentes soluções ótimas e garantir a monitoração dos afundamentos de tensão para todos os tipos de curtos-circuitos. Além disso, pela metodologia, tem-se também a prioridade de instalação dos medidores conforme a maior observabilidade dos afundamentos de tensão, possibilitando a escolha do melhor arranjo de medidores que atenda aos limites orçamentários das distribuidoras de energia.

Palavras-chave: Sistemas de Distribuição, Método das Posições de Falta, Qualidade da Energia Elétrica, Variações de Tensão de Curta Duração, Alocação Ótima de Medidores de Qualidade da Energia. 



\begin{abstract}
KEMPNER, T. R. Analysis of the robustness and sensitivity of distribution systems for optimal allocation of monitors in face of Short Duration Voltage Variations. 217 p. Ph.D. Thesis - São Carlos School of Engineering, University of São Paulo, São Carlos, 2016.

Short Duration Voltage Variations (SDVVs) are among the most difficult disturbances to be monitored, since they are caused by random and unpredictable factors. Hence, the Distribution System (DS) monitoring is an essential step for obtaining representative information for the regulation of new power quality indices for these disturbances. In this scenario, this work aims to ensure the entire observability of SDVVs, considering any short circuit occurrence in the DS, based on algorithm to achieve the monitors' optimal allocation. In order to determine the voltage magnitude at each node, the fault positions method is used, showing the influence and propagation of SDVVs on the DS. Subsequently, a resulting binary matrix is determined. This matrix observes the voltage sags, simultaneously, for all fault types. Then, the downsizing of this matrix is proposed in order to reduce the computational effort in large DSs. Furthermore, the vulnerability of each DS node is analyzed to establish the relative weighting in the optimization process. The results show a faster and more direct allocation methodology to obtain the optimal solution, because fewer computational executions are needed for different optimal solutions and to ensure the voltage sags monitoring for all short circuits types. Moreover, the power quality monitor installation priority is performed according to the higher observability of the voltage sags, making it possible to choose the best arrangement of monitors that meets the budget constraints of the power utilities.
\end{abstract}

Keywords: Distribution Systems, Fault Position Method, Power Quality, Short Duration Voltage Variation, Optimal Allocation of Power Quality Monitors. 



\section{Lista de Ilustrações}

Figura 1 - Consumo nacional anual de energia elétrica por classe.

Figura 2 - Custo anual estimado resultante de interrupções no fornecimento da energia com

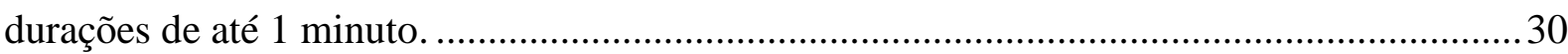

Figura 3 - Fluxograma da metodologia desenvolvida........................................................ 35

Figura 4 - Ilustração de um afundamento de tensão na ocorrência de um curto-circuito FT. .43

Figura 5 - Ilustração de uma elevação de tensão na ocorrência de um curto-circuito FFT. .... 44

Figura 6 - Ilustração de uma interrupção de tensão na ocorrência de um curto-circuito FT. .. 45

Figura 7 - Diagrama unifilar simplificado da área afetada. ................................................ 49

Figura 8 - Diagrama unifilar simplificado da área exposta................................................50

Figura 9 - Curva de sensibilidade para computadores (CBEMA), .......................................51

Figura 10 - Curva de sensibilidade para equipamentos de tecnologia da informação (ITIC). 52

Figura 11 - Curva de suportabilidade para equipamentos semicondutores. ............................53

Figura 12 - Metodologia para o cálculo de índices de afundamentos de tensão......................56

Figura 13 - Histograma tridimensional dos afundamentos de tensão. ................................... 62

Figura 14 - Gráfico de coordenação com o registro do número de afundamentos por ano.....63

Figura 15 - Severidade do afundamento de tensão para a curva SEMI. .................................65

Figura 16 - Curto-circuito FFF: Formas de onda (a), representação da falta (b).................... 78

Figura 17 - Equivalente de Thévenin para o curto-circuito trifásico...................................... 79

Figura 18 - Curto-circuito FT: Formas de onda (a), representação da falta (b)...................... 81

Figura 19 - Modelo equivalente em série do curto-circuito monofásico fase $a$...................... 81

Figura 20 - Curto-circuito FF: Formas de onda (a), representação da falta (b)...................... 83

Figura 21 - Modelo em paralelo do curto-circuito bifásico entre as fases $b$ e $c$.................... 83

Figura 22 - Curto-circuito FFT: Formas de onda (a), representação da falta (b).................... 85

Figura 23 - Circuito equivalente para um curto-circuito bifásico terra entre as fases $b$ e $c \ldots . .85$

Figura 24 - Diagrama unifilar de um circuito hipotético de três nós...................................... 87

Figura 25 - Espaçamento entre condutores (500).......................................................... 88

Figura 26 - Fluxograma da metodologia para a alocação ótima de medidores. ......................92

Figura 27 - Exemplo da MTDF para falta trifásica no SD de 13 nós do IEEE (a), e de obtenção da $\mathrm{MO}$ para $\tau \leq 0,5$ p.u. (b). ................................................................................ 93

Figura 28 - Ilustração gráfica da MTDF (a), e da MO (b).................................................. 94 
Figura 29 - Visualização gráfica da $\mathrm{MO}_{\text {Res, }}$, para $\tau \leq 0,6$ p.u.. ............................................ 96

Figura 30 - Visualização gráfica da $\mathrm{MO}_{\text {Res }}$ (a), e a $\mathrm{MO}_{\text {Red }}$ (b) para $\tau \leq 0,2$ p.u...................... 97

Figura 31 - Vetor igualdade transposto para $\tau \leq 0,2$ p.u.................................................... 98

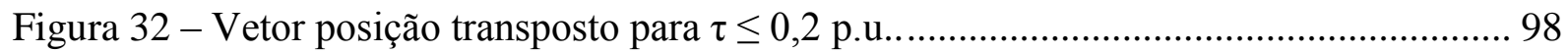

Figura 33 - Vulnerabilidade aos afundamentos de tensão para $\tau \leq 0,2$ p.u.......................... 99

Figura 34 - Prioridade de instalação dos medidores para $\tau \leq 0,2$ p.u................................... 99

Figura 35 - Exemplo do vetor de monitoração transposto. …............................................. 101

Figura 36 - Exemplo da obtenção do vetor de redundância transposto................................. 102

Figura 37 - Exemplo de como contabilizar as posições do vetor de redundância.................. 103

Figura 38 - Árvore de ramificação $($ branch). .................................................................. 106

Figura 39 - Diagrama unifilar do SD teste de 13 nós do IEEE. ........................................... 112

Figura 40 - Diagrama unifilar do SD teste de 34 nós do IEEE. ........................................... 114

Figura 41 - Diagrama unifilar do SD teste de 37 nós do IEEE. ........................................... 116

Figura 42 - Diagrama unifilar do SD teste de 123 nós do IEEE. ........................................ 118

Figura 43 - MTDF na ocorrência de faltas FFF no SD IEEE 34-nós................................... 121

Figura 44 - MTDF (fase $A$ ) durante faltas FT aplicadas no SD IEEE 34-nós....................... 122

Figura 45 - MTDF (fase $B$ ) durante faltas FT aplicadas no SD IEEE 34-nós....................... 123

Figura 46 - MTDF (fase $C$ ) durante faltas FT aplicadas no SD IEEE 34-nós. ..................... 123

Figura 47 - MTDF (fase $B$ ) durante faltas FF aplicadas no SD IEEE 34-nós....................... 124

Figura 48 - MTDF (fase $C$ ) durante faltas FF aplicadas no SD IEEE 34-nós....................... 125

Figura 49 - MTDF (fase $A$ ) durante faltas FFT aplicadas no SD IEEE 34-nós. .................... 126

Figura 50 - MTDF (fase $B$ ) durante faltas FFT aplicadas no SD IEEE 34-nós. ................... 126

Figura 51 - MTDF (fase $C$ ) durante faltas FFT aplicadas no SD IEEE 34-nós. ................... 127

Figura 52 - Área afetada no SD de 34 nós considerando uma falta FFF no nó 19.............. 128

Figura 53 - Número de nós afetados pelo afundamento de tensão no SD de 34 nós considerando diferentes tipos de falta nos nós de 1 a 17 a partir de um limiar de 0,9 p.u..... 129 Figura 54 - Número de nós afetados pelos afundamentos de tensão no SD de 34 nós considerando diferentes tipos de falta nos nós de 18 a 33 a partir de um limiar de 0,9 p.u... 130 Figura 55 - Número de nós afetados pelos afundamentos de tensão no SD de 34 nós considerando diferentes tipos de falta nos nós de 1 a 17 a partir de um limiar de 0,3 p.u..... 130 Figura 56 - Número de nós afetados pelos afundamentos de tensão no SD de 34 nós considerando diferentes tipos de falta nos nós de 18 a 33 a partir de um limiar de 0,3 p.u... 131 Figura 57 - Nós afetados pelos afundamentos de tensão no SD de 34 nós considerando diferentes tipos de falta nos nós de 1 a 17.

Figura 58 - Nós afetados pelos afundamentos de tensão no SD de 34 nós considerando diferentes tipos de falta nos nós de 18 a 33. 
Figura 59 - Número médio de nós afetados pelo afundamento de tensão considerando qualquer tipo de falta que o SD de 34 nós venha a ser submetido.

Figura 60 - Número médio de nós afetados pelo afundamento de tensão considerando qualquer tipo de falta que o SD de 13 nós venha a ser submetido.

Figura 61 - Número médio de nós afetados pelo afundamento de tensão considerando qualquer tipo de falta que o SD de 37 nós venha a ser submetido. 134

Figura 62 - Número médio de nós afetados pelo afundamento de tensão considerando qualquer tipo de falta nos nós de 1 a 59 que o SD de 123 nós venha a ser submetido 134 Figura 63 - Número médio de nós afetados pelo afundamento de tensão considerando qualquer tipo de falta nos nós de 60 a 118 que o SD de 123 nós venha a ser submetido........ 135 Figura 64 - Área de vulnerabilidade para o nó 22 considerando todas as situações de falta FFF aplicadas no SD de 34 nós

Figura 65 - Número de nós expostos aos afundamentos de tensão considerando qualquer tipo de falta que o SD de 13 nós venha a ser submetido.

Figura 66 - Número de nós expostos aos afundamentos de tensão considerando qualquer tipo de falta que o SD de 34 nós venha a ser submetido.

Figura 67 - Número de nós expostos aos afundamentos de tensão considerando qualquer tipo de falta que o SD de 37 nós venha a ser submetido.

Figura 68 - Número de nós expostos aos afundamentos de tensão considerando qualquer tipo de falta nos nós de 1 a 59 que o SD de 123 nós venha a ser submetido. 138 Figura 69 - Número de nós expostos aos afundamentos de tensão considerando qualquer tipo de falta nos nós de 60 a 118 que o SD de 123 nós venha a ser submetido.

Figura 70 - Área de vulnerabilidade do nó 1 considerando todas as situações de faltas FFF aplicadas no SD de 123 nós

Figura 71 - Vulnerabilidade aos afundamentos de tensão do SD de 13 nós para os limiares $\leq$ 0,9 p.u.; $\leq 0,5$ p.u.; $\leq 0,3$ p.u.; e $\leq 0,1$ p.u..

Figura 72 - Vetor prioridade transposto para o SD de 34 nós.

Figura 73 - Visualização gráfica da $\mathrm{MO}_{\text {Red }}$ gerada para o SD de 37 nós quando fixado um limiar $\leq 0,5$ p.u.. 148

Figura 74 - Redundância para cada nó do SD de 37 nós para a solução $\leq 0,5$ p.u.

Figura 75 - Comparação das MTDFs geradas pelo MPF e ATP durante a ocorrência de faltas FFF no SD de 34 nós.

Figura 76 - Comparação das MTDFs geradas pelo MPF e ATP durante a ocorrência de faltas FT no SD de 34 nós.

Figura 77 - Comparação das MTDFs geradas pelo MPF e ATP durante a ocorrência de faltas FF no SD de 34 nós. 
Figura 78 - Comparação das MTDFs geradas pelo MPF e ATP durante a ocorrência de faltas

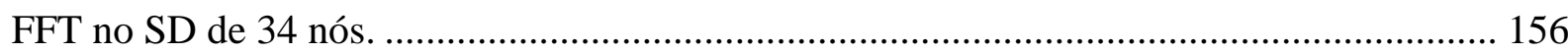

Figura 79 - Máximo erro absoluto registrado para cada posição de falta no SD de 34 nós. . 156 Figura 80 - Comparação entre as tensões remanescentes obtidas pelo MPF e ATP no SD de 34 nós durante a ocorrência de um curto-circuito FT no nó 1. 157

Figura 81 - Percentual do erro absoluto registrado em relação ao número de casos analisados no SD de 34 nós. 157

Figura 82 - Perfil da tensão na fase $A$ do SD de 34 nós, para cada cenário de carga ............ 162

Figura 83 - Precipitação acumulada (1961 a 1990)........................................................... 184

Figura 84 - MTDF durante faltas FFF aplicadas no SD IEEE 13-nós. ................................. 199

Figura 85 - MTDF (fase $A$ ) durante faltas FT aplicadas no IEEE 13-nós............................. 200

Figura 86 - MTDF (fase $B$ ) durante faltas FT aplicadas no SD IEEE 13-nós....................... 200

Figura 87 - MTDF (fase $C$ ) durante faltas FT aplicadas no SD IEEE 13-nós. ...................... 201

Figura 88 - MTDF (fase $B$ ) durante faltas FF aplicadas no SD IEEE 13-nós....................... 201

Figura 89 - MTDF (fase $C$ ) durante faltas FF aplicadas no SD IEEE 13-nós....................... 202

Figura 90 - MTDF (fase $A$ ) durante faltas FFT aplicadas no SD IEEE 13-nós. ................... 202

Figura 91 - MTDF (fase $B$ ) durante faltas FFT aplicadas no SD IEEE 13-nós. ................... 203

Figura 92 - MTDF (fase $C$ ) durante faltas FFT aplicadas no SD IEEE 13-nós. ................... 203

Figura 93 - MTDF durante faltas FFF aplicadas no SD IEEE 37-nós. ................................. 204

Figura 94 - MTDF (fase $A$ ) durante faltas FT aplicadas no SD IEEE 37-nós...................... 204

Figura 95 - MTDF (fase $B$ ) durante faltas FT aplicadas no SD IEEE 37-nós....................... 205

Figura 96 - MTDF (fase $C$ ) durante faltas FT aplicadas no SD IEEE 37-nós. ..................... 205

Figura 97 - MTDF (fase $B$ ) durante faltas FF aplicadas no SD IEEE 37-nós....................... 206

Figura 98 - MTDF (fase $C$ ) durante faltas FF aplicadas no SD IEEE 37-nós....................... 206

Figura 99 - MTDF (fase $A$ ) durante faltas FFT aplicadas no SD IEEE 37-nós. .................... 207

Figura 100 - MTDF (fase $B$ ) durante faltas FFT aplicadas no SD IEEE 37-nós. .................. 207

Figura 101 - MTDF (fase $C$ ) durante faltas FFT aplicadas no SD IEEE 37-nós. ................. 208

Figura 102 - MTDF durante faltas FFF aplicadas no SD IEEE 123 nós.............................. 209

Figura 103 - MTDF (fase $A$ ) durante faltas FT aplicadas no SD IEEE 123-nós................... 210

Figura 104 - MTDF (fase $B$ ) durante faltas FT aplicadas no SD IEEE 123-nós................... 211

Figura 105 - MTDF (fase $C$ ) durante faltas FT aplicadas no SD IEEE 123-nós. .................. 212

Figura 106 - MTDF (fase $B$ ) durante faltas FF aplicadas no SD IEEE 123-nós................... 213

Figura 107 - MTDF (fase $C$ ) durante faltas FF aplicadas no SD IEEE 123-nós................... 214

Figura 108 - MTDF (fase $A$ ) durante faltas FFT aplicadas no SD IEEE 123-nós. ............... 215

Figura 109 - MTDF (fase $B$ ) durante faltas FFT aplicadas no SD IEEE 123-nós. ............... 216

Figura 110 - MTDF (fase $C$ ) durante faltas FFT aplicadas no SD IEEE 123-nós ................. 217 


\section{Lista de Tabelas}

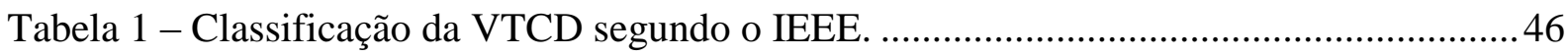

Tabela 2 - Classificação da VTCD segundo a norma europeia. .............................................. 47

Tabela 3 - Classificação da VTCD segundo o módulo oito do PRODIST...............................47

Tabela 4 - Tolerância para a tensão dos principais equipamentos na indústria.......................53

Tabela 5 - Gráfico de sensibilidade segundo a norma Sul-Africana. ......................................58

Tabela 6 - Números de afundamentos por ano (para 95\% dos pontos de medições). .............59

Tabela 7 - Números de afundamentos por ano (para 50\% dos pontos de medições). .............59

Tabela 8 - Densidade dos afundamentos de tensão, UNIPEDE. ...........................................59

Tabela 9 - Densidade dos afundamentos de tensão, norma IEC 61000-2-8 ........................... 60

Tabela 10 - Densidade dos afundamentos de tensão, norma IEEE STD 1564.........................60

Tabela 11 - Número de afundamentos de tensão registrados durante um ano..........................61

Tabela 12 - Distribuição acumulada dos afundamentos de tensão. ........................................62 62

Tabela 13 - Algoritmo para o cálculo da severidade do afundamento de tensão (SEMI).......65

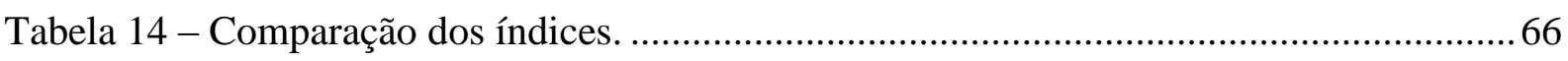

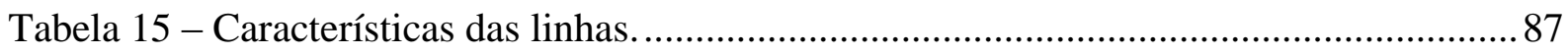

Tabela 16 - Dados dos transformadores e espaçamento entre os condutores.......................... 88

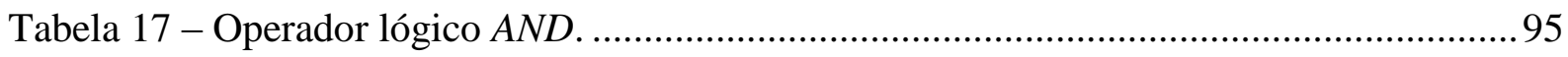

Tabela 18 - Dados dos alimentadores do SD IEEE 13-nós. ................................................ 113

Tabela 19 - Dados dos transformadores do SD IEEE 13-nós.............................................. 113

Tabela 20 - Dados dos transformadores do SD IEEE 34-nós............................................. 115

Tabela 21 - Dados dos alimentadores do SD IEEE 34-nós. ................................................... 115

Tabela 22 - Dados dos alimentadores do SD IEEE 37-nós. ................................................ 117

Tabela 23 - Dados dos transformadores do SD IEEE 37-nós................................................ 117

Tabela 24 - Dados dos transformadores do SD IEEE 123-nós............................................. 119

Tabela 25 - Prioridade de instalação dos medidores no SD de 13 nós para os limiares $\leq 0,9$ p.u.; $\leq 0,5$ p.u.; $\leq 0,3$ p.u.; e $\leq 0,1$ p.u....................................................................... 143

Tabela 26 - Resultado da alocação ótima no SD de 13 nós conforme a prioridade de instalação dos medidores. 
Tabela 27 - Número de medidores necessários para monitorar os diferentes tipos de falta para cada limiar analisado no SD de 34 nós.

Tabela 28 - Local de instalação e número de medidores necessários para monitorar qualquer tipo de falta no SD de 34 nós, conforme o limiar desejado.

Tabela 29 - Resultado da alocação ótima no SD de 34 nós, para monitorar qualquer tipo de falta, conforme a prioridade de instalação dos medidores.

Tabela 30 - Resultado da alocação ótima no SD de 37 nós conforme a prioridade de instalação dos medidores.

Tabela 31 - Outras possíveis soluções para alocação de medidores no SD de 37 nós para os limiares de 0,$9 ; 0,8 ; 0,7 ; 0,6$ e 0,4 p.u.

Tabela 32 - Número de possíveis soluções, dimensão da $\mathrm{MO}_{\mathrm{Red}}$ e número de iterações necessárias para obter a solução de alocação para cada limiar no SD de 37 nós. 148

Tabela 33 - Resultado da alocação ótima no SD de 123 nós conforme a prioridade de instalação dos medidores.

Tabela 34 - Número de possíveis soluções e o número de iterações necessárias para obter a solução ótima utilizando a $\mathrm{MO}_{\mathrm{Res}}$ e a $\mathrm{MO}_{\text {Red. }}$.

Tabela 35 - Comparação dos resultados obtidos para cada MO e pela $\mathrm{MO}_{\text {Red }}$ quando analisado o limiar $\leq 0,7$ p.u. 151

Tabela 36 - Tensões de pré-falta no SD de 34 nós, tensão na subestação é igual a 1 p.u..... 158 Tabela 37 - Resultados da alocação de medidores necessários para observar a ocorrência de faltas FT no SD de 34 nós, considerando tensões de pré-falta $(0,95 ; 1$ e 1,05 p.u.).

Tabela 38 - Outras soluções possíveis para a instalação dos medidores conforme a resistência de falta.

Tabela 39 - Soluções para monitorar faltas FT no SD de 34 nós, considerando diferentes perfis de carregamento. 162

Tabela 40 - Sugestão de metodologia para a estratificação dos parâmetros de amplitude e duração para contabilização dos eventos de VTCDs. 179

Tabela 41 - Proposta para caracterização das VTCDs. 180

Tabela 42 - Número máximo de ocorrências de VTCDs. 182

Tabela 43 - Fator de ponderação para o cálculo do FI. 182

Tabela 44 - Detalhamento das VTCDs registradas no período de monitoração.

Tabela 45 - Dados dos alimentadores do SD IEEE 123-nós. 


\section{Lista de Siglas}

ABRACE Associação Brasileira de Grandes Consumidores Industriais de Energia e de Consumidores Livres

ABRADEE Associação Brasileira de Distribuidores de Energia Elétrica

ANAFAS Análise de Falhas Simultâneas

ANEEL Agência Nacional de Energia Elétrica

ASEI Average Sag Energy Index

ATP Alternative Transients Program

BB Branch and Bound

CBEMA Computer Business Equipment Manufacturer Association

CEEE-D Companhia Estadual de Distribuição de Energia Elétrica

CEMIG Companhia Energética de Minas Gerais

CENELEC European Committee for Electrotechnical Standardization

CN Concentric Neutral

EPE Empresa de Pesquisa Energética

FI Fator de Impacto

FAU Fundação de Apoio Universitário

FF Curto-circuito bifásico (Fase-Fase)

FFF Curto-circuito trifásico (Fase-Fase-Fase)

FFT Curto-circuito bifásico-terra (Fase-Fase-Terra)

FT Curto-circuito monofásico (Fase-Terra)

IEC International Electrotechnical Commission

IEEE Institute of Electrical and Electronics Engineers

INMET Instituto Nacional de Meteorologia 
ITIC Information Technology Industry Council

MDC Método da Distância Crítica

MO Matriz de Observabilidade binária

MO $_{\text {Res }} \quad$ Matriz de Observabilidade binária Resultante

MO $_{\text {Red }}$ Matriz de Observabilidade binária Reduzida

MPF Método das Posições de Falta

MTDF Matriz de Tensão Durante a Falta

ONS Operador Nacional do Sistema Elétrico

P\&D Pesquisa e Desenvolvimento

p.u. Por Unidade

PLI Programação Linear Inteira

PRODIST Procedimentos de Distribuição de Energia Elétrica no Sistema Elétrico

Nacional

QEE Qualidade da Energia Elétrica

RMS Root Mean Square (valor eficaz)

SARFI System Average RMS variation Frequency Index

SAVDA System Average Voltage Dip Amplitude

SBQEE $\quad$ Sociedade Brasileira de Qualidade da Energia Elétrica

SD Sistema de Distribuição

SDAT Sistema de Distribuição de Alta Tensão

SDMT Sistema de Distribuição de Média Tensão

SEMI Specification for Semiconductor Processing Equipment Voltage Sag

Immunity

SEI Sag Energy Index

SEP Sistema Elétrico de Potência

UFMG Universidade Federal de Minas Gerais

VTCD Variação de Tensão de Curta Duração 


\section{Sumário}

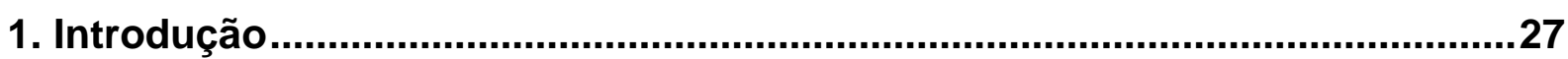

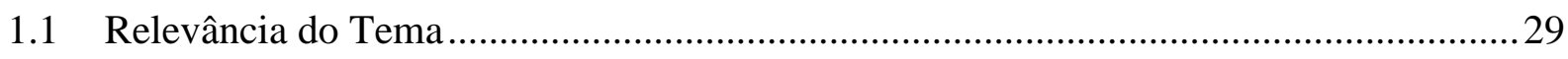

1.2 Objetivos e Contribuições da Pesquisa ……………………………………………..........

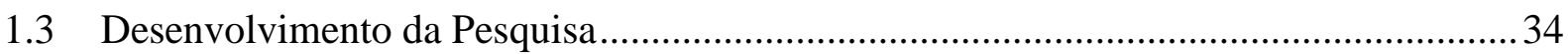

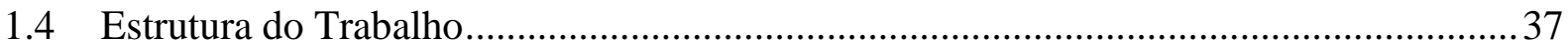

2. VTCDs: Conceitos, definições, causas e efeitos ...............................................39

2.1 Revisão Bibliográfica.................................................................................................... 39

2.2 Referencial Teórico para as VTCDs .......................................................................4

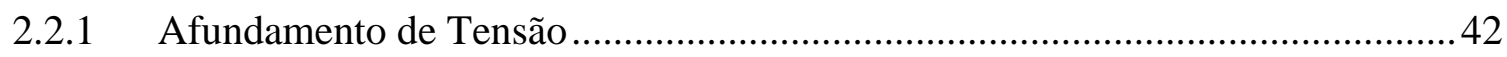

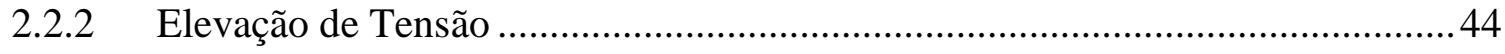

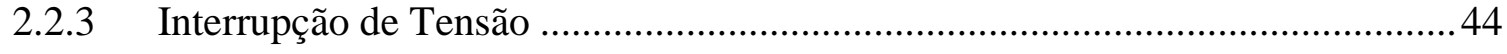

2.2.4 Normas e Regulamentações Aplicadas às VTCDs................................................4

2.3 Áreas de propagação das VTCDs ................................................................................4

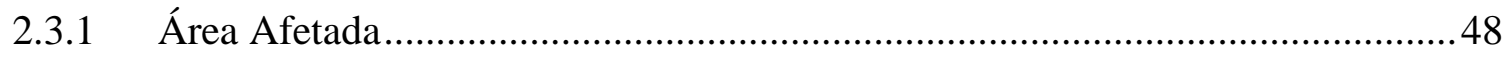

2.3.2 Área Exposta ou de Vulnerabilidade ……………………………………........ 49

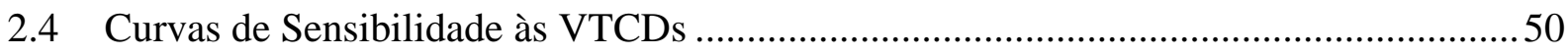

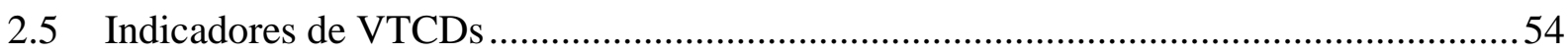

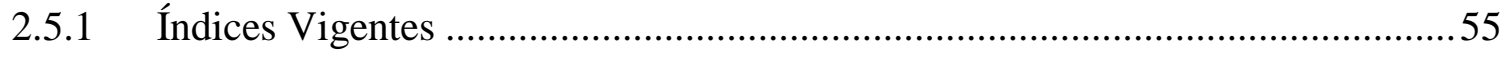

3. Metodologia de Cálculo para Estimação das VTCDs ......................................67

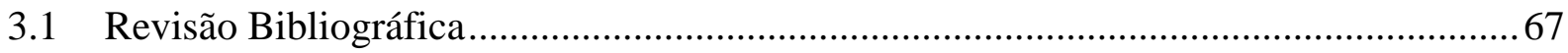

3.2 Determinação da Matriz Impedância de Barra..................................................................... 71

3.2.1 Adição de uma Impedância de Linha da Barra de Referência para uma Nova

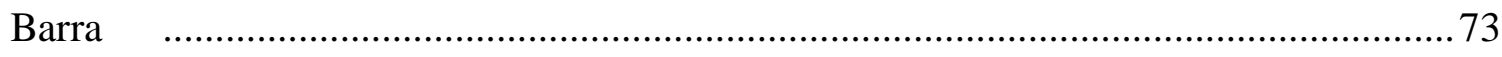


3.2.2 Adição de uma Impedância de Linha de uma Barra Existente para uma Nova

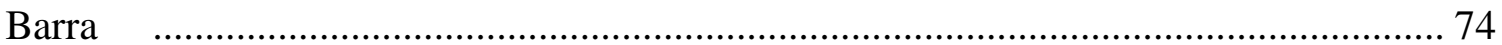

3.2.3 Adição de uma Impedância entre Duas Barras Existentes................................. 75

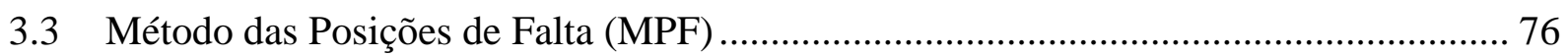

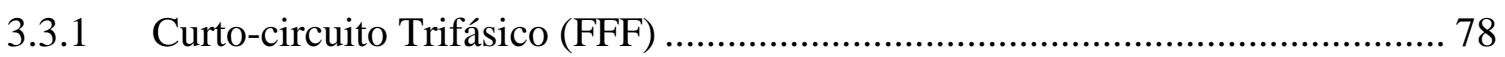

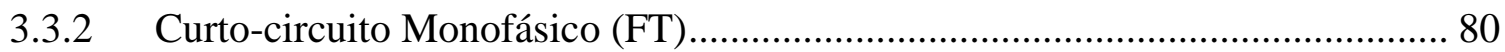

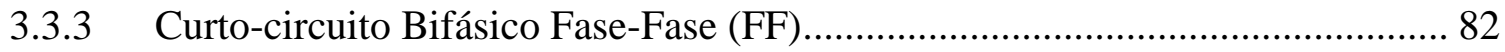

3.3.4 Curto-circuito Bifásico Fase-Fase-Terra (FFT) ............................................... 84

3.3.5 Exemplo de Aplicação da Metodologia em um SD Hipotético com 3 nós........ 87

\section{Alocação Ótima de Medidores de QEE: Aspectos Conceituais e Práticos ... 91}

4.1 Formulação Matemática do Problema ............................................................................ 91

4.1.1 Matriz de Observabilidade Binária (MO) …..................................................... 93

4.1.2 Intersecção das Matrizes de Observabilidade Binária ...................................... 95

4.1.3 Redução da Matriz de Observabilidade Resultante ......................................... 96

4.1.4 Determinação do Vetor Prioridade …................................................................. 98

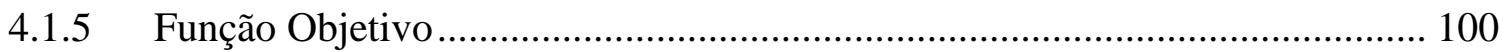

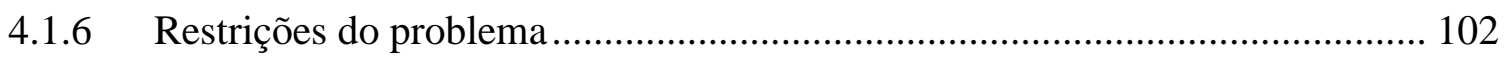

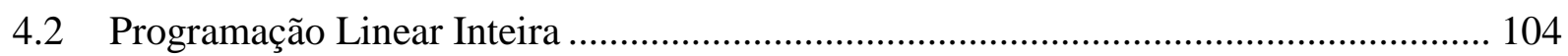

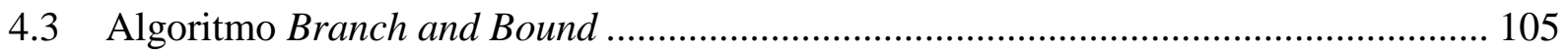

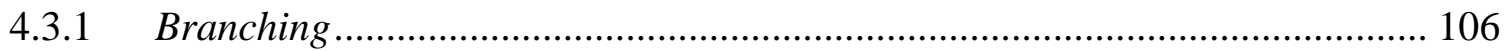

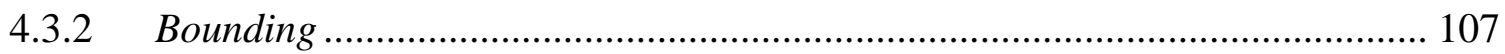

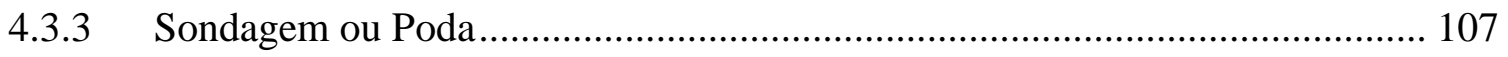

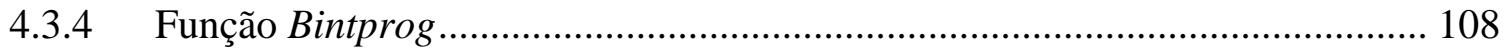

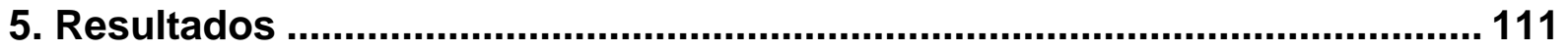

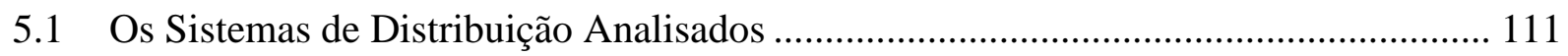

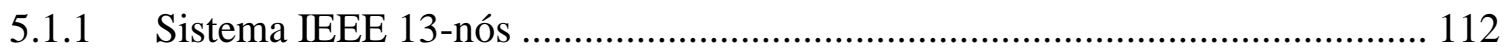

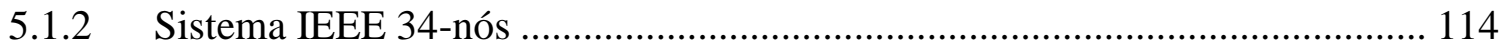

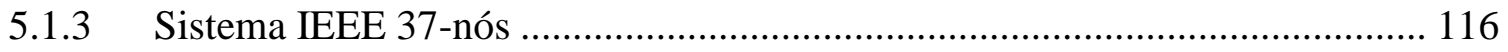

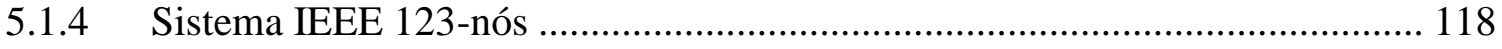

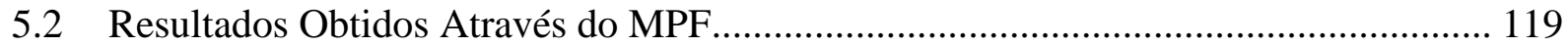

5.2.1 MTDF para Faltas Trifásicas (FFF) …..................................................... 120 


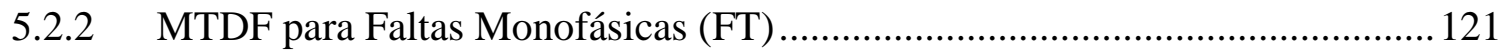

5.2.3 MTDF para Faltas Bifásicas Fase-Fase (FF) ............................................... 124

5.2.4 MTDF para Faltas Bifásicas Fase-Fase-Terra (FFT) .................................... 125

5.3 Análise das Áreas de Propagação dos Afundamentos de Tensão ................................ 127

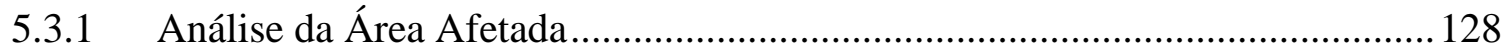

5.3.2 Análise da Área Exposta ou de Vulnerabilidade ............................................ 135

5.4 Alocação Ótima de Medidores de QEE ..................................................................... 140

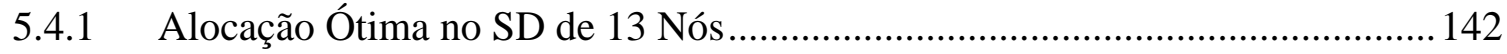

5.4.2 Alocação Ótima no SD de 34 Nós................................................................ 144

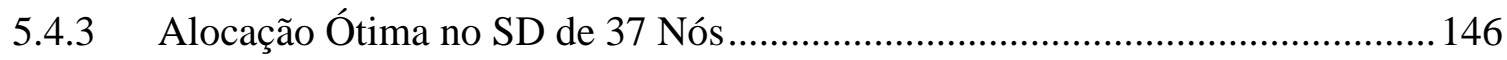

5.4.4 Alocação Ótima no SD de 123 Nós.................................................................. 149

5.5 Testes e Validações da Metodologia Proposta via o Software ATP ............................. 152

5.5.1 Comparação dos Resultados Obtidos pelo MPF no SD de 34 Nós ................... 153

5.5.2 Influência da Tensão de Pré-falta na Alocação Ótima de Medidores ............... 158

5.5.3 Influência da Resistência de Falta na Alocação Ótima de Medidores ..............159

5.5.4 Influência dos Perfis de Carregamento na Alocação Ótima de Medidores ....... 161

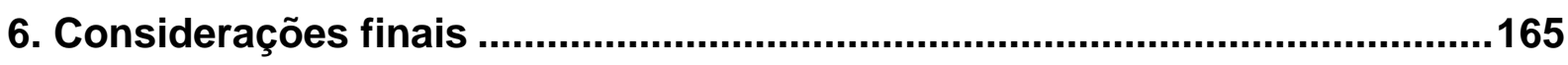

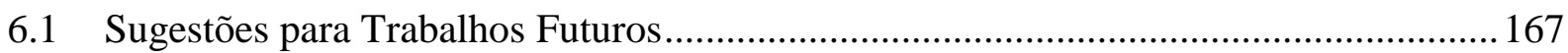

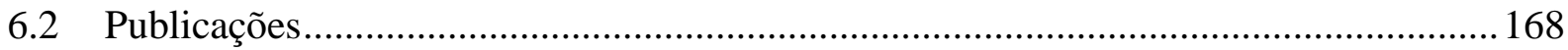

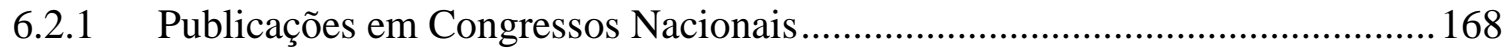

6.2.2 Publicações em Congressos Internacionais ..................................................... 168

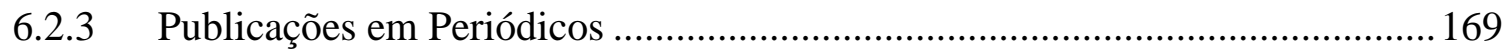

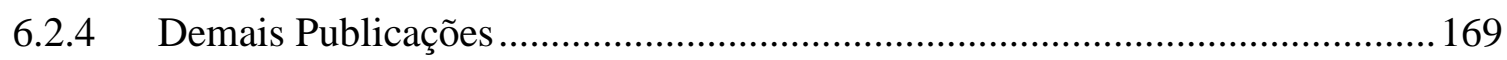

Referências Bibliográficas ..........................................................................171

Apêndice A - Consulta Pública ANEEL № 018/2014 ....................................177

Definição de Indicadores e de Limites para as VTCDs ................................................. 178

Procedimentos para o Acompanhamento das VTCDs ................................................. 185

Contribuição à Consulta Pública n ${ }^{\circ} 18 / 2014$............................................................... 188

Apêndice B - Dados dos Alimentadores no SD de 123-nós.............................197

Apêndice C - Matrizes de Tensões Durante a Falta........................................199 



\section{Capítulo 1}

\section{Introdução}

A crescente demanda pelo fornecimento de energia elétrica e a sofisticação tecnológica, principalmente devido ao desenvolvimento industrial, trazem um grande desafio às distribuidoras em fornecer qualidade no suprimento da energia elétrica aos consumidores de forma sustentável e confiável.

O elevado interesse pela avaliação da Qualidade da Energia Elétrica (QEE), utilizado para retratar, através de indicadores qualitativos e quantitativos, a continuidade do suprimento e a conformidade das formas de onda de tensão e corrente trifásicas, decorre do contínuo avanço tecnológico que alterou o perfil das cargas elétricas, com a inserção de componentes eletrônicos, que são sensíveis às variações bruscas de tensão e de corrente, deixando de operar adequadamente.

Face aos prejuízos financeiros decorrentes da falha ou má operação dos equipamentos eletroeletrônicos, é crescente a exigência dos consumidores pela melhoria da qualidade dos serviços prestados e relacionados à energia elétrica, o que torna necessária uma pronta atuação e constante acompanhamento dos órgãos reguladores.

Para atender às expectativas dos consumidores, prover informações aprimoradas, e aumentar a confiabilidade dos Sistemas Elétricos de Potência (SEPs) como um todo, surge um novo termo proveniente da língua inglesa: smart grids (redes inteligentes) que se fundamenta em uma monitoração inovativa e inteligente, controle e comunicação intensa, bem como uma massiva transferência das informações (dados) entre os vários elementos do sistema elétrico, buscando atingir e garantir melhores condições operacionais para geradores, transmissores, distribuidores e consumidores finais da energia.

Como fato, tem-se então que esta integração e interoperabilidade do sistema elétrico com tecnologias digitais, afeta direta e positivamente a QEE fornecida, pois através da instalação de smart meters (medidores inteligentes) e tecnologias de suporte, os usuários terão 
acesso a uma grande quantidade de dados, e as concessionárias farão o mesmo através de um sistema de gerenciamento dos dados disponíveis. Assim, os medidores poderão servir, por exemplo, como sensores da rede, podendo ajudar a detectar distúrbios elétricos e serem usados para indicar a necessidade de conexão ou desconexão de equipamentos ou serviços.

Outro agravante que interfere diretamente nos padrões de qualidade, de confiabilidade e de continuidade no fornecimento da energia elétrica é a característica topológica do SD brasileiro, que compreende milhares de quilômetros de linhas, sendo a maioria aérea, tornando-o assim muito mais vulneráveis aos efeitos dos fenômenos naturais e inerentes ao sistema, sejam estes oriundos de adversidades climáticas, falhas humanas, contatos por animais e árvores em partes energizadas, defeitos em equipamentos, entre outros.

Neste cenário, a ocorrência de faltas (curtos-circuitos) no SD torna-se inevitável, podendo ocasionar graves problemas relacionados a uma má QEE. Sendo assim, dentre todos os distúrbios passíveis de ocorrência na rede elétrica, e usualmente decorrentes dos curtoscircuitos, as Variações de Tensão de Curta Duração (VTCDs) são as que apresentam maior ocorrência e de rápida percepção por parte dos consumidores (MCRANAGHAN, MUELLER e SAMOTYJ, 1993; BECKER, et al., 1993; BOLLEN, QADER e ALLAN, 1998).

Normalmente, as VTCDs mais severas são originadas por curtos-circuitos francos ou de baixas impedâncias de defeito, os quais se propagam ao longo do sistema mesmo em pontos distantes de ocorrência da falta, alterando as condições ideais de fornecimento e o perfil ideal de funcionamento das cargas dos consumidores.

Como na grande maioria, estas perturbações são causadas por curtos-circuitos, prever com precisão o desempenho dos SDs frente às VTCDs torna-se uma tarefa complexa, que exige um grande número de medições para coleta de dados, e ainda, a permanência e a dependência de medidores instalados ao longo do sistema para um monitoramento eficaz. Esta tarefa complexa, além de ser relativamente onerosa, demanda de um extenso período de tempo para formar uma base de dados realmente representativa para o estudo.

Embora as VTCDs representem atualmente os eventos de maior importância na avaliação da QEE, principalmente do ponto de vista dos consumidores industriais, ainda não existe um consenso quanto a melhor forma de caracterizá-las. Neste contexto, o presente trabalho pretende propor uma nova metodologia para a caracterização e análise da propagação desse tipo de distúrbio para monitorar o desempenho do SD. Posteriormente, definidos os pontos de medições permanentes para obter informações representativas sobre os distúrbios, novos indicadores que permitam avaliar o impacto dos distúrbios sobre os consumidores finais poderão ser elaborados. 
Além disso, o constante monitoramento da QEE e a análise do SEP como um todo, de forma automatizada e em tempo real, pode ajudar a alcançar índices de satisfação e a garantir o fornecimento contínuo da energia. Consequentemente, novas metodologias que venham a proporcionar um melhor monitoramento e identificação dos distúrbios terão uma importância considerável, possibilitando a descoberta das possíveis causas e a proposição de soluções, contribuindo para uma melhora do sistema elétrico como um todo.

\subsection{Relevância do Tema}

Segundo estudos da Empresa de Pesquisa Energética (EPE, 2015), da totalidade da energia distribuída no Brasil em 2015, a maior parcela foi destinada à classe industrial como ilustra a Figura 1.

Figura 1 - Consumo nacional anual de energia elétrica por classe.

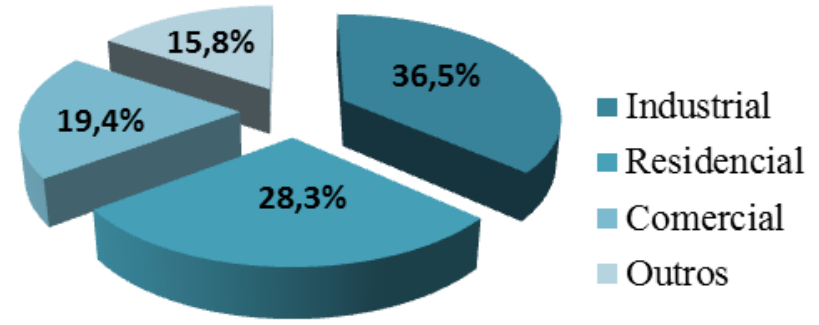

Fonte: Elaborada a partir de informações da EPE (2015).

Dentre as classes de consumidores, na ocorrência de VTCDs, os consumidores industriais são os mais afetados. Enquanto a maior parte das cargas dos consumidores residenciais recupera a operação normal assim que a tensão retorna a níveis aceitáveis, as cargas dos consumidores industriais podem ter o desempenho prejudicado e ainda levar algumas horas para que tenham sua atividade restaurada.

Ainda mais, a elevada frequência de ocorrência destes fenômenos é capaz de sensibilizar dispositivos de proteção, desligando processos, ou afetar o funcionamento de equipamentos, resultando em um número expressivo de interrupções de processos industriais que, consequentemente, podem provocar grandes prejuízos.

Estes prejuízos justificam-se analisando o tipo de carga comumente encontrada em campo, visto que a maioria dos equipamentos utilizados na automação de processos industriais modernos, como, por exemplo, os controladores lógicos programáveis, reguladores de velocidade ajustável, drives e robótica, são sensíveis às VTCDs (GOSWAMI, GUPTA e SINGH, 2008). Contudo, dos exemplos de cargas citadas, dentre outras, vale ressaltar que 
cada processo possui um determinado e peculiar nível de prejuízo econômico quando da ocorrência de paradas não programadas.

Para exemplificar os impactos econômicos das VTCDs, a Figura 2 mostra os custos estimados e decorrentes das interrupções no fornecimento da energia com durações inferiores a um minuto para diferentes setores econômicos, durante um ano de análise.

Figura 2 - Custo anual estimado resultante de interrupções no fornecimento da energia com durações de até 1 minuto.

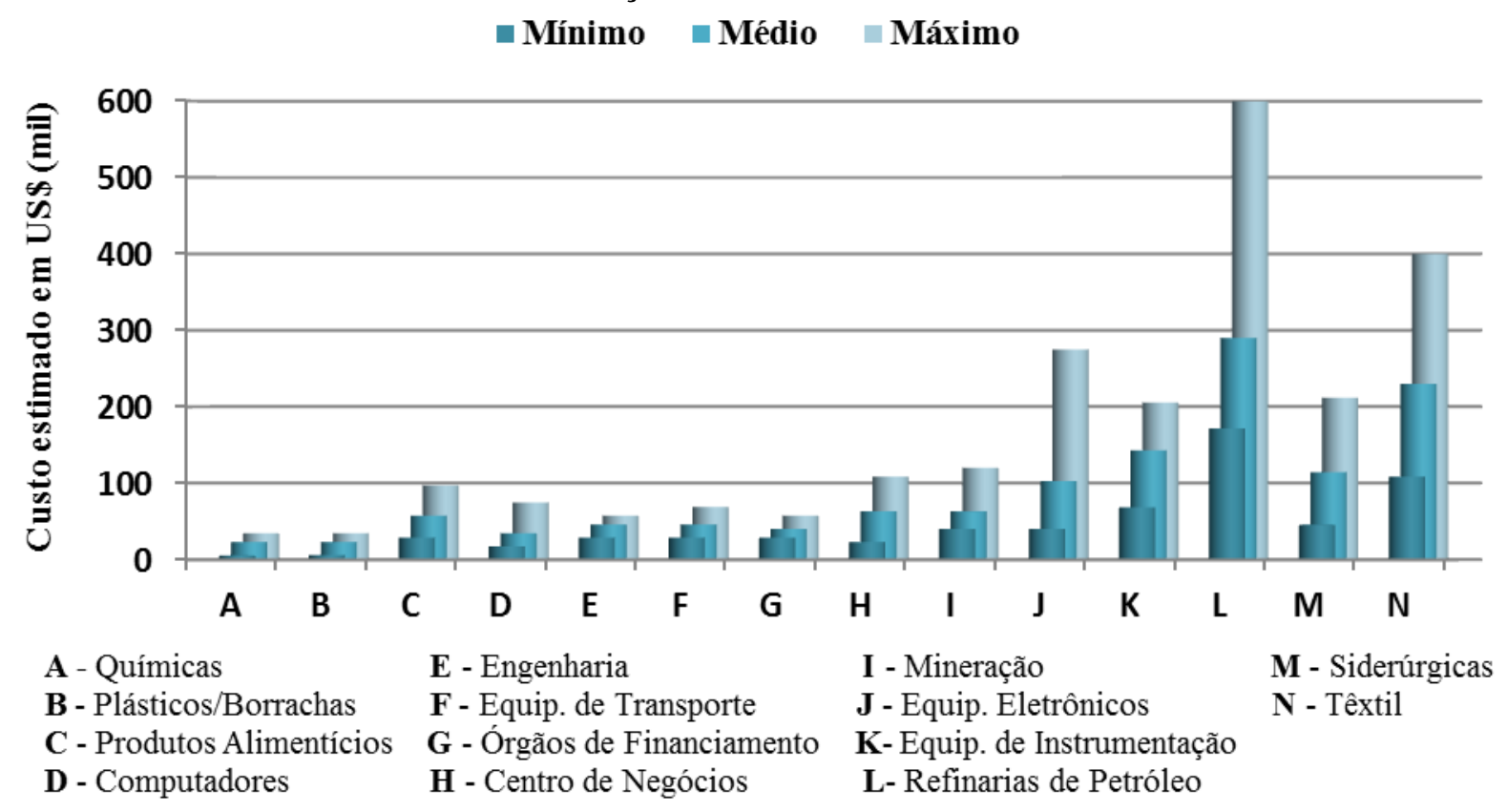

Fonte: Adaptado de Oliveira (2000).

Os principais itens de prejuízo, quando da parada de um processo por VTCD são: perda de produção; reinicialização do processo; mão-de-obra ociosa; danos em equipamentos; necessidades de reparos e atrasos de entregas (KAGAN, ROBBA e SCHMIDT, 2009). Vale comentar que tais situações dependerão da intensidade do distúrbio e sensibilidade do equipamento frente às anomalias evidenciadas.

Com o intuito de reduzir os custos associados à falta de QEE, agências reguladoras no mundo inteiro vêm lançando normas e resoluções de forma a regulamentar indicadores qualitativos e quantitativos de QEE, buscando caracterizar a continuidade de suprimento e a conformidade das formas de onda de tensão e corrente, sempre observando as condições consideradas adequadas para o bom desempenho do sistema elétrico e que atenda às necessidades de todos os agentes envolvidos (KAGAN, ROBBA e SCHMIDT, 2009).

No Brasil, a responsabilidade de estabelecer padrões mínimos de desempenho do SD, visando assegurar uma energia elétrica adequada aos consumidores industriais, comerciais e 
residenciais, recai à Agência Nacional de Energia Elétrica (ANEEL), órgão regulador e fiscalizador do sistema. A ANEEL estabelece indicadores e metas relativas à qualidade do serviço e do produto aos agentes distribuidores através dos Procedimentos de Distribuição de Energia Elétrica no Sistema Elétrico Nacional (PRODIST). Na seção 8.1 inserida no módulo oito do PRODIST é classificada e definida a terminologia das VTCDs, bem como as metodologias de medição. Entretanto, não são atribuídos valores de referência relativos à conformidade no valor eficaz da tensão que possibilitem à ANEEL fixar padrões de desempenho para estabelecer indicadores de QEE relativos a estes fenômenos (ANEEL, 2016).

Apesar de a ANEEL estabelecer que as distribuidoras devam acompanhar e disponibilizar, em bases anuais, o desempenho das barras de distribuição monitoradas, na prática, as informações quando fornecidas não retratam o real desempenho do sistema frente às VTCDs. Isso porque, a literatura atual sugere que a melhor maneira de estimar o desempenho do sistema frente às VTCDs é através da instalação de instrumentos de medição em todos os pontos do SD, considerando um constante monitoramento. Porém, o custo elevado dos medidores, de sua implementação, manutenção e gerenciamento da informação, inviabilizam esta prática.

Com base no exposto, as informações quando repassadas à agência reguladora relatam apenas os dados obtidos, geralmente, nas subestações de energia, que como será demonstrado no decorrer desta pesquisa não ilustra fidedignamente o desempenho do sistema como um todo.

Neste cenário, gera-se uma dependência mútua entre a agência reguladora e as distribuidoras de energia. A ANEEL necessita de informações de desempenho das barras de unidades consumidoras para estabelecer indicadores e, em contrapartida, pela inexistência de normas que penalizem as distribuidoras de energia, estas informações não são coletadas de forma representativa. Assim, o problema permanece e as unidades consumidoras com cargas sensíveis continuam a passar por transtornos e a serem lesadas.

Com este breve relato, torna-se evidente a necessidade de informações que permitam avaliar o desempenho das redes elétricas. Portanto, advém a importância do estudo de um método analítico propenso em determinar a robustez e sensibilidade do SD e, em consequência, os pontos mais suscetíveis às VTCDs durante a ocorrência de curtos-circuitos. Desta forma, será possível determinar os locais adequados para instalação dos equipamentos de medição, para obter uma base de dados consistente que possam inferir índices de desempenho relativos a estes fenômenos que tanto afetam a QEE. 


\subsection{Objetivos e Contribuições da Pesquisa}

Para um melhor conhecimento, análise, planejamento e aprimoramento dos SEPs, estes merecem ter as perturbações diagnosticadas, quantificadas e monitoradas por meio de um processo de medição contínuo. Entretanto, as VTCDs estão entre as perturbações mais difíceis de serem monitoradas, pois são ocasionadas por fatores aleatórios e imprevisíveis. Ou seja, a dificuldade não está só em medir a magnitude e a duração que as caracterizam, mas em determinar a frequência de ocorrência e o instante de início das mesmas. Assim, para a obtenção de informações representativas sobre as VTCDs, tornam-se necessários investimentos técnico-financeiros e longos períodos de monitoração.

Para se sobrepor às dificuldades inerentes ao deficiente monitoramento e registro histórico dos dados, que se contrapõem à definição e avaliação de indicadores específicos para as VTCDs, diversos trabalhos consultados na literatura técnico-científica apresentam diferentes metodologias para a alocação ótima de medidores de forma a diminuir os custos de aquisição e manutenção dos medidores de QEE.

Apesar da eficiência dos trabalhos consultados, nem sempre os estudos são direcionados para SDs, e alguns trabalhos não consideram todos os tipos de curtos-circuitos que o sistema elétrico possa enfrentar. Portanto, não garantem a completa observabilidade dos distúrbios.

Mesmo quando são considerados todos os tipos de curtos-circuitos, a alocação para cada tipo de falta é determinada separadamente, e, posteriormente, é necessário avaliar um arranjo de medidores que contemple todas as respostas obtidas pelo algoritmo. Como na maioria das vezes as soluções para cada tipo de falta são divergentes, em virtude do elevado número de soluções possíveis, determinar um arranjo de medidores que seja compatível para todos os tipos de falta torna-se uma tarefa complexa e que ainda envolve a necessidade de execuções consecutivas do algoritmo de otimização aplicado.

Visando superar estas limitações e contribuir com a monitoração dos SDs, esta pesquisa propõe a utilização do Método das Posições de Falta (MPF), que permitirá a obtenção das tensões remanescentes frente às possíveis situações de curtos-circuitos simétricos e assimétricos, passíveis de ocorrência em diferentes pontos da rede elétrica, viabilizando a verificação da influência de cada defeito aplicado em todos os nós do SD.

Optou-se pela utilização do MPF, pois este método analítico proporciona a modelagem mais simplificada da rede, sendo de vital importância na medida em que, geralmente, há deficiências nos bancos de dados existentes e dificuldades em se obter modelos complexos 
dos componentes. Assim, uma vez que existem entraves na obtenção de informações precisas para todas as cargas do SD a serem modeladas computacionalmente, o MPF se apresenta como uma boa alternativa para se obter o desempenho do sistema frente às VTCDs sem a necessidade da utilização de programas computacionais específicos que normalmente têm um custo associado, e requerem familiaridade com o software para utilização da ferramenta.

Desta forma, a utilização desta metodologia proporcionará importantes informações referentes à magnitude das VTCDs, ilustrando a influência e a propagação dos distúrbios em todas as barras de um desejado SD, considerando todos os tipos de curtos-circuitos passíveis de ocorrência.

Diante da dificuldade em se obter uma resposta ótima de alocação que seja compatível para todos os tipos de falta, uma vez analisado o desempenho nos pontos de suprimento de energia elétrica, propõe-se a criação de uma matriz inovadora capaz de observar de forma simultânea os afundamentos de tensão decorrentes de qualquer tipo de curto-circuito (balanceado ou desbalanceado), denominada neste trabalho de matriz de observabilidade binária resultante.

Além disso, é proposta a redução desta matriz resultante para diminuir a complexidade computacional em SDs de grande porte e obter outras possíveis soluções sem a necessidade de executar exaustivamente o algoritmo de otimização na busca de novas soluções. Assim, para cada limiar de tensão analisado, será suficiente uma única execução do algoritmo para a obtenção de várias respostas possíveis para a alocação de um número mínimo de medidores.

O trabalho também agrega em seu escopo a análise da vulnerabilidade de cada barramento do SD, que permitirá incorporar na função objetivo do problema de alocação, a prioridade de instalação dos equipamentos de medição nos barramentos que possuírem maior observabilidade dos distúrbios. Assim, será possível maximizar a capacidade de monitoração e estabelecer quais locais são mais apropriados e prioritários para a instalação dos medidores.

Cabe ainda comentar, que na literatura correlata consultada para esta pesquisa, normalmente, quando é determinado o número ótimo e a localização dos equipamentos para o monitoramento dos afundamentos da tensão, os autores reportam apenas as soluções obtidas para o limiar $\leq 0,9$ p.u.. Entretanto, pelo desenvolvimento desta tese, acredita-se que as soluções devem ser apresentadas de modo a possibilitar ao operador do sistema estabelecer o melhor arranjo de medidores de acordo com o número de equipamentos disponíveis, ou limites orçamentários para a aquisição dos mesmos. Portanto, neste trabalho, serão analisadas a soluções ótimas de alocação dos medidores para todos os limiares de tensão remanescentes compreendidos entre 0,1 e 0,9 p.u., os quais caracterizam os afundamentos de tensão. 
Determinados os pontos estratégicos de máxima observabilidade dos eventos, e após um longo período de monitoração que propicie a apuração de uma base de dados consistente do desempenho do sistema, como resultado final, espera-se que, futuramente, seja possível inferir novos indicadores que possam ser utilizados para melhor avaliar a qualidade do produto no âmbito da distribuição de energia elétrica no Brasil, tendo como foco o aperfeiçoamento da seção 8.1 do Módulo 8 do PRODIST (ANEEL, 2016), de forma a possibilitar à ANEEL acompanhar e regular as VTCDs.

\subsection{Desenvolvimento da Pesquisa}

A proposta de atividades para o desenvolvimento da pesquisa pode ser resumida, de uma maneira geral, no fluxograma da Figura 3, que será sucintamente comentada a seguir:

Conhecendo as informações sobre a configuração e os parâmetros do SD, é exequível a determinação da matriz de impedância barra de sequência positiva, negativa e zero, essenciais na utilização do MPF para a determinação da magnitude das tensões remanescentes em todos os nós de um SD, o que permitirá a obtenção de estimativas válidas e confiáveis para uma melhor análise das ocorrências das VTCDs, considerando diferentes tipos de curtoscircuitos, a saber:

- Curtos-circuitos monofásicos, envolvendo uma fase com conexão a terra (FT);

- Curtos-circuitos bifásicos, envolvendo duas fases com conexão a terra (FFT);

- Curtos-circuitos bifásicos, envolvendo duas fases (FF); e

- Curtos-circuitos trifásicos, envolvendo as três fases (FFF).

- Assim, para cada diferente tipo de curto-circuito é gerada, por fase, uma Matriz de Tensão Durante a Falta (MTDF), que permite caracterizar, para cada situação de falta analisada, os níveis das tensões remanescentes em cada um dos nós do SD.

Para melhor apresentar e comparar os resultados, de forma a facilitar a observação da propagação e da amplitude das VTCDs em torno da rede para todos os nós analisados, é proposta a visualização gráfica da MTDF, a qual irá correlacionar imediatamente a intensidade das VTCDs com cores definidas por uma escala apropriada. Esta visualização gráfica da MTDF proporcionará importantes informações referentes à propagação dos afundamentos, elevações e interrupções de tensão em torno da rede. Desta forma, será possível estimar e observar de uma maneira direta, as barras onde as cargas poderão ser sensibilizadas pelos distúrbios. 
Figura 3 - Fluxograma da metodologia desenvolvida.

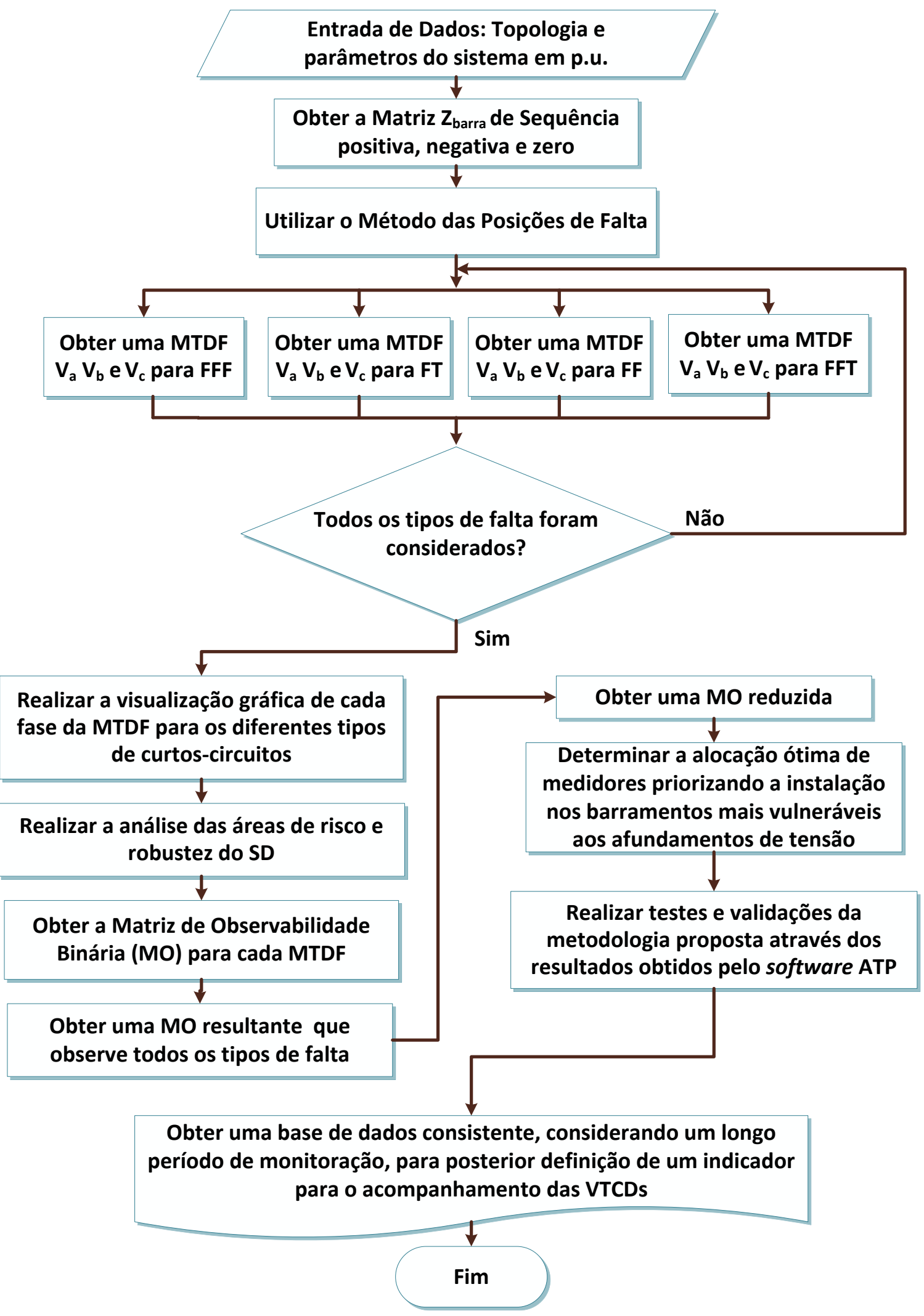

Uma vez determinado todos os pontos suscetíveis às VTCDs no SD em análise, será avaliada a robustez do sistema frente aos possíveis defeitos que podem ocorrer, tornando-se 
possível determinar as posições mais sensibilizadas pelas situações de faltas no SD, a área afetada e a área exposta, ou de vulnerabilidade, para a avaliação da probabilidade de equipamentos sensíveis serem submetidos a uma tensão abaixo de um limiar de operação préestabelecido e também para priorizar a instalação dos medidores nos pontos de maior observabilidade.

Deste procedimento, após a determinação dos barramentos mais vulneráveis às VTCDs que o sistema possa vir a ser submetido, será apresentada a alocação ótima de medidores baseada em um algoritmo Branch and Bound (BB).

$\mathrm{O}$ algoritmo BB determinará o número ótimo de medidores de QEE, bem como as barras onde os mesmos devam ser instalados para monitorar os afundamentos de tensão, de forma a priorizar a instalação dos analisadores de QEE nos barramentos mais sensibilizados pelo distúrbio, com o objetivo de garantir um arranjo de medidores que seja sensibilizado por todos os tipos de curtos-circuitos. Isto é, a localização dos medidores, obtida por meio do algoritmo proposto, assegurará que qualquer evento caracterizado pelas VTCDs seja capturado por, pelo menos, um medidor de tensão alocado no SD.

A fim de analisar a eficiência do MPF, será ainda realizada a comparação dos resultados obtidos através do MPF com os provenientes de simulações computacionais dispondo do software ATP (Alternative Transients Program). A comparação dos resultados é motivada pela possibilidade de identificar se o método analítico proposto é adequado para a realização das simulações pertinentes às VTCDs, e se o mesmo mantém a estimação dos resultados dentro de limites aceitáveis, mesmo considerando a simplificação na modelagem dos componentes do sistema a serem adotados para agilização dos procedimentos de cálculo e análises.

Além disso, a utilização do software ATP proporcionará a análise da influência de vários parâmetros que afetam as características dos afundamentos de tensão, tais como mudança da tensão pré-falta, alteração da impedância de falta, tipos de falta e a alteração dos perfis de carregamento, sendo posteriormente avaliado se esses fatores podem afetar no resultado da alocação ótima dos medidores.

Neste cenário, a metodologia apresentada irá contribuir estabelecendo os melhores locais de instalação de um número mínimo de medidores garantindo a máxima observabilidade dos eventos. Assim, garante-se que os distúrbios serão monitorados de forma eficiente o que contribuirá para a obtenção de uma base de dados consistente para a avaliação das VTCDs e, sobretudo, para a determinação futura de novos índices para avaliar e retratar este fenômeno associado à falta da QEE. 


\subsection{Estrutura do Trabalho}

O Capítulo 2 trata dos principais aspectos conceituais e práticos relacionados às VTCDs, fornecendo uma base teórica para o entendimento deste distúrbio e a conceituação das áreas de propagação e curvas de sensibilidade de determinados equipamentos que serão úteis para estabelecer a tolerância dos equipamentos frente à severidade destes distúrbios. Além disso, apresenta os principais índices vigentes, baseados em normas internacionais que tratam das VTCDs, denotando as vantagens e desvantagens dos índices apresentados.

O Capítulo 3 fornece uma base teórica do MPF e apresenta os conceitos básicos para a formulação e obtenção da magnitude das tensões na ocorrência de diferentes tipos de falta através da determinação da MTDF.

O Capítulo 4 apresenta os principais aspectos conceituais e práticos relativos à alocação otimizada de medidores, sendo apresentados todos os passos necessários para solucionar o problema com a utilização de uma metodologia de aplicação da técnica de programação linear inteira com resolução pelo algoritmo BB.

O Capítulo 5 apresenta os SDs utilizados, e exibe os resultados obtidos através do MPF. Posteriormente é demonstrada a análise das áreas de propagação dos afundamentos de tensão, que busca estimar a robustez dos SDs analisados e também a prioridade de instalação dos medidores. Em seguida, são apresentadas as soluções ótimas encontradas analisando vários limiares de afundamento de tensão passíveis de ocorrência sobre o SD. Finalmente, a metodologia será validada através de comparações com os resultados obtidos utilizando o software ATP.

Finalizando, no Capítulo 6, têm-se as considerações finais do trabalho, bem como sugestões das atividades a serem desenvolvidas para continuação da pesquisa. Por fim, são listadas as publicações geradas a partir dos resultados obtidos.

Ressalta-se que como os capítulos desta tese tratam de assuntos diversos, optou-se em colocar uma breve revisão bibliográfica de cada assunto, no início de cada capítulo, para facilitar a leitura e o entendimento do trabalho. 



\section{Capítulo 2}

\section{VTCDs: Conceitos, definições, causas e efeitos}

Este capítulo traz a definição, causas, efeitos e as principais consequências relativas às VTCDs. Relata-se também um histórico, de forma sumarizada, sobre as principais contribuições técnico-científicas pesquisadas para entender e diagnosticar os impactos e custos causados por este distúrbio, bem como as normas e recomendações nacionais e internacionais aplicáveis no contexto desta pesquisa.

Além disso, neste capítulo são descritos os aspectos conceituais e práticos referentes à propagação dos afundamentos de tensão em um SD. Para tanto, são apresentados os conceitos para a determinação da área afetada e da área exposta, necessárias para a avaliação das regiões que são mais sensibilizadas pelas possíveis faltas no SD.

Por fim são apresentadas as curvas de sensibilidade de alguns equipamentos, que permitem observar as regiões de imunidade frente às VTCDs, tornando possível analisar o nível de severidade dos distúrbios em função da magnitude e da duração dos mesmos, que poderia provocar uma disrupção, danos permanentes, ou mau funcionamento no equipamento analisado.

\subsection{Revisão Bibliográfica}

Devido à importância das VTCDs no contexto da QEE, ao se pesquisar as publicações relacionadas a este tema, depara-se com uma expressiva quantidade de trabalhos, evidenciando o elevado interesse que o assunto tem e continua despertando na comunidade técnico-científica.

É importante reforçar que dentre todos os distúrbios de QEE, o afundamento de tensão é um distúrbio que, atualmente, oferece preocupação e um grande desafio a ser enfrentado pelas distribuidoras de energia, fornecedores de equipamentos elétricos e consumidores. 
Ocorrências de afundamentos de tensão, combinadas com a sensibilidade dos equipamentos modernos, têm resultado em significativos prejuízos financeiros, devido, principalmente, a um número expressivo de interrupções nos processos industriais.

McGranaghan et al. (1993) descreveram em seu trabalho as causas dos afundamentos de tensão nas plantas industriais, relatando que a principal é decorrente de faltas (curtoscircuitos) no sistema elétrico. Os autores relataram ainda os impactos causados pelo distúrbio na operação dos equipamentos e analisaram a sensibilidade de diferentes tipos de equipamentos, incluindo dispositivos de acionamento de motores com velocidade variável, controladores lógicos programáveis e contatores.

Becker et al. (1993) evidenciaram a diferença entre uma interrupção de energia e uma interrupção causada por afundamentos momentâneos de tensão, descrevendo que mesmo não acontecendo uma interrupção no fornecimento, as cargas sensíveis podem sofrer desligamentos, interrompendo os seus processos produtivos e gerando prejuízos financeiros. Segundo os autores, prever as características do afundamento de tensão que uma carga sensível irá enfrentar durante alguns anos exige uma abordagem probabilística, sendo possível estimar os afundamentos através de simulações de curto-circuito em torno da rede elétrica e, posteriormente, observar a tensão resultante nas barras de interesse.

Dorr et al. (1997) também se mostraram interessados em avaliar o efeito das VTCDs em equipamentos sensíveis, relatando que, independente da origem dessas variações, o equipamento deve operar com certo grau de imunidade. Para isso, os autores utilizaram de dados provenientes de três importantes pesquisas sobre QEE realizadas em 1995, dentre as quais, destacou-se a do EPRI (Electric Power Research Institute). O objetivo principal da pesquisa foi obter uma melhor compreensão da sensibilidade de equipamentos devido às variações de tensão. Pelos resultados encontrados, e conforme relataram os autores, os fabricantes podem garantir (e os usuários finais podem solicitar) melhorias na tolerância de aparelhos elétricos frente a certos distúrbios de energia para garantir a compatibilidade destes com o sistema elétrico de potência.

No Brasil, Carvalho (1997) avaliou a relevância do estudo dos afundamentos de tensão, e com base nas bibliografias publicadas até então, apresentou uma visão geral deste distúrbio no contexto da QEE. O autor fez um levantamento das causas, características e fatores que contribuem na avaliação dos afundamentos. As principais causas citadas foram a partida de motores e as faltas (curtos-circuitos) no sistema elétrico, principalmente as ocasionadas por descargas atmosféricas, concluindo que o número de ocorrências dos afundamentos de tensão está diretamente relacionado com o nível ceráunico da região onde o 
sistema elétrico está inserido. $\mathrm{O}$ autor descreve ainda alguns dos fatores que podem apresentar influência na caracterização dos afundamentos, dentre os quais se destacam: o tipo e a localização da falta; a conexão dos transformadores existentes no circuito; a impedância de falta e a tensão de pré-falta.

O trabalho de Heine et al. (2002) estima o número de ocorrência anual e o custo dos afundamentos de tensão para cinco consumidores de diferentes distribuidoras. Neste trabalho, estima-se para os consumidores industriais, o custo por perda de produção decorrente dos afundamentos de tensão, e provocados por mau funcionamento de seus equipamentos eletroeletrônicos, considerando desde a parada até o reinício das operações.

Também no Brasil, Alves, Costa e Fonseca (2003) publicaram um artigo que trata dos problemas associados à ocorrência dos distúrbios da QEE, em especial aos afundamentos de tensão, apresentando uma metodologia que permite realizar a estimativa das interrupções provocadas por este distúrbio. Posteriormente, o resultado desta avaliação foi utilizado para a execução de uma estimativa detalhada do custo de interrupção do processo produtivo.

O trabalho de Aung, Milanovic e Simmons (2004) descreve um método para calcular as áreas de observabilidade e cita o conceito de área dos nós afetados por um determinado afundamento de tensão. Estas diferentes áreas representam os curtos-circuitos ocorridos em qualquer ponto da rede, que poderiam gerar um valor no nível de tensão da barra estudada inferior a um valor pré-estabelecido. Este conceito é extremamente importante quando se pretende mapear a rede quanto ao risco de mau funcionamento de equipamentos ou processos, e pode ser estendido para contemplar, além dos valores de amplitude do afundamento de tensão a duração dos eventos.

De forma a contribuir com o estudo do impacto das VTCDs em equipamentos eletrônicos alimentados por conversores CA-CC, o trabalho de Luna (2005) apresenta ensaios laboratoriais para obter curvas de tolerância, ou de sensibilidade, destes equipamentos, e, posteriormente, realiza comparações com referências às normas americanas e europeias, que são geralmente utilizadas por falta de outras curvas que sirvam de parâmetro para diagnosticar o limite dos efeitos das VTCDs. O autor conclui que apesar das normas americanas apresentarem-se mais avançadas em diversos pontos, os estudos realizados mostraram que para eventos na rede elétrica, o uso destas curvas de referência é equivocado. Isto porque os equipamentos abrangidos por essas normas são equipamentos eletrônicos e de modo geral alimentados por uma fonte $\mathrm{CC}$, ou seja, não respondem pelo valor eficaz da tensão, mas sim pela dinâmica do filtro capacitivo. 


\subsection{Referencial Teórico para as VTCDs}

A VTCD é um evento aleatório e imprevisível, caracterizado pelo desvio significativo na amplitude de tensão com duração de 0,5 ciclo de $60 \mathrm{~Hz}$ a alguns minutos de tempo, dependendo da norma a ser considerada. Enquanto perdurar o evento (distúrbio), a amplitude da VTCD é definida pelo valor extremo (mínimo ou máximo) da tensão eficaz remanescente, em relação à tensão nominal do sistema no ponto de observação. A duração da VTCD, por sua vez, é definida pelo intervalo de tempo decorrido entre o instante em que a tensão eficaz ultrapassa determinado limite de referência, definida por normas técnicas, e o instante em que a mesma retorna à operação normal (ONS, 2010).

Geralmente, as VTCDs são originárias de faltas no sistema elétrico, energização e desenergização de grandes blocos de carga, partida ou parada de grandes motores, entre outros. Dependendo da localização da falta e das condições operacionais do sistema, a falta pode causar afundamento de tensão (sag), elevação de tensão ( $s w e l l$ ) ou interrupção de tensão.

\subsubsection{Afundamento de Tensão}

O afundamento de tensão, conforme ilustrado pela Figura 4, é caracterizado por uma redução repentina da tensão em um determinado local de um sistema de fornecimento de energia elétrica, até um valor abaixo do limiar inicial, seguido por uma posterior recuperação da tensão após um curto período de tempo. O limiar inicial do valor eficaz da tensão que define o começo de um afundamento de tensão é geralmente definido como 0,9 p.u. da tensão de referência.

Os principais parâmetros que caracterizam um afundamento de tensão são a amplitude e a duração do evento. A amplitude do afundamento de tensão é a tensão remanescente registrada durante a ocorrência do distúrbio. Já a duração do evento é o tempo durante o qual o valor eficaz da tensão permanece abaixo do limiar inicial da tensão de referência. Tal situação pode ser visualizada através da Figura 4 que ilustra um afundamento de tensão monofásico de 0,2 p.u., com um decréscimo de $80 \%$ da tensão eficaz, por um período de aproximadamente 3 ciclos.

Os afundamentos são causados, em geral, por faltas (curtos-circuitos), energização de grandes cargas ou grandes motores e pela corrente de magnetização dos transformadores. Dependendo da norma observada, os afundamentos também podem ser classificados em três 
categorias conforme a sua duração. Os tempos de permanência (de manifestação do fenômeno sobre as formas de ondas da tensão do sistema em análise) normalmente transcorre desde o instante inicial do defeito até a atuação do sistema de proteção ou a completa eliminação do defeito, sendo, portanto, dependentes dos dispositivos e das filosofias de proteção adotadas pelas distribuidoras de energia (LEBORGNE, 2003).

\section{Figura 4 - Ilustração de um afundamento de tensão na ocorrência de um curto-circuito FT.}

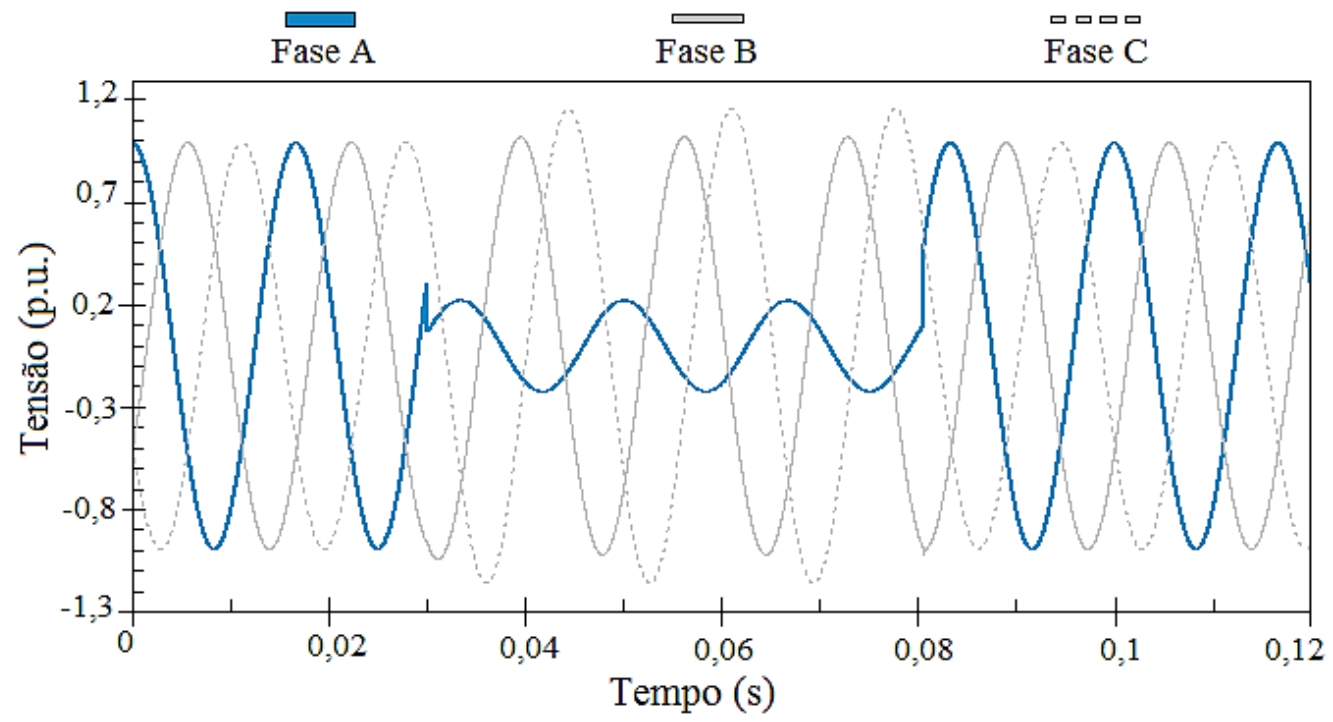

Fonte: Elaborada pela autora.

Nas últimas décadas, a evolução da tecnologia e da automatização de processos inseriu na maioria das plantas industriais, um grande leque de equipamentos sensíveis aos afundamentos de tensão. Mesmo que este seja de apenas alguns milissegundos, este pode acarretar em inúmeros problemas a equipamentos e dispositivos, em particular àqueles que fazem uso da eletrônica digital. As consequências nestes equipamentos/dispositivos vão desde a perda de dados, processamento errôneo, ou até mesmo à total paralisação do processo, e, consequentemente, perdas de produtividade, na maioria das vezes com elevados prejuízos econômicos.

Em algumas ocasiões uma interrupção programada pela distribuidora pode ser menos impactante que a ocorrência de um afundamento de tensão com duração de alguns ciclos, visto que quando a interrupção é avisada com antecedência o consumidor pode se preparar, minimizando os riscos aos processos e perdas de produção.

Face aos prejuízos decorrentes é importante que os agentes do setor elétrico (agências reguladoras, empresas de energia elétrica e consumidores finais) conheçam bem um dos fenômenos que mais afetam os SDs, e que em consequência, deterioram a QEE. 


\subsubsection{Elevação de Tensão}

A elevação de tensão (como a ilustrada pela Figura 5) é caracterizada segundo a definição do IEEE, através da norma Std. 1159 (1995), por um aumento superior a 10\%, e inferior a $80 \%$, no valor eficaz da tensão (na frequência fundamental do sistema), por um período superior a 0,5 ciclo e inferior a 1 minuto. Assim como os afundamentos de tensão, as elevações também são associadas às condições de faltas no sistema, principalmente no que diz respeito a curtos-circuitos fase-terra, visto que nestas situações, as fases sãs do circuito experimentam uma elevação de tensão. Este fenômeno também pode ser ocasionado pela saída de grandes cargas e energização de grandes bancos de capacitores. Porém, com uma incidência muito menor se comparado com as elevações oriundas das faltas fase-terra nas redes de transmissão e distribuição de energia.

Da prática, tem-se que equipamentos sensíveis podem sofrer danos quando submetidos à elevação de tensão. O aumento de tensão acima dos níveis nominais suportáveis pode danificar componentes, causando a indisponibilidade do equipamento, seja residencial, comercial ou industrial. Neste último caso, com chances de maiores prejuízos.

Figura 5 - Ilustração de uma elevação de tensão na ocorrência de um curto-circuito FFT.

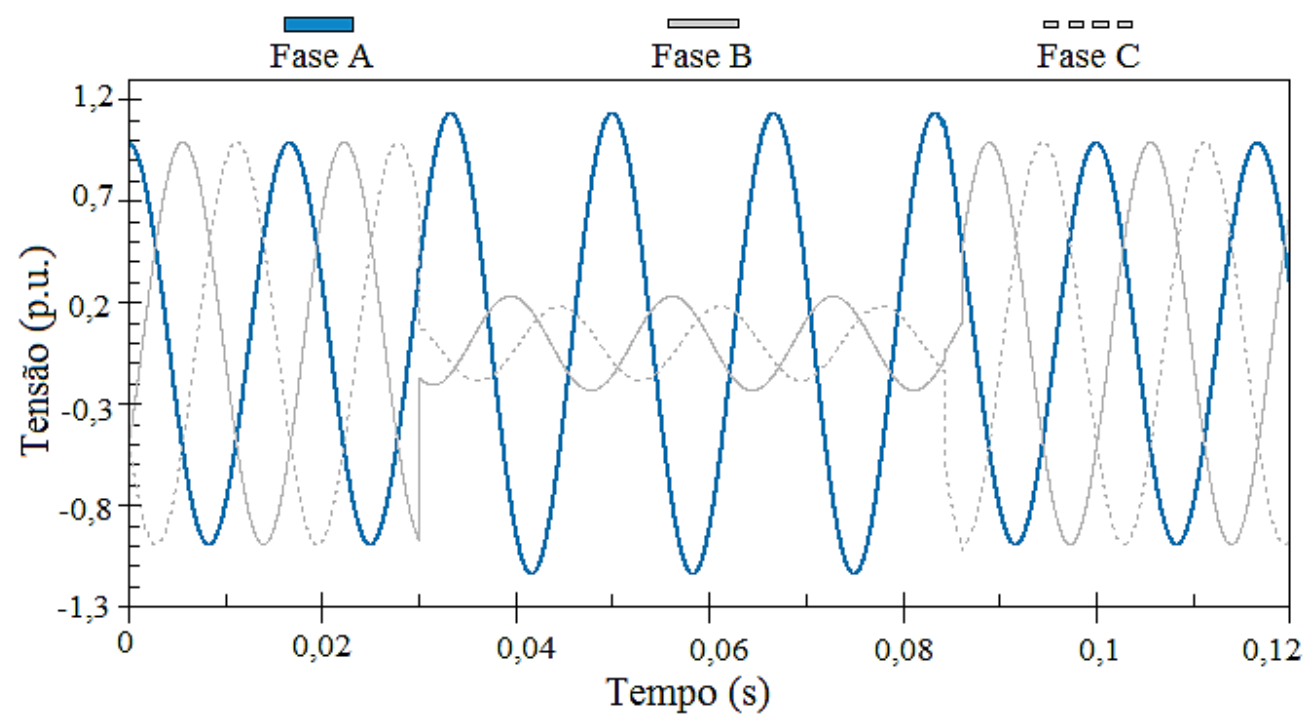

Fonte: Elaborada pela autora.

\subsubsection{Interrupção de Tensão}

A interrupção de tensão é definida quando a tensão eficaz do sistema, frequência de 60 $\mathrm{Hz}$, decresce para um valor inferior a $10 \%$ por um período, a depender da norma, de até 1 
minuto. Normalmente é causada por faltas no sistema de energia, falhas nos equipamentos e mau funcionamento do sistema de controle. A duração da interrupção é determinada pelo tempo de operação dos dispositivos de proteção, os quais dependem da filosofia adotada. $\mathrm{O}$ registro de uma interrupção de tensão durante a ocorrência de um curto-circuito monofásico é ilustrado pela Figura 6.

Figura 6 - Ilustração de uma interrupção de tensão na ocorrência de um curto-circuito FT.

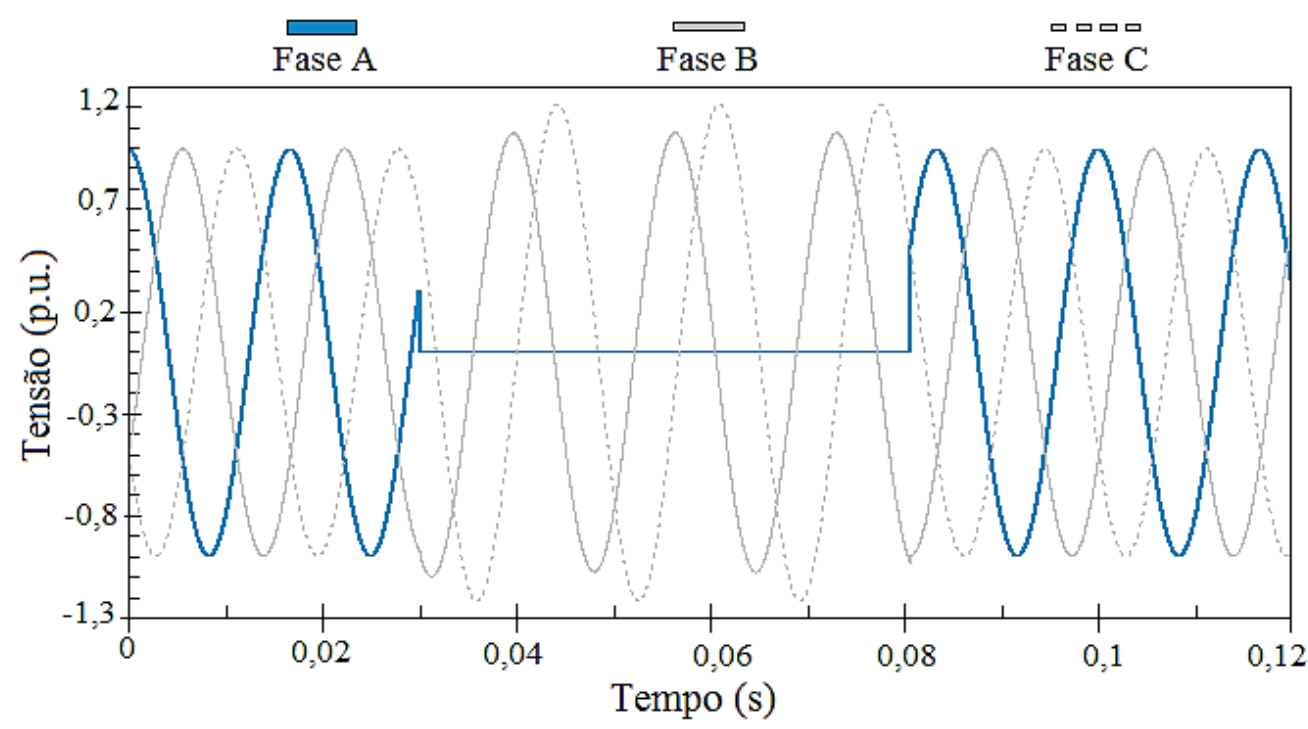

Fonte: Elaborada pela autora.

De um modo geral, as interrupções quase sempre irão causar o desligamento ou mau funcionamento dos equipamentos eletroeletrônicos. Em alguns casos, podem até causar defeitos em chaves estáticas (soft-starter) e, dependendo da duração da interrupção, podem promover o desligamento de todos os equipamentos, com exceção daqueles que possuírem suprimento alternativo de energia.

\subsubsection{Normas e Regulamentações Aplicadas às VTCDs}

Nas normas vigentes relativas às definições e classificação das VTCDs existem diferentes propostas e abordagens para a análise e quantificação deste fenômeno. A seguir são apresentadas as definições das VTCDs obtidas em quatro órgãos, sendo três internacionais (IEEE - Institute of Electrical and Electronics Engineering, IEC - International Electrotechnical Commission e CELENEC - European Committee for Electrotechnical Standardization) e pela ANEEL.

A Norma Americana IEEE Std. 1159 (1995) que trata da monitoração dos fenômenos de QEE, define cada tipo de distúrbio em função das características dos eventos registrados 
tais como: faixas de intensidade e duração. A magnitude do evento é definida como o nível extremo do valor eficaz da tensão $\left(V_{\text {res }}\right)$, tensão residual ou remanescente, em relação à tensão nominal $\left(V_{n}\right)$, expresso em porcentagem ou valor por unidade (p.u.) conforme a equação (1).

$$
\left.V_{\text {mag }} \%=\frac{V_{\text {res }}}{V_{n}} .100(\%) \text { ou } V_{\text {mag }}=\frac{V_{\text {res }}}{V_{n}} \quad \text { (p.u. }\right)
$$

Adicionalmente, o IEEE classifica os eventos, conforme a sua duração, como instantâneos, momentâneos e temporários. A Tabela 1 apresenta as denominações das VTCDs segundo a norma americana e suas faixas de magnitude e duração.

Tabela 1 - Classificação da VTCD segundo o IEEE.

\begin{tabular}{c|c|c}
\hline \hline Evento & Duração & Amplitude \\
\hline \hline Afundamento Instantâneo & $0,5-30$ ciclos & $0,1-0,9$ p.u. \\
\hline Elevação Instantânea & $0,5-30$ ciclos & $1,1-1,8$ p.u. \\
\hline \hline Interrupção Momentânea & 0,5 ciclo -3 segundos & $<0,1$ p.u. \\
\hline Afundamento Momentâneo & 30 ciclos -3 segundos & $0,1-0,9$ p.u. \\
\hline Elevação Momentânea & 30 ciclos -3 segundos & $1,1-1,4$ p.u. \\
\hline \hline Interrupção Temporária & 3 segundos -1 minuto & $<0,1$ p.u. \\
\hline Afundamento Temporário & 3 segundos -1 minuto & $0,1-0,9$ p.u. \\
\hline Elevação Temporária & 3 segundos -1 minuto & $1,1-1,2$ p.u. \\
\hline
\end{tabular}

Fonte: IEEE STD 1159 (1995).

A IEC, por outro lado, por meio da norma IEC 61000-2-1 (1990) define a intensidade do afundamento de tensão como sendo a queda do valor RMS da tensão, conforme a equação (2). A IEC considera afundamento de tensão como uma redução súbita da tensão de um ponto do sistema elétrico, com valores entre 0,10 e 0,90 p.u., seguido de seu restabelecimento após um curto período de tempo, de 0,5 ciclo a uns poucos segundos. As tensões remanescentes abaixo de 0,10 p.u. são consideradas pela IEC como interrupções. Nesta norma não consta a caracterização e a classificação de eventos de elevação de tensão.

Já a norma europeia CELENEC EN 50160 (1999), com relação às VTCDs, apresenta uma abordagem classificando os eventos entre afundamentos de tensão e interrupção de curta duração. As elevações de tensão não são abrangidas por tal norma, não sendo especificadas faixas de magnitude e duração. A magnitude da tensão é expressa pela diferença entre o valor 
nominal da tensão e o extremo do valor da tensão eficaz da tensão residual, expressa pela equação (2). A Tabela 2 apresenta a classificação dos eventos de VTCD para essa norma.

Tabela 2 - Classificação da VTCD segundo a norma europeia.

\begin{tabular}{c|c|c}
\hline \hline Evento & Duração & Amplitude \\
\hline \hline Afundamento de tensão & 0,5 ciclo -1 minuto & $0,01-0,9$ p.u. \\
\hline Interrupção de curta duração & 0,5 ciclo -3 minutos & $<0,01$ p.u. \\
\hline Sobretensão Temporária & Não definido & $>1,1$ p.u. \\
\hline
\end{tabular}

Fonte: CENELEC EN 50160 (1999).

Segundo a ANEEL, órgão regulador e fiscalizador no Brasil, através de sua resolução normativa vigente $n^{\circ}$ 469/2011 do PRODIST (ANEEL, 2016), a magnitude das VTCDs é classificada pelo valor extremo da tensão eficaz enquanto perdurar o evento, assim como a norma Std. 1159 do IEEE. A

Tabela 3 apresenta as denominações para as VTCDs e suas respectivas faixas de magnitude e duração segundo a ANEEL.

$$
V_{\text {mag }} \%=\frac{V_{n}-V_{\text {res }}}{V_{n}} .100(\%) \text { ou } V_{\text {mag }}=\frac{V_{n}-V_{\text {res }}}{V_{n}}(\text { p.u. })
$$

Tabela 3 - Classificação da VTCD segundo o módulo oito do PRODIST.

\begin{tabular}{c|c|c}
\hline \hline Evento & Duração & Amplitude \\
\hline \hline $\begin{array}{c}\text { Interrupção Momentânea } \\
\text { Momentâneo }\end{array}$ & $\begin{array}{c}\text { Inferior ou igual a três segundos } \\
\text { inferior ou igual a três segundos }\end{array}$ & $\begin{array}{c}\text { Inferior a 0,1 p.u. } \\
\text { inferior a 0,9 p.u }\end{array}$ \\
\hline Elevação Momentânea & $\begin{array}{c}\text { Superior ou igual a um ciclo e } \\
\text { inferior ou igual a três segundos }\end{array}$ & Superior a 1,1 p.u. \\
\hline \hline $\begin{array}{c}\text { Interrupção Temporária } \\
\text { Afundamento } \\
\text { Temporário }\end{array}$ & $\begin{array}{c}\text { Superior a três segundos e } \\
\text { inferior a três minutos }\end{array}$ & Inferior a 0,1 p.u. \\
\hline $\begin{array}{c}\text { Superior a três segundos e inferior } \\
\text { a três minutos }\end{array}$ & $\begin{array}{c}\text { Superior ou igual a 0,1 e } \\
\text { inferior a 0,9 p.u }\end{array}$ \\
\hline Elevação Temporária & $\begin{array}{c}\text { Superior a três segundos e inferior } \\
\text { a três minutos }\end{array}$ & Superior a 1,1 p.u. \\
\hline
\end{tabular}

Fonte: ANEEL (2016). 


\section{3 Áreas de propagação das VTCDs}

A propagação dos efeitos da VTCD depende da intensidade do distúrbio, da topologia do sistema, do tipo da falta aplicada, da potência de curto-circuito de cada barra e dos dispositivos de proteção inseridos no trecho do SD em análise.

Ao se levar em conta a influência de todos estes fatores nas características das VTCDs durante uma falta, haverá uma região onde os distúrbios serão mais evidentes. Contudo, ao se afastar do ponto de ocorrência da falta, a intensidade da perturbação pode não ser significativa ao restante do sistema. Portanto, a ocorrência de um curto-circuito em um nó do sistema não tem efeito isolado, visto que o sistema é composto por vários alimentadores e circuitos interligados de diversas formas.

Uma das maneiras possíveis de analisar a propagação dos afundamentos de tensão é realizar um estudo da influência de uma determinada falta nos demais barramentos do sistema, identificando a área afetada pelo defeito simulado. Outra maneira de realizar a análise é direcioná-la a uma determinada barra e verificar a área de vulnerabilidade. Desta forma, torna-se possível determinar as posições que são mais sensibilizadas pelas possíveis faltas no SD para a avaliação da probabilidade de equipamentos sensíveis serem submetidos a uma tensão abaixo do seu limiar de operação.

\subsection{1 Área Afetada}

A área afetada é a região de uma rede onde se observa o número de nós que são afetados pelos afundamentos de tensão devido a faltas no nó genérico " $k$ ". Em outras palavras, avalia-se a influência de uma determinada falta simulada na barra $k$ nas demais barras do sistema (CARPINELLI et al., 2009).

A extensão da propagação do distúrbio está sempre associada a uma tensão de referência, ou seja, irá depender de um limiar de tensão previamente estabelecido. Outro fator importante a ser observado é a potência de curto-circuito no nó onde a falta foi simulada. Quanto maior a potência de curto-circuito em um nó, maiores serão os afundamentos de tensão causados por uma falta simulada neste nó, ou seja, maior será a área afetada (CARPINELLI et al., 2009; GOSWAMI, GUPTA e SINGH, 2008).

Ao analisar a Figura 7, conclui-se que uma grande área experimenta tensão com intensidade inferior ou igual a 0,9 p.u., durante a ocorrência de falta na barra $k$. Os 
afundamentos mais severos, ou seja, com amplitudes inferiores ou iguais a 0,7 p.u., ficam restritos às proximidades da região onde ocorre a falta. É importante ressaltar que regiões onde há maior concentração de fontes geradoras experimentam afundamentos menos severos, porém se ocorrerem faltas nestas regiões a área afetada pelos afundamentos de tensão será maior (GOSWAMI, GUPTA e SINGH, 2008).

Figura 7 - Diagrama unifilar simplificado da área afetada.

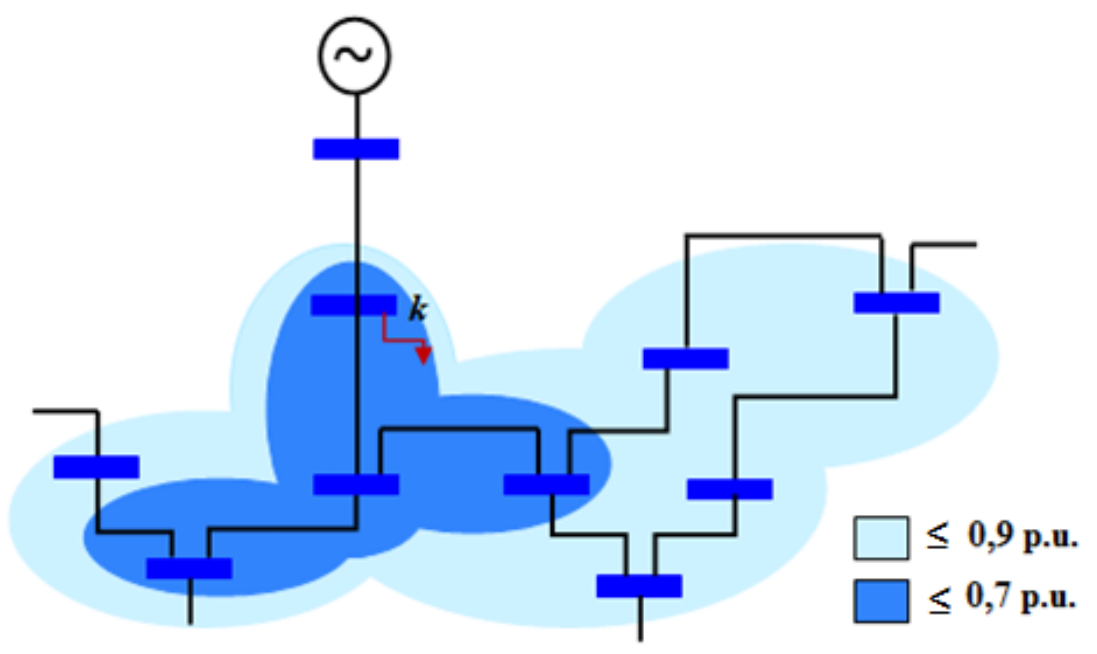

Fonte: Kempner (2012).

\subsection{2 Área Exposta ou de Vulnerabilidade}

A área exposta, ou popularmente conhecida como área de vulnerabilidade, é a região que abrange os nós e segmentos de linha onde a ocorrência de faltas levará a afundamentos de tensão no nó genérico $k$ (CARPINELLI et al., 2009). Ou seja, esta área é associada a um ponto de monitoração, uma barra de análise, onde a ocorrência de curtos-circuitos nas demais barras do sistema poderá ocasionar afundamentos de tensão na barra analisada abaixo de limites críticos, que podem resultar em desligamentos de cargas sensíveis.

Conforme ilustra a Figura 8, a simulação de faltas em todas as barras do sistema define uma área em torno de um ponto da rede (barra $k$ ) onde se encontra o consumidor e seus equipamentos ou processos sensíveis, nos quais uma falta resulta em tensão no consumidor inferior a um determinado valor. Assim sendo, o conceito de um espaço de vulnerabilidade é útil para a avaliação da probabilidade de equipamentos sensíveis serem submetidos a uma tensão mais baixa que o seu limiar de tensão. 
Figura 8 - Diagrama unifilar simplificado da área exposta.

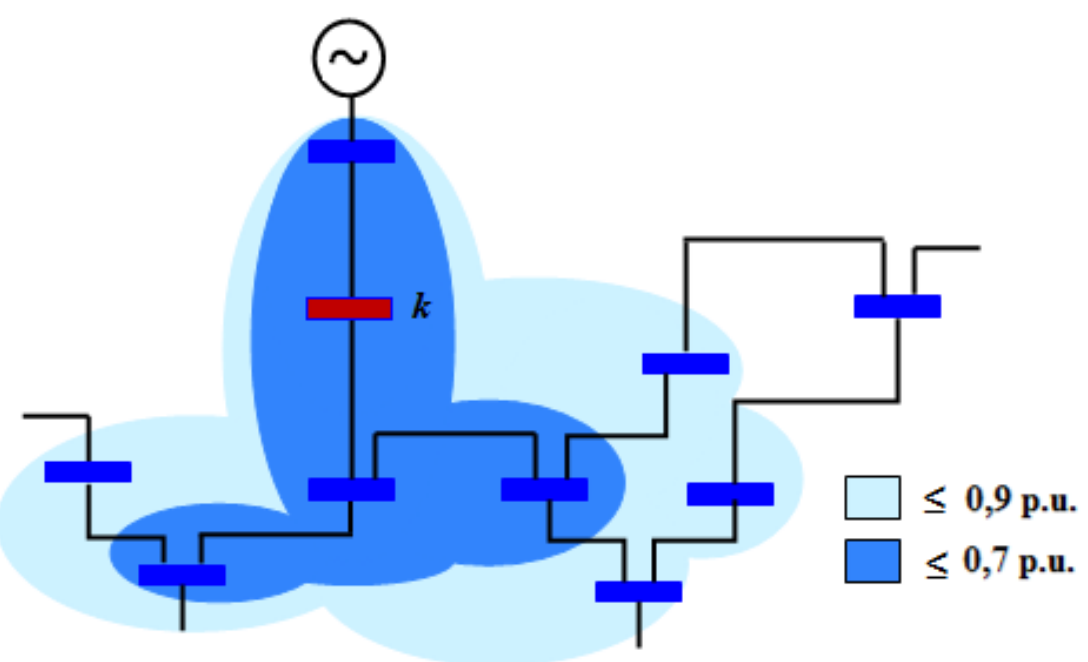

Fonte: Kempner (2012).

Outra importante observação é que as barras que estão mais vulneráveis aos afundamentos de tensão são as que estão eletricamente próximas à barra de observação. Vale ressaltar que a potência de curto-circuito terá papel predominante na obtenção da área exposta, pois quanto menor for a potência de curto-circuito no ponto monitorado, maior será a área de exposição, sendo esta suscetível a afundamentos de tensão severos (GOSWAMI, GUPTA e SINGH, 2008). Diante deste contexto, os barramentos próximos às fontes geradoras irão apresentar uma menor área de vulnerabilidade.

\subsection{Curvas de Sensibilidade às VTCDs}

O desempenho e a vida dos equipamentos elétricos são prejudicados quando são submetidos a tensões diferentes da nominal de operação, considerada pelo fabricante na concepção do equipamento. Portanto, a sensibilidade de um equipamento pode ser definida como a incapacidade deste se manter em operação na presença de alterações no fornecimento de energia além das quais foi projetado.

Deste modo, para estabelecer limites de tolerância das cargas frente às VTCDs, normalmente, são realizados ensaios empíricos com a aplicação de eventos programados em uma família de equipamentos, onde é observada a suportabilidade destes equipamentos na ocorrência dos distúrbios. Posteriormente, são elaboradas curvas de sensibilidade atendendo tais limites, cujos eixos representam a intensidade e a duração das VTCDs. 
Com o objetivo de relacionar o impacto causado pelas VTCDs com a sensibilidade de equipamentos eletroeletrônicos, fornecendo uma relação causa versus efeito, foi introduzida em 1978 por Thomas Key, a curva CBEMA (Computer Business Equipment Manufacturer Association), publicada na norma IEEE Std. 446 (1987). Esta foi originalmente desenvolvida para descrever a tolerância típica de diferentes computadores "mainframe" às variações de tensão tanto em magnitude quanto em duração do evento.

A curva original, que pressupõe afundamentos e elevações de tensão representava as regiões de operação para os equipamentos eletrônicos e os limites de mínimo e de máximo que a tensão de alimentação da rede elétrica poderia variar sem que os equipamentos eletrônicos sofressem qualquer tipo de efeito, sejam estes de desligamento ou dano, conforme ilustra a Figura 9, na qual as três regiões distintas de operação representam:

- Região A - Região de operação normal ou imunidade: os equipamentos não sofrem alteração em seu funcionamento para distúrbios de alimentação localizados nesta região.

- Região B - Região de susceptibilidade: operações nesta região apresentam possibilidade de ruptura da isolação dos equipamentos (danos permanentes aos componentes), devido às sobretensões transitórias e elevações de tensões.

- Região C - Região de sensibilidade ou desligamento: ocorre a possibilidade de falhas de operação dos equipamentos em virtude dos afundamentos de tensão ou das interrupções momentâneas.

Figura 9 - Curva de sensibilidade para computadores (CBEMA).

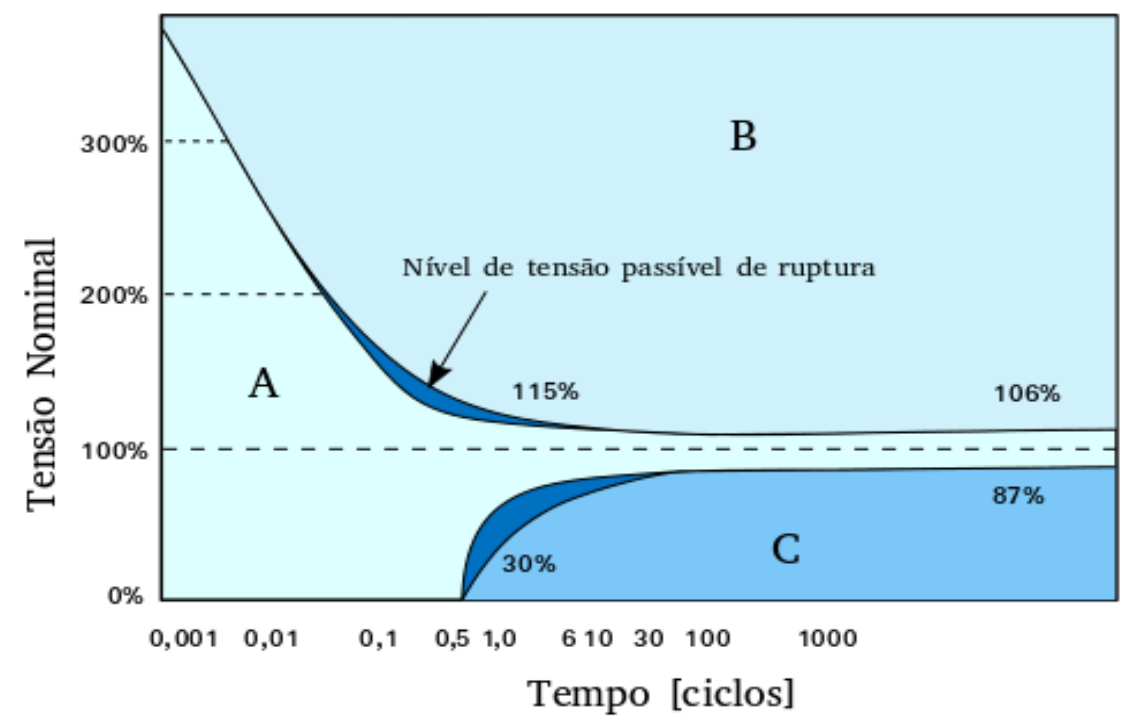

Fonte: Adaptado de IEEE STD 446 (1987). 
No ano de 2000, foram realizadas algumas modificações de faixa de amplitude em relação à curva CBEMA para melhor caracterizar a sensibilidade dos computadores e equipamentos eletrônicos relacionados à tecnologia da informação. Assim, a curva ITIC (Information Technology Industry Council), apresentada na Figura 10, tornou-se mais indicada na avaliação da sensibilidade destes equipamentos.

Figura 10 - Curva de sensibilidade para equipamentos de tecnologia da informação (ITIC).

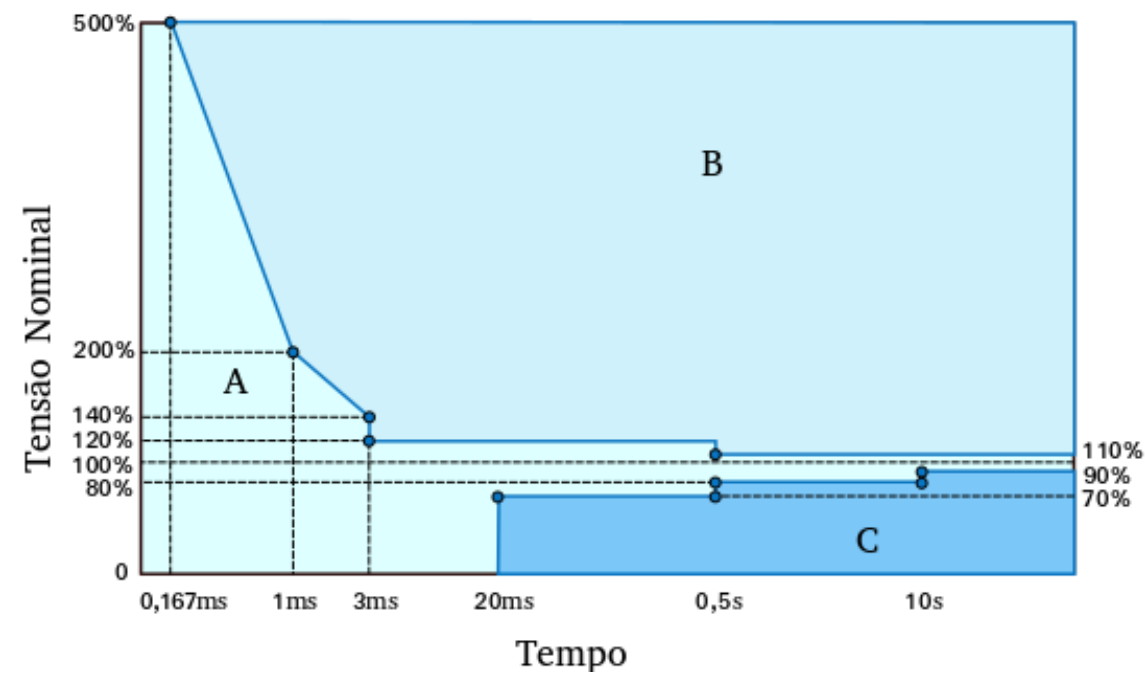

Fonte: Adaptado de ITI (CBEMA) (2000).

Outra curva desenvolvida para verificar a imunidade dos equipamentos e processos ligados a fabricantes de semicondutores, foi a curva SEMI (Specification for Semiconductor Processing Equipment Voltage Sag Immunity), publicada na norma SEMI F47-0706 (2006). Esta norma abrange apenas os afundamento de tensão, não contemplando as elevações de tensão, sendo que, os equipamentos não sofrerão alteração em seu funcionamento na ocorrência de distúrbios com magnitude e duração que contemplem a região $\mathrm{A}$, como mostrado na Figura 11.

No que tange às informações contidas na Figura 11, são toleráveis os afundamentos de tensão: de 0,1 a 0,5 p.u. com duração de até 20ms; assim como maiores que 0,5 a 0,7 p.u., com duração de até $200 \mathrm{~ms}$; os afundamentos maiores que 0,7 a 0,8 p.u. com duração até 500ms; e ainda, afundamentos maiores que 0,8 a 0,9 p.u. com até 10 segundos de duração.

Além das normas citadas, há ensaios de tolerância de vários equipamentos sensíveis às VTCDs. Na norma IEEE Std. 1346 (1998), por exemplo, foram realizados ensaios de sensibilidade dos principais equipamentos encontrados nas indústrias, sumarizados na Tabela 4 (BOLLEN, 1999). Os valores para os limites e a média apresentados na Tabela 4, referemse ao tempo (ms) e a magnitude da tensão remanescente (\%) em relação ao seu valor nominal. 
Figura 11 - Curva de suportabilidade para equipamentos semicondutores.

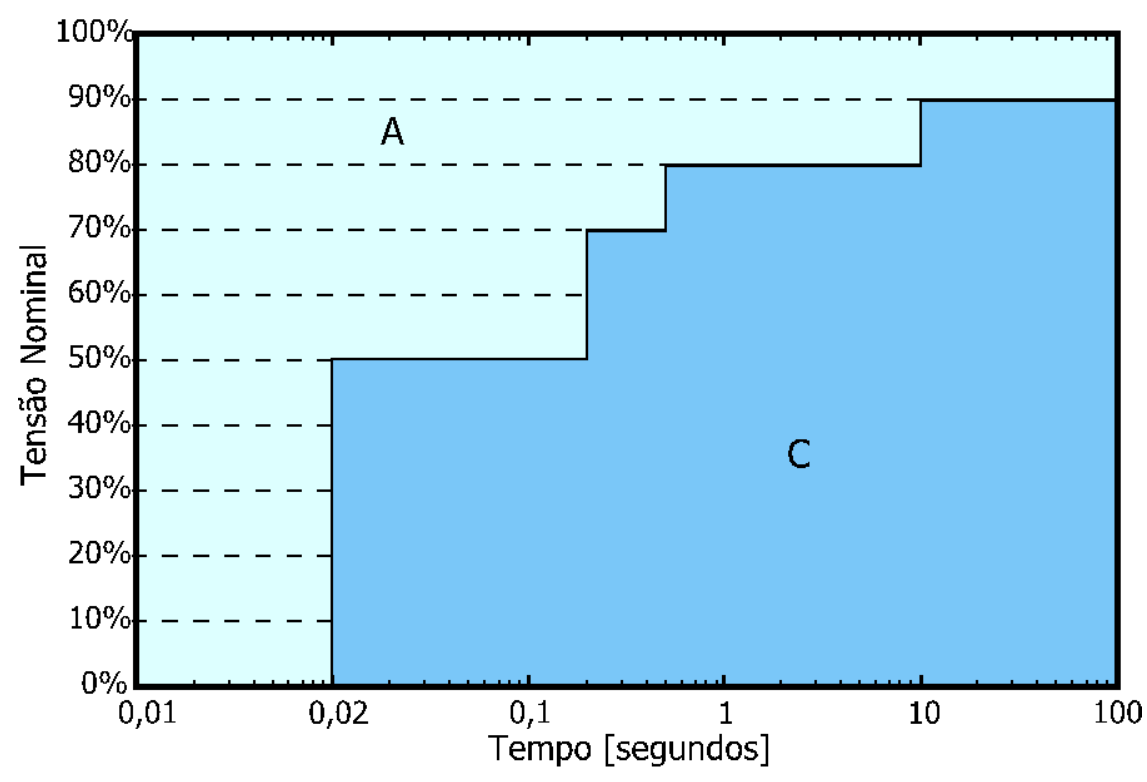

Fonte: Adaptado de SEMI F47-0706 (2006).

Tabela 4 - Tolerância para a tensão dos principais equipamentos na indústria.

\begin{tabular}{c|c|c|c}
\hline \hline \multicolumn{4}{c}{ Tolerância de tensão } \\
\hline Equipamento & Limite superior & Média & Limite inferior \\
\hline \hline CLP & $20 \mathrm{~ms}, 75 \%$ & $260 \mathrm{~ms}, 60 \%$ & $620 \mathrm{~ms}, 45 \%$ \\
\hline Cartão de entrada CLP & $20 \mathrm{~ms}, 80 \%$ & $40 \mathrm{~ms}, 55 \%$ & $40 \mathrm{~ms}, 30 \%$ \\
\hline Driver AC 5 HP & $30 \mathrm{~ms}, 80 \%$ & $50 \mathrm{~ms}, 75 \%$ & $80 \mathrm{~ms}, 60 \%$ \\
\hline Relés de controle AC & $10 \mathrm{~ms}, 75 \%$ & $20 \mathrm{~ms}, 65 \%$ & $30 \mathrm{~ms}, 60 \%$ \\
\hline Partida de motor & $20 \mathrm{~ms}, 60 \%$ & $50 \mathrm{~ms}, 50 \%$ & $80 \mathrm{~ms}, 40 \%$ \\
\hline Computador pessoal & $30 \mathrm{~ms}, 80 \%$ & $50 \mathrm{~ms}, 60 \%$ & $70 \mathrm{~ms}, 50 \%$ \\
\hline
\end{tabular}

Fonte: Bollen (1999).

No trabalho realizado por Leborgne (2003) também é analisada de forma detalhada a sensibilidade dos principais componentes e cargas presentes nos processos industriais, tais como contatores, acionamentos de velocidade variável, motores de indução, entre outros dispositivos.

Muito embora nos levantamentos bibliográficos se reconheça a existência de procedimentos de testes para a elaboração de curvas de sensibilidade dos mais distintos equipamentos, as informações relativas às curvas de suportabilidade são ainda incipientes, devido, principalmente, à diversidade de fabricantes de produtos similares e à inexistência de normas e padrões a serem obedecidos pelos fabricantes de equipamentos eletrônicos. 
Desta forma, por falta de outras curvas que sirvam de parâmetro para diagnosticar o limite dos efeitos dos afundamentos de tensão nos processos produtivos, onde principalmente os consumidores industriais estão inseridos, os limites de tolerância estabelecidos pela curva ITIC estão sendo amplamente utilizados como limites de tolerância típica de equipamentos micro processados, de forma a evitar o desligamento ou mau funcionamento dos mesmos (LUNA, 2005).

Entretanto, há de se esclarecer que esta curva não deve ser aplicada a todos os tipos de cargas sensíveis, pois não foi gerada para tal finalidade. Uma vez que os efeitos das VTCDs ocorrem de forma diferenciada, em função da sensibilidade dos equipamentos eletroeletrônicos instalados, o ideal seria cada fabricante disponibilizar informações sobre a sensibilidade do equipamento frente aos distúrbios.

Deste modo, conhecidas as curvas de sensibilidade dos equipamentos e o desempenho do sistema elétrico, seria possível analisar os locais onde ocorre maior exposição das cargas a esses distúrbios e evitar o mau funcionamento temporário ou danos permanentes dos equipamentos e até mesmo orientar na instalação de novos consumidores, com processos industriais sensíveis.

Outra vantagem da definição das curvas de sensibilidade é que indicadores de VTCDs podem ser utilizados para correlacionar os níveis de sensibilidade dos diversos tipos de equipamentos conectados ao sistema, como poderá ser observado na próxima seção.

\subsection{Indicadores de VTCDs}

Com o crescente nível de exigência dos consumidores relativos a problemas com a QEE fornecida pelas distribuidoras de energia, as agências reguladoras vêm, constantemente, definindo e atualizando normas e resoluções que visam garantir os direitos dos consumidores, de forma a melhorar a qualidade do fornecimento de energia. Nestas circunstâncias, as distribuidoras têm necessidade de avaliar seus sistemas de modo a quantificar e evidenciar os pontos críticos em suas redes elétricas.

Com o objetivo de realizar análises tanto qualitativas como quantitativas dos fenômenos que afetam a QEE, geralmente, buscam-se índices do desempenho dos SEP. Para a caracterização das VTCDs, em geral, estes índices correspondem à frequência de ocorrência dos eventos que são agrupados por faixas de amplitude e de duração, para posterior análise do impacto ocasionado em consumidores com cargas sensíveis. 
Para que seja possível obter índices de desempenho do sistema confiáveis, tornam-se necessárias campanhas de medição de qualidade, que exigem uma monitoração contínua, cujo custo é bastante elevado. Além de necessitar de instrumentação específica que atenda a normas técnicas é imprescindível que os equipamentos estejam adequadamente distribuídos, de forma que seja possível monitorar o maior número possível de ocorrência dos eventos, evidenciando a motivação e contribuição deste trabalho.

Neste cenário, nesta seção são apresentados os índices mais utilizados na literatura correlata que procuram caracterizar as VTCDs, destacando as vantagens e desvantagens na utilização de cada índice. Estes índices são baseados, geralmente, nas normas internacionais do IEC ou do IEEE, e se utilizam, na maioria das vezes, de uma abordagem estatística para retratar os resultados. Dependendo do objetivo desejado, podem ser calculados índices individuais, que levam em consideração a característica de um único evento, índices locais, que calculam o desempenho de um local específico, considerando a ocorrência de vários eventos, ou ainda, podem-se calcular índices de desempenho do sistema, que avaliam como as ocorrências de vários eventos, em locais diferentes, afetam o desempenho do SD.

\subsection{1 Índices Vigentes}

O artigo apresentado por Bollen, Sabin e Thallam (2003) apresenta um resumo das discussões sobre o desenvolvimento de índices, os quais procuram melhor retratar os afundamentos de tensão, o aprovados pelo IEEE em janeiro de 2000. O documento elaborado (IEEE STD 1564, 2001) recomenda uma metodologia para o cálculo e a definição de índices para afundamentos de tensão. Pelos autores, o cálculo de diversos índices pode ser realizado após a obtenção das tensões do sistema, provenientes de medições coletadas da rede elétrica ou de simulações computacionais. A partir destas, pode-se inferir índices para cada evento isolado, para um ponto de observação em específico, ou para um sistema mais complexo. O fluxograma desta metodologia é apresentado na Figura 12.

Pelo esquema apresentado, a partir das medições, ou simulações, certas características em função do tempo podem ser calculadas. Para a obtenção das tensões do sistema a partir de medições, torna-se necessário que os equipamentos estejam adequadamente distribuídos, de forma que seja possível monitorar determinados pontos de observação considerados importantes. 
Figura 12 - Metodologia para o cálculo de índices de afundamentos de tensão.

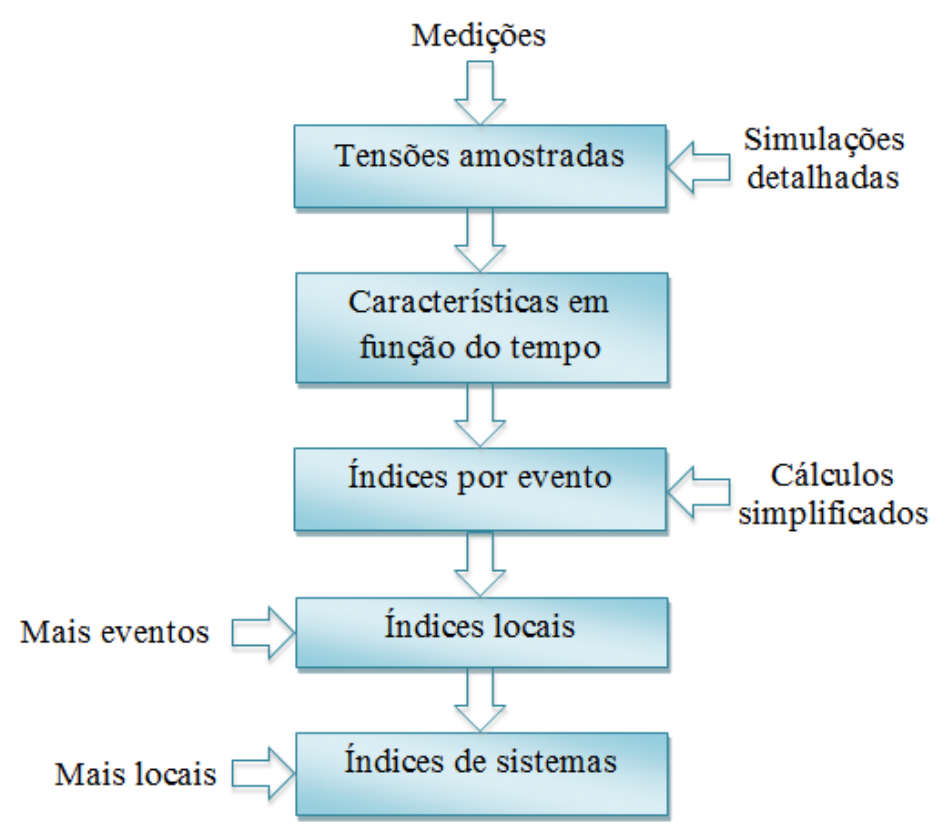

Fonte: Adaptado de Bollen, Sabin e Thallam (2003).

Após obter as tensões amostradas, para o cálculo dos índices, faz-se necessário a definição de alguns valores de referência em função do tempo, como a tensão RMS ( $\left.\mathrm{U}_{\mathrm{rms}}\right)$ relativa aos dados coletados, a tensão residual, e a duração dos eventos.

A tensão RMS é o valor da tensão média quadrática medida durante um ciclo e atualizada a cada meio ciclo. Para medições realizadas em uma única fase, a tensão RMS pode ser calculada pela equação (3), na qual $N$ é o número de amostras por ciclo, $u(k)$ representa a forma de onda de tensão amostrada, e $k$ o número de amostras.

$$
U_{r m s}(n)=\sqrt{\frac{1}{N} \sum_{k=1+n \frac{N}{2}}^{\left(\frac{n}{2}+1\right) N} u(k)^{2}}
$$

Uma vez determinada a tensão RMS e a duração dos eventos, torna-se possível o cálculo de diversos índices, sejam eles individuais, locais, ou para um sistema em específico, considerando vários pontos de monitoração. Os índices citados no artigo são o índice SARFI (System Average RMS variation Frequency Index), a utilização de tabelas que correlacionam a tensão residual e a duração dos eventos e índices de energia do afundamento, que serão descritos com maiores detalhes na sequência.

Segundo as recomendações da norma técnica (IEC 61000-4-30, 2003) e do (IEEE STD 1564, 2001), compiladas em um estudo realizado pelo grupo Cigré (2004), para obter o 
desempenho do sistema que permita o cálculo de índices relativos aos afundamentos de tensão, inicialmente, deve-se obter a amplitude e duração do distúrbio, ou a tensão residual e a duração do afundamento, considerando, no mínimo, um ano de avaliação. Sendo que, a amplitude é determinada pelo menor valor da tensão RMS amostrada, e a tensão residual é a diferença entre a tensão de referência e a amplitude do afundamento.

Posteriormente, o trabalho realizado pelo grupo Cigré (2004), aborda cada um dos índices apresentados na literatura técnica. Entre os índices abordados é citado o índice SARFI, que contabiliza o número de ocorrências dos afundamentos de tensão com duração entre meio ciclo e um minuto para um dado ponto de observação, calculado através da equação (4).

$$
\operatorname{SARFI}_{x}=\frac{\sum N_{c}}{N_{T}}
$$

Sendo:

$x$ - a informação em subscrito com relação a um limiar considerado para o cálculo $\left(\mathrm{SARFI}_{\% \mathrm{~V}}\right)$, ou relacionado a uma curva de sensibilidade $\left(\mathrm{SARFI}_{\mathrm{itic}}\right)$;;

$N_{c}$ - o número de clientes que são afetados por variações cuja magnitude é menor que o valor de referência $x$;

$N_{T}$ - o número de clientes supridos pelo alimentador, barra ou sistema analisado.

Neste índice, pelas indicações em subscrito $(x)$, quantificam-se os afundamentos de tensão abaixo dos limites especificados, ou abaixo da curva de sensibilidade. Um índice $\mathrm{SARFI}_{50}=6$, por exemplo, significa, que no local monitorado houve 6 afundamentos de tensão com tensão remanescente menor do que $50 \%$ da tensão eficaz.

O uso deste índice tem se tornado bastante popular nos EUA e em partes da Ásia, pela simplicidade da metodologia, que depende apenas do número total de eventos, e por permitir a comparação entre locais e sistemas diferentes. A desvantagem deste índice é que as informações sobre a duração dos eventos não são armazenadas, portanto, não é possível estabelecer os níveis de sensibilidade dos diversos tipos de equipamentos conectados ao SD.

Para determinar os níveis de sensibilidade dos equipamentos é citado no Cigré (2004) o uso de um gráfico que define sete regiões de sensibilidade conforme a duração do evento, definidas à partir das características de proteção e compatibilidade dos equipamentos sensíveis. Este gráfico, proposto pela norma Sul-Africana (NRS 048-2, 2003), classifica os afundamentos de acordo com a Tabela 5, onde a frequência de ocorrência dos distúrbios são distribuídos conforme a severidade e duração dos eventos. 
Tabela 5 - Gráfico de sensibilidade segundo a norma Sul-Africana.

\begin{tabular}{|c|c|c|c|}
\hline \multirow{2}{*}{$\begin{array}{c}\text { Tensão } \\
\text { remanescente }\end{array}$} & \multicolumn{3}{|c|}{ Duração } \\
\hline & $20<\mathrm{t} \leq 150(\mathrm{~ms})$ & $150<\mathrm{t} \leq 600(\mathrm{~ms})$ & $0,6<t \leq 3(s)$ \\
\hline $90>V \geq 85 \%$ & \multirow{2}{*}{\multicolumn{2}{|c|}{ Categoria Y }} & \multirow{3}{*}{ Categoria Z1 } \\
\hline $85>V \geq 80 \%$ & & & \\
\hline $80>V \geq 70 \%$ & & \multirow{3}{*}{ Categoria S } & \\
\hline $70>V \geq 60 \%$ & Categoria X1 & & \multirow{3}{*}{ Categoria Z2 } \\
\hline $60>V \geq 40 \%$ & Categoria X2 & & \\
\hline $40>V \geq 0 \%$ & \multicolumn{2}{|c|}{ Categoria T } & \\
\hline
\end{tabular}

Fonte: Adaptado de NRS 048-2 (2003).

Pela norma NRS 048-2, a intensidade do afundamento de tensão é definida como o menor valor RMS da tensão registrada nas três fases. Já a duração é caracterizada como sendo a duração associada à pior fase afetada em cada evento registrado.

$\mathrm{Na}$ Tabela 5 a área em azul (categoria Y), representa os afundamentos de tensão de amplitude reduzida que não afetam a maioria das cargas sensíveis. As categorias X1 e X2 refletem os afundamentos que não afetam o SEP por um tempo prolongado, desta forma, normalmente, o sistema elétrico é reestabelecido após a atuação da proteção, não ocasionando maiores impactos às cargas. A categoria $\mathrm{S}$ é uma região intermediária, sendo mais críticos os afundamentos com tensões remanescentes menores que 0,6 p.u.. Os afundamentos de tensão que se encaixam na categoria $\mathrm{T}$ se referem às faltas muito próximas ao ponto de observação. Já nas categorias Z1 e Z2 se concentram as variações de elevada severidade, devido à duração dos eventos, que provavelmente afetarão uma grande parte de cargas sensíveis.

Devido à existência de várias topologias de redes elétricas no país, a norma SulAfricana NRS 048-2 não estabelece limites para distribuidoras e consumidores. Entretanto, estabelece a quantidade aceitável de eventos ao ano, a qual poderá ser usada para indicar um bom desempenho da rede em termos da QEE. Estes valores são definidos por classe de tensão e por tipo de categoria conforme apresentado na Tabela 6 (para 95\% dos pontos de medição) e na Tabela 7 (para 50\% dos pontos de medição).

Apesar da norma NRS 048-2 estabelecer regiões de sensibilidade, após a apuração dos dados não é possível especificar com exatidão a amplitude e a duração do afundamento. Se ocorrerem 10 eventos do tipo $Y$, por exemplo, pela Tabela 5, sabe-se que os eventos podem ter manifestado tensões remanescentes entre 90 e $70 \%$ com duração de até 3 segundos, mas não é possível fornecer dados precisos, outra desvantagem da norma é a impossibilidade de registrar no gráfico os eventos superiores a 3 segundos, que apesar de mais raros de acontecer, trazem um grande impacto para as cargas sensíveis. 
Tabela 6 - Números de afundamentos por ano (para 95\% dos pontos de medições).

\begin{tabular}{|c|c|c|c|c|c|c|}
\hline \hline \multirow{2}{*}{$\begin{array}{c}\text { Tensão nominal } \\
(\mathbf{k V})\end{array}$} & \multicolumn{6}{|c|}{ Número de afundamentos por ano conforme a categoria } \\
\cline { 2 - 7 } & $\mathbf{X 1}$ & $\mathbf{X 2}$ & $\mathbf{T}$ & $\mathbf{S}$ & $\mathbf{Z 1}$ & $\mathbf{Z 2}$ \\
\hline \hline $6,6<\mathrm{V} \leq 44$ (rural) & 85 & 210 & 115 & 400 & 450 & 450 \\
\hline $6,6<\mathrm{V} \leq 44$ & 20 & 30 & 110 & 30 & 20 & 45 \\
\hline $44<\mathrm{V} \leq 132$ & 35 & 35 & 25 & 40 & 40 & 10 \\
\hline $220<\mathrm{V} \leq 765$ & 30 & 30 & 20 & 20 & 10 & 5 \\
\hline
\end{tabular}

Fonte: Adaptado de NRS 048-2 (2003).

Tabela 7 - Números de afundamentos por ano (para 50\% dos pontos de medições).

\begin{tabular}{|c|c|c|c|c|c|c|}
\hline \hline \multirow{2}{*}{$\begin{array}{c}\text { Tensão nominal } \\
(\mathbf{k V})\end{array}$} & \multicolumn{6}{|c|}{ Número de afundamentos por ano conforme a categoria } \\
\cline { 2 - 7 } & $\mathbf{X 1}$ & $\mathbf{X 2}$ & $\mathbf{T}$ & $\mathbf{S}$ & $\mathbf{Z 1}$ & $\mathbf{Z 2}$ \\
\hline \hline $6,6<\mathrm{V} \leq 44$ (rural) & 13 & 12 & 10 & 13 & 11 & 10 \\
\hline $6,6<\mathrm{V} \leq 44$ & 7 & 7 & 7 & 6 & 3 & 4 \\
\hline $44<\mathrm{V} \leq 132$ & 13 & 10 & 5 & 7 & 4 & 2 \\
\hline $220<\mathrm{V} \leq 765$ & 8 & 9 & 3 & 2 & 1 & 1 \\
\hline
\end{tabular}

Fonte: Adaptado de NRS 048-2 (2003).

Para correlacionar a amplitude da tensão com a duração dos afundamentos, são apresentadas várias tabelas, que se diferenciam, basicamente, pelas faixas de tensão residual e de tempo adotadas para separar os eventos. As tabelas mais usuais e referenciadas pelo Cigré são as tabelas de densidade, onde as colunas representam a duração do evento, e as linhas representam as tensões remanescentes, registradas durante um ano de apuração.

A Tabela 8 mostra, por exemplo, as faixas de amplitude e duração recomendadas pelo grupo (UNIPEDE, 1996). Na Tabela 9 estão representadas as faixas de magnitude e duração adotadas pelo (IEC 61000-4-30, 2003), e a Tabela 10 apresenta as faixas referenciadas de acordo com o (IEEE STD 1564, 2001).

Tabela 8 - Densidade dos afundamentos de tensão, como recomendado pelo grupo UNIPEDE.

\begin{tabular}{|c|c|c|c|c|c|c|c|c|}
\hline \hline \multirow{2}{*}{$\begin{array}{c}\text { Tensão } \\
\text { residual }\end{array}$} & \multicolumn{7}{|c|}{ Duração do evento } \\
\hline \hline $85-90 \%$ & $20-100 \mathrm{~ms}$ & $100-500 \mathrm{~ms}$ & $0,5-1 \mathrm{~s}$ & $1-3 \mathrm{~s}$ & $3-20 \mathrm{~s}$ & $20-60 \mathrm{~s}$ & $60-180 \mathrm{~s}$ & $60-180 \mathrm{~s}$ \\
\hline $70-85 \%$ & & & & & & & & \\
\hline $40-70 \%$ & & & & & & & & \\
\hline $10-40 \%$ & & & & & & & & \\
\hline$<10 \%$ & & & & & & & & \\
\hline
\end{tabular}

Fonte: Adaptado de Cigré (2004). 
Tabela 9 - Densidade dos afundamentos de tensão, de acordo com a norma IEC 61000-2-8.

\begin{tabular}{|c|c|c|c|c|c|c|c|c|}
\hline \multirow{2}{*}{$\begin{array}{l}\text { Tensão } \\
\text { residual }\end{array}$} & \multicolumn{8}{|c|}{ Duração do evento } \\
\hline & 1 ciclo- $0,1 \mathrm{~s}$ & $0,1-0,25 \mathrm{~s}$ & $0,25-0,5 \mathrm{~s}$ & $0,5-1 \mathrm{~s}$ & $1-3 \mathrm{~s}$ & $3-20 \mathrm{~s}$ & $20-60 \mathrm{~s}$ & $60-180 \mathrm{~s}$ \\
\hline \multicolumn{9}{|l|}{$80-90 \%$} \\
\hline \multicolumn{9}{|l|}{$70-80 \%$} \\
\hline \multicolumn{9}{|l|}{$60-70 \%$} \\
\hline \multicolumn{9}{|l|}{$50-60 \%$} \\
\hline \multicolumn{9}{|l|}{$40-50 \%$} \\
\hline \multicolumn{9}{|l|}{$30-40 \%$} \\
\hline \multicolumn{9}{|l|}{$20-30 \%$} \\
\hline \multicolumn{9}{|l|}{$10-20 \%$} \\
\hline$<10 \%$ & & & & & & & & \\
\hline
\end{tabular}

Fonte: Fonte: Adaptado de Cigré (2004).

Tabela 10 - Densidade dos afundamentos de tensão, de acordo com a norma IEEE STD 1564.

\begin{tabular}{|c|c|c|c|c|c|}
\hline \multirow{2}{*}{$\begin{array}{l}\text { Tensão } \\
\text { residual }\end{array}$} & \multicolumn{5}{|c|}{ Duração do evento } \\
\hline & $<$ 1 ciclo & 1 ciclo- $200 \mathrm{~ms}$ & $0,2-0,5 \mathrm{~s}$ & $0,5-5 \mathrm{~s}$ & $5 \mathrm{~s}-5 \mathrm{~min}$ \\
\hline $70-80 \%$ & & & & & \\
\hline $40-70 \%$ & & & & & \\
\hline $10-40 \%$ & & & & & \\
\hline$<10 \%$ & & & & & \\
\hline
\end{tabular}

Fonte: Adaptado de Cigré (2004).

A vantagem da utilização das tabelas é que as mesmas são de fácil entendimento e de simples aplicação, sendo possível especificar com maior exatidão a amplitude e a duração dos afundamentos. Dependendo da agregação das informações, é possível estabelecer índices de desempenho locais, que indicarão o número de afundamentos de tensão anual em um determinado local, ou índices de desempenho do sistema, os quais irão agregar o número de eventos ocorridos durante um ano em vários locais do sistema. Quando são coletados dados em diversos locais do SD, a informação coletada é normalmente tratada como uma massa única de dados e, após os devidos processamentos, os eventos são distribuídos uniformemente, resultando na diluição da informação entre os pontos monitorados.

A maior desvantagem da utilização das tabelas é que não há um consenso no meio técnico para a escolha das faixas de amplitude e duração, sendo que, a comparação com o desempenho (operação) dos equipamentos depende diretamente das faixas especificadas.

Para que houvesse uma uniformização, as células das tabelas deveriam ser subdivididas de acordo com os valores típicos dos afundamentos de tensão que ocorrem na prática. Como na maioria das pesquisas, como por exemplo, no estudo realizado pelo EPRI 
(2003), o número de ocorrências dos afundamentos de tensão é mais elevado na faixa de um ciclo a um segundo, as colunas pertencentes aos intervalos de maior ocorrência deveriam ser melhor particionadas. Já para durações superiores a 1 segundo, as informações poderiam ser mescladas em um número menor de colunas. Do mesmo modo, a subdivisão das células relativas à amplitude da tensão em muitos intervalos levará a muitas células vazias. Logo, os afundamentos poderiam ser agrupados conforme a sua maior incidência, como na Tabela 8 .

As informações contidas nas tabelas podem ser amostradas através de histogramas tridimensionais. Para demonstrar como estes histogramas são representados, considere os dados extraídos do estudo realizado pelo EPRI (2003), sintetizados na Tabela 11. Com base nesses dados é gerado o gráfico tridimensional ilustrado na Figura 13, onde são exibidas, simultaneamente, as intensidades, durações e frequência de ocorrência dos afundamentos.

Tabela 11 - Número de afundamentos de tensão registrados durante um ano.

\begin{tabular}{|c|c|c|c|c|c|c|c|c|c|}
\hline \multirow{2}{*}{$\begin{array}{c}\text { Tensão } \\
\%\end{array}$} & \multicolumn{9}{|c|}{ Duração em ciclos } \\
\hline & 1 & 2 & 3 & 4 & 5 & $6-10$ & $10-20$ & $20-0,5 s$ & $0,5 s-1 s$ \\
\hline $80-85$ & 0,458 & 0,773 & 0,785 & 0,952 & 0,628 & 1,292 & 1,289 & 0,305 & 0,15 \\
\hline $70-80$ & 0,42 & 1,276 & 1,197 & 0,999 & 0,545 & 1,503 & 1,948 & 0,423 & 0,28 \\
\hline $60-70$ & 0,216 & 0,778 & 0,747 & 0,469 & 0,289 & 0,81 & 0,697 & 0,168 & 0,21 \\
\hline $50-60$ & 0,089 & 0,327 & 0,464 & 0,27 & 0,236 & 0,678 & 0,658 & 0,181 & 0,16 \\
\hline $40-50$ & 0,029 & 0,108 & 0,208 & 0,148 & 0,169 & 0,506 & 0,589 & 0,181 & 0,146 \\
\hline $30-40$ & 0,011 & 0,039 & 0,092 & 0,07 & 0,068 & 0,257 & 0,372 & 0,089 & 0,089 \\
\hline $20-30$ & 0,005 & 0,02 & 0,043 & 0,041 & 0,058 & 0,151 & 0,244 & 0,082 & 0,053 \\
\hline $10-20$ & 0,004 & 0,009 & 0,02 & 0,019 & 0,032 & 0,144 & 0,2 & 0,06 & 0,057 \\
\hline $0-10$ & 0,003 & 0,003 & 0,006 & 0,033 & 0,015 & 0,154 & 0,124 & 0,049 & 0,088 \\
\hline
\end{tabular}

Fonte: Adaptado de EPRI (2003).

Outra forma de representar os índices de afundamentos de tensão é através da construção de gráficos de coordenação por meio de uma interpolação visual das curvas traçadas. Para a construção destas curvas é necessário calcular uma tabela de distribuição acumulada de distúrbios onde são utilizados os limiares de tensão como referência.

Para determinar a distribuição acumulada dos distúrbios, calcula-se o número total de ocorrências de afundamentos de tensão para um determinado limiar, através da somatória das magnitudes e duração do distúrbio (BOLLEN, 1999). Na Tabela 12, por exemplo, é possível perceber que ocorreram 20,149 afundamentos de tensão com tensões residuais abaixo de $80 \%$ da referência e duração maior ou igual a dois ciclos. A obtenção do número 20,149 é feita através da soma da área sombreada na Tabela 11.

Assim, obtém-se a Tabela 12 que traz informações sobre o número total de afundamentos iguais ou piores aos indicados pelas características das linhas e colunas da 
Tabela 11. Após o cálculo da Tabela 12, elaboram-se as curvas de contorno para o desempenho do sistema, conforme ilustra a Figura 14, que representa o número de afundamentos, por ano, em função da severidade observada. Para o exemplo mostrado na Figura 14, o ponto em vermelho representa, em média, que ocorrem 5 afundamentos de tensão por ano, com tensão residual de 0,5 p.u., e duração de dois ciclos. Também se nota, pelo ponto em azul, que, em média, menos de 1 evento por ano apresenta tensão remanescente abaixo de $40 \%$ por mais de 20 ciclos.

Figura 13 - Histograma tridimensional dos afundamentos de tensão.

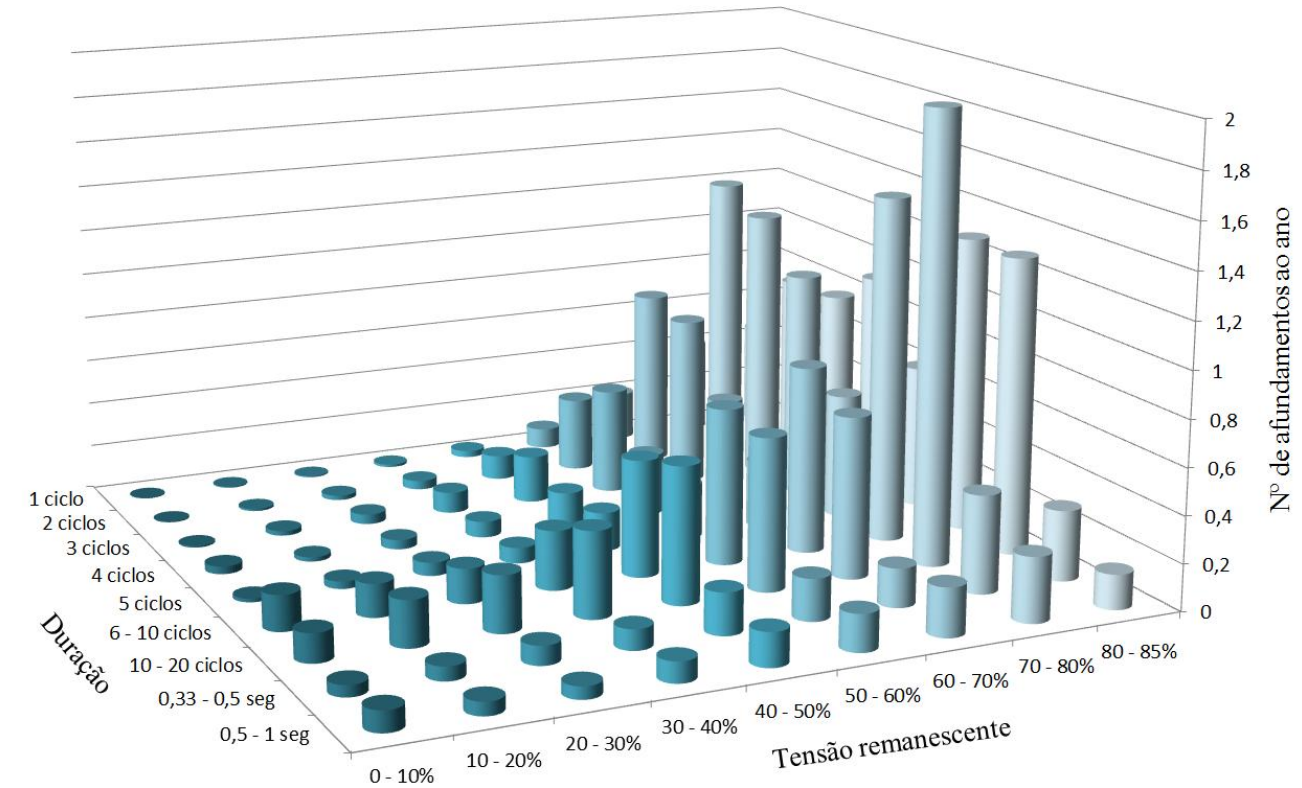

Fonte: Elaborada pela autora a partir dos dados de EPRI (2003).

Tabela 12 - Distribuição acumulada dos afundamentos de tensão.

\begin{tabular}{|c|c|c|c|c|c|c|c|c|c|}
\hline \multirow{2}{*}{$\begin{array}{c}\text { Tensão } \\
\% \\
\end{array}$} & \multicolumn{9}{|c|}{ Duração em ciclos } \\
\hline & 1 & 2 & 3 & 4 & 5 & 6 & 10 & 20 & $0,5 s$ \\
\hline 85 & 27,558 & 26,323 & 22,99 & 19,428 & 16,427 & 14,387 & 8,892 & 2,771 & 1,233 \\
\hline 80 & 20,926 & 20,149 & 17,589 & 14,812 & 12,763 & 11,351 & 7,148 & 2,316 & 1,083 \\
\hline 70 & 12,335 & 11,978 & 10,694 & 9,114 & 8,064 & 7,197 & 4,497 & 1,613 & 0,803 \\
\hline 60 & 7,951 & 7,81 & 7,304 & 6,471 & 5,89 & 5,312 & 3,422 & 1,235 & 0,593 \\
\hline 50 & 4,888 & 4,836 & 4,657 & 4,288 & 3,977 & 3,635 & 2,423 & 0,894 & 0,433 \\
\hline 40 & 2,804 & 2,781 & 2,71 & 2,549 & 2,386 & 2,213 & 1,507 & 0,567 & 0,287 \\
\hline 30 & 1,717 & 1,705 & 1,673 & 1,604 & 1,511 & 1,406 & 0,957 & 0,389 & 0,198 \\
\hline 20 & 1,02 & 1,013 & 1,001 & 0,975 & 0,923 & 0,876 & 0,578 & 0,254 & 0,145 \\
\hline 10 & 0,475 & 0,472 & 0,469 & 0,463 & 0,43 & 0,415 & 0,261 & 0,137 & 0,088 \\
\hline
\end{tabular}

Fonte: Calculado a partir da Tabela 11. 
Figura 14 - Gráfico de coordenação com o registro do número de afundamentos por ano.

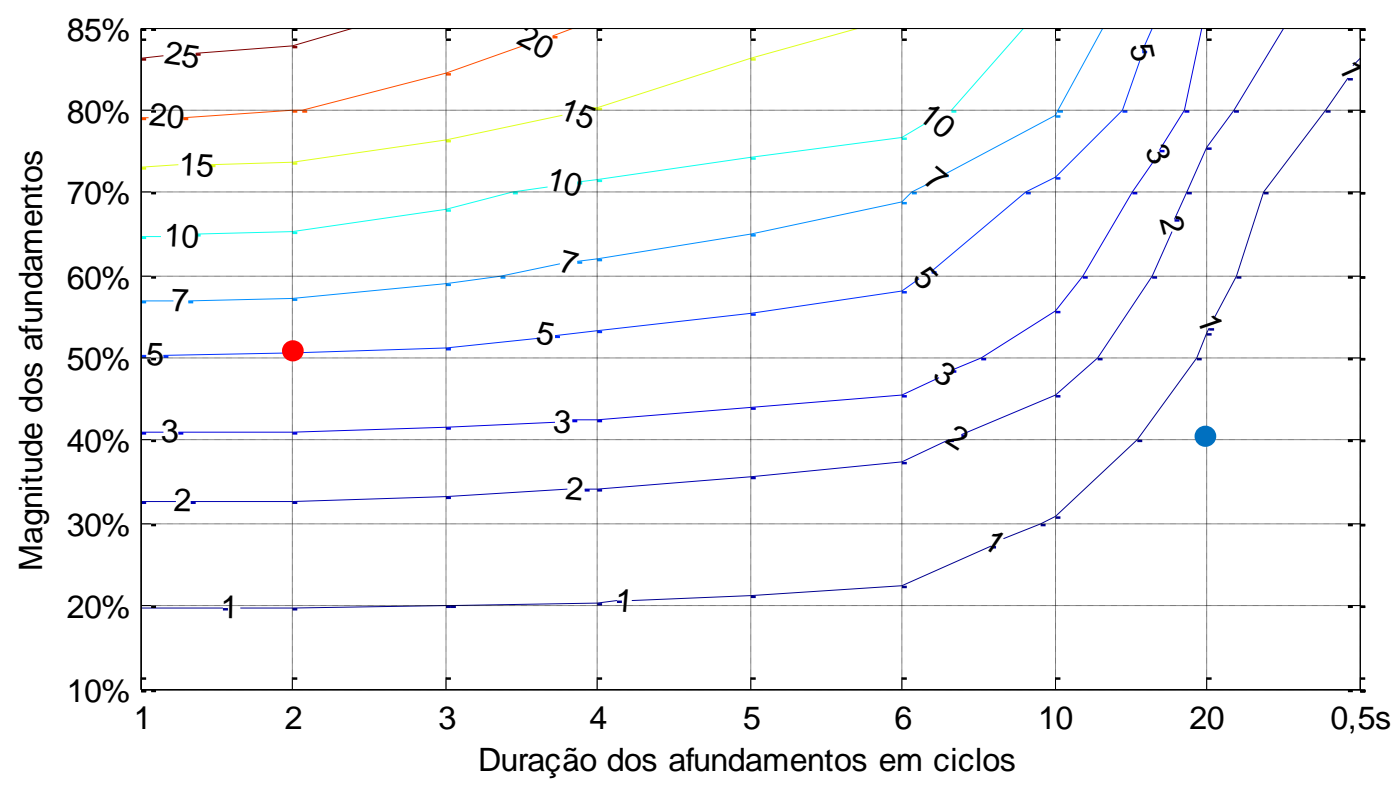

Fonte: Elaborada pela autora a partir dos dados da Tabela 12.

Apesar da complexidade de construção, o gráfico da Figura 14 pode ser diretamente comparado com a sensibilidade dos equipamentos, tornando-se adequado para a troca de dados entre o operador da rede e o consumidor industrial. Informações mais detalhadas de como correlacionar os gráficos de coordenação com curvas de sensibilidade podem ser obtidas em (CONRAD e BOLLEN, 1997) e (IEEE STD 1346, 1998).

Existem ainda, índices que caracterizam os afundamentos em função da energia que deixou de ser entregue ao consumidor, levando em consideração o comportamento da tensão no ponto de interesse ao longo de toda a duração do afundamento $(O$ a $T)$. Para o cálculo do índice de energia do afundamento, primeiro é necessário calcular a energia característica do afundamento de tensão conforme a equação (5) (IEEE STD 1564, 2014).

A integração é feita ao longo da duração do evento, isto é, para todos os valores da tensão eficaz abaixo do limiar, desta maneira, os eventos com maiores durações são penalizados.

$$
E_{v s}=\int_{0}^{T}\left[1-\left\{\frac{V_{(t)}}{V_{n o m}}\right\}^{2}\right] d t \quad \begin{aligned}
& V_{(t)}-\text { tensão eficaz durante o evento } \\
& V_{n o m}-\text { tensão nominal }
\end{aligned}
$$

O índice de energia do afundamento, conhecido na literatura internacional como Sag Energy Index (SEI), é obtido através da soma das energias dos afundamentos de tensão para todos os eventos qualificados em um dado local durante um determinado período, como mostrado na equação (6). Os índices são geralmente calculados mensalmente e anualmente. 


$$
S E I^{\text {local }}=\sum_{i_{-} 1}^{n} E_{v s(i)} \quad \begin{aligned}
& i \text {-número de afundamentos de tensão } \\
& n \text {-número de enventos registrados }
\end{aligned}
$$

O índice de energia média, Average Sag Energy Index (ASEI), calcula a média das energias dos afundamentos de tensão para todos os eventos medidos em um determinado local, durante um determinado período, como mostrado na equação (7).

$$
\text { ASEI }^{\text {local }}=\frac{1}{n} \sum_{i_{-} 1}^{n} E_{v s(i)} \quad \begin{aligned}
& i \text {-número de afundamentos de tensão } \\
& n \text {-número de enventos registrados }
\end{aligned}
$$

Para comparar os resultados de local para local, e de um período para outro, é necessário definir um limiar padronizado. Por ser de fácil aplicação e tornar simples a comparação entre os eventos, este é um índice que tem uma boa aceitação na literatura. Contudo, não é possível fornecer informações sobre as características dos afundamentos que determinam se o evento levaria as cargas a sofrerem desligamentos.

Aplicando a equação (8) é possível obter índices de energia relativos ao desempenho do $\mathrm{SD}$, realizando a somatória da energia que deixou de ser entregue a vários consumidores.

$$
S E I^{\text {sistema }}=\frac{1}{n} \sum_{\text {local_ } 1}^{n} S E I^{\text {local }}
$$

Outro índice referenciado nas pesquisas bibliográficas é o índice de severidade dos afundamentos de tensão, que é calculado comparando as tensões de curvas de sensibilidade (CBEMA, ITIC e SEMI), com a amplitude da tensão em p.u., e a duração do afundamento. A severidade do afundamento é calculada conforme a equação (9) (IEEE STD 1564, 2014).

$$
S_{e}=\frac{1-V}{1-V_{\text {curva }}(d)}
$$

Para eventos cuja magnitude do afundamento de tensão $(V)$ e duração do evento $(d)$ coincida com a magnitude da tensão na curva de referência $\left(V_{\text {curva }}\right)$, o índice de severidade é um. Eventos localizados acima da curva de referência apresentam índices de severidade menor do que um. Já eventos localizados abaixo da curva, o índice de severidade será maior que um. Para a curva SEMI (SEMI F47-0706, 2006), por exemplo, a severidade do afundamento de tensão será calculada conforme a Tabela 13, originando os índices de severidade apresentados na Figura 15, sendo que, para eventos com uma magnitude acima do limite de afundamento de tensão (maior que 0,9 p.u.), a severidade será igual à zero. 
Tabela 13 - Algoritmo para o cálculo da severidade do afundamento de tensão (curva SEMI).

\begin{tabular}{|c|c|c|}
\hline \hline$V_{\text {curva }}$ & Duração $(\boldsymbol{d})$ & Cálculo da severidade \\
\hline \hline 0,0 p.u. & $d \leq 20 \mathrm{~ms}$ & $S_{e}=1-V$ \\
\hline $\mathbf{0 , 5}$ p.u. & $20 \mathrm{~ms}<d \leq 200 \mathrm{~ms}$ & $S_{e}=2 \cdot(1-V)$ \\
\hline 0,7 p.u. & $200 \mathrm{~ms}<d \leq 500 \mathrm{~ms}$ & $S_{e}=3,3 \cdot(1-V)$ \\
\hline 0,8 p.u. & $500 \mathrm{~ms}<d \leq 10 \mathrm{~s}$ & $S_{e}=5 \cdot(1-V)$ \\
\hline 0,9 p.u. & $d>10 \mathrm{~s}$ & $S_{e}=10 \cdot(1-V)$ \\
\hline
\end{tabular}

Fonte: IEEE STD 1564 (2014).

Figura 15 - Severidade do afundamento de tensão para a curva SEMI.

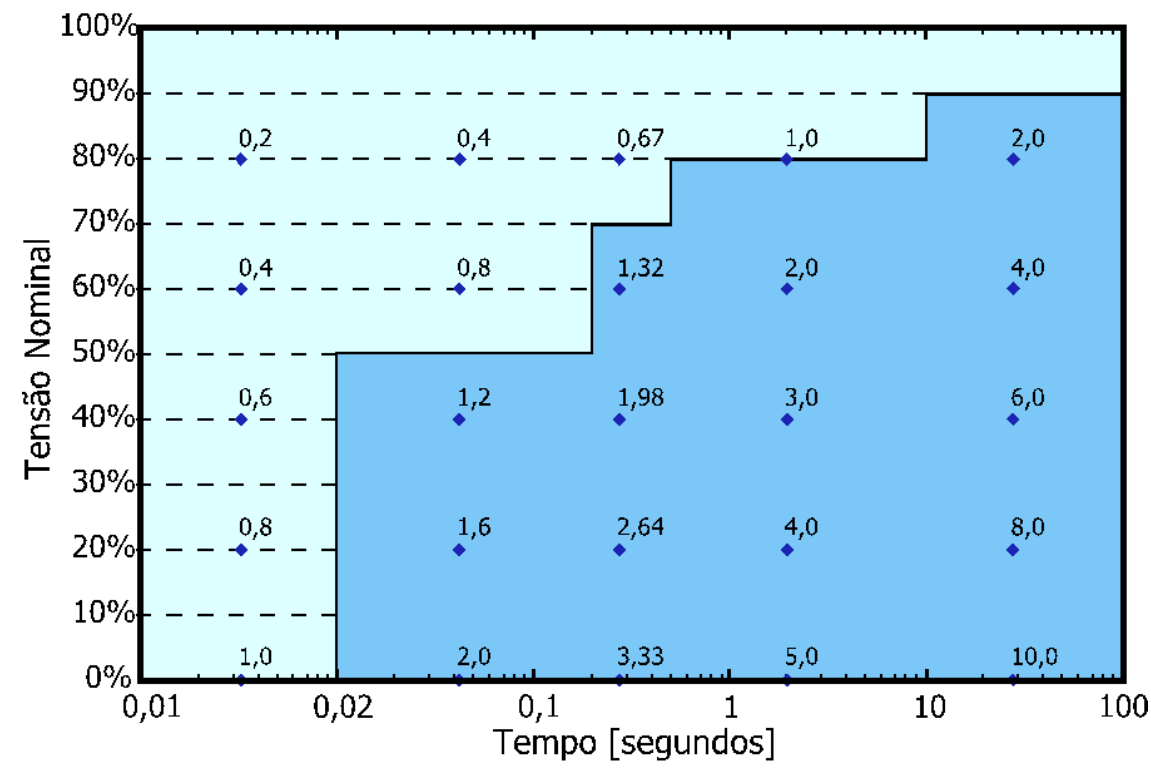

Fonte: Adaptado de IEEE STD 1564 (2014).

O cálculo do índice de severidade local é muito semelhante ao cálculo dos índices de energia, como pode ser observado pela equação (10).

$$
S_{e}^{\text {local }}=\sum_{i_{-} 1}^{n} S_{e(i)} \quad \begin{aligned}
& i \text {-número de afundamentos de tensão } \\
& n \text {-número de enventos registrados }
\end{aligned}
$$

O índice de desempenho do sistema considerando a severidade dos afundamentos de tensão é calculado conforme a equação (11).

$$
S_{e}^{\text {sistema }}=\frac{1}{n} \sum_{\text {local_1 }}^{n} S_{e}^{\text {local }}
$$

Além da simplicidade desse método, a vantagem do cálculo do índice de severidade é a possibilidade de comparação direta com curvas de sensibilidade correlacionando tanto a duração do evento como a magnitude. 
Considerando as vantagens e desvantagens apresentadas de cada índice, a Tabela 14 apresenta uma comparação entre várias características que possibilitam escolher o índice mais adequado dependendo da aplicação desejada.

Tabela 14 - Comparação dos índices.

\begin{tabular}{|l|c|c|c|c|c|c|}
\hline \hline \multicolumn{1}{|c|}{ Características do índice } & $\mathbf{1}$ & $\mathbf{2}$ & $\mathbf{3}$ & $\mathbf{4}$ & $\mathbf{5}$ & $\mathbf{6}$ \\
\hline \hline Índice de desempenho individual & & & & & $\mathrm{X}$ & $\mathrm{X}$ \\
\hline Índice de desempenho local & $\mathrm{X}$ & $\mathrm{X}$ & $\mathrm{X}$ & $\mathrm{X}$ & $\mathrm{X}$ & $\mathrm{X}$ \\
\hline Índice de desempenho do sistema & $\mathrm{X}$ & $\mathrm{X}$ & $\mathrm{X}$ & $\mathrm{X}$ & $\mathrm{X}$ & $\mathrm{X}$ \\
\hline Simplicidade do método & $\mathrm{X}$ & $\mathrm{X}$ & $\mathrm{X}$ & & $\mathrm{X}$ & $\mathrm{X}$ \\
\hline Informações sobre a duração do evento & & $\mathrm{X}$ & $\mathrm{X}$ & $\mathrm{X}$ & $\mathrm{X}$ & $\mathrm{X}$ \\
\hline Exatidão da amplitude e duração & & & $\mathrm{X}$ & $\mathrm{X}$ & & $\mathrm{X}$ \\
\hline Comparação com curvas de sensibilidade & & & $\mathrm{X}$ & $\mathrm{X}$ & & $\mathrm{X}$ \\
\hline Número de ocorrência dos eventos & $\mathrm{X}$ & $\mathrm{X}$ & $\mathrm{X}$ & $\mathrm{X}$ & & \\
\hline Quantidade aceitável de eventos & & $\mathrm{X}$ & & & & \\
\hline
\end{tabular}

Índices:

$\begin{array}{lll}\mathbf{1} \text { - SARFI } & \mathbf{3} \text { - Tabelas } & \mathbf{4} \text { - Gráfico de coordenação } \\ \mathbf{2} \text { - NRS 048 } & \mathbf{4} \text { - Gráfico de coordenação } & \mathbf{5} \text { - Energia do afundamento }\end{array}$

É importante salientar que nenhum dos índices existentes apresenta valores limites de ocorrência dos eventos, apesar da norma NRS 048-2 estabelecer a quantidade aceitável de eventos ao ano, (o que pode vir a indicar um bom desempenho da rede em termos da QEE), é relatado que devido à existência de várias topologias de redes elétricas no país, não é possível estabelecer limites aceitáveis para distribuidoras e consumidores.

Para finalizar este item, cabe colocar que, embora ainda não exista um consenso quanto a melhor forma de caracterizar as VTCDs, com normas padronizadas para o cálculo e determinação de índices, os estudos já realizados, e os que ainda serão, são de fundamental importância para garantir a regulação dos serviços, através da criação, supervisão e controle de indicadores para a QEE. Neste sentido, a exigência de índices de qualidade adequados, por parte dos órgãos reguladores, criará condições para preservar e melhorar a QEE, garantindo um atendimento adequado e contínuo aos consumidores finais.

Devido à necessidade de definição de limites aceitáveis para as VTCDs, fundamental para um desejado avanço no entendimento e controle dos referidos distúrbios de modo a se ter uma efetiva melhora da QEE, no Brasil, foi realizada pela ANEEL uma consulta pública (CP $N^{o} 18 / 2014,2014$ ), com a proposição de estabelecer um indicador e limites de ocorrência das VTCDs, de forma a obter subsídios para a regulamentação destes distúrbios. As contribuições encaminhadas à ANEEL, referindo-se à adequabilidade dos limites propostos e alternativas para a revisão da seção 8.1 do Módulo 8 do PRODIST, são discutidas no Apêndice A. 


\section{Capítulo 3}

\section{Metodologia de Cálculo para Estimação das VTCDs}

Determinar a intensidade das VTCDs é de vital importância para estabelecer a influência e a propagação deste distúrbio sobre todas as barras do SD. Essas informações são fundamentais para a análise da robustez do SD e também para o estabelecimento da compatibilidade entre os níveis de sensibilidade dos diversos tipos de equipamentos conectados ao sistema. Assim sendo, neste capítulo é apresentada uma revisão bibliográfica com uma breve descrição de várias pesquisas que se utilizaram do MPF para a previsão das VTCDs, sendo também citadas as comparações deste método analítico com outras metodologias de cálculo e simulações computacionais na ocorrência de defeitos no sistema elétrico.

Ainda neste capítulo serão apresentados os conceitos necessários para a previsão da magnitude destes fenômenos através do MPF. Esta metodologia é inerentemente baseada na matriz impedância de barra de sequência do sistema. Portanto, é indispensável a contextualização para a obtenção desta matriz para, posteriormente, obter uma matriz que registra as tensões em todos os nós do SD para cada tipo de curto-circuito.

\subsection{Revisão Bibliográfica}

Um dos trabalhos pioneiros referentes à importância de se estudar os afundamentos de tensão originados por faltas no sistema elétrico foi publicado por Conrad, Little e Grigg (1991), no qual os autores descrevem algumas técnicas gerais para a predição, redução e prevenção dos problemas associados aos afundamentos momentâneos de tensão. O MPF, utilizado pelos autores para obter as tensões remanescentes durante a ocorrência de curtoscircuitos, consiste em calcular o número de eventos esperados para cada elemento da rede e classificá-los em uma tabela pela amplitude, duração e frequência. A amplitude dos 
afundamentos é determinada por simulações de curtos-circuitos, a duração pelos valores típicos de ajustes das proteções existentes e a frequência pela taxa de falhas e dados de confiabilidade.

A norma IEEE STD 493 (1997) propõe metodologias para calcular as características dos afundamentos de tensão, tais como, intensidade, duração e frequência de ocorrência. A intensidade do afundamento em um determinado local pode ser obtida através do cálculo do curto-circuito quando são conhecidas as impedâncias da rede, a impedância da falta e a localização da falta. A duração do evento pode ser estimada conhecendo-se os tempos típicos de atuação das proteções envolvidas. Através do conhecimento das estatísticas de faltas do sistema pode-se estimar o número de afundamentos de tensão para qualquer nó de interesse.

Um importante trabalho referente à estimativa dos afundamentos de tensão é apresentado por Bollen, Qader e Allan (1998). Neste trabalho, é relatado que para obter informações estatísticas relevantes sobre os afundamentos de tensão é necessário um longo período de monitoração. Portanto, uma alternativa proposta foi a utilização de metodologias para a previsão estocástica dos afundamentos. Assim sendo, dois métodos foram sugeridos pelos autores: o Método da Distância Crítica (MDC) e o MPF. Ambos os métodos foram aplicados ao mesmo sistema e, posteriormente, os resultados foram comparados. Os resultados evidenciaram que o MPF é mais eficiente, fornecendo uma boa visão dos afundamentos originados por simulações de curto-circuito. Já o MDC fornece resultados menos precisos, porém menos cálculos e dados são requisitados para a modelagem desta metodologia.

Quaia e Tosato (2003) propõem um método analítico para estimar os afundamentos de tensão em redes de alta tensão. A metodologia proposta é baseada no MPF, mas o cálculo é consideravelmente mais simples, pois através da matriz impedância de barra do sistema, obtêm-se com um mínimo esforço uma segunda matriz definida como "voltage sags matrix", que fornece valiosas informações sobre a propagação dos afundamentos de tensão em toda a rede. Esta matriz apresenta a amplitude dos afundamentos de tensão para cada barra do sistema avaliado, devido às faltas trifásicas em todos os outros barramentos do sistema. $\mathrm{O}$ método permite uma determinação mais precisa da área exposta ou de vulnerabilidade, pois é possível determinar o afundamento de tensão para qualquer posição de falta, não sendo necessária a escolha de uma distância correta para simular a situação de falta. Para obter o afundamento em pontos intermediários ao longo da linha, os autores descrevem que basta introduzir uma nova barra na matriz impedância, usando o algoritmo de construção da matriz. A limitação do método, segundo os autores, é que apenas faltas trifásicas foram consideradas, 
devido ao fato que ao se considerar faltas assimétricas seria necessário o modelo completo da rede e o conhecimento das taxas de falhas relevantes para todos os tipos de faltas, sendo que estes dados raramente estão disponíveis.

Silva (2004), em sua dissertação de mestrado, fez uma análise comparativa dos resultados entre duas ferramentas de simulações de curto-circuito. Uma pelo cálculo de curtocircuito convencional através do programa ANAFAS (Análise de Falhas Simultâneas), e a outra por cálculos de transitórios eletromagnéticos utilizando o programa ATP. Em ambas as análises foi utilizado como caso teste o Sistema Elétrico de Suprimento do Estado de Mato Grosso. Foram realizadas diversas simulações considerando faltas monofásicas, bifásicas, bifásicas-terra e trifásicas, levando-se em consideração algumas variáveis de interesse, tais como: localização, tipo e impedância de falta, modelagem de geradores e do regulador de tensão. A média das divergências das intensidades dos afundamentos de tensão calculadas pelos dois programas em todos os casos simulados foi inferior a 5\%, valor este considerado satisfatório para efeito de comparação de resultados referentes aos afundamentos de tensão. Em muitos casos, as intensidades dos afundamentos de tensão calculadas pelo ATP foram mais severas do que pelo ANAFAS, justificadas pelo autor pelo fato de haver diferenças nas tensões pré-falta dos barramentos monitorados. Por fim, o autor conclui que a utilização de ferramentas que utilizam o método de cálculo de curto-circuito não comprometem de forma significativa a precisão dos resultados. Assim, uma das principais contribuições deste trabalho, é a de destacar a vantagem da utilização de um programa de modelagem simples e que apresenta maior agilidade no cálculo de afundamentos de tensão, pois os resultados obtidos são muito próximos aos resultados de um programa mais sofisticado como o ATP.

Carvalho Filho et al. (2008) avaliam dois métodos para o cálculo do afundamento de tensão. Um dos métodos é o programa ANAFAS e o outro o ATP. Ambos os métodos são validados de maneira determinística levando em conta o resultado de seis meses de medição em campo. Em função das incertezas inerentes à determinação das características das faltas, foram realizadas avaliações detalhadas sobre a influência das tensões pré-falta, posições e impedâncias de falta. Na comparação das magnitudes dos afundamentos de tensão obtidas pelos dois métodos com as medições reais, os resultados demonstraram-se muito próximos. Em mais de $90 \%$ dos casos simulados o erro da magnitude do afundamento de tensão foi inferior a $10 \%$. Os poucos casos com erros superiores a $10 \%$ aparecem quando as faltas são muito próximas dos pontos de monitoração. Nestas situações, a posição exata da falta e a impedância de falta afetaram consideravelmente a magnitude calculada. A conclusão final do artigo é que os resultados dos casos simulados se aproximam das medições, e a escolha do 
programa a ser utilizado depende do tipo de estudo. O programa ANAFAS é recomendado para o cálculo estocástico do desempenho do sistema, enquanto o programa ATP é aconselhável para o estudo detalhado dos eventos individuais. Resultados mais detalhados da validação destas ferramentas de simulação a partir dos resultados de medição podem ser encontrados em Novaes (2007).

O artigo publicado por Goswami, Gupta e Singh (2008) propõe um método analítico para a previsão dos afundamentos de tensão em SDs. Assim como o artigo publicado por Quaia e Tosato (2003), o método também se baseia na matriz impedância da rede, porém, o artigo fornece uma formulação para a obtenção dos afundamentos de tensão em todas as barras do sistema de forma direta. Os autores relatam que faltas nos níveis de transmissão e distribuição causam efeitos diferentes em um SEP, destacando que quando ocorrem faltas no nível de transmissão, um grande número de usuários será afetado pelo afundamento de tensão, mas, normalmente, não ocorre a interrupção no fornecimento de energia. Já no nível de distribuição, devido à interligação do sistema ser menor, um número menor de usuários será afetado pelos afundamentos. Contudo, ocorrerá a interrupção no fornecimento de energia elétrica para determinados grupos de consumidores. Logo, a ocorrência de falta neste nível acarreta em menor confiabilidade do sistema. $\mathrm{O}$ artigo também descreve as formas gráficas para apresentar os efeitos de uma falta nos SDs (área afetada) e da área onde faltas causam afundamentos severos em uma determinada carga (área de vulnerabilidade).

Um importante trabalho para o desenvolvimento desta tese é apresentado por Carpinelli et al. (2009). Neste trabalho são utilizados dois métodos para estimar a severidade do afundamento da tensão: o MDC e o MPF. As aplicações numéricas, em ambos os métodos, referem-se a uma rede de transmissão real e um SD real, onde a diferença entre os dois métodos é verificada através dos resultados obtidos. Para obter informações imediatas a partir dos resultados do MPF, é proposta uma visualização gráfica em cores da MTDF que fornece uma visão compacta de todas as tensões registradas em todos os nós do sistema de energia elétrica. Para cada elemento da MTDF é atribuído um grau da escala de cinza que é proporcional ao valor da tensão durante a falta, onde os afundamentos de tensão mais severos são representados por um grau mais escuro. Apesar de normalmente o MPF ser aplicado aos sistemas em malha, como os sistemas de transmissão, este método mostrou-se eficiente mesmo para sistemas com estrutura radial, como os SDs. Através da visualização gráfica da MTDF os autores concluem que apenas o MPF pode dar uma visão global do desempenho do sistema de energia elétrica. Ainda segundo os autores, o MPF proporciona informações que o MDC não fornece, tais como: 
- propagação dos afundamentos de tensão em torno da rede;

- amplitude dos afundamentos de tensão para todos os nós;

- amplitude dos afundamentos de tensão causados por cada nó;

- áreas afetadas e expostas para todos os nós;

- nós onde a ocorrência de faltas acarreta afundamentos de tensão críticos em outros nós; e

- nós onde as cargas poderiam experimentar o maior número de afundamentos de tensão.

Dentre as metodologias apresentadas nesta breve revisão bibliográfica e sabendo da existência de entraves na obtenção de informações precisas para todas as cargas do SD, a serem modeladas computacionalmente, o MPF apresenta-se como uma boa opção para se obter o desempenho do sistema frente as VTCDs sem a necessidade da utilização de programas computacionais específicos.

Assim, será indispensável a determinação da matriz impedância de barra, apresentada na sequência, para determinar a amplitude das tensões remanescentes e, consequentemente, possibilitar a análise da influência e da propagação destes distúrbios sobre todos os nós do SD.

\subsection{Determinação da Matriz Impedância de Barra}

A matriz impedância de barra $\left(\boldsymbol{Z}_{\text {barra }}\right)$, também conhecida como matriz de impedância nodal, pode ser determinada através da inversão da matriz admitância de barra $\left(\boldsymbol{Y}_{\text {barra }}\right)$. Entretanto, a formulação para obter diretamente a matriz $\boldsymbol{Z}_{\text {barra }}$ é mais simples do que inverter computacionalmente $\boldsymbol{Y}_{\text {barra }}$, principalmente para sistemas de grande porte (STEVENSON, 1986).

A matriz $\boldsymbol{Z}_{\text {barra }}$ contém as impedâncias no ponto de cada nó (barra) com relação a um nó (barra) de referência escolhido arbitrariamente. A impedância no ponto de um nó é a impedância equivalente entre ele e a referência. Os elementos da impedância de $\boldsymbol{Z}_{\text {barra }}$ na diagonal principal são chamados de impedâncias próprias dos nós. Já os elementos fora da diagonal principal são chamados de impedâncias de transferência dos nós.

Portanto, para a obtenção da matriz $\boldsymbol{Z}_{\text {barra }}$, inicialmente, parte-se do conhecimento das impedâncias das seções do sistema. Um alimentador de distribuição é modelado por uma 
matriz de impedância trifásica, a qual inclui as impedâncias próprias e as mútuas entre as fases. Essa matriz é obtida a partir das equações de Carson e pelo método de redução de Kron (KERSTING, 2007). Considerando-se um alimentador não transposto, sua matriz de impedância trifásica $\left(\boldsymbol{Z}_{a b c}\right)$ é apresentado em (12).

Contudo, as impedâncias próprias e mútuas são distintas entre si, pois os sistemas elétricos de distribuição são normalmente sistemas assimétricos.

$$
Z_{a b c}=\left[\begin{array}{ccc}
z_{a a} & z_{a b} & z_{a c} \\
z_{b a} & z_{b b} & z_{b c} \\
z_{c a} & z_{c b} & z_{c c}
\end{array}\right]
$$

Em Kersting (2007), é proposta a modificação da matriz $\boldsymbol{Z}_{a b c}$ de uma linha não transposta do sistema, idealizando-a como a impedância de uma linha transposta, em que as impedâncias próprias são iguais entre si, assim como também as mútuas. A equação (13) mostra a impedância própria $\left(z_{p}\right)$, que é definida como a média entre as impedâncias próprias de $\boldsymbol{Z}_{a b c}$.

$$
z_{p}=\frac{1}{3}\left(z_{a a}+z_{b b}+z_{c c}\right)
$$

Em (14), tem-se a impedância mútua $\left(z_{m}\right)$ como sendo a média entre as impedâncias mútuas de $\boldsymbol{Z}_{a b c}$.

$$
z_{m}=\frac{1}{3}\left(z_{a b}+z_{b c}+z_{c a}\right)
$$

Tais observações resultam na matriz de impedância de fases modificada $\left(\overline{\boldsymbol{Z}}_{a b c}\right)$, apresentada em (15).

$$
\overline{\boldsymbol{Z}}_{a b c}=\left[\begin{array}{ccc}
z_{p} & z_{m} & z_{m} \\
z_{m} & z_{p} & z_{m} \\
z_{m} & z_{m} & z_{p}
\end{array}\right]
$$

Para defeitos desequilibrados em redes elétricas, a complexidade envolvida na análise do curto-circuito pode ser consideravelmente reduzida utilizando-se o método das componentes simétricas (FORTESCUE, 1918). Portanto, utilizando a matriz $\overline{\boldsymbol{Z}}_{a b c}$ (15), é possível obter diretamente através de (16) e (17), uma matriz diagonal de impedância de 
sequência, como apresentado em (18). Esta matriz apresenta o elemento de sequência zero $\left(z_{00}\right)$, e as impedâncias de sequência positiva e negativa. Nesta, os elementos de sequência positiva e negativa são iguais $\left(z_{11}=z_{22}\right)$.

$$
\begin{gathered}
z_{00}=z_{p}+2 z_{m} \\
z_{11}=z_{22}=z_{p}-z_{m} \\
\boldsymbol{Z}_{012}=\left[\begin{array}{lll}
z_{00} & 0 & 0 \\
0 & z_{11} & 0 \\
0 & 0 & z_{22}
\end{array}\right]
\end{gathered}
$$

Para cada sequência, a partir de um algoritmo de modificação ou adição de uma matriz $\boldsymbol{Z}_{\text {barra }}$ já existente (ANDERSON, 1973; BROWN, 1975; STEVENSON, 1986), é possível modificar a matriz $\boldsymbol{Z}_{\text {barra }}$ de um sistema, pela adição independente de cada nova linha desejada. Desta maneira, a matriz $\boldsymbol{Z}_{\text {barra }}$ poderá ser atualizada para cada nova linha adicionada.

Como primeiro passo para a construção da matriz $\boldsymbol{Z}_{\text {barra }}$ de sequência, observa-se o diagrama unifilar do SD e se define uma barra como de referência (BROWN, 1975).

A primeira linha a ser selecionada deve ser uma linha que liga a barra de referência a alguma barra do sistema. Já a seleção das linhas subsequentes pode partir de uma ordem aleatória, de maneira que, à medida que cada nova linha é selecionada, seja possível ligá-la ao sistema previamente construído.

Sendo assim, cada linha selecionada do diagrama unifilar deve pertencer a um dos três tipos:

1. Linha que liga a barra de referência a uma nova barra;

2. Linha que liga uma barra já incluída a uma nova barra; e

3. Linha entre duas barras já incluídas no sistema.

\subsubsection{Adição de uma Impedância de Linha da Barra de Referência para uma Nova Barra}

Inicialmente, para cada seção do SD determinam-se as impedâncias de sequência de linha, observando as conexões ou barras que compõem o SD, com a consequente 
representação do seu diagrama unifilar. A primeira linha a ser adicionada deve ser uma linha que liga a barra de referência a alguma barra do sistema. Considerando, por exemplo, uma linha conectada à barra de referência através de uma impedância $z_{a}$, a matriz $\boldsymbol{Z}_{b a r r a}$ será inicialmente constituída por esta única impedância. Da existência de uma segunda barra também conectada à barra de referência através de uma impedância $z_{b}$, a nova matriz $\boldsymbol{Z}_{\text {barra }}$ será fornecida pela expressão (19), sendo as impedâncias próprias definidas pelas duas impedâncias de linha ligadas à barra de referência e as impedâncias mútuas iguais a zero.

$$
Z_{\text {barra }}=\left[\begin{array}{cc}
z_{a} & 0 \\
0 & z_{b}
\end{array}\right]
$$

Para as próximas modificações da matriz, adicionam-se as outras barras existentes, sempre observando o tipo de linha selecionada. Geralmente as barras de uma rede devem ser numeradas para concordar com a ordem na qual elas devem ser adicionadas a $\boldsymbol{Z}_{\text {barra }}$, seguindo uma sequência de numeração conforme esta matriz é construída.

\subsubsection{Adição de uma Impedância de Linha de uma Barra Existente para uma Nova Barra}

Ao utilizar esta rotina, considerando a inserção de uma nova barra conectada ao sistema, através de uma impedância de linha $z_{c}$ a uma barra $k$ já inserida ao sistema, resulta na adição de uma nova coluna que é transposta de uma nova linha como em (20).

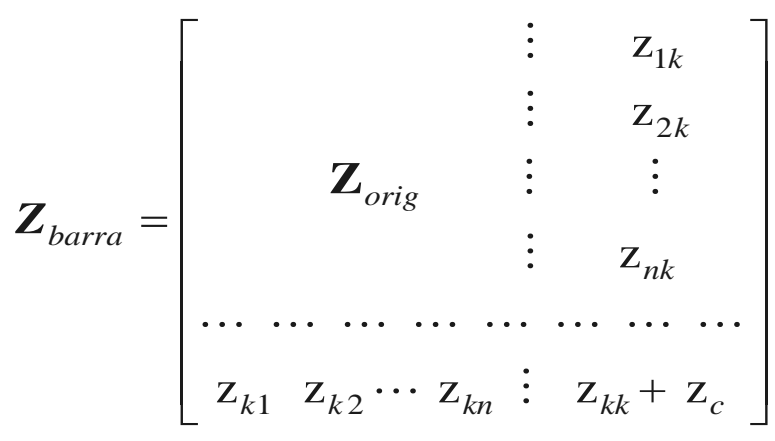

Sendo $\boldsymbol{Z}_{\text {orig }}$ a matriz determinada anteriormente à inclusão desta nova barra ao sistema. Os elementos da nova coluna serão iguais aos elementos da coluna $k$, à qual a nova barra inserida ao sistema foi conectada. Já os elementos da nova linha são resultantes da transposição desta nova coluna. 
A nova impedância própria da matriz $\boldsymbol{Z}_{\text {barra }}$ é originada da adição da impedância de linha $\left(z_{c}\right)$ incluída ao sistema com a impedância própria $\left(z_{k k}\right)$ no ponto que esta foi adicionada (barra $k$ ).

\subsubsection{Adição de uma Impedância entre Duas Barras Existentes}

Toda vez que $\boldsymbol{Z}_{\text {barra }}$ for modificada, será novamente identificada como $\boldsymbol{Z}_{\text {orig }}$. Ao adicionar um ramo com impedância $\left(z_{d}\right)$ entre duas barras $j$ e $k$ já existentes, a nova matriz $\boldsymbol{Z}_{\text {barra }}$ será fornecida como em (21).

As impedâncias mútuas da nova coluna da matriz $\boldsymbol{Z}_{\text {barra }}$ serão originadas da subtração das impedâncias dos nós às quais a nova impedância de linha foi adicionada. Neste caso, a impedância $z_{d}$ foi adicionada entre as barras $j$ e $k$. Portanto, as novas impedâncias mútuas serão fornecidas pela coluna $j$ menos a coluna $k$ de $\boldsymbol{Z}_{\text {orig }}$. A nova linha da matriz $\boldsymbol{Z}_{\text {barra }}$ é resultante da transposição desta nova coluna. A nova impedância própria $z_{d d}$ será fornecida pela equação (22) .

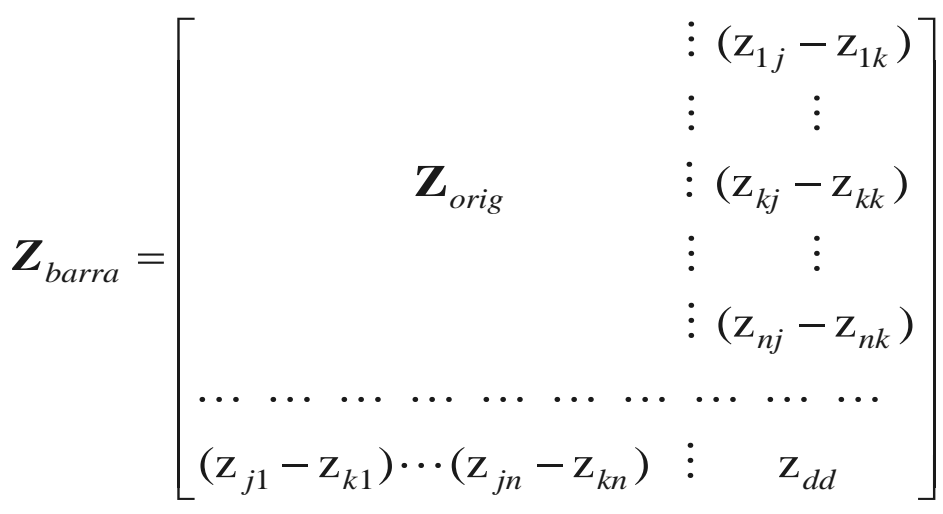

$$
\begin{aligned}
& z_{d d}=z_{d}+z_{j j}+z_{k k}-2 z_{j k}
\end{aligned}
$$

Como a impedância $\dot{z}_{d}$ foi apenas adicionada entre duas barras já existentes, não sendo inserida uma nova barra ao sistema, faz-se necessária a redução da matriz quadrada (21), para que a mesma fique compatível com o número de barras existentes. Assim sendo, para obter a nova matriz $\boldsymbol{Z}_{\text {barra }}$ é necessário recalcular todos os elementos da matriz $\boldsymbol{Z}_{\text {orig }}$ conforme a equação (23). 


$$
Z_{\text {barra }(\text { novo })}=Z_{\text {orig }}-\frac{1}{z_{d d}} \cdot Z_{(n+1)}
$$

Sendo $\dot{Z}_{(n+1)}$ definido pela expressão (24), (OLGUIN, 2005).

$$
Z_{(n+1)}=\left[\begin{array}{c}
z_{1 j}-z_{1 k} \\
\vdots \\
z_{j j}-z_{j k} \\
z_{k j}-z_{k k} \\
\vdots \\
z_{n j}-z_{n k}
\end{array}\right] \cdot\left[\begin{array}{c}
z_{j 1}-z_{k 1} \\
\vdots \\
z_{j j}-z_{k j} \\
z_{j k}-z_{k k} \\
\vdots \\
z_{j n}-z_{k n}
\end{array}\right]^{t}
$$

Seguindo esta rotina, ao final, são originadas três matrizes impedância de barra, sendo uma de sequência positiva $\left(\boldsymbol{Z}_{1}\right)$, uma de sequência negativa $\left(\boldsymbol{Z}_{2}\right)$ e outra de sequência zero $\left(\boldsymbol{Z}_{0}\right)$. A determinação destas matrizes será de vital importância para a determinação das MTDFs por meio do MPF, conforme observado na próxima seção.

\subsection{Método das Posições de Falta (MPF)}

O MPF, também conhecido como curto-circuito deslizante, foi proposto pela primeira vez por Conrad, Little, e Grigg (1991), e tem sido amplamente utilizado no cálculo das VTCDs em sistemas elétricos de potência de grande porte. Seu princípio está baseado na sistemática de simular curtos-circuitos em posições diferentes ao longo do sistema elétrico, principalmente nas linhas de transmissão e de distribuição e observar o comportamento da tensão nos barramentos de interesse.

Da literatura correlata, tem-se que o MPF pode ser aplicado, principalmente, nos sistemas em malha, como os sistemas de transmissão. Contudo em (GOSWAMI, GUPTA e SINGH, 2008; CARPINELLI et al., 2009) constata-se que este método é eficiente e pode fornecer uma visão global da resposta do sistema de energia para as situações de defeito (curto-circuito), até mesmo quando a rede é radial, como nos SDs.

A importância do uso desta metodologia deve-se, sobretudo, ao fato dos curtoscircuitos serem as principais causas das VTCDs devido à existência de milhares de quilômetros de linhas aéreas no sistema elétricos, sujeitas a toda a sorte de fenômenos naturais e inerentes ao sistema. Nos SDs o problema é mais crítico porque são geralmente desprovidos de cabos guarda (de proteção) (LEBORGNE, 2003). 
Estas faltas em linhas aéreas podem ser de natureza temporária ou permanente, com ou sem o envolvimento da terra. As VTCDs decorrentes de faltas temporárias são, em sua grande maioria, devido à ocorrência de descargas atmosféricas, fenômenos naturais, contatos de animais e árvores com partes energizadas do sistema, as quais não resultam em danos permanentes no sistema de isolação, sendo que o sistema pode ser prontamente restabelecido por meio de religamentos automáticos. Alguns dos fatores que influenciam nas características das VTCDs é o tipo de curto-circuito e a localização da ocorrência da falta. Como fato, tem-se que faltas ao longo do sistema elétrico podem gerar distúrbios em barramentos vizinhos e remotos. Portanto, os consumidores finais conectados a esses barramentos podem ter seus equipamentos sensibilizados resultando no mau funcionamento ou na completa interrupção de seus processos.

Neste contexto, a seguir será apresentado o MPF que permitirá a obtenção de informações valiosas sobre a amplitude das tensões remanescentes em todos os nós de um SD, através de cálculos de curtos-circuitos trifásicos, bifásicos fase-fase, bifásicos fase-fase-terra e monofásicos.

Assim, para cada diferente tipo de curto-circuito é gerada, por fase, uma MTDF que permite caracterizar, para cada situação de falta analisada, os níveis das tensões remanescentes em cada um dos nós do SD.

Para cada caso de estudo, serão necessárias e então representadas as redes de sequência conectadas de acordo com o tipo de curto-circuito. É importante ressaltar que não existem fontes de tensão nas redes de sequência negativa e zero. A fonte de tensão em todos os curtos-circuitos será representada apenas pela sequência positiva. Desta forma, considerando estes conceitos e utilizando o método das componentes simétricas (FORTESCUE, 1918), a MTDF para cada fase é construída conforme (25) (OLGUIN, 2005).

$$
\begin{gathered}
M T D F_{a}=\left|\dot{V}_{p r e f}^{1}+\Delta \dot{V}_{0}+\Delta \dot{V}_{1}+\Delta \dot{V}_{2}\right| \\
M T D F_{b}=\left|a^{2} \cdot \dot{V}_{p r e f}^{1}+\Delta \dot{V}_{0}+a^{2} \cdot \Delta \dot{V}_{1}+a \cdot \Delta \dot{V}_{2}\right| \\
M T D F_{c}=\left|a \cdot \dot{V}_{p r e f}^{1}+\Delta \dot{V}_{0}+a \cdot \Delta \dot{V}_{1}+a^{2} \cdot \Delta \dot{V}_{2}\right|
\end{gathered}
$$

Sendo:

$\dot{V}_{p r e f}^{1}$ : A matriz de tensões pré-falta de sequência positiva;

$a$ : um número complexo igual a $\mathrm{e}^{\mathrm{j} 120^{\circ}}$; e 
$\Delta \dot{V}_{0} ; \Delta \dot{V}_{1} ; \Delta \dot{V}_{2}$ : As matrizes de tensões de sequência zero, positiva e negativa, respectivamente;

\subsubsection{Curto-circuito Trifásico (FFF)}

A Figura 16 (a) demonstra as formas de onda da tensão durante a ocorrência de um curto-circuito trifásico em um determinado ponto do SD, observa-se na Figura 16 (b) que as três fases são levadas à terra por meio de uma resistência, conhecida como resistência de falta $\left(R_{f}\right)$. Caso não exista resistência de falta, diz-se que o curto-circuito é franco. Como no curtocircuito trifásico todas as correntes são equilibradas não há diferença no curto-circuito sem ou com o envolvimento da terra.

Figura 16 - Curto-circuito FFF: Formas de onda (a), representação da falta (b).

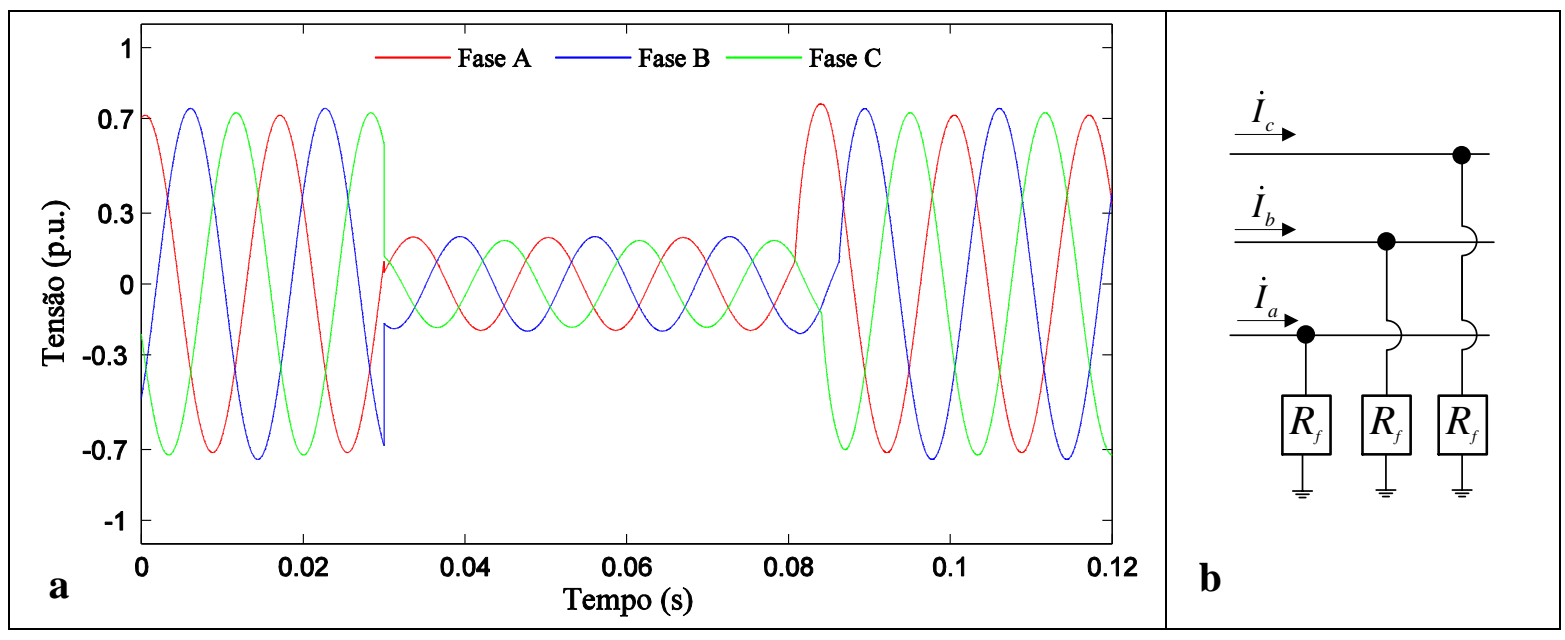

Fonte: Elaborada pela autora.

As correntes $\dot{I}_{a}, \dot{I}_{b}$ e $\dot{I}_{c}$ representadas na Figura 16 (b) são as correntes que fluem à terra durante a condição de defeito. Considerando que o sistema está operando à vazio, ou seja, sem carga e que no local de ocorrência do curto-circuito, a linha seja ideal, isto é, sem resistência de falta, as tensões fasoriais no local de falta, designadas por $\dot{V}_{a}, \dot{V}_{b}$ e $\dot{V}_{c}$, são representadas pela equação (26) (KINDERMANN, 1992).

$$
\dot{V}_{a}=\dot{V}_{b}=\dot{V}_{c}=0
$$

Decompondo em componentes simétricas, tem-se: 


$$
\dot{V}_{a 0}=\dot{V}_{a 1}=\dot{V}_{a 2}=0
$$

Como os curtos-circuitos trifásicos são simétricos, somente a sequência positiva é necessária para se obter a corrente no ponto da falta $\left(i_{f}^{a 1}\right)$. A Figura 17 representa o equivalente de Thévenin para o curto-circuito trifásico. Sendo que, $\dot{v}_{p r e f}^{a}$ é a tensão fasorial na fase $a$, no local de defeito antes da ocorrência do curto-circuito, $z_{f f}^{1}$ é a impedância de Thévenin de sequência positiva vista pelo ponto de defeito e $\dot{V}_{a 1}$ é a tensão fasorial de sequência positiva, que neste caso é igual a zero.

Figura 17 - Equivalente de Thévenin para o curto-circuito trifásico.

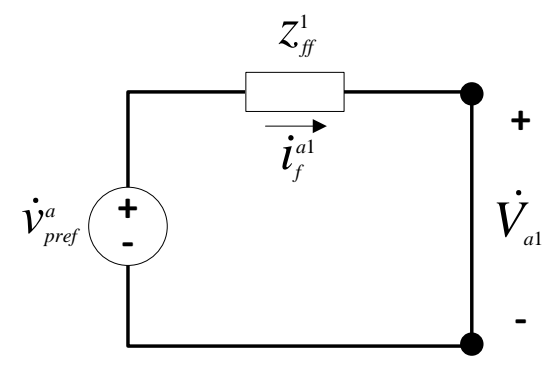

Fonte: Adaptado de Kindermann (1992).

Assim:

$$
i_{f}^{a 1}=\frac{\dot{v}_{p r e f(f)}^{a}}{z_{f f}^{1}}
$$

De acordo com o teorema da superposição pode-se determinar a tensão verificada no nó $k$ durante uma situação de falta trifásica no nó $f\left(\dot{v}_{k f}\right)$, utilizando as equações (29), (30) e (31) (OLGUIN, 2005).

$$
\begin{gathered}
\dot{v}_{k f}=\dot{v}_{p r e f(k)}+\Delta \dot{v}_{k f} \\
\Delta \dot{v}_{k f}=z_{k f} \cdot-i_{f}^{a 1} \\
\dot{v}_{k f}=\dot{v}_{p r e f(k)}-\frac{z_{k f}}{z_{f f}} \cdot \dot{v}_{p r e f(f)}
\end{gathered}
$$


Pelo exposto, considerando um sistema hipotético de 13 barras e assumindo as tensões pré-falta como sendo 1 p.u., através da equação (31) se obtém a MTDF que registra as tensões em todos os nós do SD para cada situação de falta trifásica considerada, conforme a equação (32).

Observa-se através da equação (32) que a MTDF é uma matriz quadrada de ordem $n$, onde $n$ é número de nós do sistema. Cada elemento de linha $(i)$ desta matriz indica os valores das tensões para um curto-circuito aplicado na coluna $(j)$. Portanto, os elementos da diagonal principal serão sempre zero, pois a impedância de curto-circuito onde a falta trifásica será simulada é a própria impedância da barra observada.

$$
\mathrm{MTDF}=\left[\begin{array}{cccccc}
0 & 1-\frac{Z_{1,2}}{Z_{2,2}} & \cdots & 1-\frac{Z_{1,8}}{Z_{8,8}} & \cdots & 1-\frac{Z_{1,13}}{Z_{13,13}} \\
1-\frac{Z_{2,1}}{Z_{1,1}} & 0 & \cdots & 1-\frac{Z_{2,8}}{Z_{8,8}} & \cdots & 1-\frac{Z_{2,13}}{Z_{13,13}} \\
\vdots & \vdots & 0 & \vdots & \vdots & \vdots \\
1-\frac{Z_{8,1}}{Z_{1,1}} & 1-\frac{Z_{8,2}}{Z_{2,2}} & \cdots & 0 & \cdots & 1-\frac{Z_{8,13}}{Z_{13,13}} \\
\vdots & \vdots & \vdots & \vdots & 0 & \vdots \\
1-\frac{Z_{13,1}}{Z_{1,1}} & 1-\frac{Z_{13,2}}{Z_{2,2}} & \cdots & 1-\frac{Z_{13,8}}{Z_{8,8}} & \cdots & 0
\end{array}\right]
$$

Portanto, é possível observar que o MPF está inerentemente relacionado com as impedâncias de barra da rede de distribuição. Assim sendo, uma vez determinada a matriz de impedância de barra de sequência positiva $\left(Z_{1}\right)$ a MTDF para curtos-circuitos trifásicos pode ser obtida de forma direta através da equação (33). Sendo, $\dot{V}_{p r e f}^{1}$ a matriz de tensões pré-falta de sequência positiva e diag representa os valores diagonais das matrizes (CARPINELLI et al., 2007).

$$
\operatorname{MTDF}_{a ; b ; c}^{F F F}=\left|\dot{V}_{p r e f}^{1}-Z_{1} \cdot\left(\operatorname{diag}\left(Z_{1}\right)\right)^{-1} \cdot \operatorname{diag}\left(\dot{V}_{p r e f}^{1}\right)\right|
$$

\subsubsection{Curto-circuito Monofásico (FT)}

O curto-circuito monofásico ocorre quando há contato entre uma fase e a terra, como mostrado na Figura 18 (b). 
Figura 18 - Curto-circuito FT: Formas de onda (a), representação da falta (b).

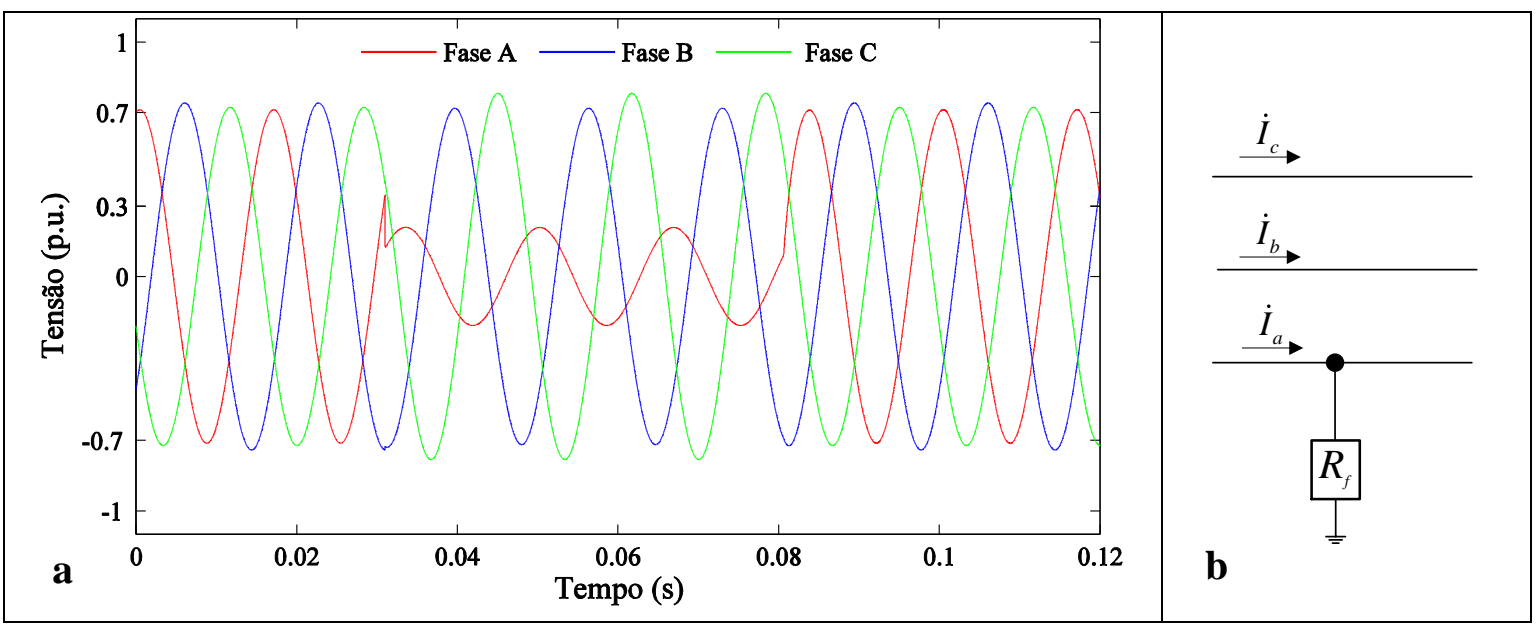

Fonte: Elaborada pela autora.

Considerando as mesmas condições apresentadas para o curto-circuito trifásico, ou seja, desprezando a corrente de carga após a falta, uma vez que sua intensidade é bem menor que a corrente de curto-circuito, e que a corrente $\dot{I}_{a}$, representada na Figura 18 (b), flui à terra sem a presença da resistência de falta $\left(R_{f}\right)$, tem-se:

$$
\dot{I}_{b}=\dot{I}_{c}=0 \quad e \quad \dot{V}_{a}=0
$$

Essas condições, quando decompostas em componentes simétricas, resultam:

$$
\dot{I}_{a 0}=\dot{I}_{a 1}=\dot{I}_{a 2}
$$

Pela análise da equação (35) para representar a igualdade das correntes de sequência desenha-se o circuito equivalente de sequência positiva, negativa e zero em série, conforme ilustra a Figura 19.

\section{Figura 19 - Modelo equivalente em série do curto-circuito monofásico fase $a$.}

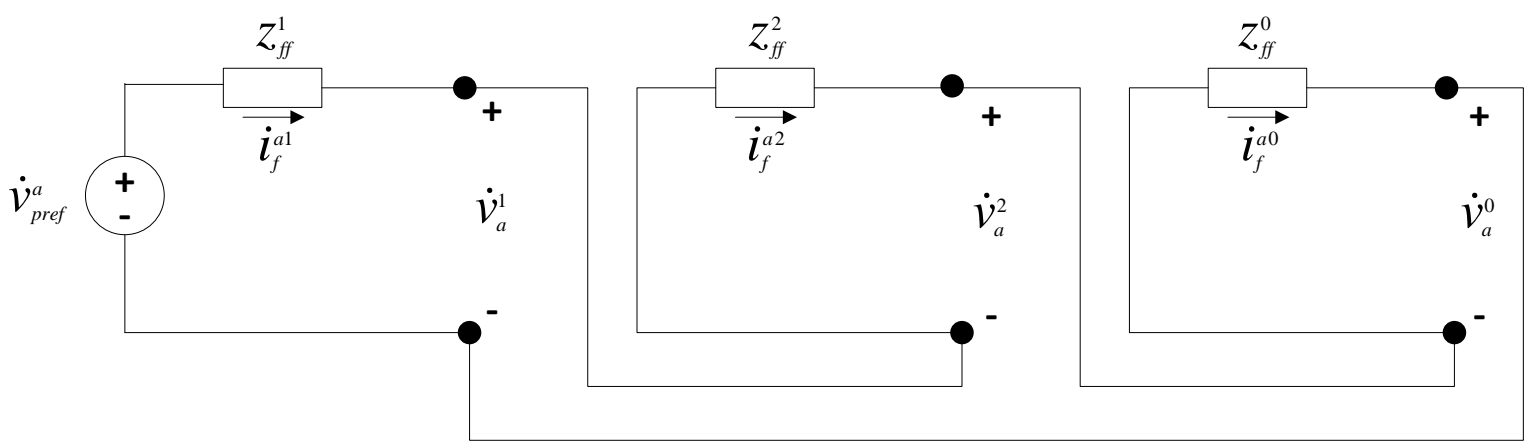

Fonte: Adaptado de Kindermann (1992). 
Pela análise de circuitos elétricos da Figura 19, determina-se:

$$
i_{f}^{a 1}=i_{f}^{a 2}=i_{f}^{a 0}=\frac{\dot{v}_{p r e f(f)}^{a}}{z_{f f}^{1}+z_{f f}^{2}+z_{f f}^{0}}
$$

Substituindo a expressão (36) na equação (30), adquire-se:

$$
\begin{aligned}
& \Delta \dot{v}_{k f}^{1}=-z_{k f}^{1} \cdot \frac{\dot{v}_{p r e f(f)}^{a}}{z_{f f}^{1}+z_{f f}^{2}+z_{f f}^{0}} \Rightarrow \Delta \dot{V}_{1}=-Z_{1} \cdot\left(\operatorname{diag}\left(Z_{1}+Z_{2}+Z_{0}\right)\right)^{-1} \cdot \operatorname{diag}\left(\dot{V}_{p r e f}^{1}\right) \\
& \Delta \dot{v}_{k f}^{2}=-z_{k f}^{2} \cdot \frac{\dot{v}_{p r e f(f)}^{a}}{z_{f f}^{1}+z_{f f}^{2}+z_{f f}^{0}} \Rightarrow \Delta \dot{V}_{2}=-Z_{2} \cdot\left(\operatorname{diag}\left(Z_{1}+Z_{2}+Z_{0}\right)\right)^{-1} \cdot \operatorname{diag}\left(\dot{V}_{p r e f}^{1}\right) \\
& \Delta \dot{v}_{k f}^{0}=-z_{k f}^{0} \cdot \frac{\dot{v}_{p r e f(f)}^{a}}{z_{f f}^{1}+z_{f f}^{2}+z_{f f}^{0}} \Rightarrow \Delta \dot{V}_{0}=-Z_{0} \cdot\left(\operatorname{diag}\left(Z_{1}+Z_{2}+Z_{0}\right)\right)^{-1} \cdot \operatorname{diag}\left(\dot{V}_{p r e f}^{1}\right)
\end{aligned}
$$

A MTDF para cada fase durante a ocorrência de um curto-circuito monofásico é obtida de forma direta através da substituição das equações (37),(38) e (39) na expressão (25). Originando as MTDF para a fase $a,(40)$, fase $b,(41)$ e fase $c,(42)$.

$$
\begin{gathered}
M T D F_{a}^{F T}=\left|\dot{V}_{\text {pref }}^{1}-\left(Z_{1}+Z_{2}+Z_{0}\right) \cdot\left(\operatorname{diag}\left(Z_{1}+Z_{2}+Z_{0}\right)\right)^{-1} \cdot \operatorname{diag}\left(\dot{V}_{\text {pref }}^{1}\right)\right| \\
\operatorname{MTDF}_{b}^{F T}=\left|a^{2} \cdot \dot{V}_{p r e f}^{1}-\left(a^{2} \cdot Z_{1}+a \cdot Z_{2}+Z_{0}\right) \cdot\left(\operatorname{diag}\left(Z_{1}+Z_{2}+Z_{0}\right)\right)^{-1} \cdot \operatorname{diag}\left(\dot{V}_{\text {pref }}^{1}\right)\right| \\
\operatorname{MTDF}_{c}^{F T}=\left|a \cdot \dot{V}_{\text {pref }}^{1}-\left(a \cdot Z_{1}+a^{2} \cdot Z_{2}+Z_{0}\right) \cdot\left(\operatorname{diag}\left(Z_{1}+Z_{2}+Z_{0}\right)\right)^{-1} \cdot \operatorname{diag}\left(\dot{V}_{\text {pref }}^{1}\right)\right|
\end{gathered}
$$

\subsubsection{Curto-circuito Bifásico Fase-Fase (FF)}

O curto-circuito bifásico FF ocorre quando duas fases de um sistema estão em contato. Este contato pode ser através de uma resistência de falta entre as duas fases $\left(R_{f f}\right)$, como por exemplo, entre as fases b e c (Figura 20 (b)), ou pode ser franco. Considerando na Figura 20 (b) que o curto-circuito seja franco e que o sistema está operando à vazio, tem-se: 


$$
\dot{I}_{a}=0 \quad \dot{I}_{b}=-\dot{I}_{c} \quad \dot{V}_{b}=\dot{V}_{c}
$$

Figura 20 - Curto-circuito FF: Formas de onda (a), representação da falta (b).

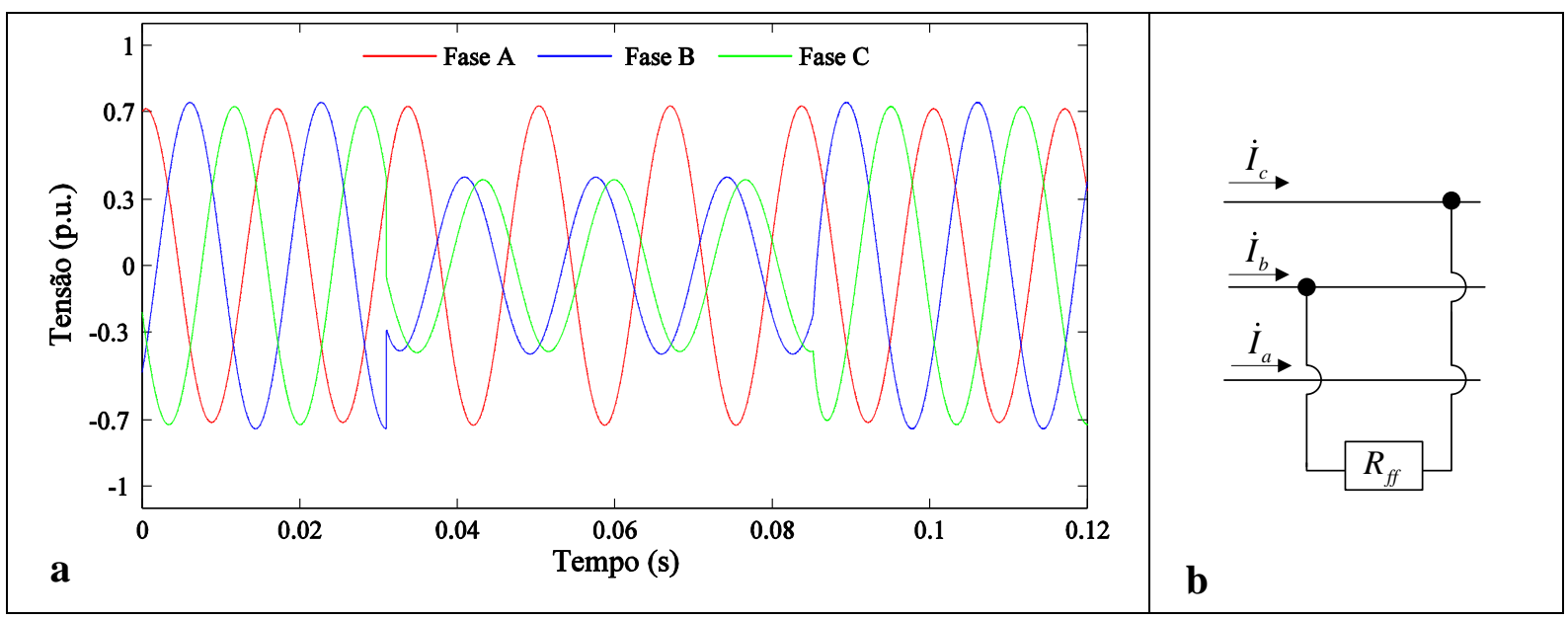

Fonte: Elaborada pela autora.

Decompondo em componentes simétricas:

$$
\begin{array}{ll}
\dot{I}_{a 0}=0 & \dot{I}_{a 1}=-\dot{I}_{a 2} \\
\dot{V}_{a 0}=0 & \dot{V}_{a 1}=\dot{V}_{a 2}
\end{array}
$$

Pelas equações (44) e (45) observa-se que, como o curto-circuito não envolve a terra, em faltas bifásicas FF a componente de sequência zero não entra nos cálculos da corrente de curto-circuito, além disso, as correntes de sequência positiva e negativa são iguais em módulo. Portanto, os modelos de sequência positiva e negativa são conectados em paralelo, conforme a Figura 21.

Figura 21 - Modelo em paralelo do curto-circuito bifásico entre as fases $b$ e $c$.

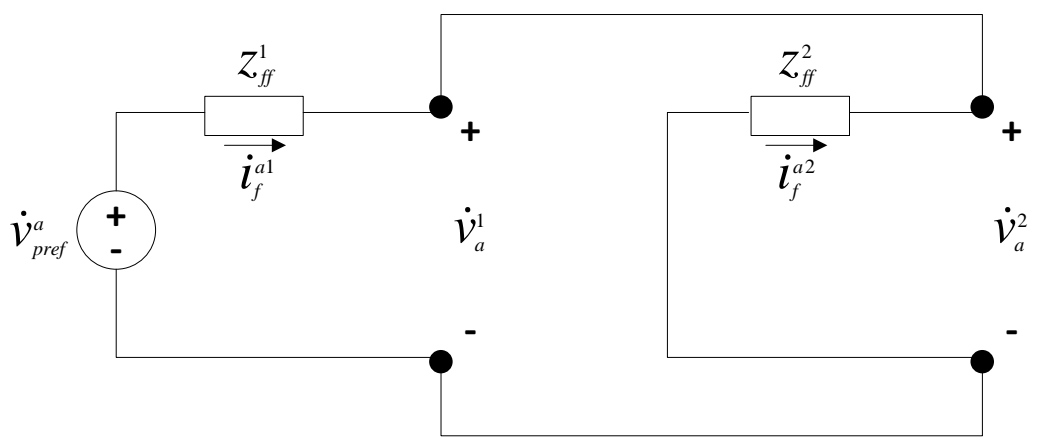

Fonte: Adaptado de Kindermann (1992). 
Pela representação do equivalente de Thévenin, da Figura 21 obtém-se:

$$
i_{f}^{a 1}=\frac{\dot{v}_{p r e f(f)}^{a}}{z_{f f}^{1}+z_{f f}^{2}} \quad e \quad i_{f}^{a 2}=-\frac{\dot{v}_{p r e f(f)}^{a}}{z_{f f}^{1}+z_{f f}^{2}}
$$

Calculando $\Delta \dot{V}_{1}$ e $\Delta \dot{V}_{2}$ (OLGUIN, 2005; CARPINELLI et al., 2007).

$$
\begin{aligned}
& \Delta \dot{v}_{k f}^{1}=-z_{k f}^{1} \cdot \frac{\dot{v}_{p r e f(f)}^{a}}{z_{f f}^{1}+z_{f f}^{2}} \Rightarrow \Delta \dot{V}_{1}=-Z_{1} \cdot\left(\operatorname{diag}\left(Z_{1}+Z_{2}\right)\right)^{-1} \cdot \operatorname{diag}\left(\dot{V}_{p r e f}^{1}\right) \\
& \Delta \dot{v}_{k f}^{2}=z_{k f}^{2} \cdot \frac{\dot{v}_{p r e f(f)}^{a}}{z_{f f}^{1}+z_{f f}^{2}} \Rightarrow \Delta \dot{V}_{2}=Z_{2} \cdot\left(\operatorname{diag}\left(Z_{1}+Z_{2}\right)\right)^{-1} \cdot \operatorname{diag}\left(\dot{V}_{p r e f}^{1}\right)
\end{aligned}
$$

Sabendo que $\Delta \dot{V}_{0}=0$ e substituindo (47) e (48) em (25) obtém-se:

$$
\begin{gathered}
\operatorname{MTDF}_{a}^{F F}=\left|\dot{V}_{\text {pref }}^{1}+Z_{2}-Z_{1} \cdot\left(\operatorname{diag}\left(Z_{1}+Z_{2}\right)\right)^{-1} \cdot \operatorname{diag}\left(\dot{V}_{\text {pref }}^{1}\right)\right| \\
M T D F_{b}{ }^{F F}=\left|a^{2} \cdot \dot{V}_{p r e f}^{1}+\left(-a^{2} \cdot Z_{1}+a Z_{2}\right) \cdot\left(\operatorname{diag}\left(Z_{1}+Z_{2}\right)\right)^{-1} \cdot \operatorname{diag}\left(\dot{V}_{\text {pref }}^{1}\right)\right| \\
\operatorname{MTDF}_{c}^{F F}=\left|a \cdot \dot{V}_{p r e f}^{1}+\left(-a \cdot Z_{1}+a^{2} \cdot Z_{2}\right) \cdot\left(\operatorname{diag}\left(Z_{1}+Z_{2}\right)\right)^{-1} \cdot \operatorname{diag}\left(\dot{V}_{\text {pref }}^{1}\right)\right|
\end{gathered}
$$

\subsubsection{Curto-circuito Bifásico Fase-Fase-Terra (FFT)}

No curto-circuito bifásico FFT além das duas fases se encontrarem, as mesmas vão a terra. A Figura 22 representa este curto-circuito entre as fases $b$ e $c$ a terra.

Considerando, na Figura 22 (b), $R_{f}$ igual a zero e o sistema operando sem carga, as tensões fasoriais nas fases $b$ e $c$ e a corrente na fase $a$ serão nulas, como na equação (52).

$$
\dot{I}_{a}=0 \quad \text { e } \quad \dot{V}_{b}=\dot{V}_{c}=0
$$

Decompondo (52) em componentes simétricas, obtêm-se:

$$
\dot{V}_{a 0}=\dot{V}_{a 1}=\dot{V}_{a 2}
$$


Figura 22 - Curto-circuito FFT: Formas de onda (a), representação da falta (b).

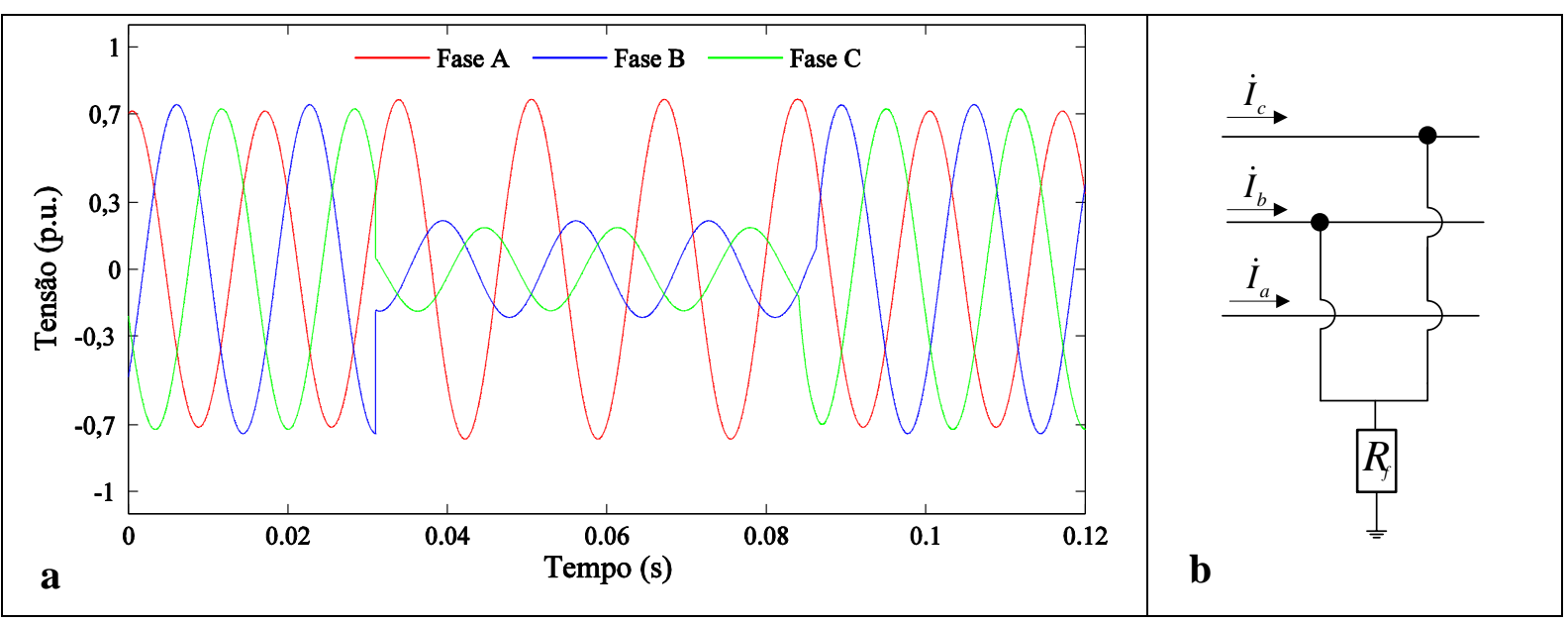

Fonte: Elaborada pela autora.

Pelo teorema de Fortescue (FORTESCUE, 1918) a corrente verdadeira da fase $a$ é igual a soma das três correntes de sequência, isto é:

$$
\dot{I}_{a}=\dot{I}_{a 0}+\dot{I}_{a 1}+\dot{I}_{a 2}
$$

Pela condição de defeito $\dot{I}_{a}=0$, portanto:

$$
\dot{I}_{a 0}+\dot{I}_{a 1}+\dot{I}_{a 2}=0
$$

Para satisfazer simultaneamente as expressões (54) e (55), os circuitos equivalentes de sequência positiva, negativa e zero, deverão ser conectados em paralelo, conforme a Figura 23.

Figura 23 - Circuito equivalente para um curto-circuito bifásico terra entre as fases $b$ e $c$.

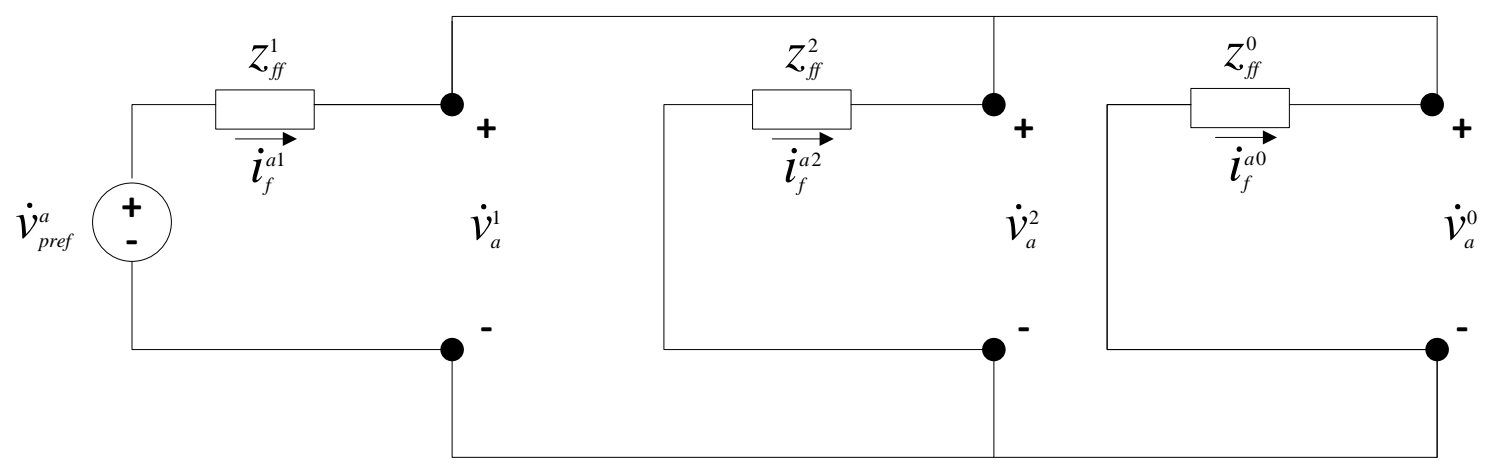

Fonte: Adaptado de Kindermann (1992).

Pelo circuito equivalente de Thévenin representado na Figura 23, obtêm-se: 


$$
\begin{aligned}
& i_{f}^{a 1}=\frac{\dot{v}_{p r e f(f)}^{a}}{z_{f f}^{1}+\frac{z_{f f}^{0} \cdot z_{f f}^{2}}{z_{f f}^{0}+z_{f f}^{2}}}=\frac{\left(z_{f f}^{0}+z_{f f}^{2}\right)}{z_{f f}^{1} \cdot z_{f f}^{0}+z_{f f}^{1} \cdot z_{f f}^{2}+z_{f f}^{0} \cdot z_{f f}^{2}} \cdot \dot{v}_{p r e f(f)}^{a} \\
& i_{f}^{a 2}=-i_{f}^{a 1} \cdot \frac{z_{f f}^{0}}{z_{f f}^{0}+z_{f f}^{2}}=-\frac{z_{f f}^{0}}{z_{f f}^{1} \cdot z_{f f}^{0}+z_{f f}^{1} \cdot z_{f f}^{2}+z_{f f}^{0} \cdot z_{f f}^{2}} \cdot \dot{v}_{p r e f(f)}^{a} \\
& i_{f}^{a 0}=-i_{f}^{a 1} \cdot \frac{z_{f f}^{2}}{z_{f f}^{0}+z_{f f}^{2}}=-\frac{z_{f f}^{2}}{z_{f f}^{1} \cdot z_{f f}^{0}+z_{f f}^{1} \cdot z_{f f}^{2}+z_{f f}^{0} \cdot z_{f f}^{2}} \cdot \dot{v}_{p r e f(f)}^{a}
\end{aligned}
$$

Substituindo as equações (56), (57) e (58) na equação (30) e fazendo:

$$
D=\left(\operatorname{diag}\left(Z_{1}\right) \cdot \operatorname{diag}\left(Z_{0}\right)\right)+\left(\operatorname{diag}\left(Z_{1}\right) \cdot \operatorname{diag}\left(Z_{2}\right)\right)+\left(\operatorname{diag}\left(Z_{0}\right) \cdot \operatorname{diag}\left(Z_{2}\right)\right)
$$

Adquire-se $\Delta \dot{V}_{1}, \Delta \dot{V}_{2}$ e $\Delta \dot{V}_{0}$ :

$$
\begin{gathered}
\Delta \dot{V}_{1}=-Z_{1} \cdot\left(\operatorname{diag}\left(Z_{0}\right)+\operatorname{diag}\left(Z_{2}\right)\right) \cdot(D)^{-1} \cdot \operatorname{diag}\left(\dot{V}_{\text {pref }}^{1}\right) \\
\Delta \dot{V}_{2}=Z_{2} \cdot \operatorname{diag}\left(Z_{0}\right) \cdot(D)^{-1} \cdot \operatorname{diag}\left(\dot{V}_{\text {pref }}^{1}\right) \\
\Delta \dot{V}_{0}=Z_{2} \cdot \operatorname{diag}\left(Z_{2}\right) \cdot(D)^{-1} \cdot \operatorname{diag}\left(\dot{V}_{\text {pref }}^{1}\right)
\end{gathered}
$$

E substituindo as equações (60), (61) e (62) em (25), obtêm-se de forma direta as MTDFs, para cada fase, que pode ser calculada após a obtenção da matriz $\boldsymbol{Z}_{\text {barra }}$ de sequência positiva, negativa e zero. Como pode ser observado nas equações a seguir:

$$
\begin{gathered}
M T D F_{a}^{F F T}=\left|\dot{V}_{\text {pref }}^{1}+\left(\left(Z_{2}-Z_{1}\right) \cdot \operatorname{diag}\left(Z_{0}\right)+\left(Z_{0}-Z_{1}\right) \cdot \operatorname{diag}\left(Z_{2}\right)\right) \cdot(D)^{-1} \cdot \operatorname{diag}\left(\dot{V}_{\text {pref }}^{1}\right)\right| \\
\operatorname{MTDF}_{b}^{F F T}=\left|a^{2} \cdot \dot{V}_{\text {pref }}^{1}+\left(\left(a \cdot Z_{2}-a^{2} \cdot Z_{1}\right) \cdot \operatorname{diag}\left(Z_{0}\right)+\left(Z_{0}-a^{2} \cdot Z_{1}\right) \cdot \operatorname{diag}\left(Z_{2}\right)\right) \cdot(D)^{-1} \cdot \operatorname{diag}\left(\dot{V}_{\text {pref }}^{1}\right)\right|
\end{gathered}
$$




$$
\operatorname{MTDF}_{c}^{F F T}=\left|a \cdot \dot{V}_{p r e f}^{1}+\left(\left(a^{2} \cdot Z_{2}-a \cdot Z_{1}\right) \cdot \operatorname{diag}\left(Z_{0}\right)+\left(Z_{0}-a \cdot Z_{1}\right) \cdot \operatorname{diag}\left(Z_{2}\right)\right) \cdot(D)^{-1} \cdot \operatorname{diag}\left(\dot{V}_{p r e f}^{1}\right)\right|
$$

\subsubsection{Exemplo de Aplicação da Metodologia em um SD Hipotético com 3 nós}

Conforme exposto neste capítulo, o MPF se mostra como uma boa alternativa para se obter as tensões remanescentes em todos os nós, mesmo não tendo dados precisos das cargas, dos bancos de capacitores e dos reguladores de tensão presentes no SD. Desta forma, não há a necessidade de utilização de programas computacionais específicos, que requerem por parte do usuário familiaridade com o software e um grande número de simulações.

Utilizando um SD hipotético de três nós como apresentado na Figura 24, assumindo que o sistema é trifásico e que o cabo utilizado é o mesmo para todos os seguimentos de linha, conforme os dados especificados na Tabela 15, a matriz de impedância de linha pode ser obtida utilizando as equações de Carson e pelo método de redução de Kron (KERSTING, 2007).

Tabela 15 - Características das linhas.

\begin{tabular}{cccc}
\hline \hline Fase & Fase ACSR & Neutro ACSR & Espaçamento \\
\hline \hline ABCN & $556,50026 / 7$ & $4 / 06 / 1$ & 500 \\
\hline
\end{tabular}

Figura 24 - Diagrama unifilar de um circuito hipotético de três nós.

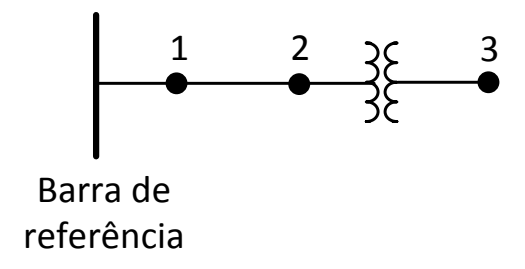

Fonte: Elaborada pela autora.

A Figura 25 mostra o espaçamento 500 (trifásico, 4 fios), em metros, e as configurações entre os condutores fase-fase e os condutores fase-neutro. 
Figura 25 - Espaçamento entre condutores (500).

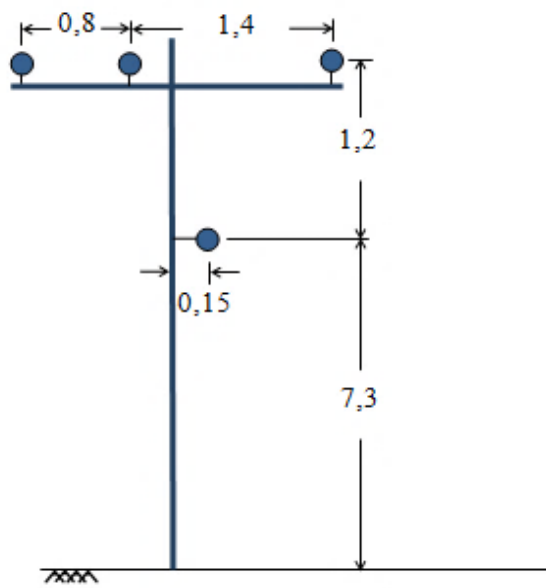

Fonte: Adaptado de Kersting (2001).

Considerando-se um alimentador não transposto, a matriz impedância de fase ( $\left.\boldsymbol{Z}_{a b c}\right)$ é obtida como apresentado em (66).

$$
\boldsymbol{Z}_{a b c}=\left[\begin{array}{lll}
0,2153+j 0,6325 & 0,0969+j 0,3117 & 0,0982+j 0,2632 \\
0,0969+j 0,3117 & 0,2097+j 0,6511 & 0,0954+j 0,2392 \\
0,0982+j 0,2632 & 0,0954+j 0,2392 & 0,2121+j 0,6430
\end{array}\right][\Omega / k m]
$$

Aplicando a transformação de sequências (FORTESCUE, 1918), a matriz $\boldsymbol{Z}_{a b c}$ pode ser transformada em uma matriz de impedância de sequência $\boldsymbol{Z}_{012}$, resultando na matriz exibida em (67).

$$
\boldsymbol{Z}_{012}=\left[\begin{array}{ccc}
0,4060+j 1,1849 & 0 & 0 \\
0 & 0,1156+j 0,3708 & 0 \\
0 & 0 & 0,1156+j 0,3708
\end{array}\right][\Omega / k m]
$$

Seguindo a metodologia apresentada na seção 3.2 e considerando os dados apresentados na Tabela 16, a matriz impedância de barra de sequência positiva pode ser obtida em p.u. considerando o valor da impedância base conforme (68).

Tabela 16 - Dados dos transformadores e espaçamento entre os condutores.

\begin{tabular}{cccccccc}
\hline \hline Nó A & Nó B & Potência kVA & $\mathbf{k V}$-alta & $\mathbf{k V - b a i x a}$ & $\mathbf{R}(\boldsymbol{\%})$ & $\mathbf{X}(\%)$ & Comp. \\
\hline \hline 0 & 1 & 5.000 & $115-\Delta$ & $4,16-\mathrm{Y}$ & 1 & 8 & $0,609 \mathrm{~km}$ \\
1 & 2 & - & - & - & - & - & $0,152 \mathrm{~km}$ \\
2 & 3 & 500 & $4,16-\mathrm{Y}$ & $0,48-\mathrm{Y}$ & 1,1 & 2 & 0 \\
\hline
\end{tabular}




$$
Z_{\text {base }}=\frac{V_{\text {base }}^{2}}{S_{\text {base }}}=\frac{4.160^{2}}{5.000 .000}=3,461 \Omega
$$

Assim, analisando a Figura 24, a primeira linha a ser adicionada deve ser uma linha que liga a barra de referência a alguma barra do sistema, ou seja, o nó 1 é o primeiro nó à ser adicionado. Logo, a matriz $\boldsymbol{Z}_{\text {barra }}$ será inicialmente constituída pela impedância de sequência positiva $(0,1156+j 0,3708)$ apresentado em (67) multiplicada pela distância existente entre o nó 0 e 1 , conforme as matrizes abaixo:

$$
\begin{gathered}
Z_{1}=Z_{0-1}^{11}[0,0704+j 0,226] \quad \Omega \\
Z_{1}=Z_{0-1}^{11}=[0,0204+j 0,065] \quad \text { p.u. }
\end{gathered}
$$

Após a primeira impedância ser inserida, a matriz $\boldsymbol{Z}_{\text {barra }}$ é atualizada a cada nova linha à ser adicionada. Observando o diagrama unifilar da Figura 24 o próximo segmento de linha à ser adicionado é do nó 1 para o nó 2 , que se refere à adição de uma impedância de linha de uma barra já existente para uma nova barra. Considerando a inserção de um novo nó conectado ao sistema, a nova matriz $\boldsymbol{Z}_{\text {barra }}$ resulta na adição de uma nova coluna que é transposta de uma nova linha, onde se repetem as impedâncias da coluna referente à barra onde esta nova impedância foi inserida. Neste caso, as impedâncias mútuas serão coincidentes com as impedâncias mútuas da coluna 1e a nova impedância própria terá origem da somatória entre as impedâncias próprias da barra 1 e da barra 2. Portanto a nova matriz $\boldsymbol{Z}_{\text {barra }}$ é calculada como em (71).

$$
\boldsymbol{Z}_{1}=\left[\begin{array}{ll}
0,0204+j 0,065 & 0,0204+j 0,065 \\
0,0204+j 0,065 & 0,0254+j 0,082
\end{array}\right] p . u .
$$

Na sequência a matriz $\boldsymbol{Z}_{\text {barra }}$ é alterada novamente, seguindo a mesma metodologia, ou seja, as novas impedâncias mútuas serão iguais às impedâncias determinadas no passo anterior, e a nova impedância própria será determinada pela somatória das impedâncias do nó 2 e do nó 3, como apresentado em (72).

$$
\boldsymbol{Z}_{1}=\left[\begin{array}{lll}
0,0204+j 0,0653 & 0,0204+j 0,0653 & 0,0204+j 0,0653 \\
0,0204+j 0,0653 & 0,0254+j 0,0816 & 0,0254+j 0,0816 \\
0,0204+j 0,0653 & 0,0254+j 0,0816 & 0,1354+j 0,2816
\end{array}\right] \text { p.u. }
$$


Definida a matriz impedância de barra de sequência positiva para os $n$ nós do sistema, repetem-se todos os passos da metodologia, iniciando com a impedância própria de sequência zero $\left(z_{00}=0,4060+j 1,1849\right)$, apresentada em (67). Dando origem assim, à matriz $\boldsymbol{Z}_{\text {barra }}$ de sequência zero, conforme (73).

$$
\boldsymbol{Z}_{0}=\left[\begin{array}{lll}
0,0715+j 0,2087 & 0,0715+j 0,2087 & 0,0715+j 0,2087 \\
0,0715+j 0,2087 & 0,0894+j 0,2609 & 0,0894+j 0,2609 \\
0,0715+j 0,2087 & 0,0894+j 0,2609 & 0,1994+j 0,4609
\end{array}\right] p . u .
$$

Dada à utilização de componentes simétricas, a matriz de sequência negativa $\left(\boldsymbol{Z}_{2}\right)$ será igual à de sequência positiva conforme já mostrado em (72).

Definidas as matrizes impedância de barra de sequência, a obtenção das MTDF se dá através da aplicação direta da formulação apresentada na seção 3.3. Por exemplo, para faltas trifásicas, utilizando a equação (33) e assumindo as tensões pré falta como sendo 1 p.u., a MTDF é obtida da seguinte forma:

$$
\begin{aligned}
& M T D F_{a ; b ; c}^{F F F}=\left|\dot{V}_{p r e f}^{1}-Z_{1} \cdot\left(\operatorname{diag}\left(Z_{1}\right)\right)^{-1} \cdot \operatorname{diag}\left(\dot{V}_{p r e f}^{1}\right)\right|=
\end{aligned}
$$

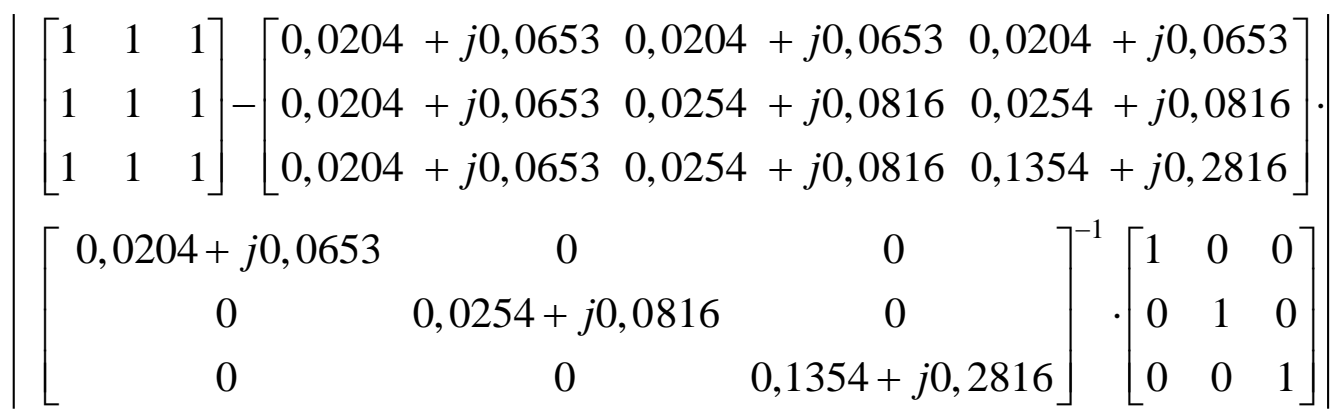

$$
\begin{aligned}
& M T D F_{a ; b ; c}^{F F F}=\left[\begin{array}{ccc}
0 & 0,2000 & 0,7841 \\
0 & 0 & 0,7304 \\
0 & 0 & 0
\end{array}\right] \text { p.u. }
\end{aligned}
$$

Conforme será posteriormente ilustrado, após a determinação de todas as MTDFs, torna-se viável a análise da robustez do SD frente às possíveis faltas que possam ocorrer, através da análise das áreas de propagação das VTCDs, o que dará recursos para determinar os melhores locais para a instalação de medidores de QEE com a máxima observabilidade dos afundamentos de tensão, através da alocação ótima de medidores de QEE. 


\section{Capítulo 4}

\section{Alocação Ótima de Medidores de QEE: Aspectos Conceituais e Práticos}

Devido às restrições de recursos financeiros para a aquisição e manutenção de equipamentos em campo para realizar um monitoramento completo no SD, bem como pela dificuldade em determinar os melhores locais para instalação dos equipamentos de monitoramento que propiciem a observação das VTCDs no sistema como um todo, a metodologia proposta neste capítulo buscará determinar o número mínimo de medidores de QEE, bem como as posições em que os mesmos devem ser instalados, analisando simultaneamente curtos-circuitos balanceados e desbalanceados. Além disso, a capacidade de observabilidade dos eventos será maximizada através da análise de vulnerabilidade de cada nó, que também permitirá estabelecer a prioridade de instalação dos medidores.

Para facilitar o entendimento e a observação dos resultados ao leitor, são apresentadas a seguir a descrição da metodologia adotada e o equacionamento do problema proposto, que serão exemplificados utilizando o SD teste do IEEE de 13 nós (DISTRIBUTION TEST FEEDERS, 2010).

\subsection{Formulação Matemática do Problema}

A metodologia de alocação ótima está sumarizada no fluxograma apresentado na Figura 26 onde serão utilizadas as MTDFs que caracterizam os afundamentos de tensão, obtidas através da formulação apresentada no capítulo 3. Nas seções seguintes são apresentadas a formulação matemática para a análise simultânea dos curtos-circuitos passíveis de ocorrência no SD, através da Matriz de Observabilidade binária (MO) que monitora os afundamentos de tensão decorrentes de qualquer ocorrência de falta, e os conceitos básicos necessários para a compreensão da metodologia para determinar o número ótimo de medidores, bem como os melhores locais para a instalação dos mesmos usando o algoritmo BB. 
Figura 26 - Fluxograma da metodologia para a alocação ótima de medidores.

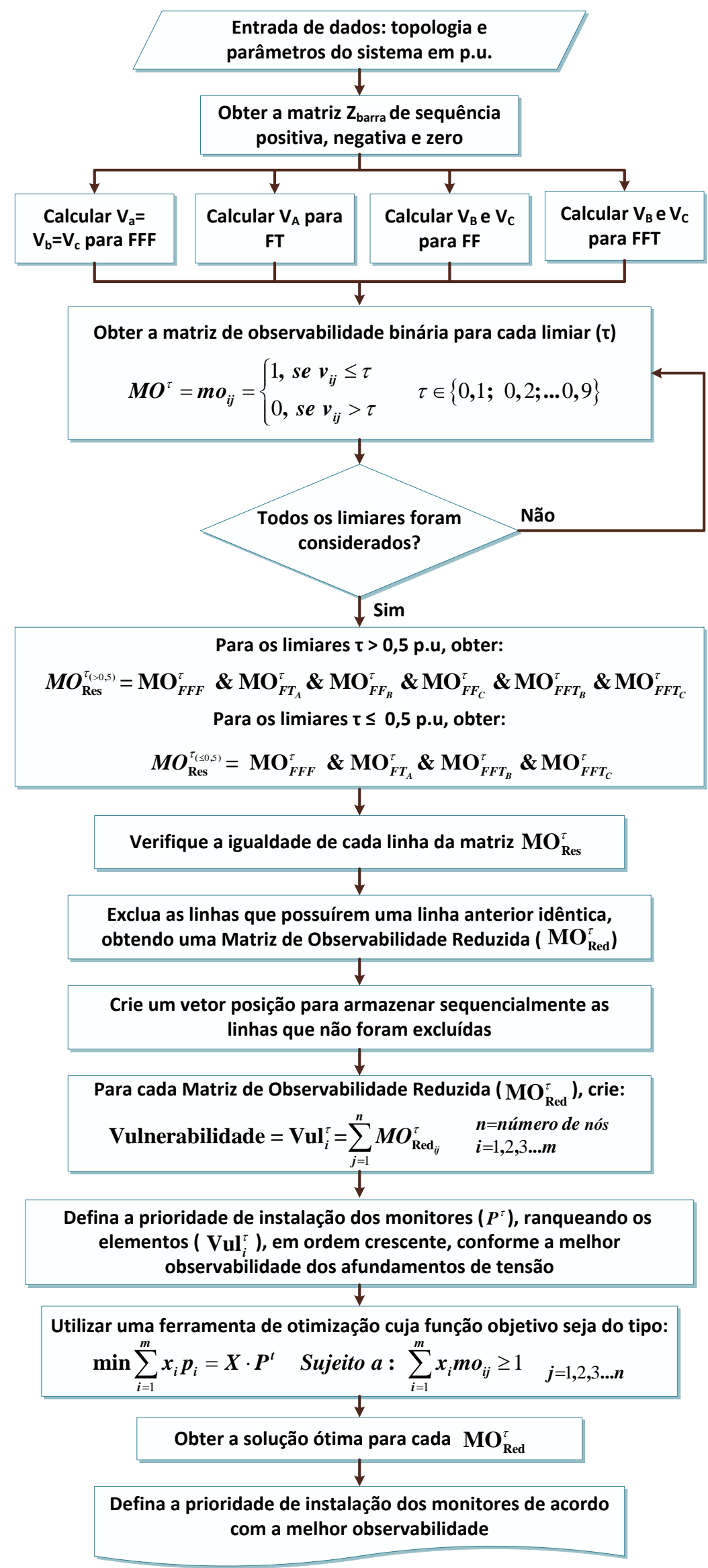




\subsubsection{Matriz de Observabilidade Binária (MO)}

O conceito de observabilidade é utilizado nesta pesquisa com o intuito de quantificar o alcance da monitoração de um medidor instalado em um determinado ponto do sistema frente às possíveis ocorrências de afundamentos de tensão a que o sistema possa vir a ser submetido.

Para simplificar e tornar a avaliação dos afundamentos de tensão mais objetiva, a partir das seis MTDFs que caracterizam os afundamentos de tensão (geradas através do equacionamento apresentado na seção 3.3), definem-se as MOs, que são obtidas fixando-se um determinado limiar tensão $(\tau)$. Ou seja, o valor da magnitude das tensões de falta, a partir do qual se deseja que os medidores sejam sensibilizados.

A MO é definida considerando que cada coluna representa a posição de falta, isto é, um nó do SD em avaliação em que foi aplicado um curto-circuito. Já as linhas da MO representam se um medidor será ou não sensibilizado por cada falta considerada. Desta forma, as linhas da MO representam os nós candidatos à instalação dos medidores. A fim de ilustrar a obtenção de uma MO, suponha a MTDF apresentada na Figura 27 (a), gerada para faltas trifásicas, através da equação (33), utilizando os dados do SD de 13 nós do IEEE (DISTRIBUTION TEST FEEDERS, 2010).

Figura 27 - Exemplo da MTDF para falta trifásica no SD de 13 nós do IEEE (a), e de obtenção da MO para $\tau \leq 0,5$ p.u. (b).
(a) $-\mathrm{MTDF}^{\mathrm{FFF}}$
(b) $-\mathrm{MO}^{\mathrm{FFF}}$

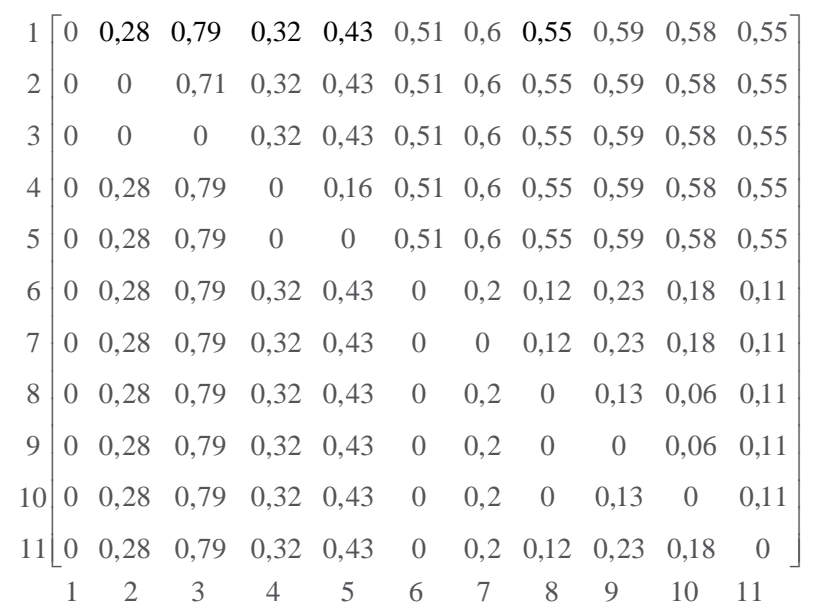

\begin{tabular}{|c|c|c|c|c|c|c|c|c|c|c|}
\hline & 1 & 1 & 0 & 1 & 1 & 0 & 0 & 0 & 0 & 0 \\
\hline & 1 & 1 & 0 & 1 & 1 & 0 & 0 & 0 & 0 & 0 \\
\hline & 1 & 1 & 1 & 1 & 1 & 0 & 0 & 0 & 0 & 0 \\
\hline & 1 & 1 & 0 & 1 & 1 & 0 & 0 & 0 & 0 & 0 \\
\hline & 1 & 1 & 0 & 1 & 1 & 0 & 0 & 0 & 0 & 0 \\
\hline & 1 & 1 & 0 & 1 & 1 & 1 & 1 & 1 & 1 & 1 \\
\hline & 1 & 1 & 0 & 1 & 1 & 1 & 1 & 1 & 1 & 1 \\
\hline & 1 & 1 & 0 & 1 & 1 & 1 & 1 & 1 & 1 & 1 \\
\hline & 1 & 1 & 0 & 1 & 1 & 1 & 1 & 1 & 1 & 1 \\
\hline & 1 & 1 & 0 & 1 & 1 & 1 & 1 & 1 & 1 & 1 \\
\hline & 1 & 1 & 0 & 1 & 1 & 1 & 1 & 1 & 1 & 1 \\
\hline & 1 & 2 & 3 & 4 & 5 & 6 & & & & \\
\hline
\end{tabular}

Para avaliar os afundamentos de tensão é necessário fixar um limiar, $\tau$, compreendido entre 0,9 e 0,1 p.u.. Desta forma, as posições da MO são preenchidas com 0 (zero), caso o valor da tensão de falta de cada nó seja superior ao limiar fixado, e com 1 (um), caso contrário 
(OLGUIN, VUINOVICH e BOLLEN, 2006). Assim, fixando $\tau$ igual a 0,5 p.u., obtém-se a MO ilustrada na Figura 27 (b).

A determinação da MO fica ainda mais evidente observando a visualização gráfica elaborada conforme a Figura 28, que correlaciona a intensidade dos afundamentos de tensão apresentados na Figura 27 com cores definidas por uma escala apropriada. Assim, após a definição de um limiar igual a 0,5 p.u. as posições da MO são preenchidas com zero (branco), caso o valor da tensão de falta de cada barra seja superior ao limiar fixado, e com um (azul), quando as tensões remanescentes registradas forem iguais ou inferiores ao limiar estabelecido.

Figura 28 - Ilustração gráfica da MTDF (a), e da MO (b) geradas para faltas FFF.

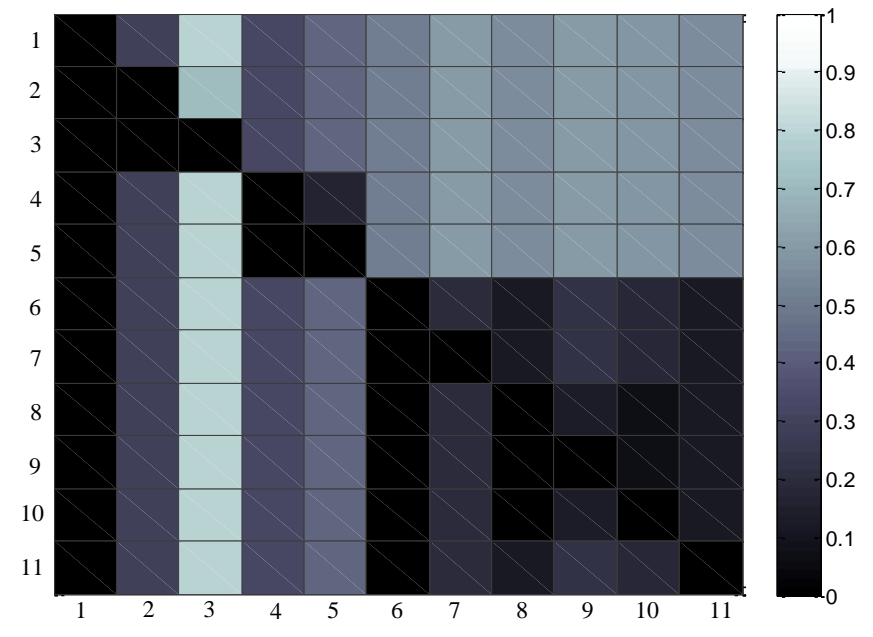

(a)

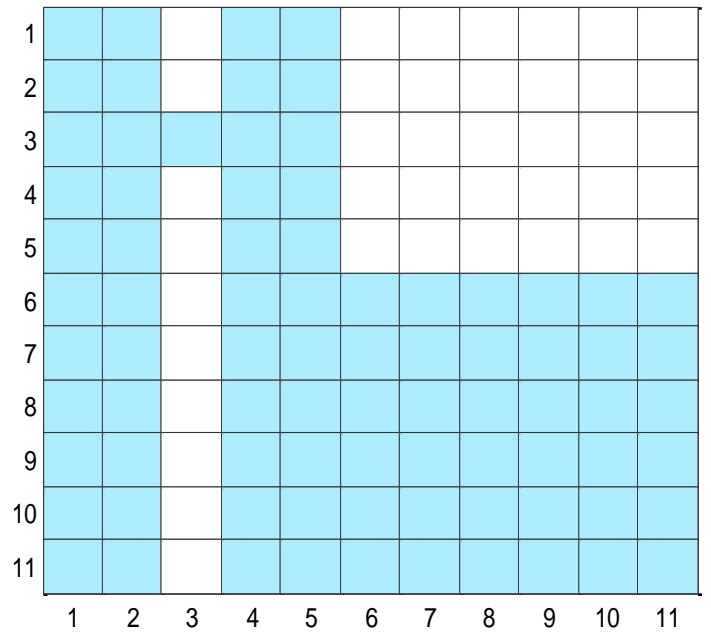

(b) $1 \leq 0,5$ p.u. $0>0,5$ p.u..

Cabe comentar que definir um limiar de tensão que melhor caracterize os afundamentos de tensão não é uma tarefa fácil, pois, como será apresentado no decorrer deste trabalho, quanto maior o limiar analisado, maior será a sensibilidade do medidor. Em contrapartida, menor será a redundância das medidas devido um número menor de medidores ser requerido para caracterizar o desempenho do sistema, o que pode comprometer a confiabilidade da monitoração, além de sobrecarregar a capacidade de armazenamento do equipamento.

Portanto, cabe ao operador do sistema estabelecer o melhor limiar para a análise dos afundamentos de tensão, em função do custo benefício da instalação dos medidores. Neste sentido, neste trabalho serão analisados todos os limiares que compreendem os afundamentos de tensão (de 0,1 a 0,9 p.u.), dando origem a nove MOs para cada uma das seis MTDFs geradas, totalizando 54 (cinquenta e quatro) MOs. 


\subsubsection{Intersecção das Matrizes de Observabilidade Binária}

Uma vez determinada as MOs, o problema para determinar o número ótimo de medidores de QEE e as respectivas localizações pode ser formulado. Assim sendo, utilizando as metodologias convencionais de alocação otimizada de medidores (ALMEIDA e KAGAN, 2010; ESPINOSA-JUÁREZ, HERNANDES, e OLGUIN, 2009; OLGUIN, VUINOVICH, e BOLLEN, 2006), inicialmente seria necessário determinar a alocação para cada uma das 54 matrizes geradas na etapa anterior, para, posteriormente, avaliar um arranjo de medidores que contemplasse as respostas obtidas pelo algoritmo, compatível para todos os tipos de falta.

Uma forma de diminuir o esforço computacional e tornar esta análise mais simples e objetiva é realizar a intersecção das MOs, para cada limiar analisado, utilizando um operador lógico $A N D(\&)$.

Assim sendo, para um dado limiar $\tau$, cada elemento das seis MOs é analisado conforme o exemplo da Tabela 17, sendo o resultado igual a 0 (zero) se algum elemento das matrizes possuírem valores nulos, e igual a 1(um) apenas se todos os elementos analisados forem iguais a um. Desta forma, somente os afundamentos de tensão observáveis para todos os tipos de falta farão parte da Matriz de Observabilidade Binária Resultante ( $\left.\mathrm{MO}_{\mathrm{Res}}\right)$.

Tabela 17 - Operador lógico AND.

\begin{tabular}{ccccccc}
\hline \hline $\begin{array}{c}\text { Entrada: } \\
\mathrm{MO}_{\mathrm{ij}}^{\mathrm{FFF}}\end{array}$ & $\begin{array}{c}\text { Entrada: } \\
\mathrm{MO}_{\mathrm{ij}}^{\mathrm{FT}_{a}}\end{array}$ & $\begin{array}{c}\text { Entrada: } \\
\mathrm{MO}_{\mathrm{ij}}^{\mathrm{FF}}\end{array}$ & $\begin{array}{c}\text { Entrada: } \\
\mathrm{MO}_{\mathrm{ij}}^{\mathrm{FF}}\end{array}$ & $\begin{array}{c}\text { Entrada: } \\
\mathrm{MO}_{\mathrm{ij}}^{\mathrm{FT}} \mathrm{FT}_{b}\end{array}$ & $\begin{array}{c}\text { Entrada: } \\
\mathrm{MO}_{\mathrm{ij}} \mathrm{FFT}_{c}\end{array}$ & $\begin{array}{c}\text { Saída: } \\
\mathrm{MO}_{\mathrm{ij}}^{\mathrm{Res}}\end{array}$ \\
\hline 0 & 0 & 1 & 0 & 1 & 1 & $\mathbf{0}$ \\
0 & 1 & 1 & 1 & 0 & 1 & $\mathbf{0}$ \\
1 & 0 & 0 & 1 & 0 & 1 & $\mathbf{0}$ \\
1 & 1 & 1 & 1 & 1 & 1 & $\mathbf{1}$ \\
\hline
\end{tabular}

Durante a ocorrência de curtos-circuitos FF sobre o SD de 13 nós, assim como para os demais SDs analisados, foi observado que as tensões remanescentes registradas, normalmente, são maiores que 0,5 p.u.. Portanto, quando definido um limiar menor ou igual a 0,5 p.u. a $\mathrm{MO}_{\text {Res }}$ deve ser definida pela equação (75), desconsiderando as MOs decorrentes de curtoscircuitos FF. Para os limiares maiores que 0,5 p.u. a $\mathrm{MO}_{\text {Res }}$ é definida como (76). A Figura 29 mostra graficamente como a $\mathrm{MO}_{\mathrm{Res}}$ é obtida no SD de 13 nós para $\tau \leq 0,6$ p.u..

$$
\begin{gathered}
M O_{\mathrm{Re}}^{\tau_{(\leq 0,5)}}=M O_{F F F}^{\tau} \& M O_{F T_{A}}^{\tau} \& M O_{F F T_{B}}^{\tau} \& M O_{F F T_{C}}^{\tau} \\
M O_{\mathrm{Res}}^{\tau_{(>0,5)}}=M O_{F F F}^{\tau} \& M O_{F T_{A}}^{\tau} \& M O_{F F_{B}}^{\tau} \& M O_{F F_{C}}^{\tau} \& M O_{F F T_{B}}^{\tau} \& M O_{F F T_{C}}^{\tau}
\end{gathered}
$$


Figura 29 - Visualização gráfica da $\mathrm{MO}_{\text {Res, }}$ para $\tau \leq 0,6$ p.u.. Sendo, $1 \leq 0,6$ p.u. e 0 > 0,6 p.u..
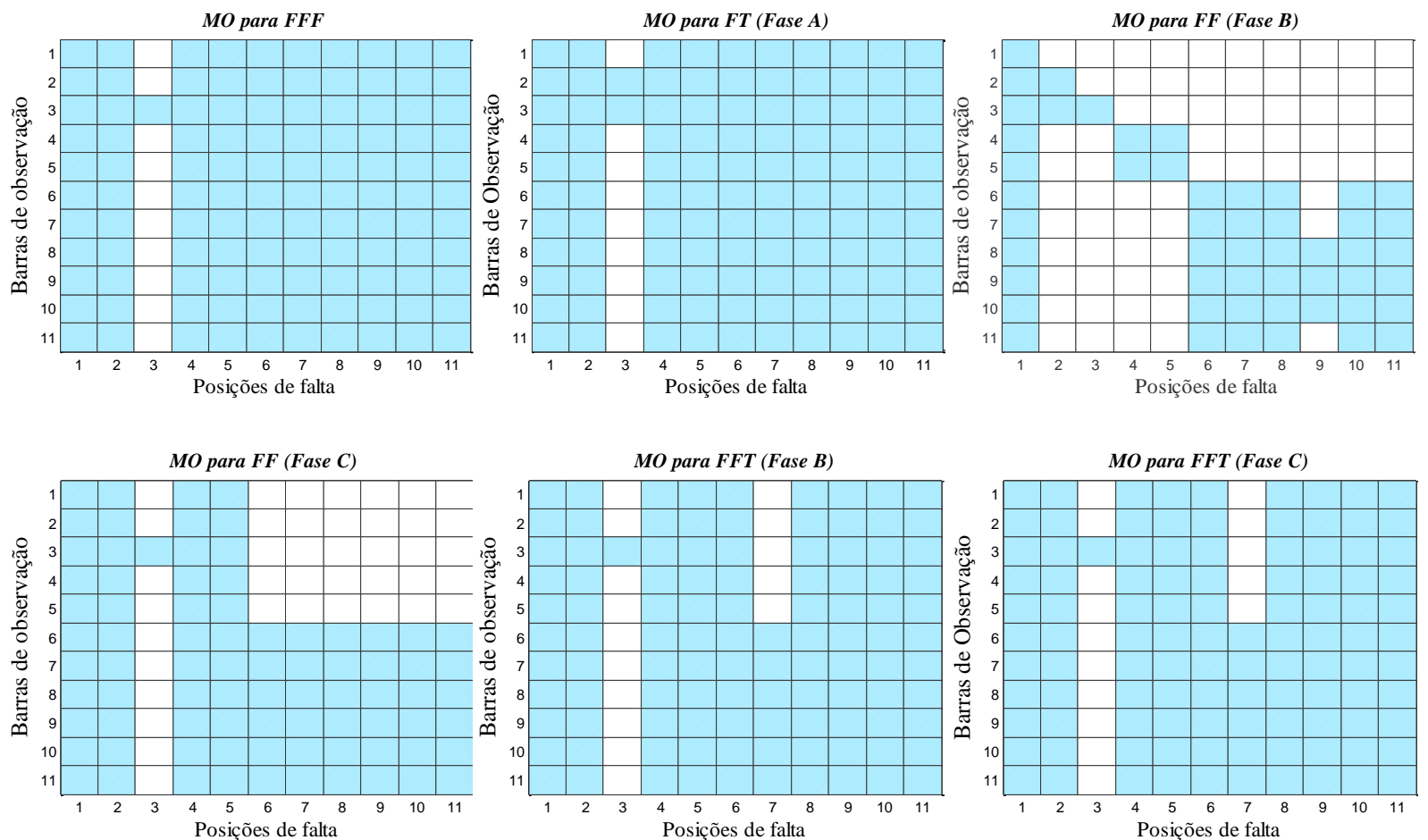

MO Resultante (0,6 p.u.)

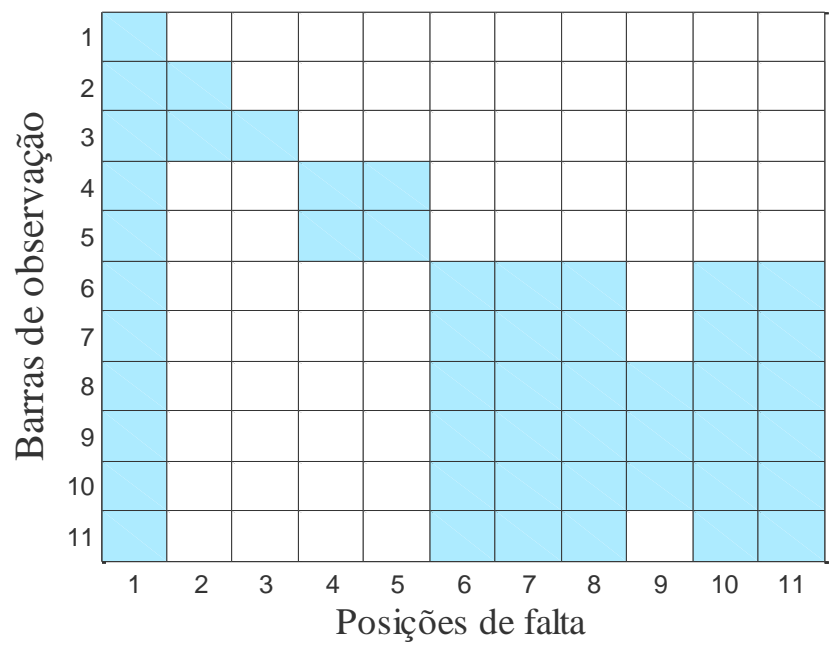

Ao final são geradas nove MOs resultantes, uma para cada limiar de tensão. Após esta etapa, propõe-se a redução destas matrizes para, posteriormente, analisar de forma simultânea a vulnerabilidade dos barramentos para os diferentes tipos de falta.

\subsubsection{Redução da Matriz de Observabilidade Resultante}

Dependendo da instância do problema, a utilização de alguns algoritmos de otimização torna-se inexequível com o crescimento exponencial do número de soluções possíveis, o que 
torna inviável a procura de uma solução de valor ótimo global. Nestes casos, métodos heurísticos costumam ser empregados para encontrar as soluções ótimas locais (sub-ótimas).

Com o objetivo de contornar este problema, nesta etapa, é proposta a redução da $\mathrm{MO}_{\text {Res }}$ para diminuir o número de operações matemáticas, bem como predeterminar outras possíveis soluções ótimas para a alocação dos medidores de QEE, atenuando o esforço computacional do algoritmo de otimização.

A redução das MOs resultantes é admissível pelo fato de existirem algumas barras com capacidade de observabilidade semelhantes. Como exemplo, a Figura 30 (a), mostra a $\mathrm{MO}_{\text {Res }}$ no SD de 13 barras do IEEE que atenderá um limiar $\leq 0,2$ p.u., onde se observa a igualdade entre as linhas 4 e 5 , entre as linhas 6 e 11 e também entre as linhas 8, 9 e 10 . Por esta análise, pode-se diminuir o posto das linhas da $\mathrm{MO}_{\text {Res }}(n x n)$, mantendo apenas as linhas linearmente independentes, dando origem a uma $\mathrm{MO}$ reduzida $\left(\mathrm{MO}_{\mathrm{Red}}\right)($ mxn $)$ como mostra a Figura 35 (b). Assim, apenas uma das linhas que forem idênticas é mantida, excluindo-se as linhas com observabilidade redundante.

Figura 30 - Visualização gráfica da $\mathrm{MO}_{\text {Res }}(\mathrm{a})$, e a MO $\mathrm{Med}_{\text {Red }}(\mathrm{b})$ para $\tau \leq 0,2$ p.u.. MO Resultante (0,2 p.u.)

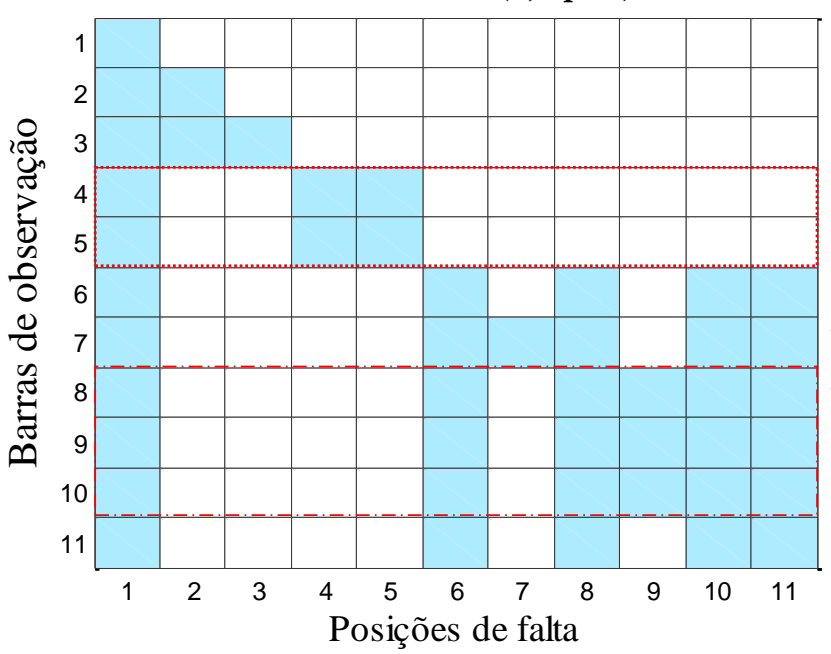

(a)

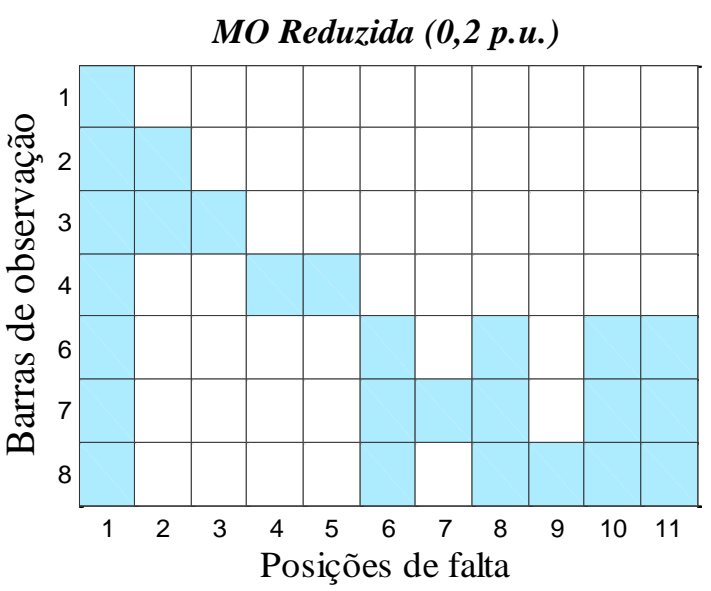

(b)

Além disso, por exemplo, caso o algoritmo de otimização determine a instalação do medidor no barramento 8 , observa-se que os barramentos 9 e 10 também seriam pontos adequados para alocar o medidor, visto que possuem a mesma observabilidade (Figura 30 (a)).

Desta forma, não é necessário seguir o procedimento normalmente adotado de executar várias vezes o algoritmo de otimização para a obtenção de novas soluções. 
Consequentemente, a observabilidade do sistema não é comprometida e o esforço computacional para a obtenção do número ótimo de medidores é diminuída, principalmente em sistemas de grande porte.

Por conseguinte, para analisar todas as possíveis soluções é necessário criar um vetor igualdade que armazenará as informações dos barramentos que possuírem a mesma observabilidade. A Figura 31 mostra o vetor igualdade transposto que armazena as informações da Figura 30 (a).

Figura 31 - Vetor igualdade transposto para $\tau \leq 0,2$ p.u..

Igualdade $^{0,2}=\left[\begin{array}{cccccccccccc}(1) & (2) & (3) & (4) & (5) & (6) & (7) & (8) & (9) & (10) & (11) \\ 1 & 2 & 3 & 4 & 4 & 6 & 7 & 8 & 8 & 8 & 6\end{array}\right]^{\mathrm{t}}$

Como a matriz é reduzida, torna-se necessário também armazenar as posições das linhas que não foram excluídas. Como exemplo, tem-se que a linha 5 da Figura 30 (b), corresponde à linha 6 da $\mathrm{MO}_{\text {Res }}$ (Figura 30(a)). Portanto, o vetor posição deverá armazenar as informações conforme a Figura 32. Assim, caso a solução ótima aponte para a instalação do medidor na linha 7 da $\mathrm{MO}_{\mathrm{Red}}$, sabe-se que esta linha corresponde ao barramento 8 no SD.

Figura 32 - Vetor posição transposto para $\tau \leq 0,2$ p.u..

Posição $^{0,2}=\left[\begin{array}{ccccccc|}(1) & (2) & (3) & (4) & (5) & (6) & (7) \\ 1 & 2 & 3 & 4 & 6 & 7 & 8\end{array}\right]^{\mathrm{t}}$

\subsubsection{Determinação do Vetor Prioridade}

A determinação do vetor prioridade $(P)$ irá auxiliar na ponderação entre as soluções a serem obtidas, de forma a priorizar a alocação dos medidores nos barramentos que possuírem maior observabilidade. Uma maneira de maximizar a capacidade de monitoração dos afundamentos de tensão é priorizar a instalação dos medidores nos barramentos que apresentam maior vulnerabilidade.

A análise da vulnerabilidade tem como objetivo avaliar como as ocorrências dos curtos-circuitos se propagam e afetam as diversas barras do sistema, sobretudo aquelas onde estão instalados equipamentos sensíveis, principalmente, nos consumidores industriais.

Como fato, dependendo da intensidade e da duração do distúrbio, bem como da sensibilidade do equipamento frente aos afundamentos, as cargas podem ser mais ou menos sensíveis, podendo apresentar funcionamento inadequado e temporário, ou danos permanentes (irreversíveis). 
Uma forma direta de determinar a sensibilidade do SD, para cada possível ponto de instalação do medidor, é realizar o somatório de cada linha da $\mathrm{MO}_{\mathrm{Red}}$, conforme (77).

$$
V u l_{i}^{\tau}=\sum_{i=1}^{m} M O_{\operatorname{Red}_{i j}}^{\tau} \quad \tau \in\left\{\begin{array}{c}
\{0,1 ; 0,2 ; \ldots 0,9\} \\
i=1,2,3 \ldots m
\end{array}\right.
$$

Analisando a $\mathrm{MO}_{\mathrm{Red}}$ da Figura 30 (b), nota-se que se o medidor fosse instalado no barramento um (linha 1), por exemplo, este seria sensibilizado apenas se ocorresse uma falta no próprio barramento 1. Caso a alocação fosse no barramento oito (linha 7 da $\mathrm{MO}_{\mathrm{Red}}$ ), este medidor seria sensibilizado pela ocorrência de faltas em seis barramentos. Tendo como objetivo a observabilidade máxima dos afundamentos de tensão, o local ideal para a instalação do medidor é no barramento mais exposto a este distúrbio.

Desta forma, para cada limiar de tensão, torna-se possível determinar, de forma simultânea, as posições que são mais sensibilizadas pelas possíveis faltas no SD. Para a $\mathrm{MO}_{\mathrm{Red}}$ apresentada na Figura 30 (b) a vulnerabilidade de cada barramento é apresentada na Figura 33.

Como pode ser observado na Figura 33, os barramentos 7 e 8 (que correspondem às linhas 6 e 7 da $\left.\mathrm{MO}_{\mathrm{Red}}\right)$ possuem a mesma vulnerabilidade, sendo os nós mais expostos aos afundamentos de tensão. Assim sendo, caso o medidor seja alocado em algum destes barramentos, um número maior de afundamentos será observável.

Figura 33 - Vulnerabilidade aos afundamentos de tensão para $\tau \leq \mathbf{0 , 2}$ p.u..

$$
V u l^{0,2}=\sum M O_{\text {Red }}^{\leq 0,2 p . u .}=\left[\begin{array}{cccccccc}
(1) & (2) & (3) & (4) & (5) & (6) & (7) \\
1 & 2 & 3 & 3 & 5 & 6 & 6
\end{array}\right]^{\mathrm{t}}
$$

Seguindo esta ideia, o vetor $P$ é determinado atribuindo a cada elemento do vetor $V u l$ um valor correspondente à prioridade de instalação dos medidores, conforme a observabilidade da monitoração. Assim, os barramentos são ranqueados em ordem crescente da maior vulnerabilidade para a menor, sendo que os nós com mesma vulnerabilidade recebem a mesma prioridade de instalação dos medidores. A Figura 34 ilustra como o vetor prioridade transposto é originado para a Figura 33.

Figura 34 - Prioridade de instalação dos medidores para $\tau \leq 0,2$ p.u..

$$
P^{0,2}=\left[\begin{array}{ccccccc}
(1) & (2) & (3) & (4) & (5) & (6) & (7) \\
5 & 4 & 3 & 3 & 2 & 1 & 1
\end{array}\right]^{t}
$$


Desta forma, os menores coeficientes inteiros serão prioritários na busca da solução ótima. Portanto, se houver uma solução factível que englobe as posições com os menores coeficientes, o algoritmo fornecerá a solução ótima indicando a instalação nos barramentos com a maior observabilidade dos afundamentos de tensão.

Vale comentar que, mesmo associando a prioridade de instalação dos medidores, se não houver uma resposta factível para solução do problema que englobe a posição vetorial de menor índice do vetor $P$, a resposta ótima irá fornecer a solução com o menor índice possível. Logo, este problema prioriza a obtenção do número mínimo de medidores, não necessariamente instalando o medidor no nó mais vulnerável.

\subsubsection{Função Objetivo}

A preocupação fundamental na solução do problema da alocação ótima de medidores de QEE reside na determinação das posições em que devem ser instalados os equipamentos para minimizar o número de medidores.

Portanto, a função objetivo do problema é apresentada através da expressão (78). Pela sua definição, nota-se que a intenção da mesma é minimizar o somatório dos elementos do vetor monitoração $(X)$ associando a prioridade $(P)$ de instalação dos medidores conforme a maior observabilidade dos afundamentos de tensão.

$$
\min f(x)=\min \sum_{i=1}^{m} x_{i} \cdot p_{i}=\boldsymbol{X} \cdot P^{t}
$$

O vetor $X$, é um vetor binário de dimensão $(m x l)$ fixada de acordo com o número de

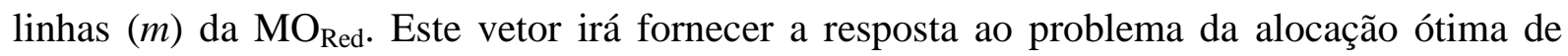
medidores, indicando o número mínimo de medidores necessários para monitorar o SD, bem como em quais nós os mesmos devem ser instalados.

Assim, o vetor $X$ será definido por um vetor variável de decisão, conforme a expressão (79), sendo que, pela formulação do problema, cada posição do vetor será candidata a ter um medidor alocado.

$$
X=\left[\begin{array}{lllll}
x(1) & x(2) & x(3) & \ldots & x(m)
\end{array}\right]^{t}
$$

A decisão pela instalação de um medidor ou não em um determinado nó é feita através do preenchimento de cada uma das posições do vetor. As mesmas são então preenchidas por 0 (zero) ou 1 (um), indicando a não instalação, ou a instalação de um medidor, respectivamente. 
A expressão (80) ilustra a condição de decisão do vetor de monitoração (ESPINOSAJUÁREZ, HERNANDES e OLGUIN, 2009):

$$
x_{(i)}=\left\{\begin{array}{l}
1, \text { para instalação do medidor no nó } i \\
0, \text { caso contrário }
\end{array}\right.
$$

A fim de ilustrar o vetor de monitoração, a Figura 35, exibe um exemplo para o sistema de 13 nós, no qual a resposta de alocação é dada para os índices 3, 4, 6 e 7. Que conforme o vetor posição apresentado na Figura 32, sugere a instalação de equipamentos de monitoração nos nós 3, 4, 7 e 8 .

Figura 35 - Exemplo do vetor de monitoração transposto.

$$
X_{0,2}^{t}=\begin{array}{|c|c|c|c|c|c|c|}
(1) & (2) & (3) & (4) & (5) & (6) & (7) \\
\hline 0 & 0 & 1 & 1 & 0 & 1 & 1 \\
\hline
\end{array}
$$

Caso não haja recursos imediatos para a instalação simultânea de todos os medidores, conforme o conjunto de soluções apresentado na Figura 35, basta seguir a ordem prioritária que foi definida pelo estudo da vulnerabilidade do SD (Figura 34). Desta forma, caso a disponibilidade seja para a instalação de apenas dois equipamentos, ao invés de quatro como sugere a resposta ótima, recomenda-se a instalação dos equipamentos nos nós 7 e 8 , pois a observabilidade frente aos afundamentos de tensão destes nós é superior à observabilidade dos nós 3 e 4. Assim, um número maior de eventos será monitorado, mesmo que a observabilidade dos afundamentos de tensão não seja completa.

Ainda, considerando-se a indisponibilidade, ou um maior custo associado à instalação do medidor em um determinado barramento, há a possibilidade de explorar o espaço de possíveis soluções avaliando o vetor de igualdade (Figura 31). Para exemplificar, temos que a solução fornecida na Figura 35, para o limiar $\leq 0,2$ p.u., pode ser substituída por qualquer outra alocação que tenha a mesma observabilidade, ou seja, $X_{0,2}^{t}=\left\{\mathrm{x}_{(3)}, \mathrm{x}_{(4)}, \mathrm{x}_{(7)}, \mathrm{x}_{(8)}\right\}$, tal que $\mathrm{x}_{(3)} \in \mathrm{X}_{3}=\{3\}, \mathrm{x}_{(4)} \in \mathrm{X}_{4}=\{4,5\}, \mathrm{x}_{(7)} \in \mathrm{X}_{7}=\{7\}$ e $\mathrm{x}_{(8)} \in \mathrm{X}_{8}=\{8,9,10\}$. Portanto, para este limiar, obtêm-se 6 soluções possíveis, obtidas apenas com a análise do vetor igualdade.

Assim, como não é necessário executar o algoritmo exaustivamente para obter cada uma das soluções factíveis, o custo computacional torna-se bem menor, principalmente quando o número de soluções possíveis é elevado. 


\subsubsection{Restrições do problema}

Mediante o uso do conceito de observabilidade, o qual representa a capacidade de um medidor instalado em um dado nó do SD ser sensibilizado pelos afundamentos de tensão passíveis de ocorrência, as restrições do problema devem garantir que todo o sistema seja observável. Ou seja, devem garantir que cada afundamento de tensão que ocorra no SD seja visto por pelo menos um dos medidores instalados. Para que esta condição se estabeleça, a multiplicação da $\mathrm{MO}_{\text {Red }}$ transposta pelo vetor $X$ deve ser maior ou igual a $B$, que é um vetor de uns com dimensão ( $n x l)$, conforme a expressão (81) (OLGUIN, VUINOVICH e BOLLEN, 2006; ALMEIDA, 2010).

$$
\text { Rest }=\sum_{i=1}^{m} m o_{i j} \cdot x_{i} \geq 1=M O_{\mathrm{Red}}^{t} \cdot X \geq B
$$

A expressão (82) ilustra a restrição do problema na forma matricial, utilizando-se da matriz de observabilidade binária fornecida pela Figura 30 (b).

$$
\text { Rest }^{0,2}=\left[\begin{array}{ccccccc}
1 & 1 & 1 & 1 & 1 & 1 & 1 \\
0 & 1 & 1 & 0 & 0 & 0 & 0 \\
0 & 0 & 1 & 0 & 0 & 0 & 0 \\
0 & 0 & 0 & 1 & 0 & 0 & 0 \\
0 & 0 & 0 & 1 & 0 & 0 & 0 \\
0 & 0 & 0 & 0 & 1 & 1 & 1 \\
0 & 0 & 0 & 0 & 0 & 1 & 0 \\
0 & 0 & 0 & 0 & 1 & 1 & 1 \\
0 & 0 & 0 & 0 & 0 & 0 & 1 \\
0 & 0 & 0 & 0 & 1 & 1 & 1 \\
0 & 0 & 0 & 0 & 1 & 1 & 1
\end{array}\right] \cdot\left[\begin{array}{l}
x_{(1)} \\
x_{(2)} \\
x_{(3)} \\
x_{(4)} \\
x_{(5)} \\
x_{(6)} \\
x_{(7)}
\end{array}\right] \geq\left[\begin{array}{l}
1 \\
1 \\
1 \\
1 \\
1 \\
1 \\
1 \\
1 \\
1 \\
1 \\
1
\end{array}\right]
$$

A multiplicação da $\mathrm{MO}_{\text {Red }}$ transposta pelo vetor $X$ irá contabilizar o número de medidores que serão capazes de monitorar o afundamento de tensão em um determinado nó. Desta forma, ao multiplicar a $\mathrm{MO}_{\text {Red }}$ da Figura 30 (b) pelo vetor monitoração da Figura 35, obtém-se a redundância das medidas conforme o vetor apresentado na Figura 36. Neste caso, como todas as posições do vetor redundância são maiores ou iguais a um, as restrições do problema foram atendidas para o arranjo de medidores proposto.

Figura 36 - Exemplo da obtenção do vetor de redundância transposto.

$\mathrm{V}_{\text {red }}{ }^{\mathrm{t}}=$\begin{tabular}{|c|c|c|c|c|c|c|c|c|c|c|}
$(1)$ & $(2)$ & $(3)$ & $(4)$ & $(5)$ & $(6)$ & $(7)$ & $(8)$ & $(9)$ & $(10)$ & $(11)$ \\
\hline & 1 & 1 & 1 & 1 & 2 & 1 & 2 & 1 & 2 & 2 \\
\hline
\end{tabular}


A Figura 37 ilustra como cada posição do vetor de redundância contabiliza o número de medidores sensibilizados pelo afundamento de tensão. Primeiramente os medidores são alocados nos nós de observação. Neste caso, como sugerido pelo vetor de monitoração da Figura 35, os medidores são alocados nas linhas 3, 4, 6 e 7. Logo após, para cada posição de falta simulada, percorre-se cada coluna da matriz $\mathrm{MO}_{\mathrm{Red}}$ e contabilizam-se quantos medidores alocados foram sensibilizados pelo afundamento de tensão.

Figura 37 - Exemplo de como contabilizar as posições do vetor de redundância.

MO Reduzida (0,2 p.u.)

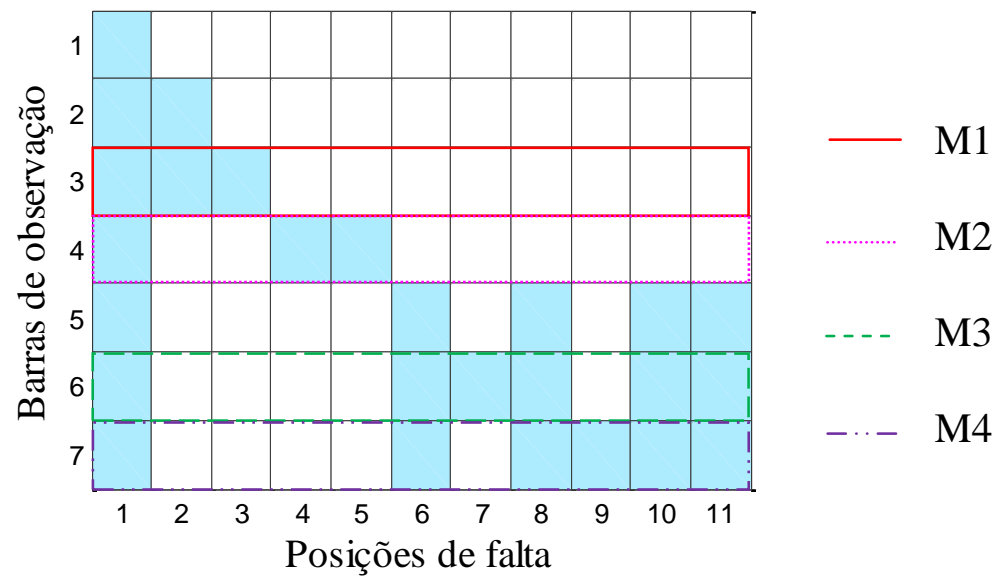

Ao se observar na Figura 37, a coluna 6, por exemplo, verifica-se que os medidores alocados nas linhas 6 e 7 (M3 e M4) foram sensibilizados pelo afundamento de tensão. Assim, a posição 6 (seis) do vetor de redundância da Figura 36 recebe o valor 2 (dois). Do mesmo modo, analisando-se a coluna 1 , verifica-se que os quatro medidores alocados serão sensibilizados pelo afundamento de tensão. Portanto, a primeira posição do vetor de redundância recebe a numeração 4 (quatro), conforme pode ser observado na Figura 36.

Pela abordagem matemática apresentada, percebe-se que o problema de alocação ótima de medidores de QEE recai em um problema clássico de Programação Linear Inteira (PLI) com variáveis binárias. Isto é, tanto a função objetivo quanto as restrições aparecem como funções lineares nas variáveis de decisão e podem assumir apenas valores binários.

Portanto, com o objetivo de obter o número mínimo de medidores e os nós em que os mesmos devam ser instalados, de forma a garantir que pelo menos um dos medidores seja sensibilizado pelos afundamentos de tensão para cada um dos curtos-circuitos simulados, será utilizado o algoritmo BB que se utiliza de técnicas de PLI. Neste sentido, na sequência são apresentados os conceitos necessários para o entendimento do algoritmo proposto para a obtenção da solução ótima. 
Cabe comentar que apesar de se ter optado neste trabalho pela utilização do algoritmo BB para a obtenção dos resultados, a metodologia poderá ser facilmente aplicada dispondo de métodos heurísticos ou outras ferramentas de otimização que utilizem lógica binária.

\subsection{Programação Linear Inteira}

A PLI foi desenvolvida em 1930 por economistas para a alocação de recursos durante a segunda guerra mundial. É um método de otimização aplicável para a solução de problemas cuja função objetivo é de maximização ou minimização, sendo que as restrições aparecem como funções lineares nas quais todas as variáveis de decisão são discretas (assumem valores inteiros).

Um problema básico de programação linear pode ser definido como um processo de encontrar as condições que resultam no máximo ou no mínimo valor de uma função. Portanto, a formulação matemática para se obter o valor mínimo, ou máximo, de uma função utilizando PLI pode ser expressa da seguinte maneira (RAO, 2009):

Encontrar $\boldsymbol{x}=\left[x_{1}, x_{2}, x_{3}, \ldots, x_{m}\right]^{\mathrm{t}}$ que minimiza $f(\boldsymbol{x})$ sujeito as restrições:

$g_{j}(\boldsymbol{x}) \leq 0, \mathrm{j}=1,2,3 \ldots, \mathrm{m}$

$l_{j}(\boldsymbol{x})=0, \mathrm{j}=1,2,3 \ldots, \mathrm{p}$

Sendo:

$\boldsymbol{x}$ - um vetor com $m$ elementos, denominado de vetor das variáveis de projeto;

$f(\boldsymbol{x})$ - a função objetivo;

$g_{j}(\boldsymbol{x})$ - as restrições descritas como inequações; e

$l_{j}(\boldsymbol{x})$ - as restrições descritas como equações.

Se o problema consiste em encontrar o valor máximo de uma função, basta alterar o sinal da função objetivo conforme a equação (83).

$$
\min [f(x)]=\max [-f(x)]
$$

A formulação do problema a ser solucionado nesta tese recai em um problema clássico de PLI de minimização cuja função objetivo é:

$$
\min f(x)=c_{1} \cdot x_{1}+c_{2} \cdot x_{2}+c_{3} \cdot x_{3} \ldots+c_{m} \cdot x_{m}
$$

Sujeito às restrições do tipo: 


$$
A \cdot x \geq b=\left[\begin{array}{ccc}
a_{11} & a_{12} \ldots & a_{1 n} \\
a_{21} & a_{22} \ldots & a_{2 n} \\
\vdots & \\
a_{m 1} & a_{m 2} \ldots & a_{m n}
\end{array}\right] \cdot\left[\begin{array}{c}
x_{1} \\
x_{2} \\
\vdots \\
x_{m}
\end{array}\right] \geq\left[\begin{array}{c}
b_{1} \\
b_{2} \\
\vdots \\
b_{n}
\end{array}\right]
$$

Neste trabalho, o vetor custo $(C)$ é substituído pelo vetor $(P)$ que irá priorizar a instalação dos medidores nos nós mais vulneráveis aos afundamentos de tensão. A matriz de observabilidade binária transposta (matriz "A"), e o vetor de monitoração (vetor " $x$ ") serão representados por variáveis binárias que são um caso especial de variáveis inteiras que apenas podem assumir os valores 0 (zero) ou 1 (um), podendo desempenhar o papel de variável principal ou de decisão, ou como variáveis auxiliares sendo utilizadas para exprimir certas condições.

\subsection{Algoritmo Branch and Bound}

O método BB, proposto por Land e Doig (1960) é um algoritmo exato de enumeração implícita, cuja estrutura de resolução se baseia na construção de uma árvore fundamentada na Programação Linear (PL) para explorar o espaço de busca.

Embora este algoritmo não teste explicitamente todas as soluções possíveis, garante a otimalidade da solução obtida. Para isso, o algoritmo divide o espaço de soluções factíveis em subespaços, evitando, desta maneira, verificar todas as soluções possíveis, permitindo ao método maior velocidade e eficiência (SOARES, 2006).

Portanto, o objetivo principal do algoritmo BB é evitar o crescimento da árvore inteira o máximo possível. Para isso, o algoritmo realiza o crescimento da árvore pela seleção apenas dos nós mais promissores em cada estágio através de três etapas apresentadas na sequência.

1. Dividir o problema original em subproblemas mais simples de resolver, ou seja, efetuar partições no espaço das soluções (Branching);

2. Avaliar os subproblemas, utilizando os limites calculados de forma a determinar qual é, na melhor das hipóteses, o valor do ótimo (Bounding); e

3. Eliminar os subproblemas que não podem conduzir a uma solução ótima (Sondagem ou poda). 


\subsubsection{Branching}

Esta etapa consiste em dividir o problema principal num conjunto de subproblemas menores, de modo a facilitar a análise, eliminando soluções inviáveis, sem comprometer a integridade da solução desejada (KAWAMURA, 2006).

$\mathrm{O}$ algoritmo $\mathrm{BB}$ cria uma árvore de busca na qual cada nó representa um problema e os ramos representam as novas restrições que devem ser consideradas. Através das ramificações exploram-se todas as possíveis soluções.

A raiz da árvore representa um problema que se deseja solucionar, onde $S$ é o seu conjunto de soluções. A divisão deste problema em um subconjunto de problemas menores é realizada através de uma partição do conjunto de soluções factíveis do problema original em espaços menores, isto é, com um menor número de soluções possíveis a serem averiguadas.

O particionamento a partir de variáveis binárias é feito fixando-se soluções com $x_{i}=0$ ou $x_{i}=1$. Para isso, são criados novos nós na árvore associados a cada novo subproblema específico, que possui determinadas variáveis fixas em 0 ou 1, e outras livres para assumir valores inteiros. Cada um dos subproblemas trabalha com uma diferente parte do espaço de solução que será resolvido, ou é novamente particionado, gerando dois outros subproblemas de forma recursiva (REIS, 2007). Assim, o algoritmo induz a uma árvore de enumeração. A Figura 38 ilustra as divisões ou ramificações de uma árvore binária que possui 3 variáveis binárias $x_{1}, x_{2}$ e $x_{3}$

Figura 38 - Árvore de ramificação (branch).

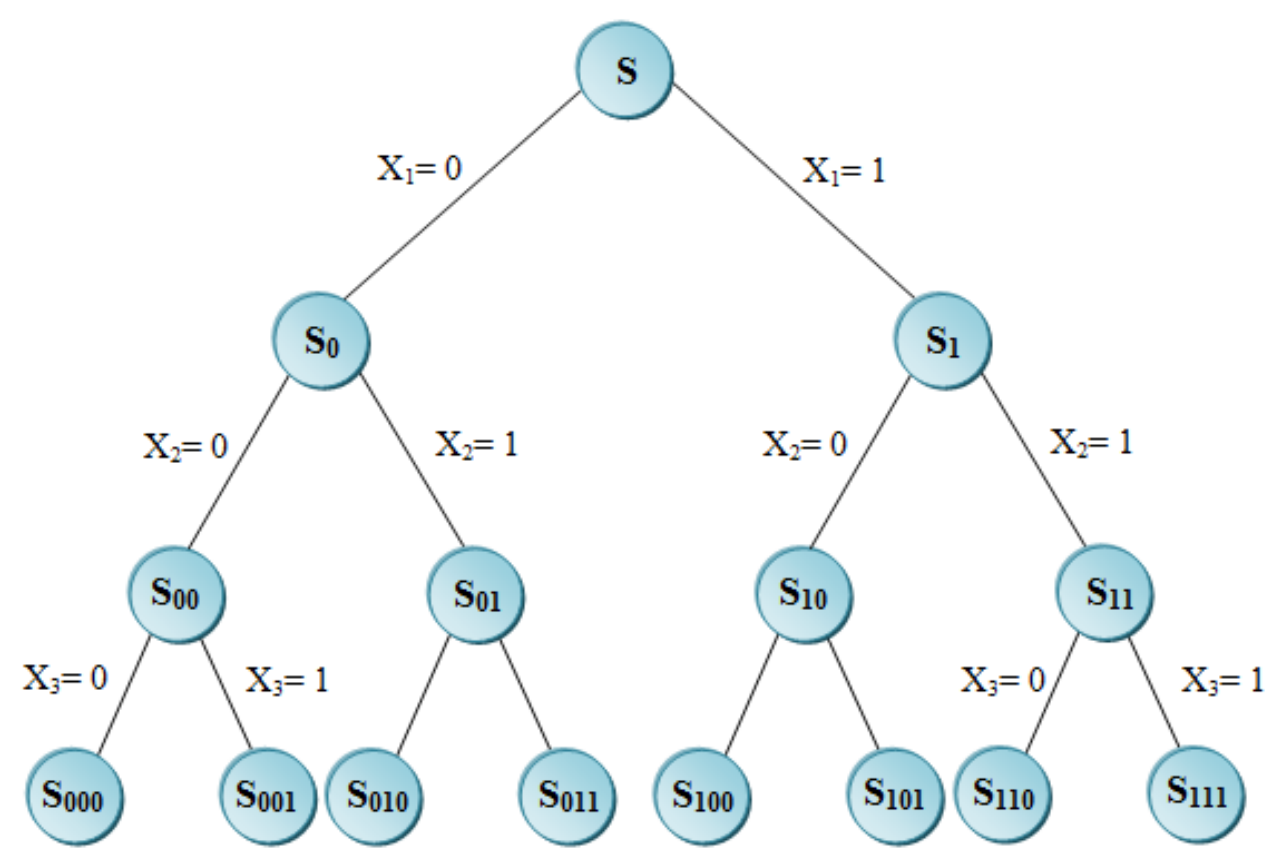

Fonte: Adaptado de Wolsey (1998). 
Para otimizar um problema desse tipo, uma das soluções seria listar todas as soluções possíveis e verificar qual a melhor. No entanto, como o número de variáveis é igual a $m$, seria necessário resolver $2^{m}$ programas lineares do último nível para obter a solução ótima.

Felizmente alguns dos nós correspondem a soluções não admissíveis (infactíveis). Além disso, o uso de limites inferiores e superiores permitem em geral percorrer esta árvore de enumeração eliminando ramificações dessa estrutura.

\subsubsection{Bounding}

Para limitar o crescimento da árvore, em cada um dos subproblemas é necessário obter uma avaliação de qual é o melhor valor que o ótimo pode ter. Esta avaliação é realizada por meio de comparações com limitantes, normalmente conhecidos por limites inferior e superior.

A forma de obter um limitante é resolver uma forma relaxada do problema, que seja de fácil resolução através de PL. A relaxação consiste em, provisoriamente, ignorar algumas restrições do problema principal, visando torná-lo mais fácil de resolver (OLIVEIRA, 2011). Embora possam ser consideradas outras formas de relaxamento, o mais usual, é considerar o relaxamento linear, ou seja, relaxar as restrições que impõem que as variáveis sejam inteiras.

Para problemas de minimização, a solução para o problema de PL-relaxado fornece um limitante superior para o problema inteiro binário de programação. Este limitante não necessariamente é o valor ótimo, mas tem o papel de servir como parâmetro para avaliar as soluções obtidas, ou seja, soluções com valores superiores ao limitante superior são descartadas por se tratarem de soluções piores do que a atualmente conhecida. Por sua vez, o limitante inferior, em um problema de minimização, é uma estimativa da função objetivo tendo como base a solução parcial até então obtida (KAWAMURA, 2006).

À medida que a árvore de busca vai crescendo, o algoritmo atualiza os limites inferior e superior da função objetivo, usando, para problemas de minimização, os menores limites obtidos a cada passo. O cálculo do limitante inferior é baseado na solução de um subconjunto da solução resolvendo um problema relaxado, enquanto que o problema inteiro é calculado considerando a solução completa, o limitante inferior, nesses casos, é sempre menor ou igual do que o valor ótimo do problema inteiro.

\subsubsection{Sondagem ou Poda}

Este procedimento definirá quais problemas serão particionados (expandidos na árvore de busca) ou podados. Desta maneira, realiza-se uma análise para determinar quais são as 
soluções promissoras e quais deverão ser descartadas. Para isso, a condição que deve ser satisfeita é que o conjunto de soluções viáveis do problema original esteja contido no conjunto de soluções viáveis do problema relaxado.

Durante a busca na árvore, os nós, considerados como subconjuntos de soluções, são analisados e podem ser podados devido a três situações:

1. Infactibilidade: $\mathrm{O}$ problema relaxado não tem solução viável, então o mesmo é verdadeiro para o problema principal. Ou seja, o subconjunto de soluções gerado é vazio. Isso pode acontecer quando as restrições do problema são violadas no momento em que se fixam as variáveis na expansão da árvore.

2. Limitante: $\mathrm{O}$ valor da solução objetivo encontrado para o problema relaxado é pior do que a melhor solução atualmente conhecida (solução incumbente). Essa situação ocorre num problema de minimização, quando o limitante inferior, que representa uma estimativa da função objetivo no nó analisado, tem valor pior (maior) do que o limitante superior, que representa a melhor solução conhecida até então.

3. Otimalidade: São soluções viáveis cujo valor exato da função objetivo pode ser calculado. Ou seja, se a solução ótima do problema relaxado é inteira e o valor da solução objetivo é melhor que a melhor solução inteira encontrada até então, nesse caso, o ramo pode ser descartado, pois já foi totalmente explorado.

\subsubsection{Função Bintprog}

Para a determinação da alocação ótima de medidores, utilizou-se de um toolbox do software MATLAB ${ }^{\circledR}$, cuja função empregada é o bintprog (MATHWORKS, 2015) que emprega técnicas de PLI, com base no algoritmo BB, para resolver problemas de programação binária com o objetivo de obter o número mínimo de medidores e os nós em que os mesmos devam ser instalados.

O algoritmo bintprog procura uma solução ótima para o problema de PLI binária, resolvendo uma série de problemas de PL na forma relaxada, em que se desconsidera a restrição de as variáveis binárias serem inteiras, ou seja, admite-se $0 \leq X \leq 1$.

A função objetivo do problema é minimizar a função:

$$
\min _{x} f^{t} \cdot x
$$


Sujeito à restrição:

$$
A \cdot x \leq b
$$

No entanto, conforme já apresentado, para o problema de alocação proposto, a restrição do problema é:

$$
A \cdot x \geq b
$$

Sendo assim, com base em (87) e (88), tem-se o seguinte:

$$
A \cdot x \leq b \text { é equivalente a }-A \cdot x \geq-b
$$

Para esta pesquisa, o problema foi encaminhado através da chamada da função bintprog no software MATLAB ${ }^{\circledR}$ representada por:

$$
x=\operatorname{bintprog}(f,-A,-b)
$$

Sendo que:

$\boldsymbol{f}$ - é o vetor prioridade $(P)$, de dimensão $(m x l)$, sendo $m$ o número de linhas da $\mathrm{MO}_{\text {Red }}$; $\boldsymbol{x}$ - é o vetor de monitoração binário, com dimensão (mxl);

$\boldsymbol{b}$ - é uma matriz de uns, sendo sua dimensão $(n x l)$, em que $n$ é igual ao número de nós do SD; e

$\boldsymbol{A}$ - é a $\mathrm{MO}_{\text {Red }}$ transposta para um limiar pré-estabelecido, com dimensão (nxm). 



\section{Capítulo 5}

\section{Resultados}

Este capítulo apresentará os resultados obtidos para os SDs da base de testes do IEEE (13, 34, 37 e 123 nós). Inicialmente, será apresentada a MTDF obtida pelo MPF para cada tipo de falta e elaborada uma visualização gráfica destas matrizes para melhor ilustrar a propagação das VTCDs. Posteriormente, será realizada a análise das áreas de propagação dos afundamentos de tensão que viabiliza estimar a robustez dos SDs analisados. Após esta análise, serão apresentadas as soluções ótimas de alocação dos medidores encontradas analisando vários limiares de afundamento de tensão passíveis de ocorrência sobre o SD.

Na sequência, com o intuito de validar o MPF, os resultados obtidos por este método analítico serão comparados com simulações computacionais do software ATP, via a interface gráfica do software ATPDraw. A utilização do software ATP também irá proporcionar a análise da influência de vários parâmetros que afetam as características das VTCDs, tais como mudança da tensão de pré-falta, alteração da impedância de falta e alteração dos perfis de carregamento, sendo posteriormente avaliado se esses fatores afetam o resultado da alocação ótima de medidores.

Cabe esclarecer que todo o procedimento computacional necessário para considerar as formulações matemáticas, abordadas nos capítulos 3 e 4 deste documento, foi implementado dispondo do programa MATLAB ${ }^{\circledR}$.

\subsection{Os Sistemas de Distribuição Analisados}

Os SDs da base do IEEE foram escolhidos pela facilidade de reprodução do trabalho, pois todos os parâmetros e orientações para a modelagem dos mesmos podem ser consultados em (DISTRIBUTION TEST FEEDERS, 2010) e em (KERSTING, 2001), respectivamente. 


\subsubsection{Sistema IEEE 13-nós}

O SD teste de 13 nós do IEEE consiste em um alimentador pequeno e exibe algumas características interessantes, as quais proporcionam a realização de testes representativos para pequenos alimentadores. O sistema é curto e altamente carregado e desequilibrado, além de apresentar linhas aéreas e subterrâneas, com trechos monofásicos, bifásicos e trifásicos conforme ilustra a Figura 39. As numerações dos nós do sistema foram atribuídas e adaptadas para este estudo de acordo com a construção da matriz impedância de barra.

Figura 39 - Diagrama unifilar do SD teste de 13 nós do IEEE.

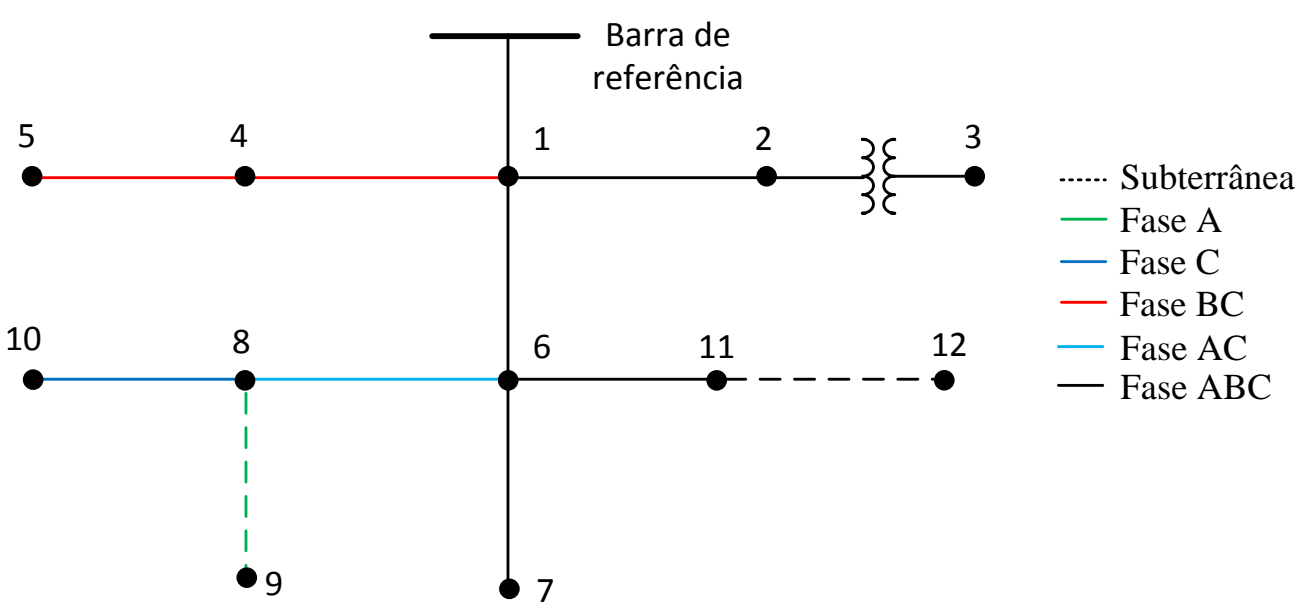

Fonte: Adaptado de DISTRIBUTION TEST FEEDERS, 2010.

Este sistema apresenta sete configurações distintas, as quais se diferenciam pelo tipo de cabo utilizado nos alimentadores, espaçamento e número de fases (DISTRIBUTION TEST FEEDERS, 2010). As expressões de (91) à (99) apresentam os valores das impedâncias de sequência de cada configuração de linha utilizadas para obter a MTDF pelo MPF.

$$
\begin{aligned}
Z_{601}^{012} & =\left[\begin{array}{ccc}
0,6534+\mathrm{j} 1,9069 & 0 & 0 \\
0 & 0,5921+j 0,7602 & 0 \\
0 & 0 & 0,5921+j 0,7602
\end{array}\right][\Omega / \text { milha }] \\
Z_{602}^{012} & =\left[\begin{array}{ccc}
1,0596+j 2,0704 & 0 & 0 \\
0 & 0,5921+j 0,7602 & 0 \\
0 & 0 & 0,5921+j 0,7602
\end{array}\right][\Omega / \text { milha }] \\
Z_{603 / 604}^{012} & =\left[\begin{array}{ccc}
1,0221+j 1,2074 & 0 & 0 \\
0 & 0,8155+j 0,7483 & 0 \\
0 & 0 & 0,8155+j 0,7483
\end{array}\right][\Omega / \text { milha }]
\end{aligned}
$$




$$
\begin{aligned}
& Z_{605}^{012}=\left[\begin{array}{ccc}
0,4431+j 0,4492 & 0 & 0 \\
0 & , 4431+j 0,4492 & 0 \\
0 & 0 & , 4431+j 0,4492
\end{array}\right][\Omega / \text { milha }] \\
& Z_{606}^{012}=\left[\begin{array}{ccc}
1,4107+j 0,4664 & 0 & 0 \\
0 & 0,4874+j 0,4151 & 0 \\
0 & 0 & 0,4874+j 0,4151
\end{array}\right][\Omega / \text { milha }] \\
& Z_{607}^{012}=\left[\begin{array}{ccc}
0,4475+j 0,1708 j & 0 & 0 \\
0 & 0,4475+j 0,1708 & 0 \\
0 & 0 & 0,4475+j 0,1708
\end{array}\right][\Omega / \text { milha }]
\end{aligned}
$$

O comprimento (Compr.) e as configurações (Config.) de cada segmento de linha que interliga dois nós são apresentados na Tabela 18.

Tabela 18 - Dados dos alimentadores do SD IEEE 13-nós.

\begin{tabular}{cccc}
\hline \hline Nó A & Nó B & Compr. (m) & Config. \\
\hline \hline 0 & 1 & 609,6 & 601 \\
1 & 2 & 152,4 & 602 \\
1 & 4 & 152,4 & 603 \\
1 & 6 & 609,6 & 601 \\
2 & 3 & 0 & XFM -1 \\
4 & 5 & 91,44 & 603 \\
6 & 7 & 304,8 & 601 \\
6 & 8 & 91,44 & 604 \\
6 & 11 & 0 & CHAVE \\
8 & 9 & 243,84 & 607 \\
8 & 10 & 91,44 & 605 \\
11 & 12 & 152,4 & 606 \\
\hline
\end{tabular}

Fonte: Adaptado de DISTRIBUTION TEST FEEDERS, 2010.

O sistema IEEE 13-nós contém dois transformadores abaixadores de tensão. As características de ambos os transformadores estão na Tabela 19. Foram utilizados os dados da potência e tensão do lado de baixa do transformador da subestação como valores base para a transformação das impedâncias série de sequências em impedâncias por unidade (p.u.).

Tabela 19 - Dados dos transformadores do SD IEEE 13-nós.

\begin{tabular}{lccccc}
\hline \hline & kVA & kV-alta & kV-baixa & R(\%) & $\mathbf{X}(\%)$ \\
\hline \hline Subestação & 5.000 & $115-\Delta$ & $4,16-$ GR.Y & 1 & 8 \\
XFM - 1 & 500 & $4,16-$ GR. Y & $0,48-$ GR.Y & 1,1 & 2 \\
\hline
\end{tabular}

Fonte: Adaptado de DISTRIBUTION TEST FEEDERS, 2010. 


\subsubsection{Sistema IEEE 34-nós}

O SD de 34 nós do IEEE faz parte da rede de abastecimento de energia do estado do Arizona, nos Estados Unidos da América. Este é um sistema aéreo com tensão nominal de $24,9 \mathrm{kV}$ que possui trechos trifásicos e monofásicos que alimentam cargas desequilibradas concentradas e distribuídas. O diagrama unifilar do SD teste de 34 nós pode ser observado na Figura 40.

Figura 40 - Diagrama unifilar do SD teste de 34 nós do IEEE.

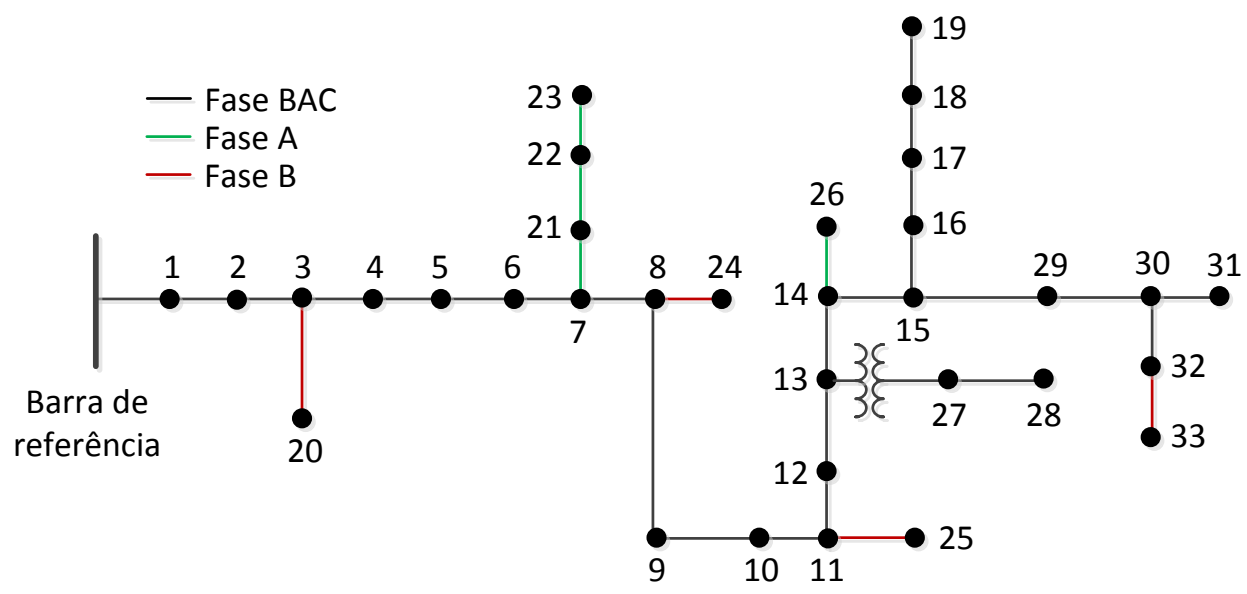

Fonte: Adaptado de DISTRIBUTION TEST FEEDERS, 2010.

Este sistema apresenta quatro configurações distintas para as linhas de distribuição. As expressões de (97) à (101) apresentam os valores das impedâncias de sequência para cada tipo de configuração de linha empregada.

$$
\begin{aligned}
Z_{300}^{012} & =\left[\begin{array}{ccc}
1,7498+j 2,3718 & 0 & 0 \\
0 & 1,1201+j 0,8333 & 0 \\
0 & 0 & 1,1201+j 0,8333
\end{array}\right][\Omega / \text { milha }] \\
Z_{301}^{012} & =\left[\begin{array}{ccc}
2,3875+j 2,5782 & 0 & 0 \\
0 & 1,6901+j 0,8411 & 0 \\
0 & 0 & 1,6901+j 0,8411
\end{array}\right][\Omega / \text { milha }] \\
Z_{302}^{012} & =\left[\begin{array}{ccc}
0,9332+j 0,4952 & 0 & 0 \\
0 & 0,9332+j 0,4952 & 0 \\
0 & 0 & 0,9332+j 0,4952
\end{array}\right][\Omega / \text { milha }]
\end{aligned}
$$




$$
\begin{aligned}
Z_{303}^{012} & =\left[\begin{array}{ccc}
0,9332+j 0,4952 & 0 & 0 \\
0 & 0,9332+j 0,4952 & 0 \\
0 & 0 & 0,9332+j 0,4952
\end{array}\right][\Omega / \text { milha }] \\
Z_{304}^{012} & =\left[\begin{array}{ccc}
1,1143+j 0,000 & 0 & 0 \\
0 & 1,1143+j 0,000 & 0 \\
0 & 0 & 1,1143+j 0,000
\end{array}\right][\Omega / \text { milha }]
\end{aligned}
$$

O sistema IEEE 34-nós contém dois transformadores abaixadores de tensão cujas características são mostradas na Tabela 20.

Tabela 20 - Dados dos transformadores do SD IEEE 34-nós.

\begin{tabular}{lccccc}
\hline \hline & kVA & kV-alta & kV-baixa & R(\%) & $\mathbf{X}(\%)$ \\
\hline \hline Subestação & 2.500 & $69-\Delta$ & $24,9-$ GR.Y & 1 & 8 \\
XFM - 1 & 500 & $24,9-$ GR.Y & $4,16-$ GR.Y & 1,9 & 4,08 \\
\hline
\end{tabular}

Fonte: Adaptado de DISTRIBUTION TEST FEEDERS, 2010.

O comprimento (Compr.) e as configurações (Config.) de cada segmento de linha que interliga dois nós são apresentados na Tabela 21 (DISTRIBUTION TEST FEEDERS, 2010).

Tabela 21 - Dados dos alimentadores do SD IEEE 34-nós.

\begin{tabular}{cccc|cccc}
\hline \hline Nó $\mathbf{A}$ & Nó $\mathbf{B}$ & $\begin{array}{c}\text { Compr. } \\
(\mathbf{K m})\end{array}$ & Config. & Nó A & Nó $\mathbf{B}$ & $\begin{array}{c}\text { Compr. } \\
(\mathbf{K m})\end{array}$ & Config. \\
\hline 0 & 1 & 0,786 & 300 & 13 & 27 & 0 & XFM - \\
1 & 2 & 0,527 & 300 & 13 & 14 & 1,493 & 301 \\
2 & 3 & 9,823 & 300 & 14 & 26 & 0,493 & 302 \\
3 & 20 & 1,769 & 303 & 14 & 15 & 1,777 & 301 \\
3 & 4 & 11,43 & 300 & 15 & 29 & 0,615 & 301 \\
4 & 5 & 9,061 & 300 & 15 & 16 & 0,085 & 301 \\
5 & 6 & 0,003 & 301 & 16 & 17 & 0,411 & 301 \\
6 & 7 & 0,094 & 301 & 17 & 18 & 1,109 & 301 \\
7 & 21 & 0,521 & 302 & 18 & 19 & 0,161 & 301 \\
7 & 8 & 3,112 & 301 & 21 & 22 & 14,67 & 302 \\
8 & 24 & 0,923 & 303 & 22 & 23 & 4,188 & 302 \\
8 & 9 & 0,256 & 301 & 27 & 28 & 3,218 & 300 \\
9 & 10 & 6,230 & 301 & 29 & 30 & 0,816 & 301 \\
10 & 11 & 0,158 & 301 & 30 & 31 & 0,262 & 301 \\
11 & 25 & 7,111 & 303 & 30 & 32 & 0,085 & 301 \\
11 & 12 & 11,22 & 301 & 32 & 33 & 1,481 & 304 \\
12 & 13 & 0,003 & 301 & 32 & & & \\
\hline
\end{tabular}

Fonte: Adaptado de DISTRIBUTION TEST FEEDERS, 2010. 


\subsubsection{Sistema IEEE 37-nós}

O SD teste de 37 nós do IEEE, localizado na Califórnia, é um sistema atípico, pois é totalmente conectado em delta, sendo todos os cabos subterrâneos e trifásicos. O sistema é bastante desequilibrado devido aos alimentadores não transpostos e as cargas trifásicas desequilibradas que compõem o SD. O diagrama unifilar do SD teste de 37 nós do IEEE pode ser observado na Figura 41.

Figura 41 - Diagrama unifilar do SD teste de 37 nós do IEEE.

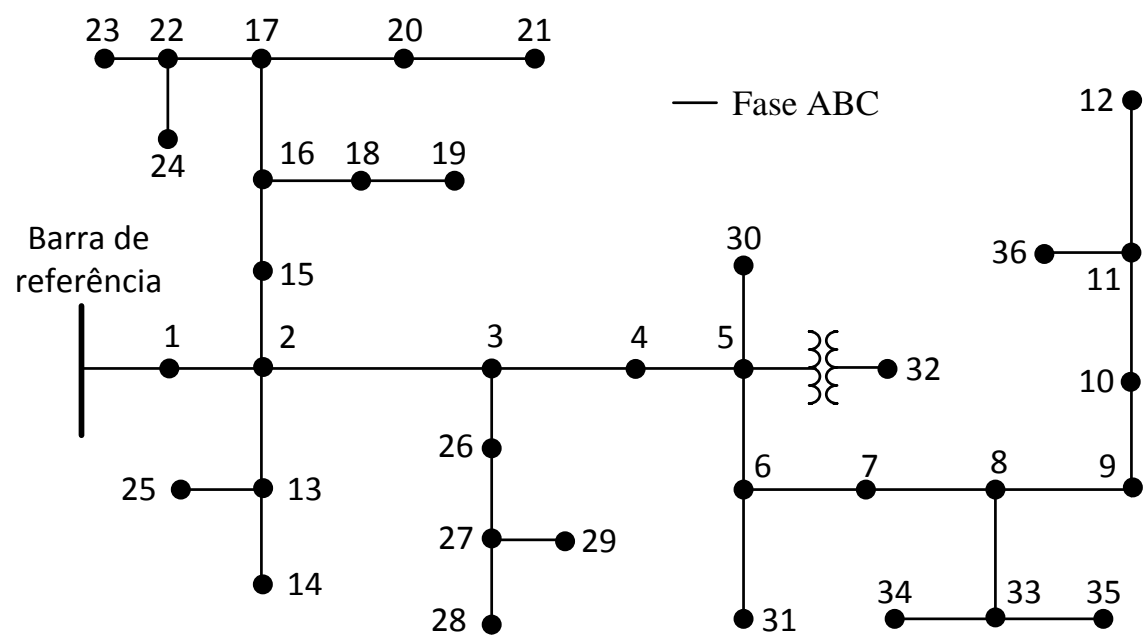

Fonte: Adaptado de DISTRIBUTION TEST FEEDERS, 2010.

Este sistema apresenta quatro configurações distintas para as linhas de distribuição. As expressões de (102) à (105) apresentam os valores das impedâncias de sequência de cada configuração de linha.

$$
\begin{aligned}
Z_{721}^{012} & =\left[\begin{array}{ccc}
0,3955+j 0,1180 & 0 & 0 \\
0 & 0,2272+j 0,2333 & 0 \\
0 & 0 & 0,2272+j 0,2333
\end{array}\right][\Omega / \text { milha }] \\
Z_{722}^{012} & =\left[\begin{array}{ccc}
0,7658+j 0,2035 & 0 & 0 \\
0 & 0,3166+j 0,3294 & 0 \\
0 & 0 & 0,3166+j 0,3294
\end{array}\right][\Omega / \text { milha }] \\
Z_{723}^{012} & =\left[\begin{array}{ccc}
2,2516+j 1,0413 & 0 & 0 \\
0 & 0,8189+j 0,4670 & 0 \\
0 & 0 & 0,8189+j 0,4670
\end{array}\right][\Omega / \text { milha }]
\end{aligned}
$$




$$
Z_{724}^{012}=\left[\begin{array}{ccc}
3,1213+j 1,2704 & 0 & 0 \\
0 & 1,5879+j 0,5105 & 0 \\
0 & 0 & 1,5879+j 0,5105
\end{array}\right][\Omega / \text { milha }]
$$

O comprimento (Compr.) e as configurações (Config.) de cada segmento de linha que interliga dois nós são apresentados na Tabela 22.

Tabela 22 - Dados dos alimentadores do SD IEEE 37-nós.

\begin{tabular}{cccc|cccc}
\hline \hline Nó A & Nó $\mathbf{B}$ & $\begin{array}{c}\text { Compr. } \\
(\mathbf{m})\end{array}$ & Config. & Nó A & Nó B & $\begin{array}{c}\text { Compr. } \\
(\mathbf{m})\end{array}$ & Config. \\
\hline \hline 0 & 1 & 563,88 & 721 & 11 & 36 & 60,96 & 724 \\
1 & 2 & 292,61 & 722 & 13 & 14 & 97,536 & 724 \\
2 & 3 & 402,34 & 722 & 13 & 25 & 73,152 & 724 \\
2 & 13 & 121,92 & 724 & 15 & 16 & 158,496 & 723 \\
2 & 15 & 109,73 & 723 & 16 & 17 & 243,84 & 723 \\
3 & 4 & 182,88 & 723 & 16 & 18 & 24,384 & 724 \\
3 & 26 & 73,152 & 724 & 17 & 20 & 182,88 & 723 \\
4 & 5 & 60,96 & 723 & 17 & 22 & 280,42 & 724 \\
5 & 6 & 97,536 & 723 & 18 & 19 & 158,496 & 724 \\
5 & 30 & 182,88 & 723 & 20 & 21 & 85,344 & 724 \\
6 & 7 & 97,536 & 723 & 22 & 23 & 234,65 & 724 \\
6 & 31 & 97,536 & 724 & 22 & 24 & 36,576 & 724 \\
7 & 8 & 170,69 & 723 & 26 & 27 & 85,344 & 723 \\
8 & 9 & 195,07 & 723 & 27 & 28 & 85,344 & 724 \\
8 & 33 & 158,496 & 724 & 27 & 29 & 60,96 & 724 \\
9 & 10 & 121,92 & 723 & 32 & 5 & 0 & XFM -1 \\
10 & 11 & 121,92 & 723 & 33 & 34 & 390,14 & 724 \\
11 & 12 & 121,92 & 723 & 33 & 35 & 60,96 & 724 \\
\hline
\end{tabular}

Fonte: Adaptado de DISTRIBUTION TEST FEEDERS, 2010.

A Tabela 23 mostra as características do transformador da subestação, que está localizado antes da barra de referência, usado para transformar a tensão de transmissão (230 $\mathrm{kV}$ ) em tensão de distribuição $(4,8 \mathrm{kV})$, e do transformador XFM-1 que está conectado entre os nós 5 e 32.

Tabela 23 - Dados dos transformadores do SD IEEE 37-nós.

\begin{tabular}{lccccc}
\hline \hline & kVA & kV-alta & kV-baixa & R(\%) & $\mathbf{X}(\%)$ \\
\hline \hline Subestação & 2.500 & $230-\Delta$ & $4,8-\Delta$ & 2 & 8 \\
XFM - 1 & 500 & $4,8-\Delta$ & $0,48-\Delta$ & 0,09 & 1,81 \\
\hline
\end{tabular}

Fonte: Adaptado de DISTRIBUTION TEST FEEDERS, 2010. 


\subsubsection{Sistema IEEE 123-nós}

Os sistema teste de 123 nós do IEEE opera com uma tensão nominal de 4,16 kV e apresenta segmentos de linha aéreos e subterrâneos, com trechos monofásicos, bifásicos e trifásicos. A Figura 42 mostra o diagrama unifilar do SD modificado para este estudo, desconsiderando-se os barramentos com chaves normalmente abertas, e optando-se pela numeração sequencial das barras que estão eletricamente próximas umas das outras.

Figura 42 - Diagrama unifilar do SD teste de 123 nós do IEEE.

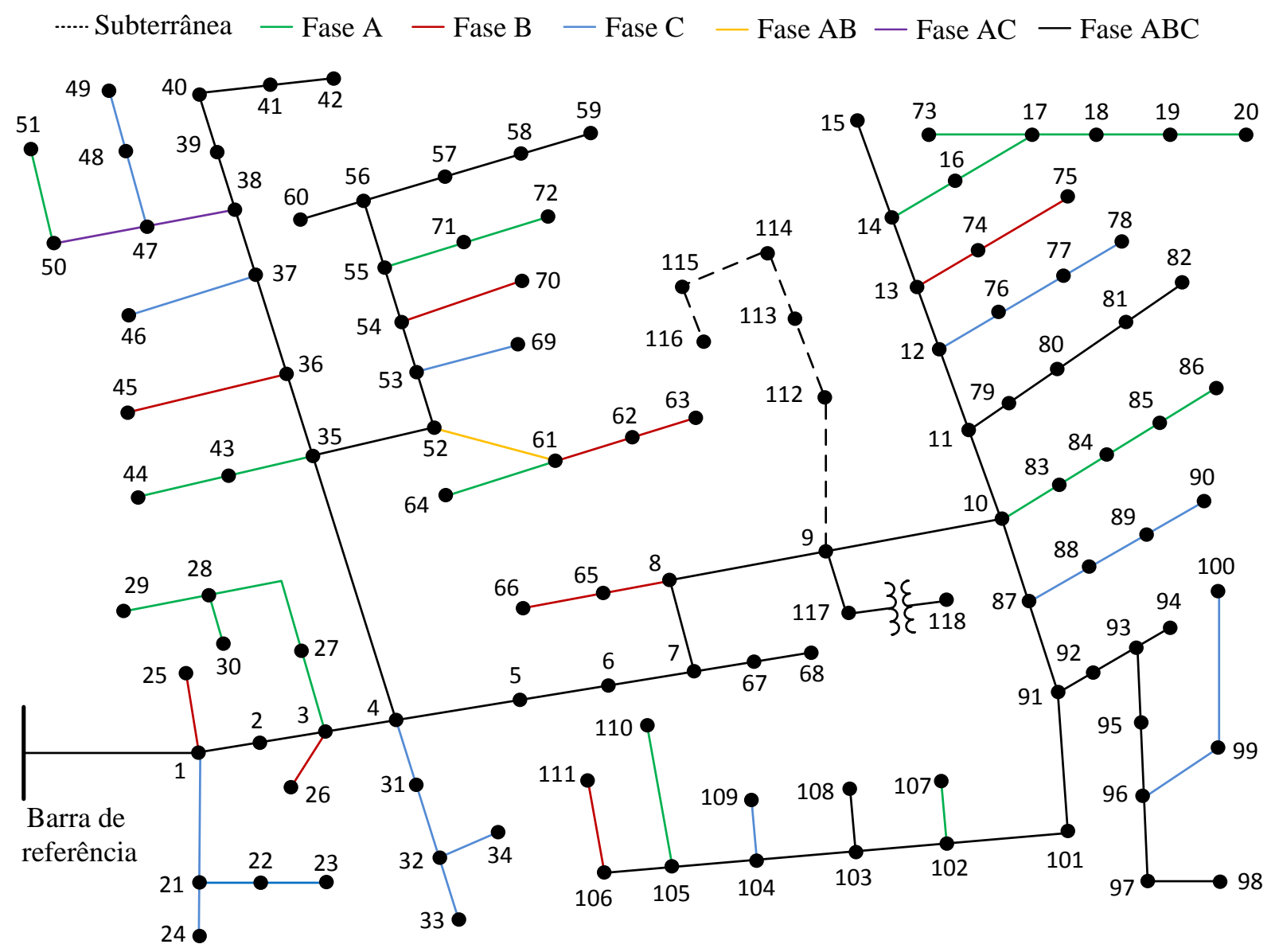

Fonte: Adaptado de DISTRIBUTION TEST FEEDERS, 2010.

Este sistema apresenta doze configurações distintas para as linhas de distribuição, as quais, após a transformação para impedância de sequência, resultam em quatro expressões apresentadas de (106) à (109).

$$
Z_{1-6}^{012}=\left[\begin{array}{ccc}
0,736+j 1,9372 & 0 & 0 \\
0 & 0,3061+j 0,6270 & 0 \\
0 & 0 & 0,3061+j 0,6270
\end{array}\right][\Omega / \text { milha }]
$$




$$
\begin{aligned}
Z_{7 / 8}^{012} & =\left[\begin{array}{ccc}
0,4087+j 0,9710 & 0 & 0 \\
0 & 0,2552+j 0,5861 & 0 \\
0 & 0 & 0,2552+j 0,5861
\end{array}\right][\Omega / \text { milha }] \\
Z_{9-11}^{012} & =\left[\begin{array}{ccc}
0,4431+j 0,4492 & 0 & 0 \\
0 & 0,4431+j 0,4492 & 0 \\
0 & 0 & 0,4431+j 0,4492
\end{array}\right][\Omega / \text { milha }] \\
Z_{12}^{012} & =\left[\begin{array}{ccc}
2,5462+j 1,2539 & 0 & 0 \\
0 & 1,0142+j 0,4832 & 0 \\
0 & 0 & 1,0142+j 0,4832
\end{array}\right][\Omega / \text { milha }]
\end{aligned}
$$

Devido ao elevado número de nós do $\mathrm{SD}$, o comprimento (Compr.) e as configurações (Config.) de cada segmento de linha que interliga dois nós são apresentados no Apêndice B. A Tabela 23 mostra as características do transformador da subestação que está localizado antes da barra de referência, e do transformador XFM-1 que está conectado entre os nós 117 e 118.

Tabela 24 - Dados dos transformadores do SD IEEE 123-nós.

\begin{tabular}{lccccc}
\hline \hline & kVA & kV-alta & kV-baixa & R(\%) & $\mathbf{X}(\%)$ \\
\hline Subestação & 5.000 & $115-\Delta$ & $4,16-$ GR.Y & 1 & 8 \\
XFM - 1 & 500 & $4,16-\Delta$ & $0,48-\Delta$ & 1,27 & 2,72 \\
\hline
\end{tabular}

Fonte: Adaptado de DISTRIBUTION TEST FEEDERS, 2010.

\subsection{Resultados Obtidos Através do MPF}

Utilizando a metodologia apresentada no capítulo 3 e as matrizes de impedância série para cada configuração do $\mathrm{SD}$, fornecidas em $\Omega /$ milha em DISTRIBUTION TEST FEEDERS, 2010, aplicou-se o método das componentes simétricas (FORTESCUE, 1918), obtendo-se as matrizes de impedância série de sequências para cada um dos SDs analisados conforme apresentados na seção 5.1.

Para a determinação das tensões remanescentes em todos os nós dos SDs, inicialmente, para cada $S D$ foi obtida a matriz $Z_{\text {barra }}$ de sequência positiva, negativa e zero. Em seguida, foi utilizado o MPF considerando os diferentes tipos de curtos-circuitos, sendo que, para cada tipo de falta analisada, originou-se uma MTDF por fase que será representada 
através de uma visualização gráfica para facilitar a observação dos resultados.

Nestas representações gráficas, cada elemento da MTDF é representado por um esquema gráfico associado a cores, através de uma escala de grau correspondente à intensidade das VTCDs manifestadas, sendo que cada coluna da MTDF representa a posição de falta aplicada, isto é, os nós onde foi aplicado um curto-circuito. Já nas linhas são armazenadas as amplitudes das tensões remanescentes registradas em cada nó do SD devido à ocorrência da situação de falta considerada.

Em virtude do grande número de MTDFs geradas para cada SD, o procedimento para obter cada MTDF será descrito apenas para o SD de 34 nós, sendo que as visualizações gráficas das demais MTDFs (geradas para os sistemas de 13, 37 e 123 nós), encontram-se disponibilizada para consulta no Apêndice $\mathrm{C}$ deste documento.

\subsubsection{MTDF para Faltas Trifásicas (FFF)}

Para a análise de curtos-circuitos trifásicos francos, o comportamento do sistema foi estabelecido apenas pela matriz de impedância de barra de sequência positiva, utilizando-se a equação (33). Desta maneira, para o SD de 34 nós, obteve-se de forma direta a MTDF representada graficamente pela Figura 43, onde é possível observar de maneira compacta todas as tensões registradas, em todos os nós do SD.

Cabe reforçar que as tensões manifestadas com amplitudes remanescentes menores que 0,9 p.u., bem como as maiores do que 0,1 p.u. da tensão eficaz (valor nominal), são definidas como afundamentos de tensão.

Pela análise gráfica da Figura 43, pode ser confirmado que na ocorrência de uma falta trifásica no nó 1 (coluna um), os níveis das tensões remanescentes registrados neste nó, bem como em todos os outros nós do SD foram próximos ou iguais a zero (representado pela cor preta). Tal constatação caracteriza uma interrupção no fornecimento da energia elétrica, que já era esperada devido à conexão direta do nó 1 à subestação de energia (Figura 40).

Ainda na Figura 43, verifica-se que na ocorrência de uma falta trifásica no nó 2, que também está próximo à subestação, somente no nó 1 não ocorrerá uma interrupção de energia. Mesmo assim, este nó apresenta níveis severos de afundamento de tensão. Em outras palavras, isso significa que quanto mais próximo à fonte geradora ocorrer um curto-circuito trifásico, mais severos serão os afundamentos de tensão registrados nos demais nós do SD. 
Figura 43 - MTDF na ocorrência de faltas FFF no SD IEEE 34-nós.

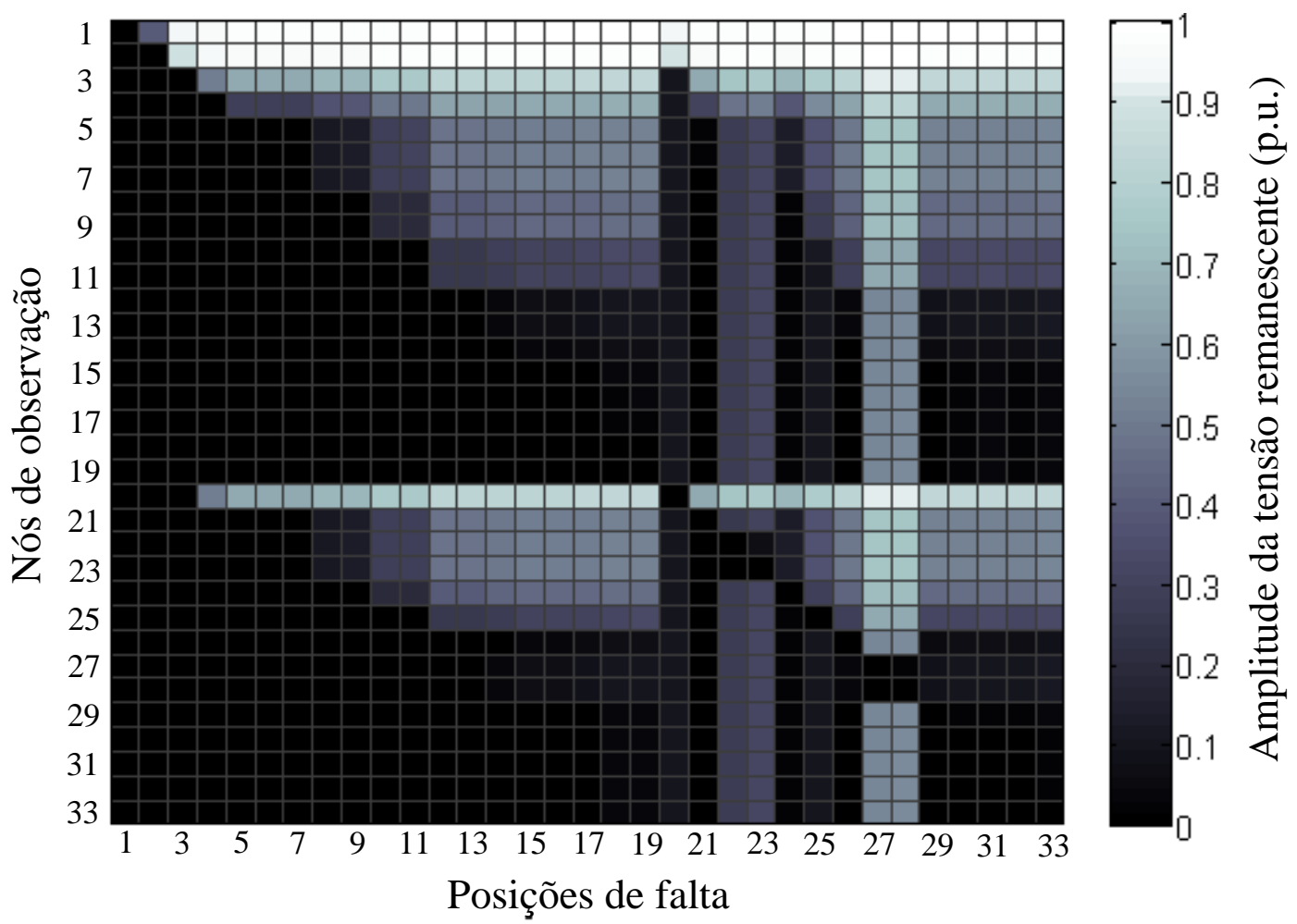

Assim como na análise do nó 1, ao se observar a tensão remanescente nos demais nós onde o defeito foi simulado (diagonal principal da Figura 43), consta-se que também ocorrerá uma interrupção no fornecimento da energia. Portanto, a diagonal principal da MTDF representa os pontos críticos das simulações de curto-circuito.

Cabe comentar que estas mesmas interpretações são válidas para todos os tipos de ocorrências de faltas a serem apresentadas e analisadas no decorrer deste trabalho.

\subsubsection{MTDF para Faltas Monofásicas (FT)}

Para a falta monofásica foi considerado o curto-circuito na fase $A$, obtendo-se pelas equações de (40) à (42) uma MTDF para cada fase do SD.

A Figura 44 ilustra a MTDF gerada para a fase $A$, no SD de 34 nós, durante a ocorrência de faltas monofásicas em todos os nós do sistema. Comparando-se esta imagem com a Figura 43, percebe-se claramente a semelhança entre a matriz gerada para as faltas trifásicas.

Pela análise destas figuras (Figura 43 e Figura 44) nota-se que os nós mais afetados pelos afundamentos de tensão são os que estão eletricamente próximos ao nó onde a falta foi 
aplicada. Ao focar a atenção na coluna 26 da MTDF da Figura 44, por exemplo, e paralelamente observar o diagrama unifilar do SD de 34 nós (Figura 40), constata-se que ocorrerão interrupções e afundamentos de tensão severos nos nós que se encontram eletricamente próximos ao ponto de falta (nó 26). À medida que a distância elétrica aumenta com relação ao local onde o curto-circuito foi aplicado, ou seja, nos nós mais distantes do nó 26, os afundamentos de tensão tendem a ser menos severos.

Figura 44 - MTDF (fase $A$ ) durante faltas FT aplicadas no SD IEEE 34-nós.

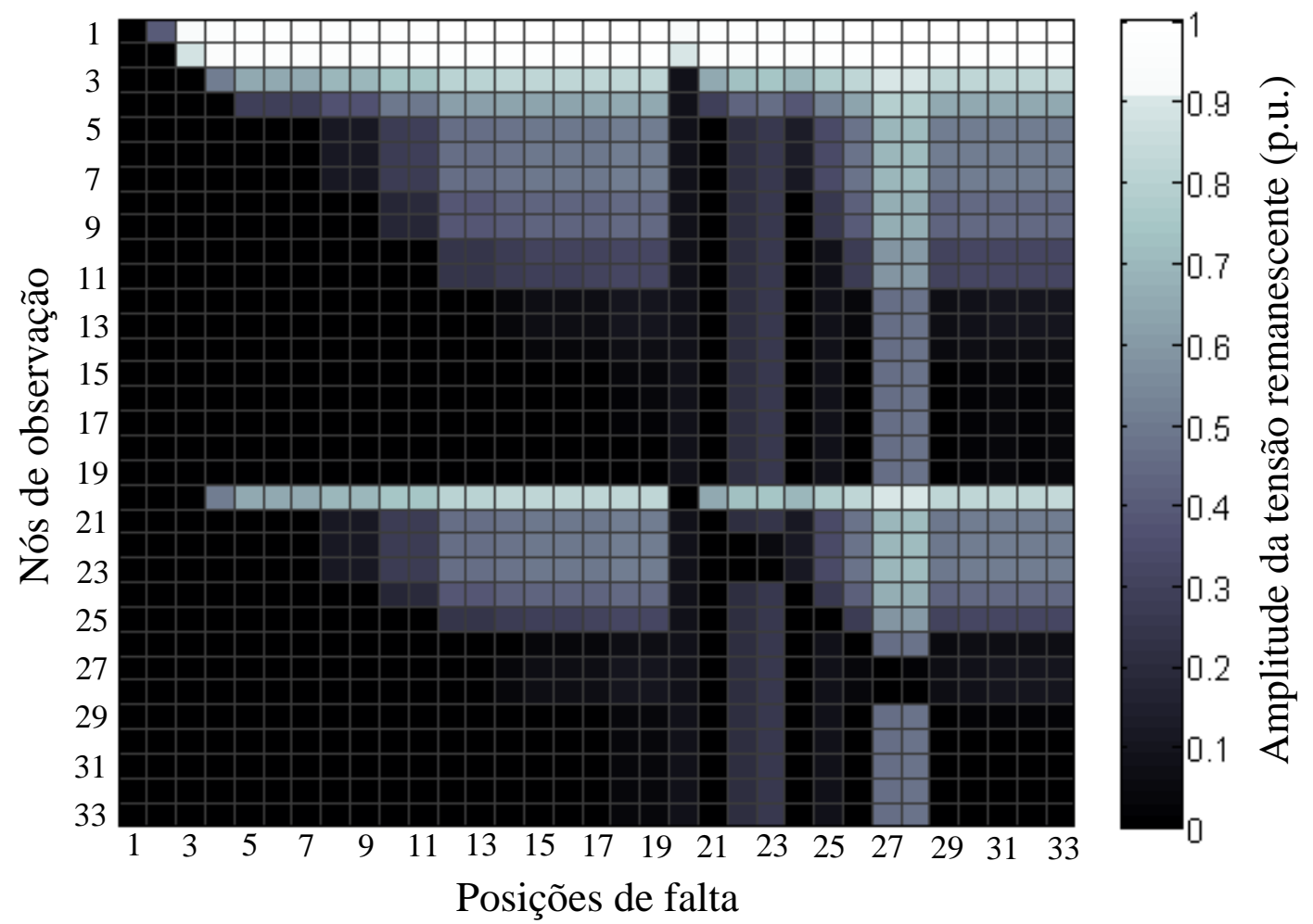

Ainda analisando a propagação dos efeitos das faltas monofásicas no SD de 34 nós, percebe-se que nas fases $B$ e $C$ ocorrerá uma elevação de tensão em consequência ao curtocircuito aplicado na fase $A$, como pode ser observado pela Figura 45 (fase $B$ ) e Figura 46 (fase $C$ ).

Na comparação da Figura 45 com a Figura 46, percebe-se que as amplitudes das elevações de tensão foram superiores na fase $B$, sendo que em alguns nós a amplitude da tensão remanescente registrada foi de 1,25 p.u..

Pela Figura 44, observa-se que as colunas que apresentam os afundamentos de tensão menos severos são as colunas 27 e 28 . O mesmo é válido na análise da Figura 45, sendo que estas colunas apresentam níveis menos elevados de tensão. Constata-se pelo diagrama unifilar do SD de 34 nós (Figura 40), que a montante do nó 27, há um transformador abaixador de tensão. Em função deste, quando aplicado um curto-circuito no nó 27 , ou nó 28 , todas as 
tensões remanescentes registradas na fase $A$ (Figura 44), à montante do transformador, foram superiores a 0,46 p.u..

Figura 45 - MTDF (fase B) durante faltas FT aplicadas no SD IEEE 34-nós.
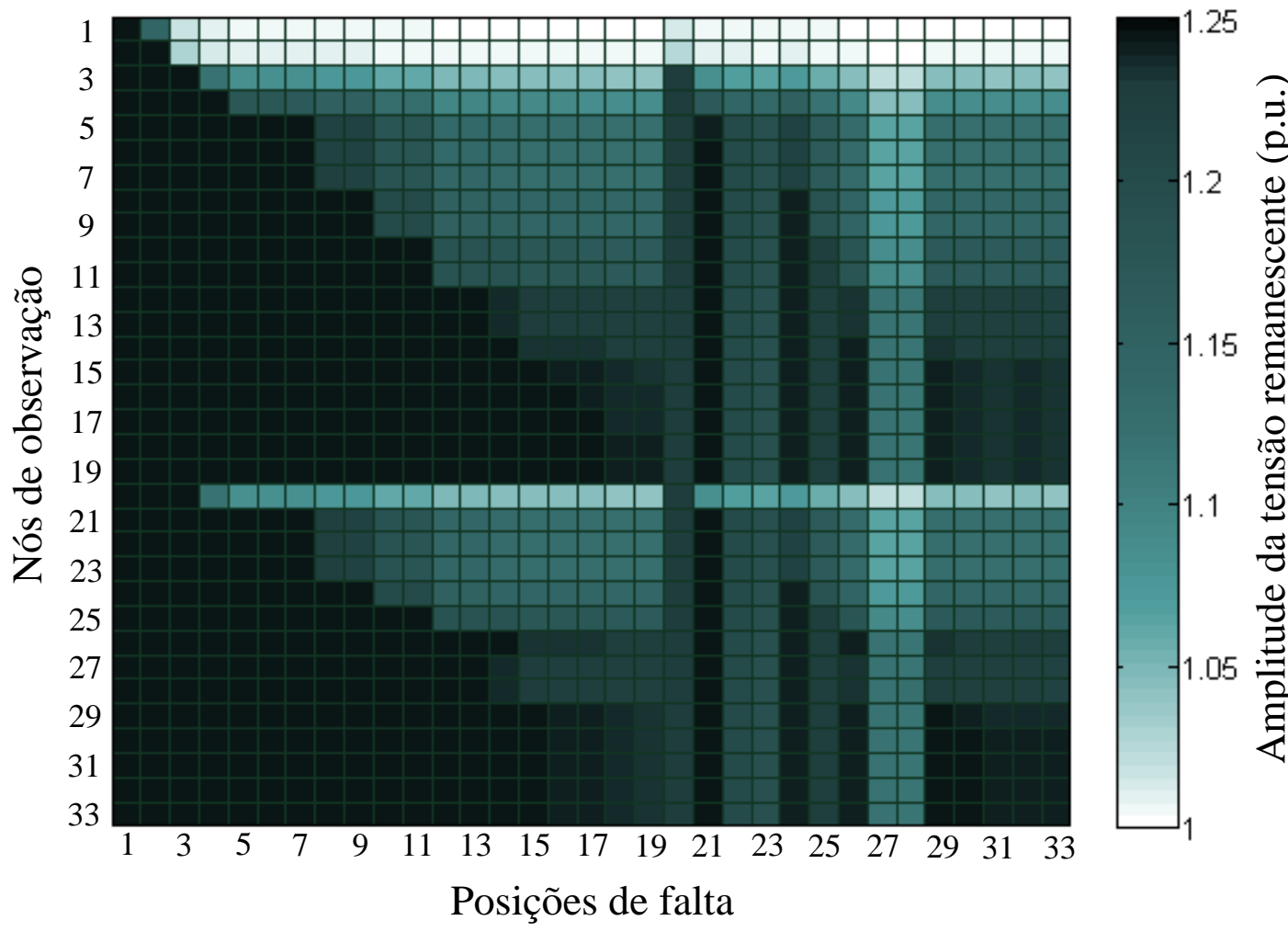

Figura 46 - MTDF (fase $C$ ) durante faltas FT aplicadas no SD IEEE 34-nós.
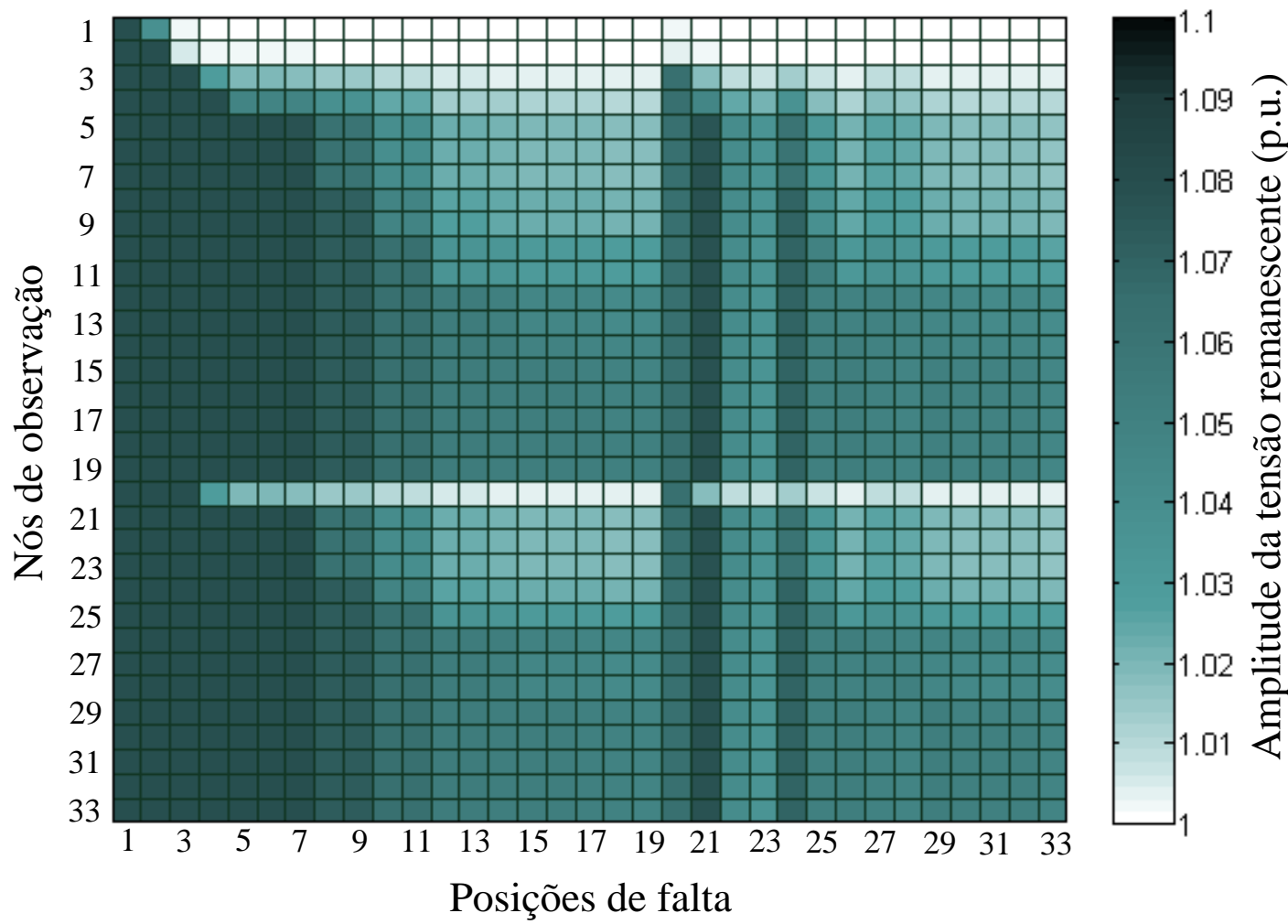

Posições de falta 


\subsubsection{MTDF para Faltas Bifásicas Fase-Fase (FF)}

Para as faltas bifásicas fase-fase considerou-se o curto-circuito entre as fases $B$ e $C$, obtendo-se uma MTDF para cada fase através das equações de (49) à (51). Como foi considerada a tensão de pré-falta igual a 1 p.u., na fase $A$ as tensões remanescentes registradas em todos os nós foram iguais à tensão de pré-falta. Portanto, durante a ocorrência de faltas FF, não há a necessidade de representar graficamente a MTDF para a fase $A$.

Nas fases em falta $(B$ e $C$ ), observou-se que durante a ocorrência do curto-circuito FF, estas fases apresentam afundamentos de tensão maiores ou iguais a 0,5 p.u., não ocorrendo interrupções de tensão, que são caracterizadas por tensões inferiores a 0,1 p.u.. Para o sistema de 34 nós, tais observações podem ser constatadas pela Figura 47 (fase $B$ ) e pela Figura 48 (fase $C$ ), sendo que a fase $B$ apresentou os níveis de afundamentos de tensão mais severos, perceptíveis pela tonalidade mais escura do gráfico.

Figura 47 - MTDF (fase $B$ ) durante faltas FF aplicadas no SD IEEE 34-nós.

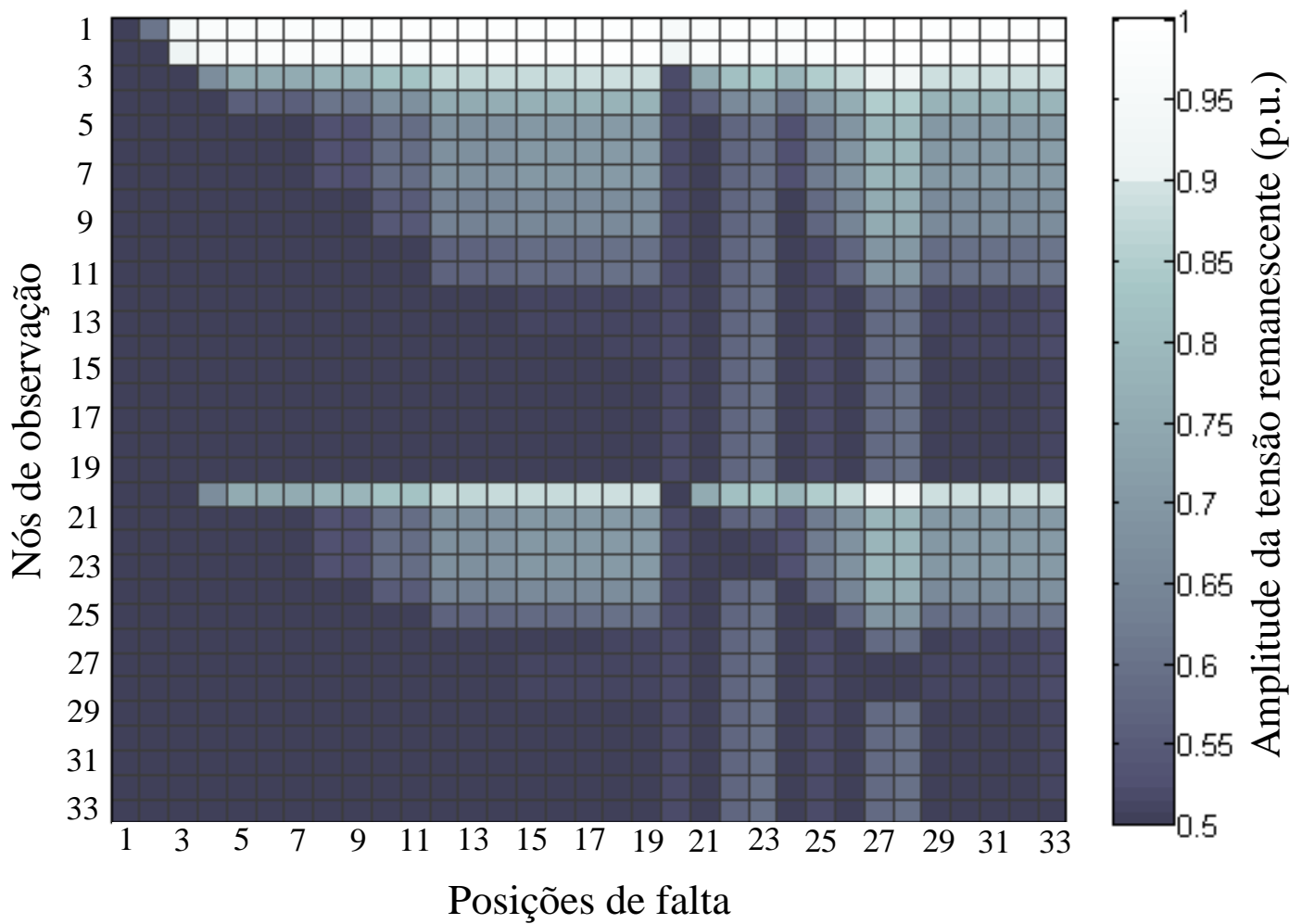

Para todos os tipos de falta retratados percebe-se que os nós menos afetados pelos afundamentos de tensão são os nós que estão eletricamente próximos à subestação. No SD de 34 nós, estão mais próximos à subestação os nós 1,2, 3 e 20. Utilizando como exemplo a Figura 47, percebe-se pela análise das linhas correspondentes aos nós 1 e 2, que as tensões remanescentes registradas são maiores que 0,9 p.u. para a maioria dos nós observados. 
Neste cenário, se um medidor de QEE fosse alocado em algum desses nós (1 ou 2) ou na própria subestação, muitos afundamentos de tensão passíveis de ocorrência no SD não seriam observados. Por este motivo, considera-se apropriada a instalação dos medidores de QEE nos locais onde um maior número de eventos possa ser observado, contrariando as práticas usuais das distribuidoras de energia em instalar os equipamentos de medição nas subestações dos SDs.

Figura 48 - MTDF (fase $C$ ) durante faltas FF aplicadas no SD IEEE 34-nós.

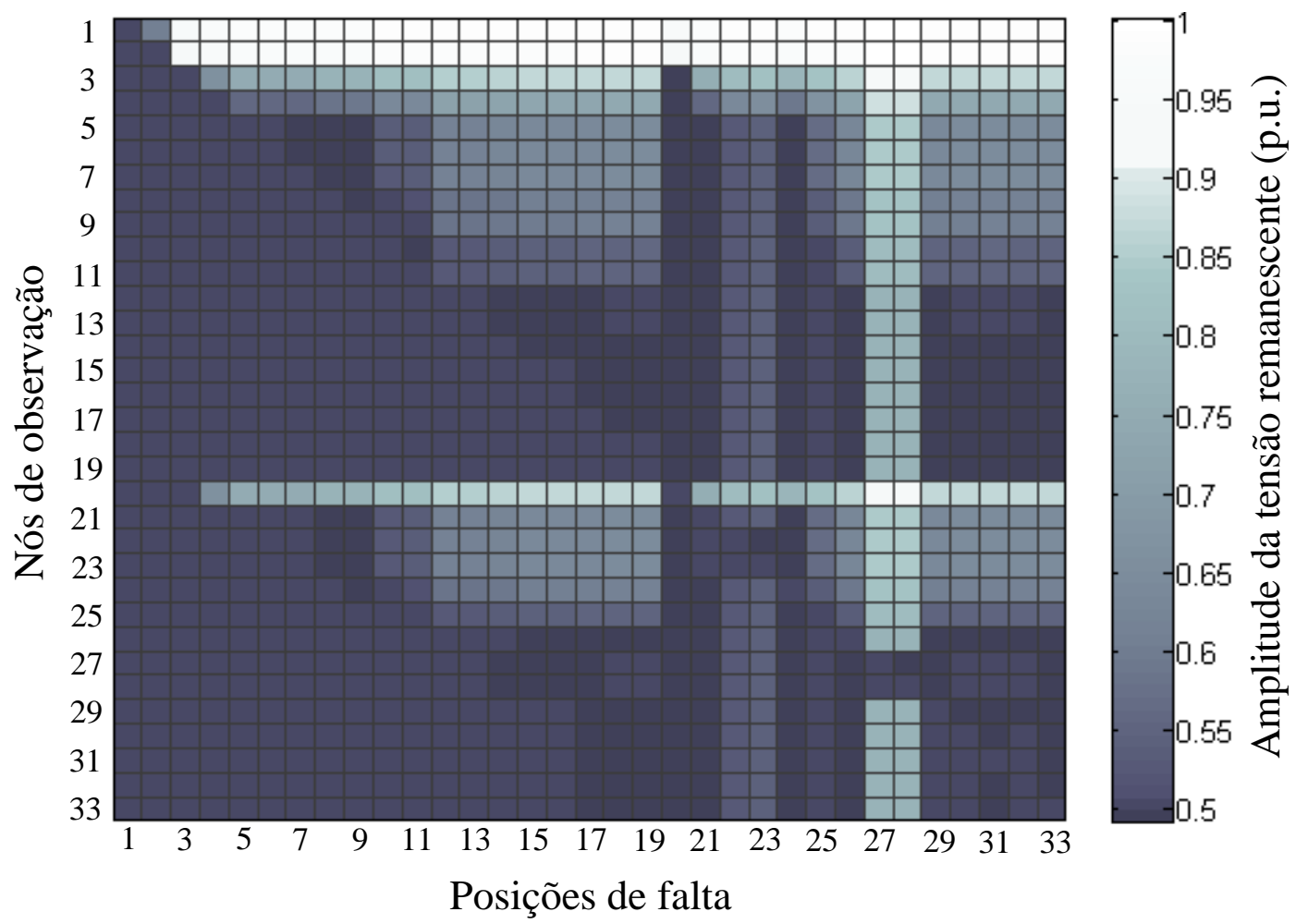

\subsubsection{MTDF para Faltas Bifásicas Fase-Fase-Terra (FFT)}

As MTDFs para cada fase do SD durante a ocorrência de curtos-circuitos FFT entre as fases $B$ e $C$, foram obtidas utilizando-se as equações de (63) à (65). Pelos resultados, percebese pela Figura 49 que ocorrerão elevações de tensão na fase sã (fase $A$ ) do SD de 34 nós.

Assim como na análise dos afundamentos de tensão, as elevações de tensão também irão se propagar com maior severidade nas proximidades do local de ocorrência da falta. Ao analisar a coluna 17 da Figura 49, por exemplo, percebe-se que as elevações de tensões são mais críticas nos nós 16 à 19 e de 29 à 33, que são, justamente, os nós que estão eletricamente próximos e à jusante do nó 17 , onde a falta foi aplicada. 
Figura 49 - MTDF (fase $A$ ) durante faltas FFT aplicadas no SD IEEE 34-nós.

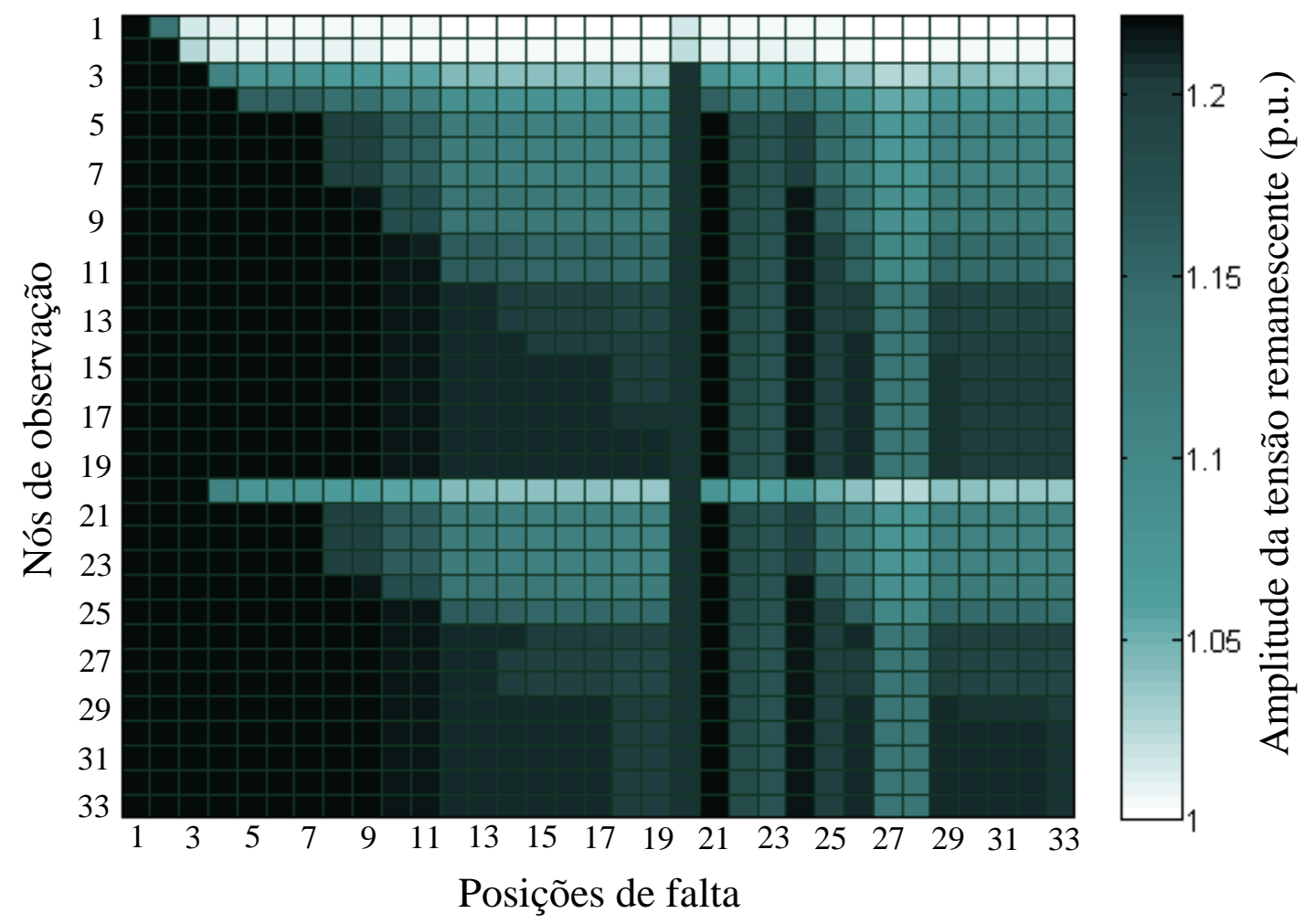

Figura 50 - MTDF (fase B) durante faltas FFT aplicadas no SD IEEE 34-nós.

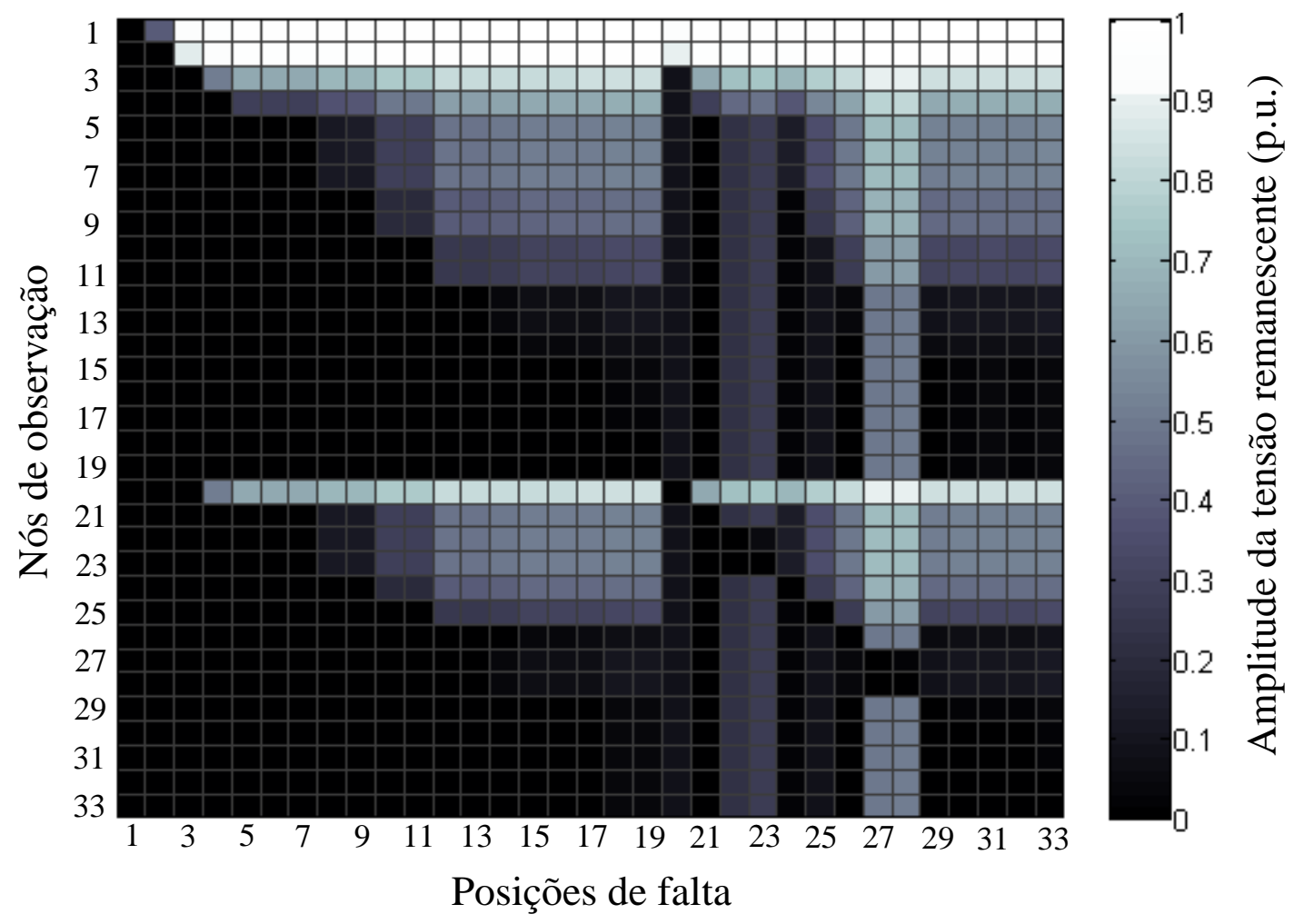


Além disso, percebe-se que o comportamento da MTDF que registra as elevações de tensão possui características muito semelhantes às MTDFs geradas para as fases em falta, sendo que, os nós que apresentam os níveis mais elevados de tensão também registram os afundamentos mais severos. Ao observar simultaneamente a Figura 49, Figura 50 e a Figura 51 é possível perceber uma grande similaridade entre as duas matrizes. Portanto, ao analisar os casos mais críticos dos afundamentos de tensão, consequentemente, abrangem-se os casos mais graves de elevações de tensão.

Figura 51 - MTDF (fase $C$ ) durante faltas FFT aplicadas no SD IEEE 34-nós.

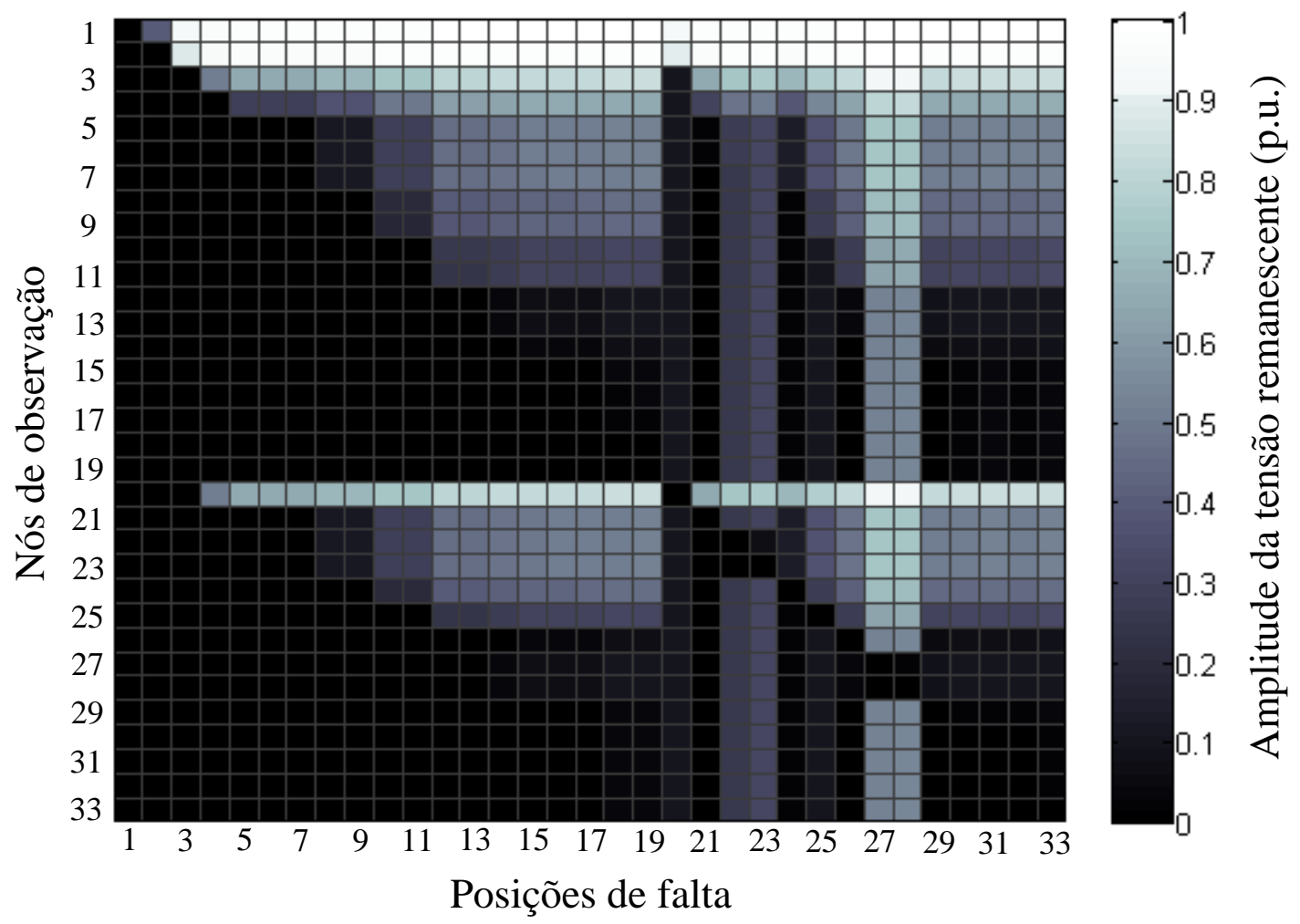

\subsection{Análise das Áreas de Propagação dos Afundamentos de Tensão}

A análise das áreas de propagação dos afundamentos de tensão tem como objetivo avaliar como as ocorrências de curtos-circuitos afetam os diversos nós do SD, sobretudo aqueles onde estão instalados equipamentos sensíveis, como é o caso da grande maioria dos consumidores industriais.

Assim sendo, uma vez pré-estabelecido um limiar de tensão, torna-se possível mapear as áreas de risco que equipamentos eletroeletrônicos sensíveis possam vir a ser submetidos, 
através da delimitação da área afetada e da área exposta ou de vulnerabilidade. Destaca-se também que a demarcação destas áreas propicia uma análise mais aprofundada da robustez do SD em avaliação frente aos afundamentos de tensão.

\subsubsection{Análise da Área Afetada}

De posse dos dados das tensões remanescentes registradas em todos os nós do sistema elétrico, através da MTDF, torna-se possível mapear as áreas de propagação dos afundamentos de tensão.

Uma forma direta de se observar a área afetada é através da visualização gráfica da MTDF, pois cada coluna desta matriz contém as informações necessárias para identificar a área da rede afetada por curtos-circuitos, em qualquer um dos nós do SD.

Assim, ao analisar a coluna 19 da MTDF trifásica do SD de 34 nós (Figura 43), por exemplo, é possível representar graficamente a área afetada para um determinado limiar de tensão pré-estabelecido conforme ilustra a Figura 52. Esta figura representa a influência de uma falta FFF no nó 19 nos demais nós do SD para três diferentes limiares de tensão $(0,9 ; 0,5$ e 0,3 p.u.).

Figura 52 - Área afetada no SD de 34 nós considerando uma falta FFF no nó 19.
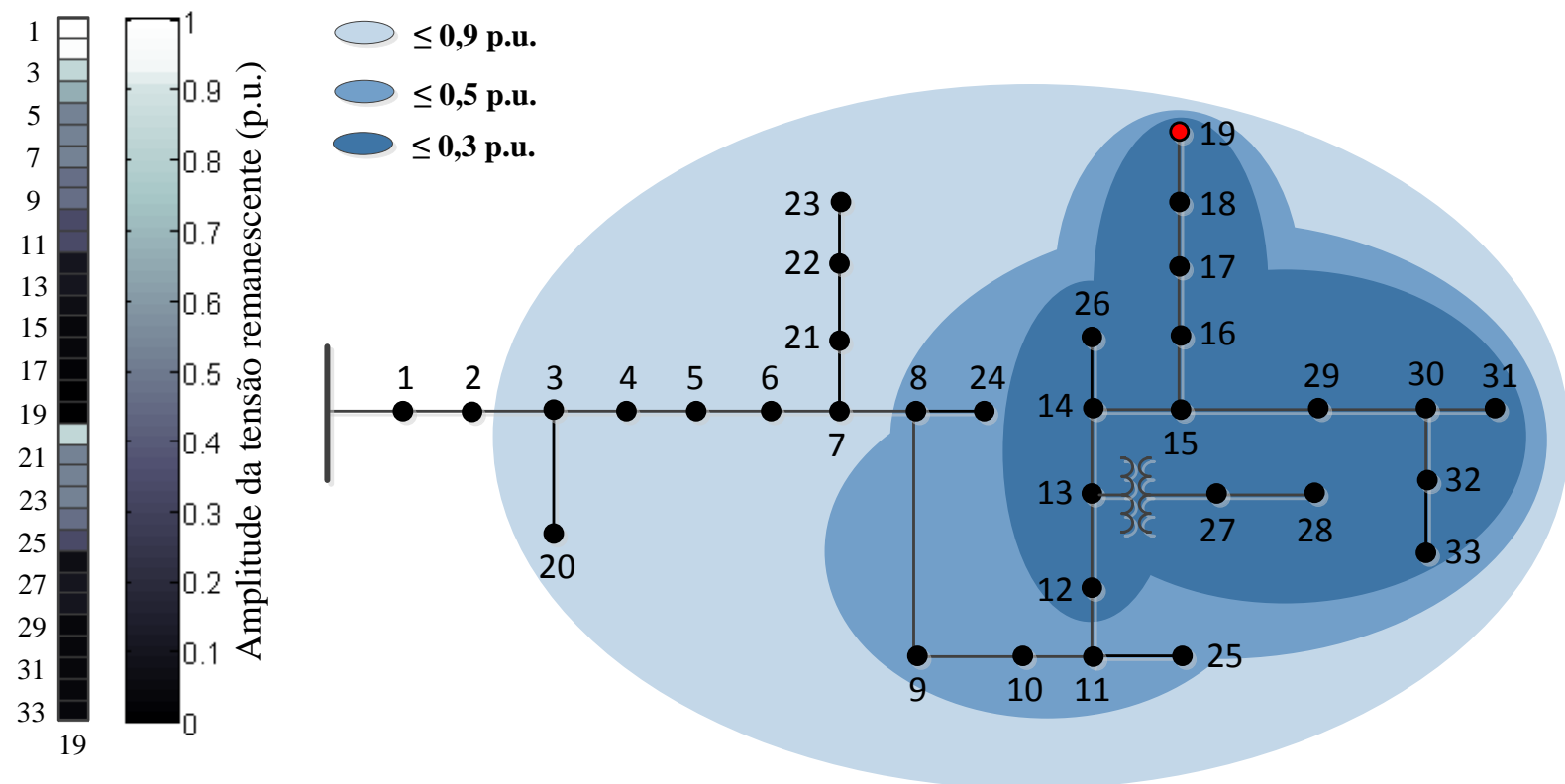
Constata-se pela Figura 52 que, quando o limiar desejado para a tensão foi menor ou igual a 0,9 p.u. da tensão eficaz de operação do SD, apenas os nós 1 (um) e 2 (dois) não foram afetados pelo afundamento de tensão. Quando o limiar de tensão foi restringido para uma tensão menor ou igual a 0,5 p.u., a área afetada por esta situação de falta tornou-se bem menor. Na sequência, o limiar de tensão foi fixado em 0,3 p.u., sendo que a área afetada pelos afundamentos de tensão ficou restrita às proximidades do nó 19 , onde a falta foi aplicada. Logo, estas observações permitem comprovar que a região em torno do ponto de falta sofre afundamentos de tensão com intensidades diferentes, sendo mais severos quanto mais próximos estiverem da situação que os originou (curto-circuito trifásico) e vice-versa.

Nota-se ainda pela Figura 52 que na ocorrência de uma falta trifásica no nó 19, considerando o liminar menor ou igual a 0,9 p.u., o número de nós afetados pelo afundamento de tensão foi 31 , visto que os nós 1 e 2 apresentaram tensões maiores que 0,9 p.u.. Quando fixado um limiar em 0,5 p.u. o número de nós afetados passou para 22 , e quando fixado um limiar em 0,3 p.u., 16 nós foram afetados.

Fazendo esta mesma análise durante a ocorrência dos demais tipos de faltas em todos os nós do SD de 34 nós, a partir de um limiar menor ou igual 0,9 p.u., foi gerada a Figura 53, para curtos-circuitos nos nós de 1 a 17, e a Figura 54, para as faltas nos nós de 18 a 33. Sendo que, para a falta FT, utilizou-se a MTDF obtida para a fase $A$, e para as faltas bifásicas FF e FFT, analisou-se a fase $B$, pois como visto anteriormente, para o SD de 34 nós esta fase apresentou os afundamentos de tensão mais severos.

Figura 53 - Número de nós afetados pelo afundamento de tensão no SD de 34 nós considerando diferentes tipos de falta nos nós de 1 a 17 a partir de um limiar de 0,9 p.u..

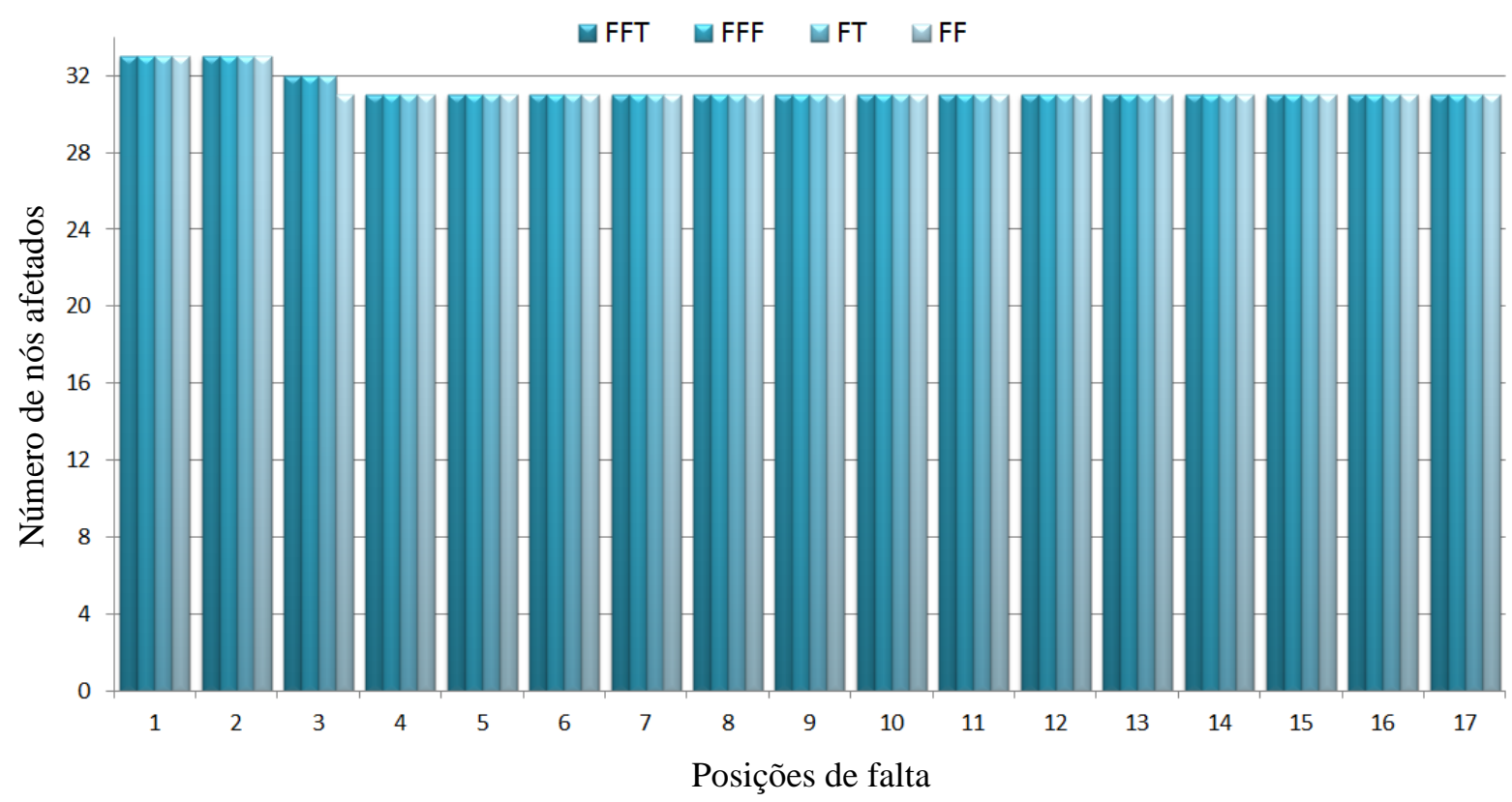


Figura 54 - Número de nós afetados pelos afundamentos de tensão no SD de 34 nós considerando diferentes tipos de falta nos nós de 18 a 33 a partir de um limiar de 0,9 p.u..

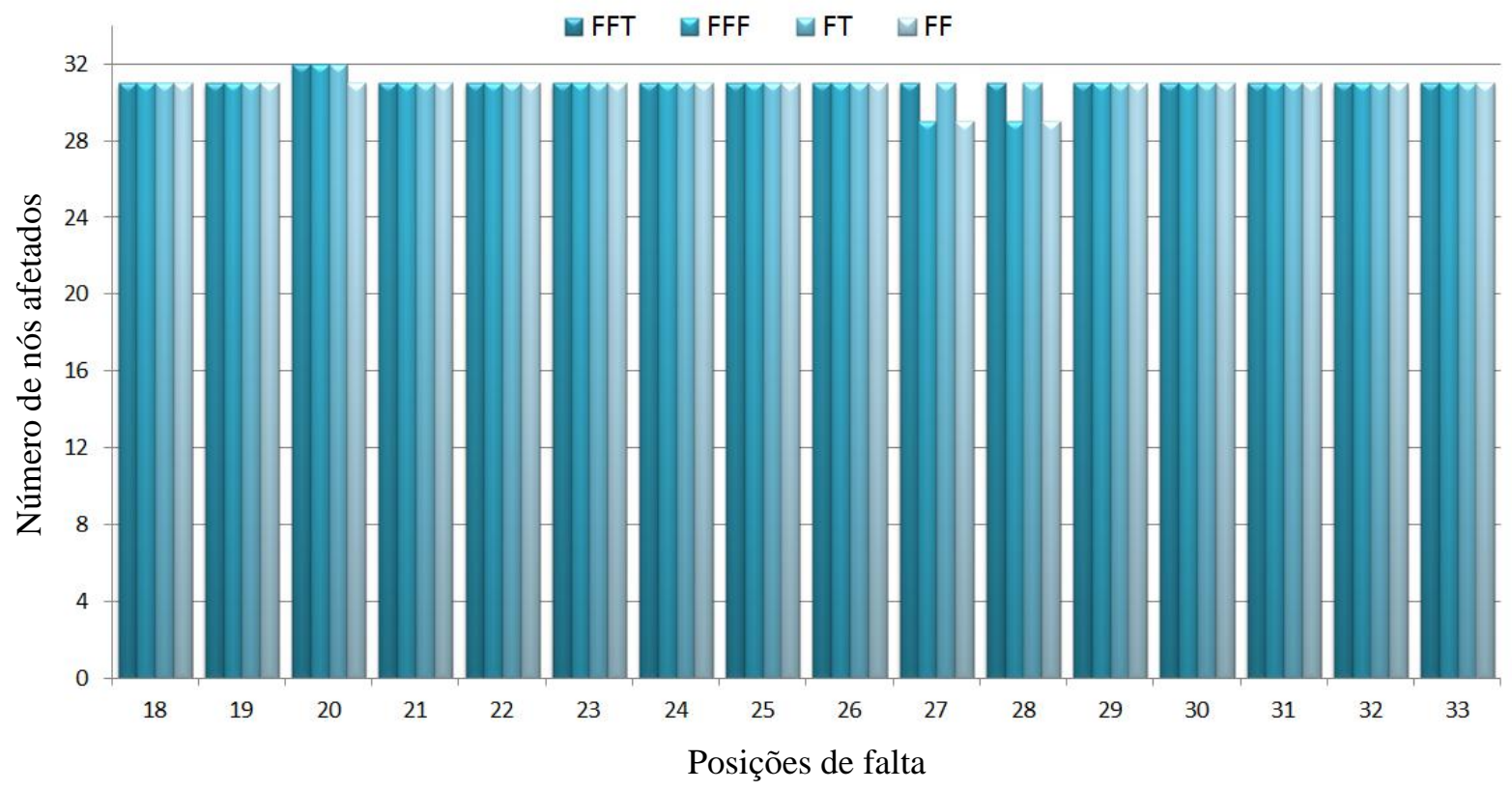

Como já comentado, à medida que o limiar de tensão é diminuído, a área afetada também tende a diminuir, restringindo-se às proximidades do nó onde a falta ocorreu. Isso ocorre devido ao afundamento de tensão ser mais severo na região mais próxima ao local de ocorrência da falta. Desta forma, ao comparar os gráficos da Figura 54 e da Figura 56, percebe-se claramente a redução do número de nós afetados quando analisado o limiar de tensão menor ou igual a 0,3 p.u..

Figura 55 - Número de nós afetados pelos afundamentos de tensão no SD de 34 nós considerando diferentes tipos de falta nos nós de 1 a 17 a partir de um limiar de 0,3 p.u..

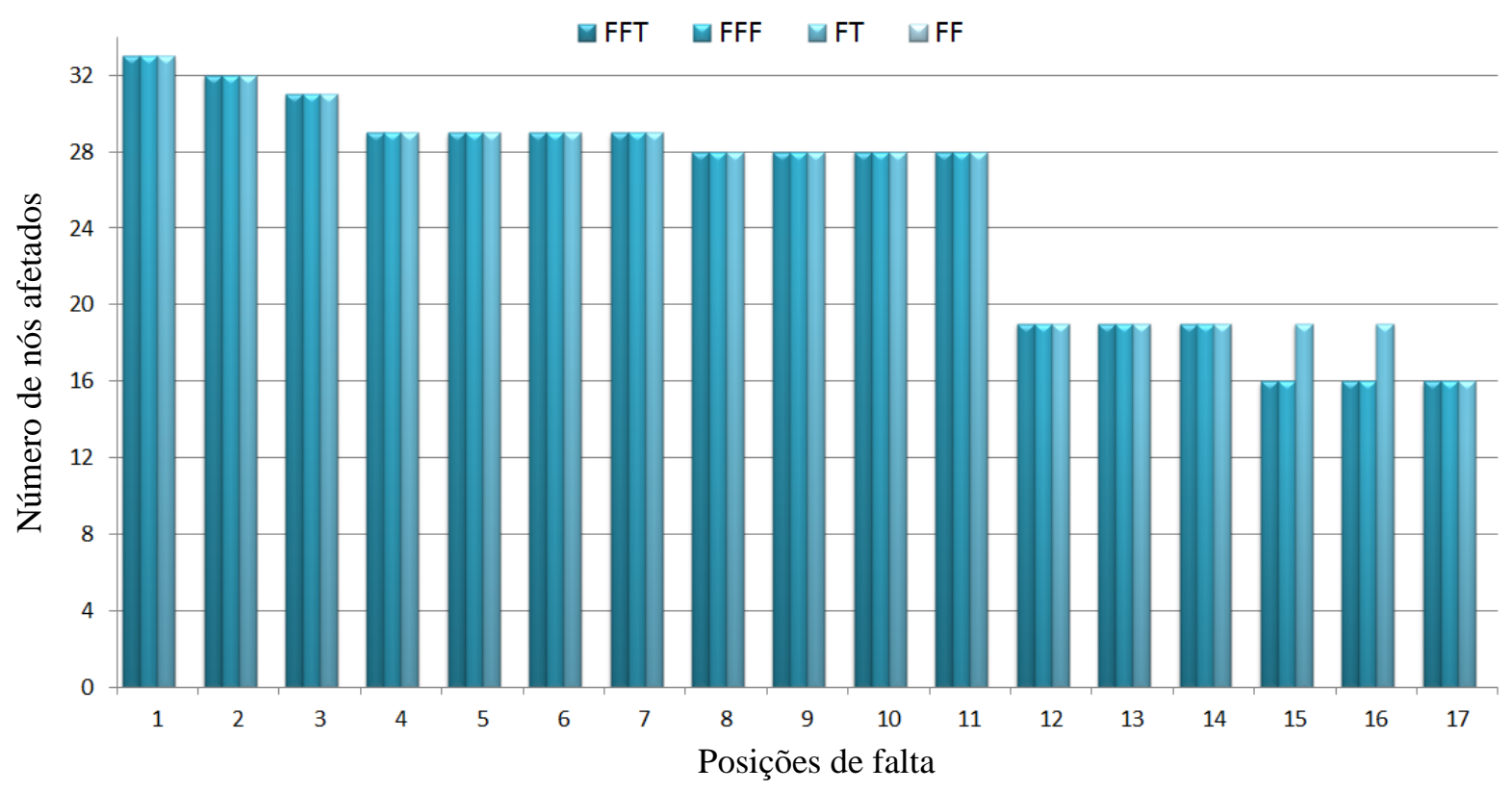


Figura 56 - Número de nós afetados pelos afundamentos de tensão no SD de 34 nós considerando diferentes tipos de falta nos nós de 18 a 33 a partir de um limiar de 0,3 p.u..

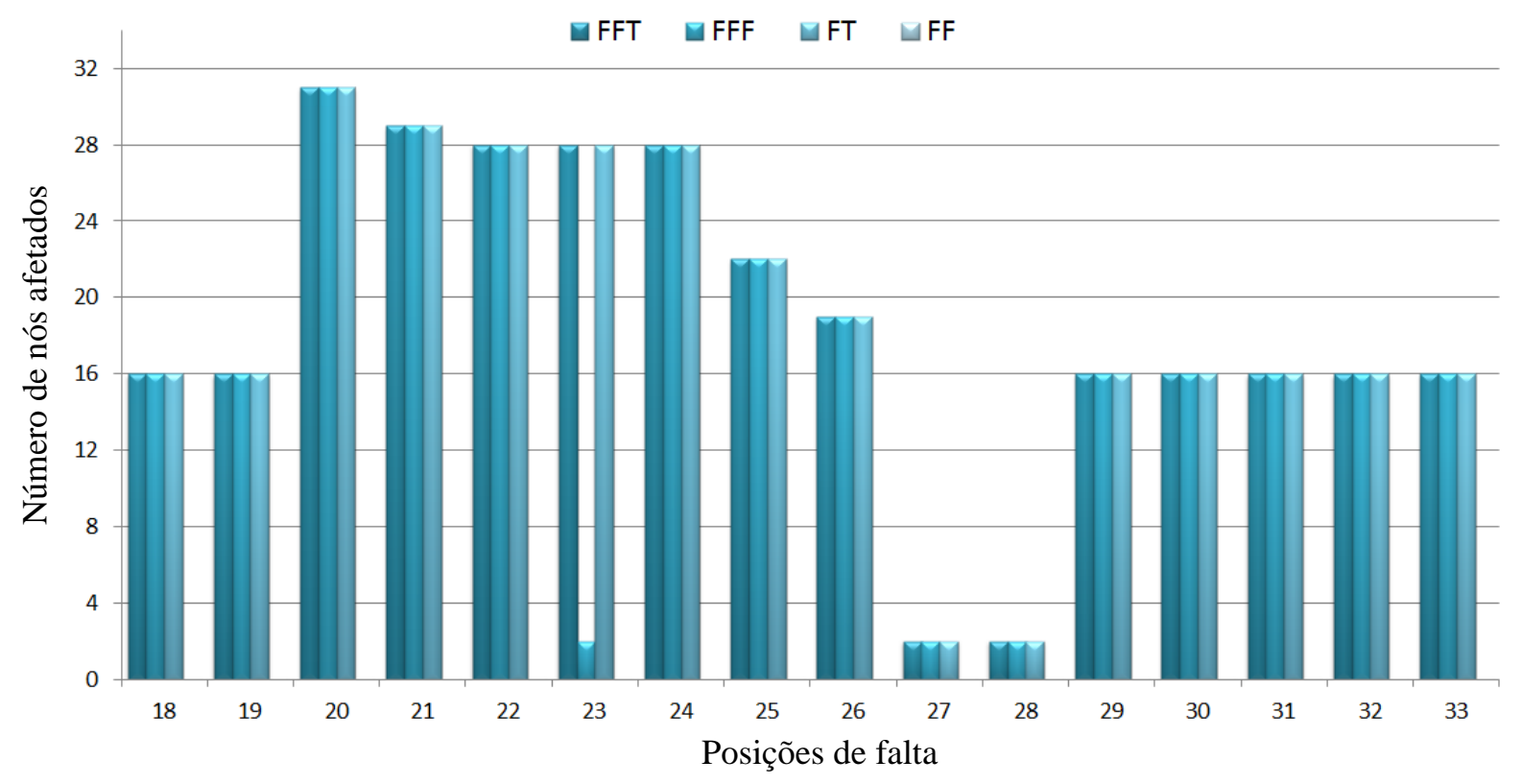

Realizando esta mesma análise para todos os limiares que compreendem os afundamentos de tensão ( 0,$1 ; 0,2$ à 0,9 p.u.), e calculando o valor médio, através da soma do número de nós afetados para cada limiar em cada posição de falta, gerou-se a Figura 57, para as faltas nos nós de 1 a 17, e a Figura 58, para os diferentes tipos de curtos-circuitos nos nós de 18 a 33 .

Figura 57 - Nós afetados pelos afundamentos de tensão no SD de 34 nós considerando diferentes tipos de falta nos nós de 1 a 17 a partir de uma média entre os limiares de 0,1 a 0,9 p.u..

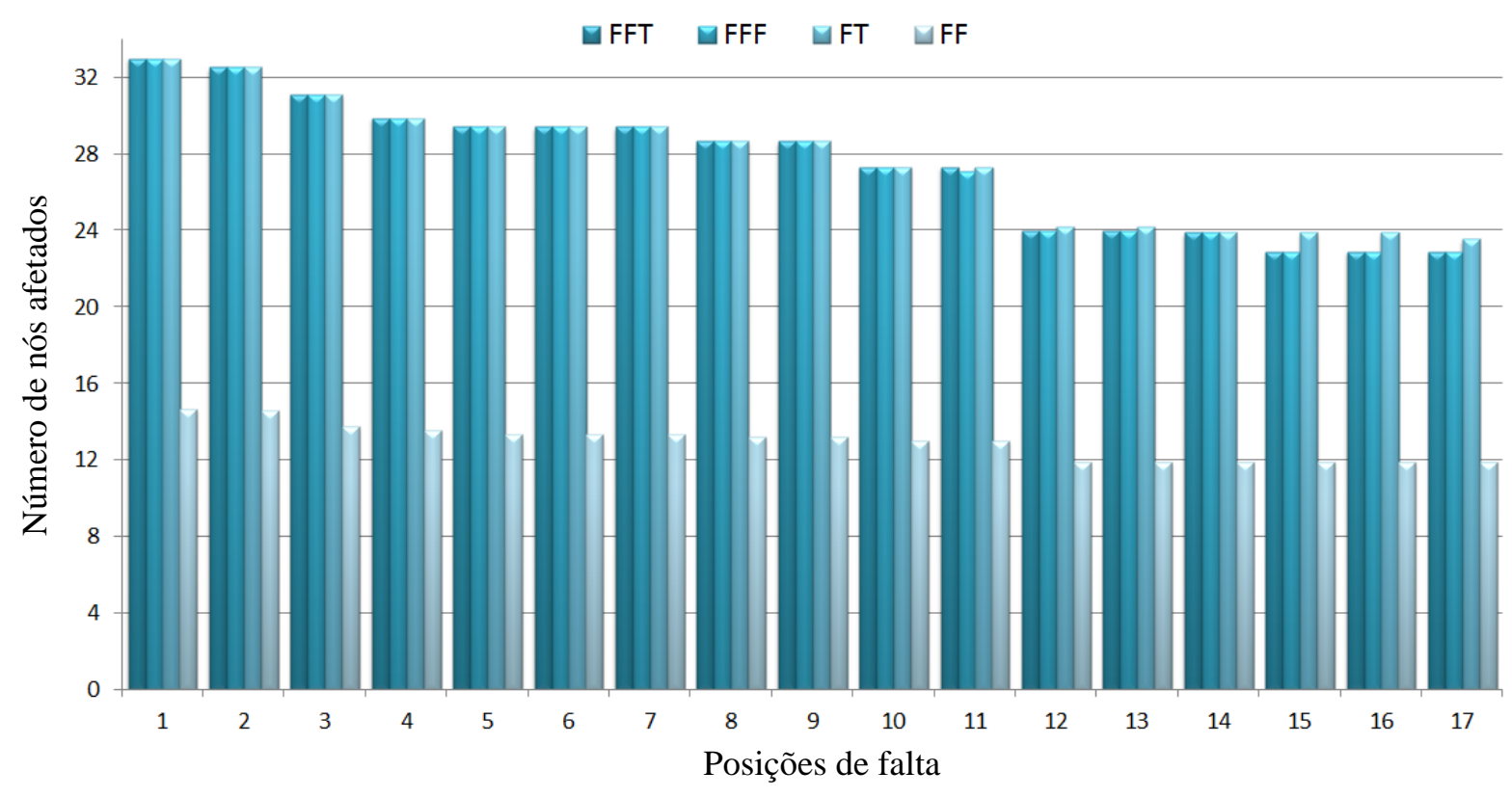


Figura 58 - Nós afetados pelos afundamentos de tensão no SD de 34 nós considerando diferentes tipos de falta nos nós de 18 a 33 a partir de uma média entre os limiares de 0,1 a 0,9 p.u..

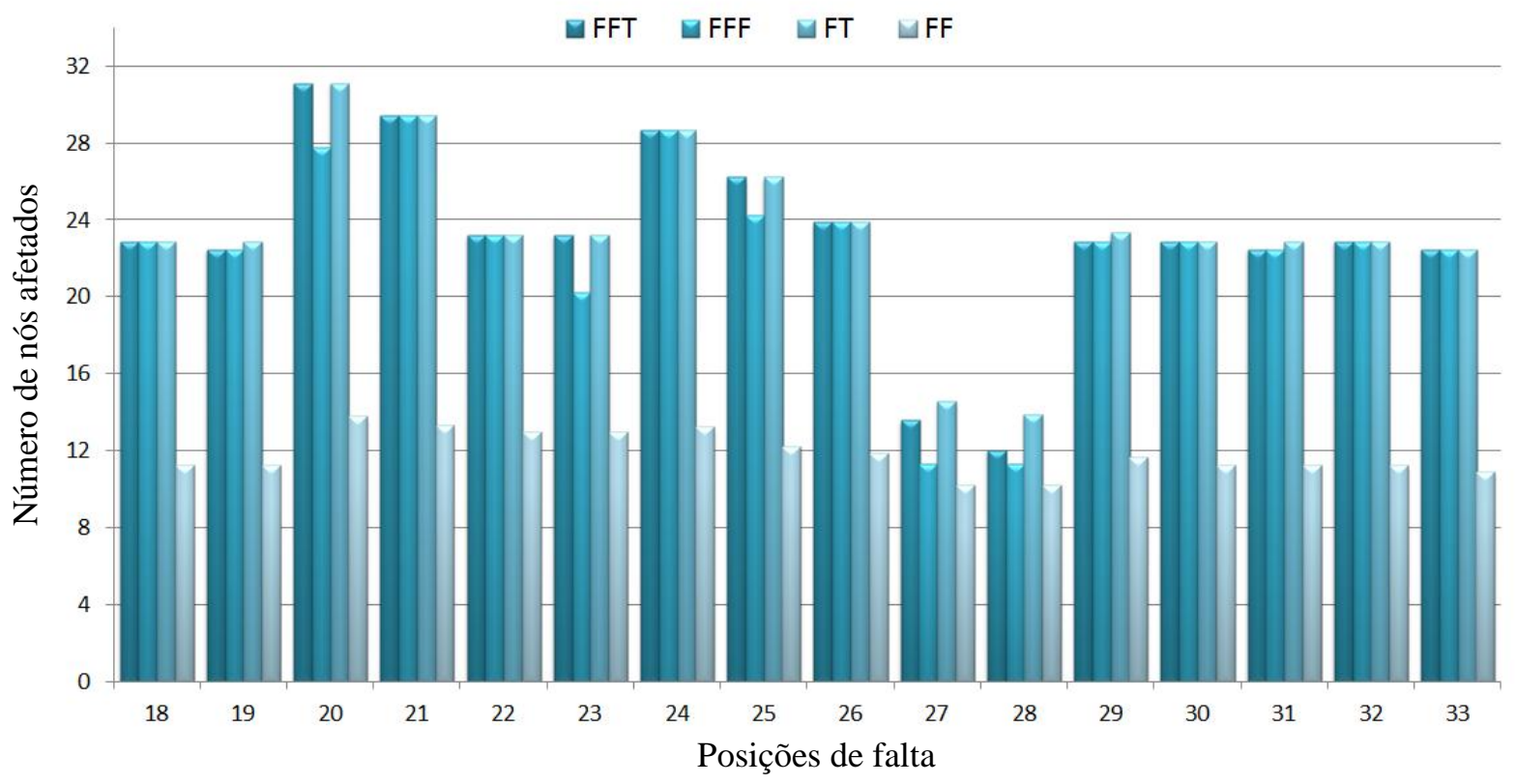

A Figura 57 e a Figura 58 registram o número médio de nós afetados entre o limiar de 0,1 a 0,9 p.u., para cada situação de falta nos nós. Da análise destas figuras, é possível perceber que as faltas FFT e FT irão afetar um maior número de nós, sendo que quanto mais próximo à subestação ocorrer uma falta, maior será o número de nós afetados por esta situação de falta e mais severos serão os afundamentos de tensão registrados, como pode ser evidenciado pelos nós 1 e 2 (Figura 57) .

Cabe comentar que, como a falta FF apresenta apenas afundamentos de tensão iguais ou superiores a 0,5 p.u., quando realizada a média entre todos os limiares ( Figura 57 e Figura 58), esta apresentou um valor mediano bem menor quando comparada com os demais tipos de falta.

A Figura 59 retrata ainda o número médio de nós afetados em decorrência de qualquer tipo de falta que o SD de 34 nós possa vir a ser submetido. Pela ilustração é possível reafirmar que um número maior de consumidores será sensibilizado pelos afundamentos de tensão durante a ocorrência de faltas nos nós mais próximos das fontes geradoras. Em contrapartida, quando acontecerem curtos-circuitos nos nós 27 e 28, localizados a jusante do transformador abaixador de tensão, um menor número de nós será afetado.

Para os demais SDs foram seguidas as mesmas considerações e análises adotadas para o SD de 34 nós. Entretanto, para os SDs de 13 e 37 nós, consideraram-se as MTDFs da fase $C$ para as faltas bifásicas FF e FFT, por estas registrarem os afundamentos de tensão mais severos. 
Figura 59 - Número médio de nós afetados pelo afundamento de tensão considerando qualquer tipo de falta que o SD de 34 nós venha a ser submetido.

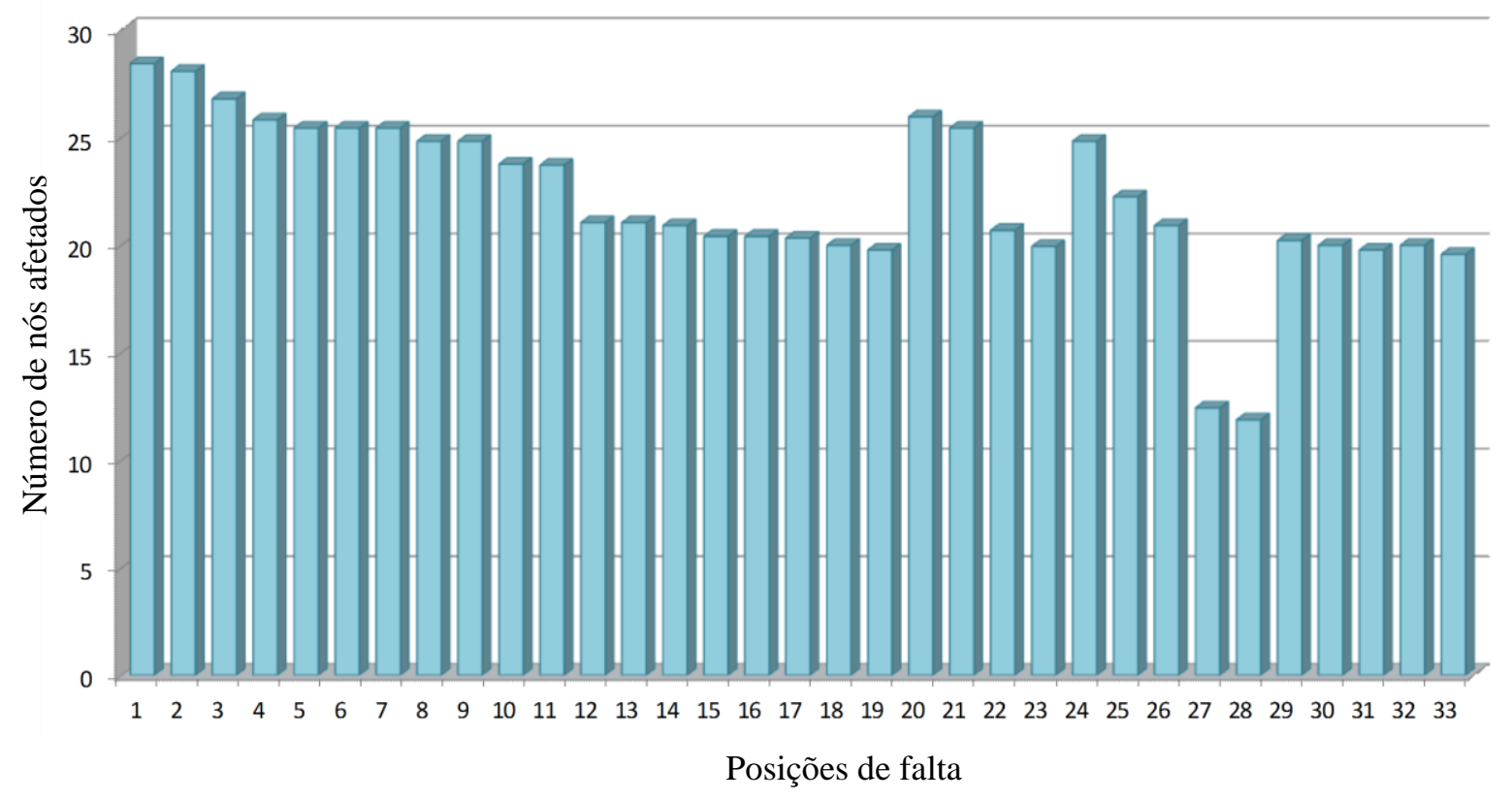

Realizando a análise para qualquer tipo de falta que o SD de 13 nós possa ser submetido, percebe-se pela Figura 60 que um número maior de consumidores será afetado se ocorrerem faltas próximas à subestação, sendo que, a ocorrência de faltas no nó 3, localizado a jusante do transformador (Figura 39), irá afetar um menor número de nós.

Figura 60 - Número médio de nós afetados pelo afundamento de tensão considerando qualquer tipo de falta que o SD de 13 nós venha a ser submetido.

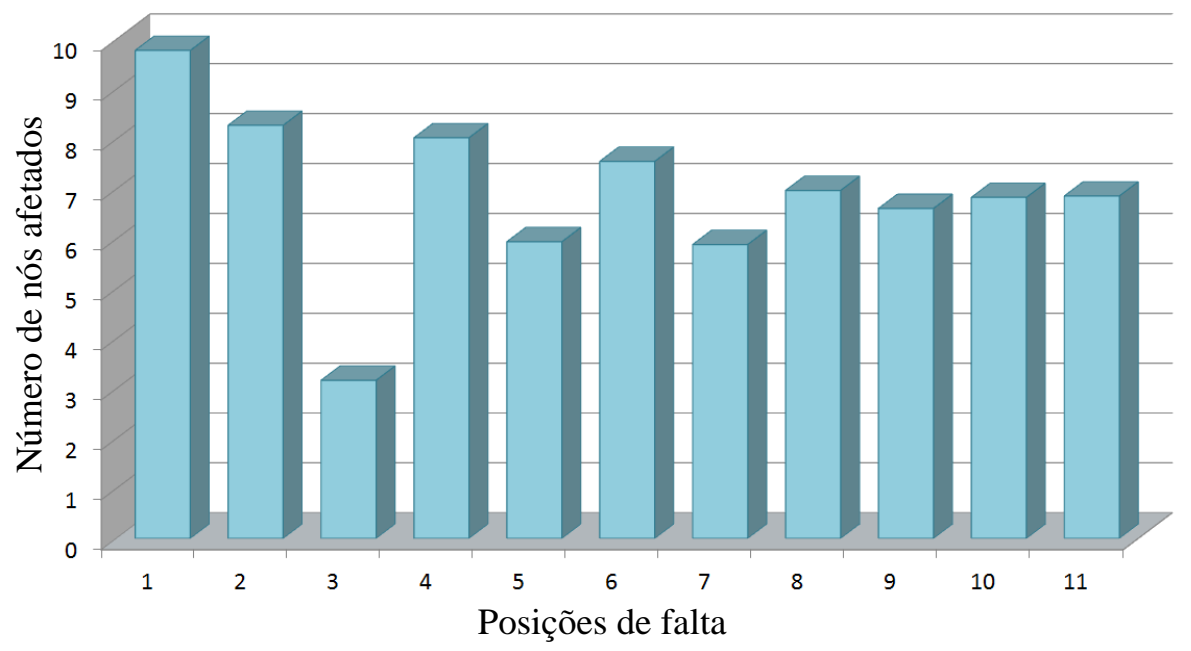

Para o SD de 37 nós a média de nós afetados na ocorrência de qualquer tipo de falta está representada na Figura 61. Neste caso, um menor número de nós será afetado na ocorrência de curtos-circuitos no nó 32, localizado logo após o transformador (Figura 41). 
Figura 61 - Número médio de nós afetados pelo afundamento de tensão considerando qualquer tipo de falta que o SD de 37 nós venha a ser submetido.

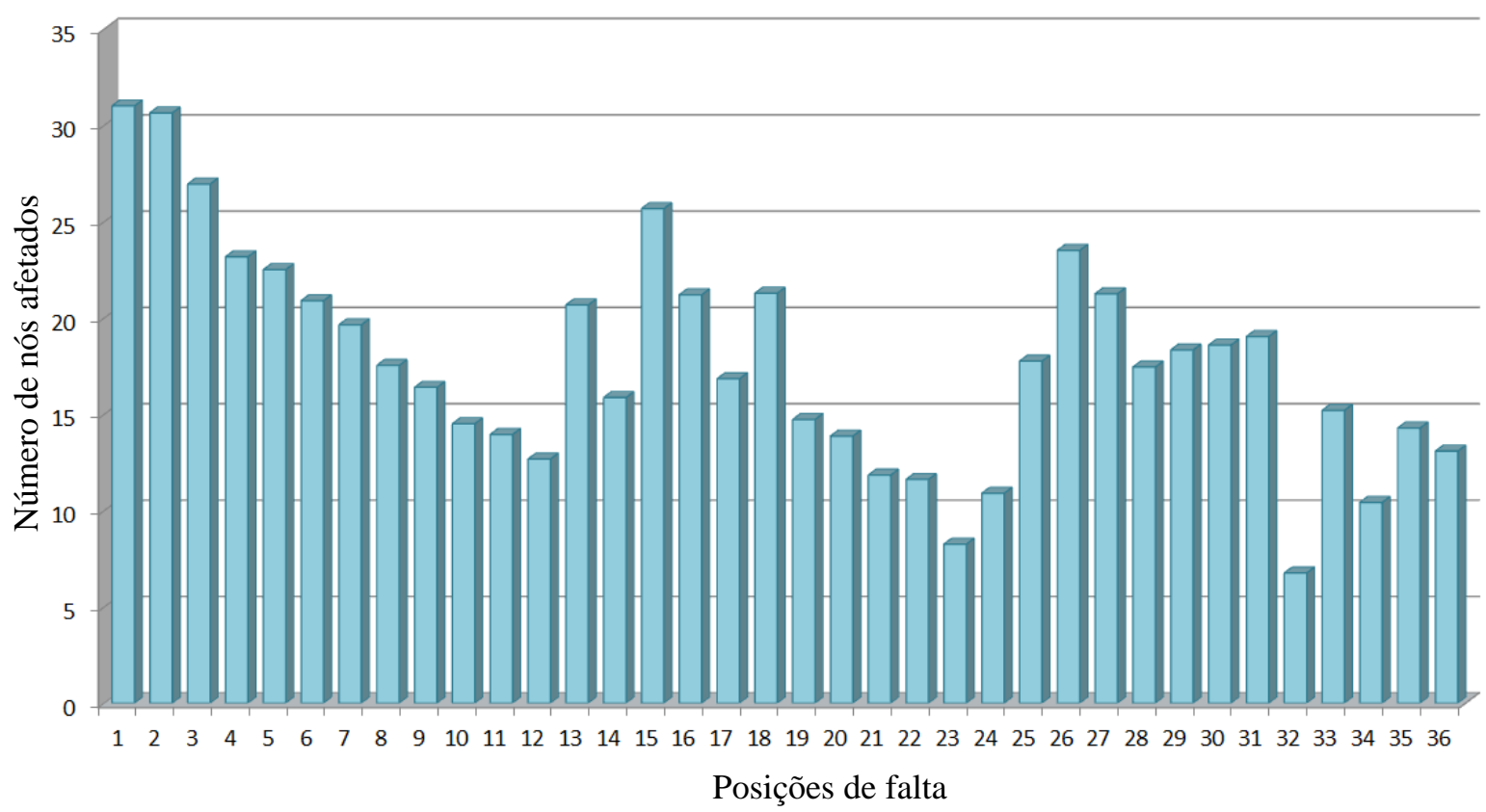

No sistema de 123 nós (Figura 42), a fase $B$ apresentou os afundamentos de tensão mais severos. Portanto, utilizou-se a MTDF gerada para esta fase para determinar a área afetada pelas faltas FF e FFT. A Figura 62 ilustra o número médio de nós afetados por qualquer tipo de falta efetuada nos nós de 1 a 59. Já na Figura 63 se observa em média quantos nós serão afetados na ocorrência de qualquer curto-circuito realizado nos nós 60 a 118.

Figura 62 - Número médio de nós afetados pelo afundamento de tensão considerando qualquer tipo de falta nos nós de 1 a 59 que o SD de 123 nós venha a ser submetido.

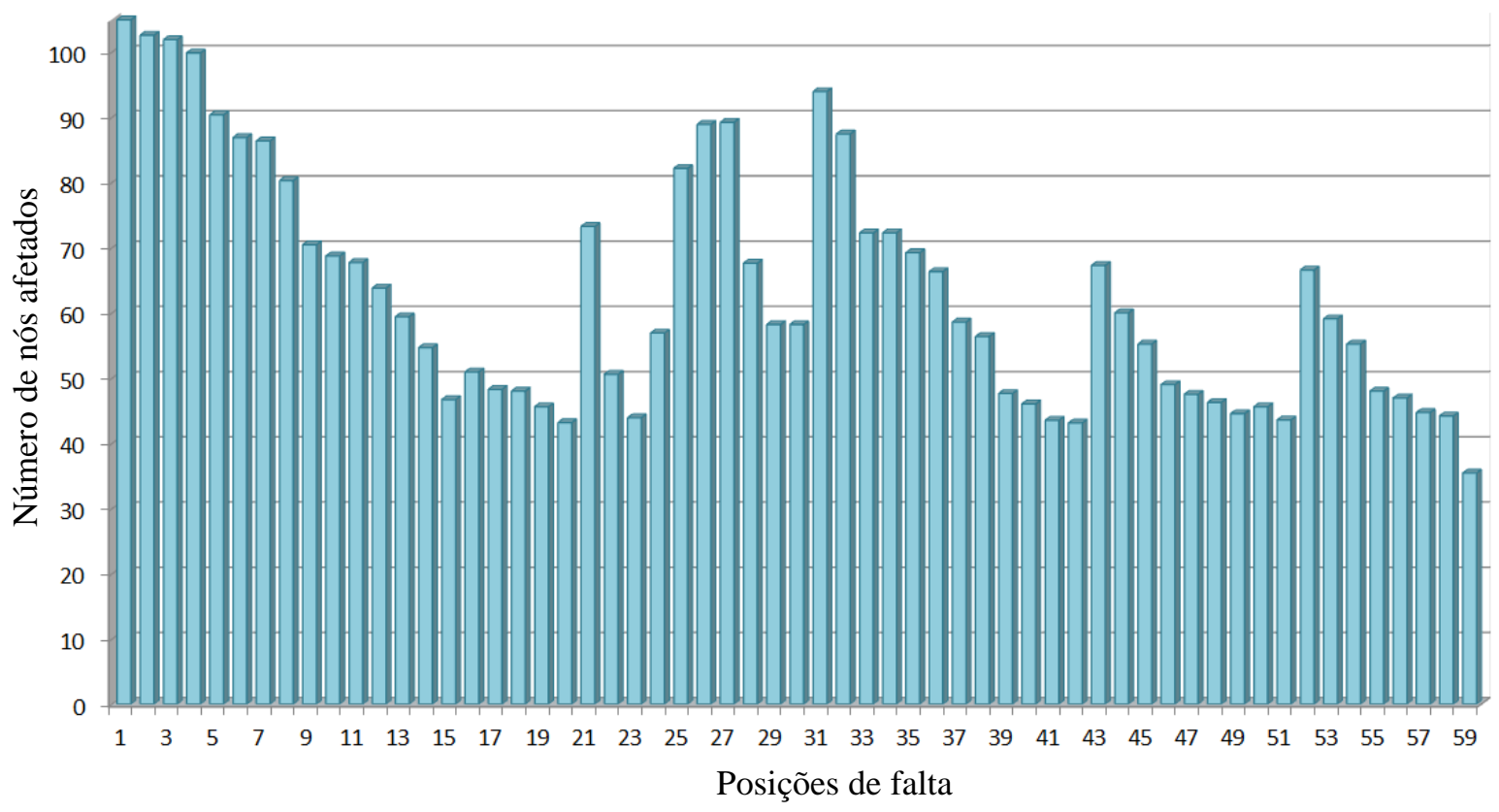


Figura 63 - Número médio de nós afetados pelo afundamento de tensão considerando qualquer tipo de falta nos nós de 60 a 118 que o SD de 123 nós venha a ser submetido.

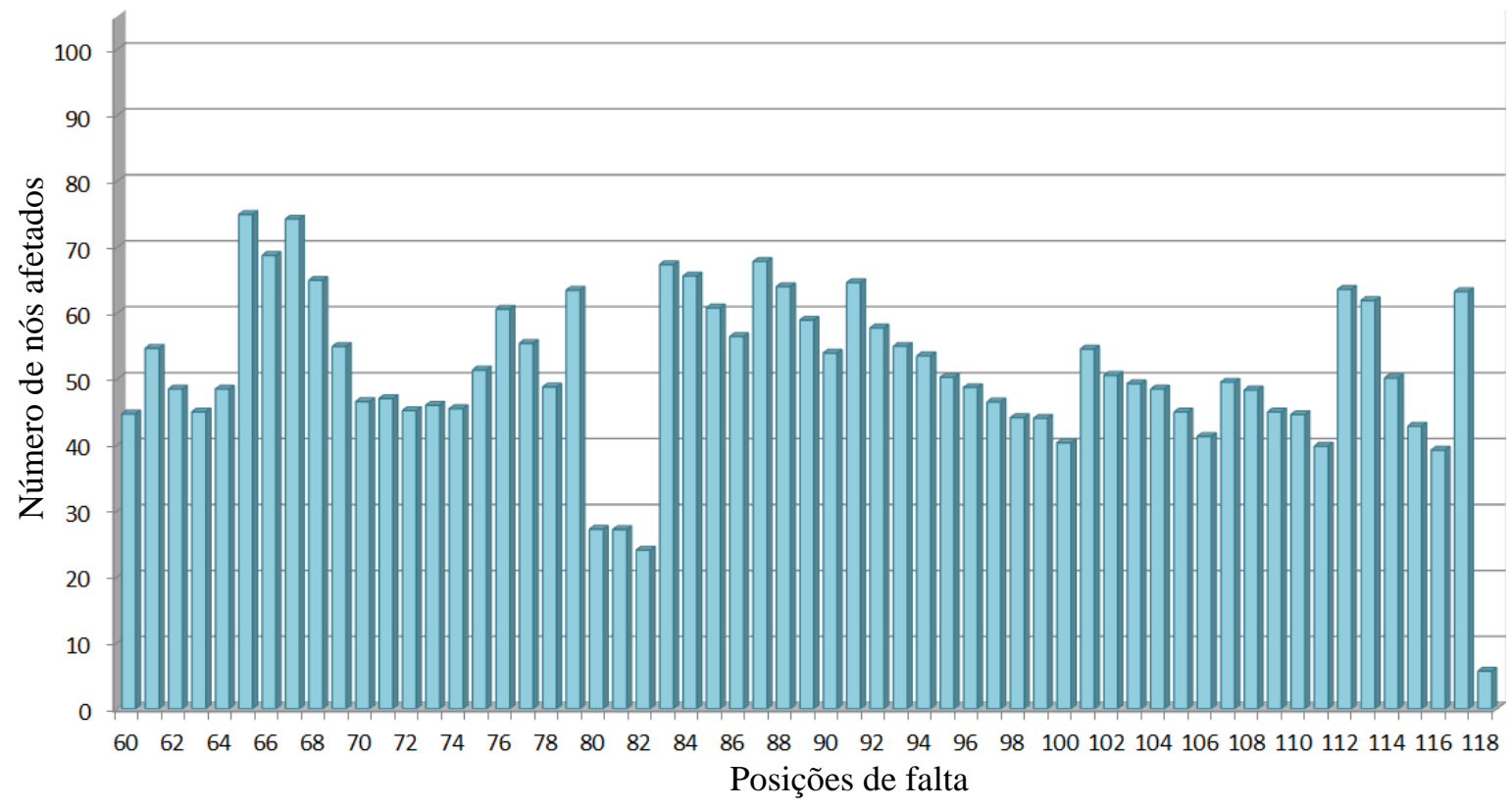

\subsubsection{Análise da Área Exposta ou de Vulnerabilidade}

O conceito de área de vulnerabilidade foi desenvolvido com o objetivo de demarcar as regiões do sistema elétrico onde haverá a ocorrência de afundamentos de tensão abaixo de limites críticos que possam resultar em desligamentos de cargas sensíveis instaladas no nó de observação.

Ao contrário da análise da área afetada onde é fixada uma posição de falta e são observadas as magnitudes da tensão em todos os outros nós do sistema, na análise da área de vulnerabilidade, fixa-se um nó de interesse, e se observam as tensões remanescentes provocadas neste nó por situações de faltas aplicadas nos demais e distintos nós do SD.

Assim sendo, uma forma direta de analisar a área de vulnerabilidade é através da visualização gráfica de cada linha da MTDF que contém a amplitude das tensões remanescentes para cada nó em observação. Para exemplificar, ao observar a linha 22 da MTDF, devido à aplicação de faltas trifásicas em todos os outros nós do SD de 34 nós (Figura 43), é possível representar graficamente a área de vulnerabilidade para cada limiar de tensão desejado conforme ilustra a Figura 64.

O gráfico da Figura 64 mostra o nível das tensões no nó 22 para todas as posições de faltas aplicadas. Portanto, ao considerar a ocorrência de uma falta trifásica no nó 29, por exemplo, é possível observar que a tensão no nó 22 é menor que 0,9 p.u. e maior que 0,5 p.u.. 
Figura 64 - Área de vulnerabilidade para o nó 22 considerando todas as situações de falta FFF aplicadas no SD de 34 nós.

Amplitude da tensão remanescente (p.u.)

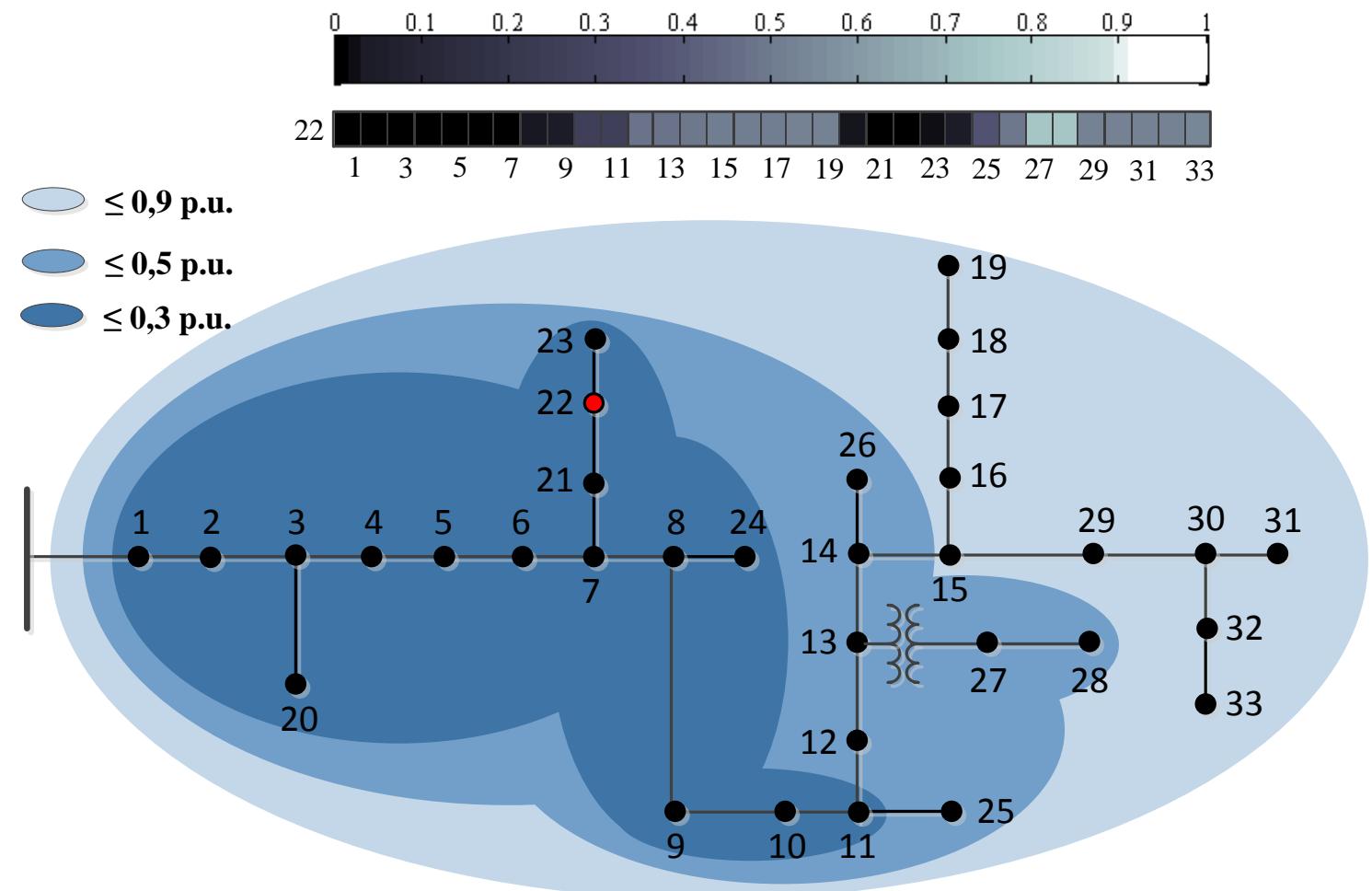

A fim de proporcionar uma visão geral dos nós expostos aos afundamentos de tensão, foi adotado o mesmo procedimento da área afetada, considerando, inicialmente, uma média entre todos os limiares de tensão, para cada tipo de falta. Posteriormente, calculou-se uma média para todos os nós vulneráveis aos afundamentos de tensão na incidência de qualquer tipo de falta.

Sendo assim, ao considerar a incidência de qualquer tipo de curto-circuito para a análise dos casos mais severos de afundamentos de tensão no SD de 13 nós, é notável pela Figura 65 que os nós menos expostos aos afundamentos de tensão são os nós que estão eletricamente próximos à fonte geradora. Portanto, os nós 1, 2 e 4 são os nós menos propensos a sofrer afundamentos de tensão severos, sendo vulneráveis aos afundamentos somente se ocorrer faltas (curtos-circuitos) nos nós que estiverem nas suas proximidades.

Conforme ilustra a Figura 66, Figura 67 e Figura 68, os mesmos resultados verificados no SD de 13 nós também são válidos para os demais SDs, visto que, os nós localizados eletricamente próximos à subestação, são os que apresentam menor área de vulnerabilidade. Consequentemente, são os locais mais indicados para a instalação de equipamentos sensíveis e menos indicados a ter medidores de QEE instalados. 
Figura 65 - Número de nós expostos aos afundamentos de tensão considerando qualquer tipo de falta que o SD de 13 nós venha a ser submetido.

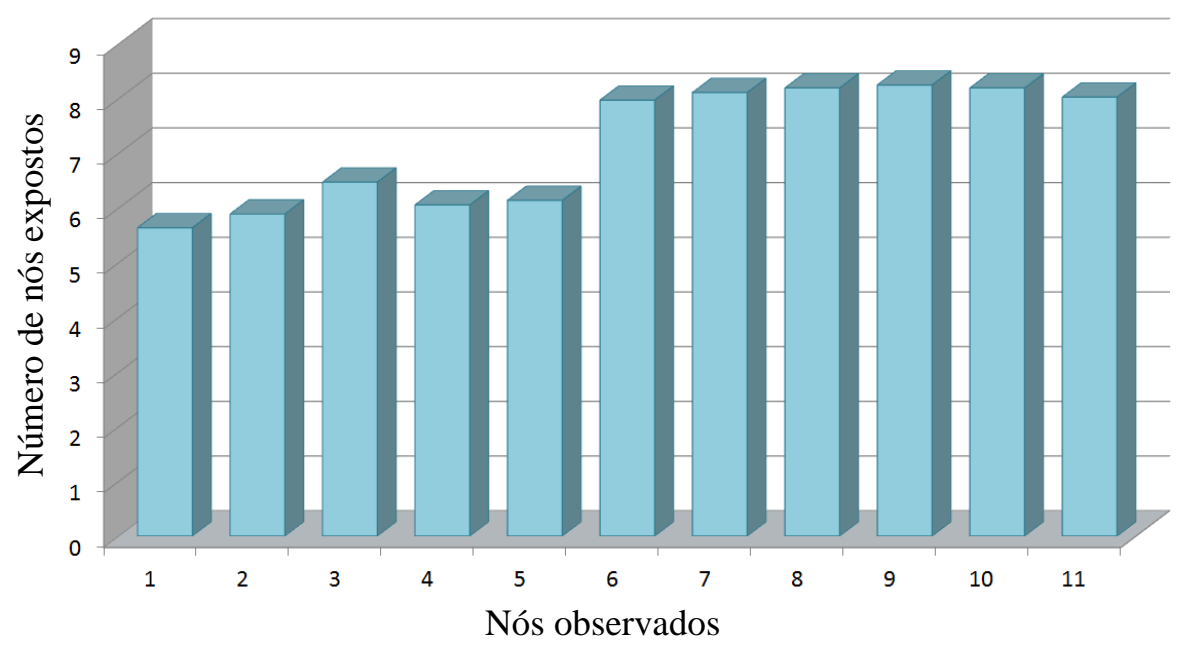

Figura 66 - Número de nós expostos aos afundamentos de tensão considerando qualquer tipo de falta que o SD de 34 nós venha a ser submetido.

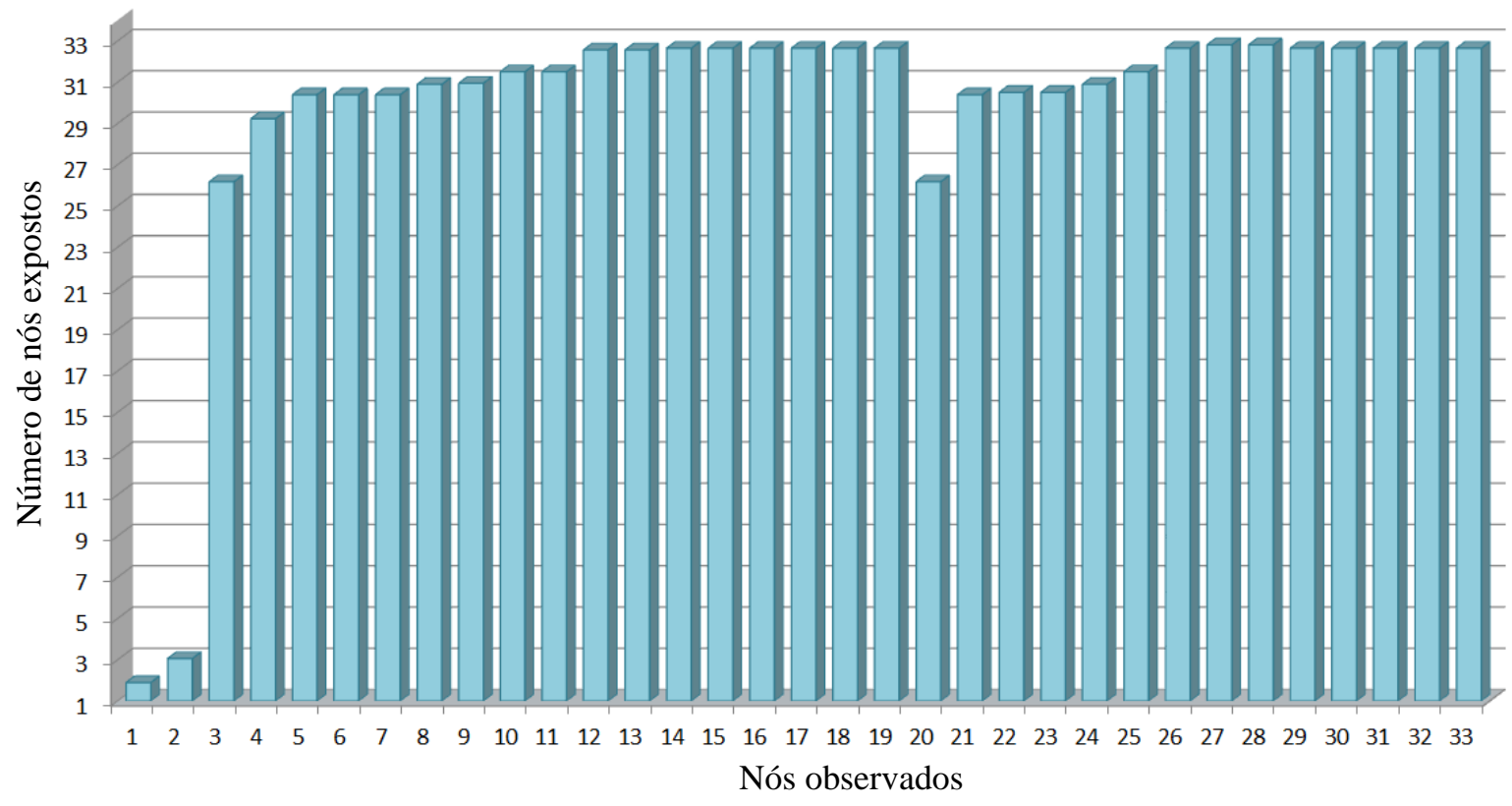

Percebe-se ainda da Figura 65 à Figura 69, que os nós mais distantes da subestação estarão mais suscetíveis às VTCDs, pois manifestam maior vulnerabilidade aos afundamentos de tensão na ocorrência de qualquer tipo de falta, como é o caso, principalmente, dos nós 8, 9 e 10 no SD de 13 nós, dos nós 27 e 28 no SD de 34 nós, dos nós 11, 12 e 36 no SD de 37 nós, e dos nós 106, 110 e 111 no SD de 123 nós.

Neste cenário, como estes locais apresentam uma maior área de vulnerabilidade, os mesmos possuem uma maior visibilidade dos distúrbios. Desta forma, é possível estabelecer uma máxima observabilidade para todos os eventos decorrentes de qualquer tipo de curtocircuito, tornando-se locais propícios para receber a alocação de medidores. 
Figura 67 - Número de nós expostos aos afundamentos de tensão considerando qualquer tipo de falta que o SD de 37 nós venha a ser submetido.

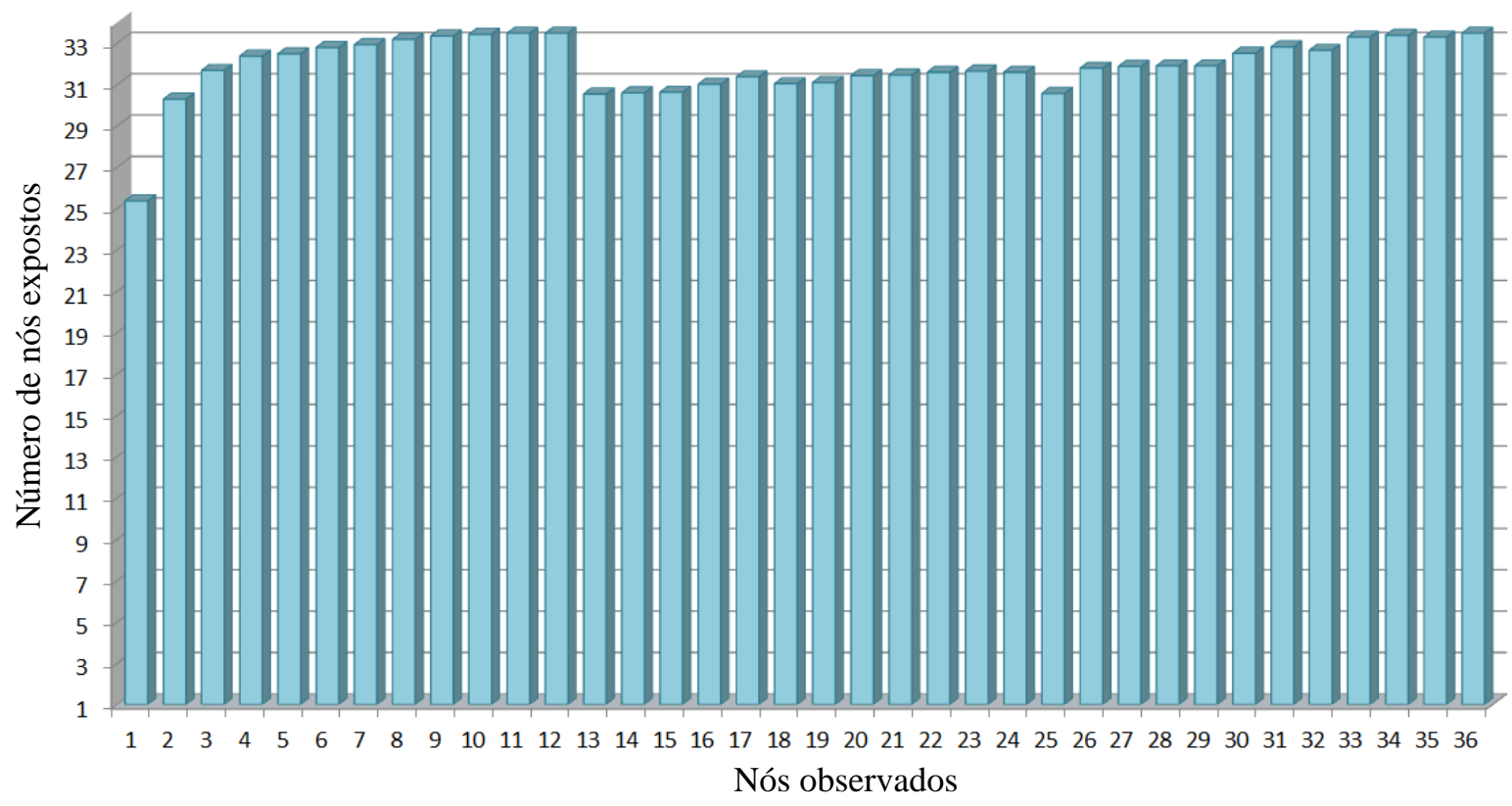

Figura 68 - Número de nós expostos aos afundamentos de tensão considerando qualquer tipo de falta nos nós de 1 a 59 que o SD de 123 nós venha a ser submetido.

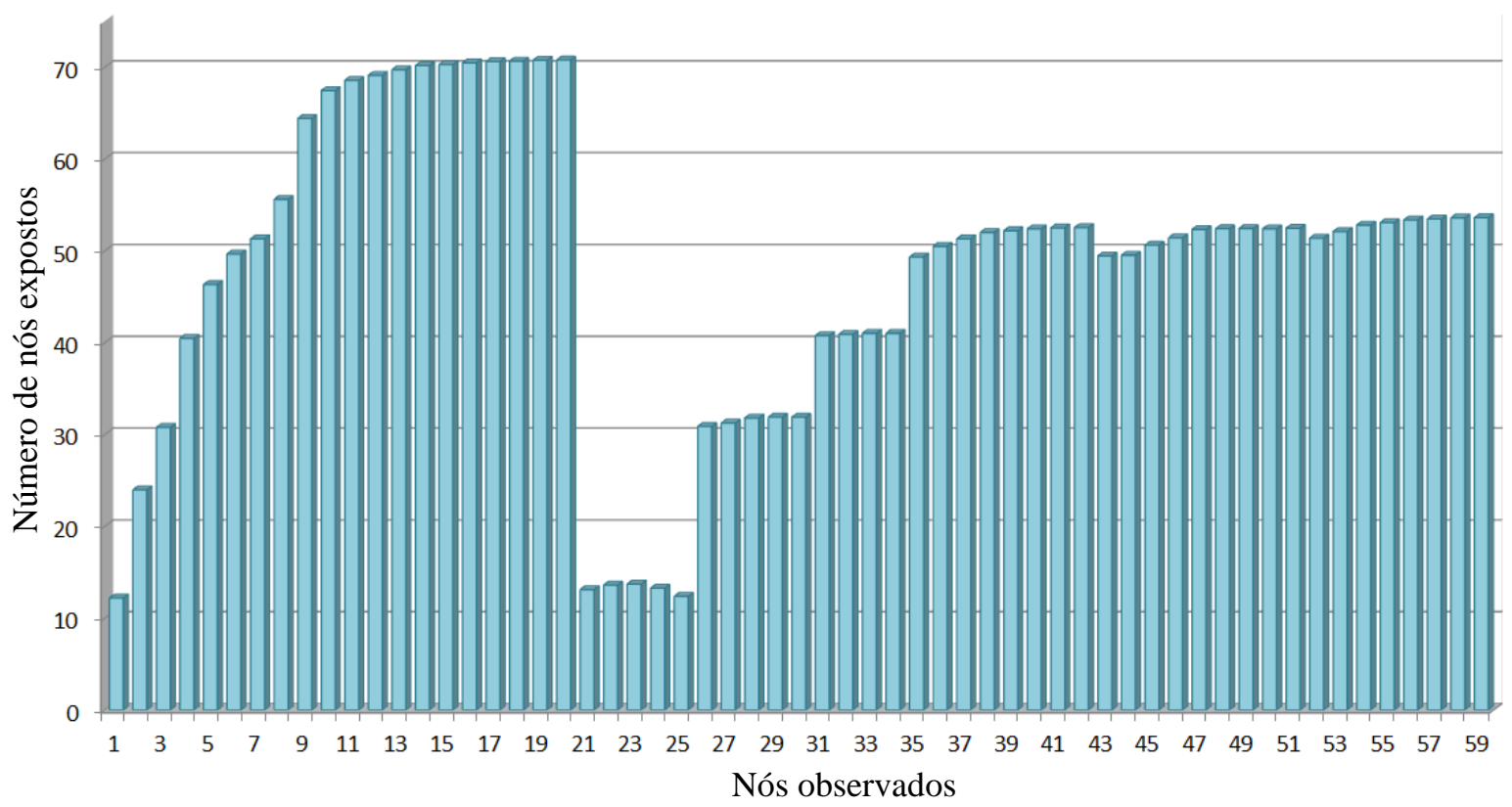

Como já constatado pelas análises gráficas, devido à área de vulnerabilidade ser menor nos nós próximos a subestação, estes locais não são indicados para instalar os medidores de QEE. Ao mapear a área de vulnerabilidade no nó 1 do SD de 123 nós, Figura 70, por exemplo, percebe-se que quando definido o limiar de tensão de 0,9 p.u., 46 nós não serão abrangidos pela área de vulnerabilidade, ou seja, as ocorrências de faltas trifásicas em 46 nós do SD não serão observadas pelo nó 1 . 
Figura 69 - Número de nós expostos aos afundamentos de tensão considerando qualquer tipo de falta nos nós de 60 a 118 que o SD de 123 nós venha a ser submetido.

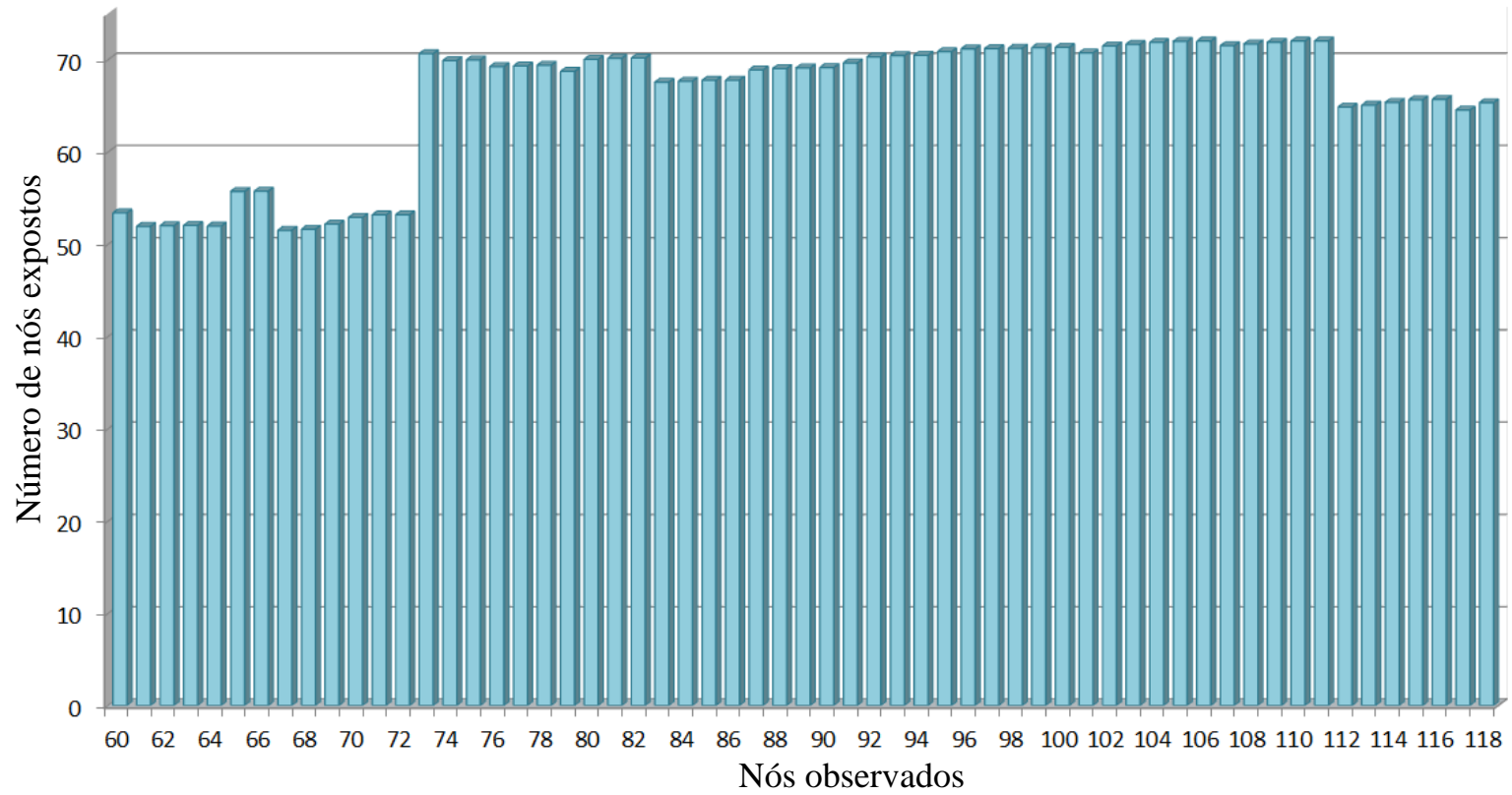

Figura 70 - Área de vulnerabilidade do nó 1 considerando todas as situações de faltas FFF aplicadas no SD de 123 nós.

Amplitude da tensão remanescente (p.u.)

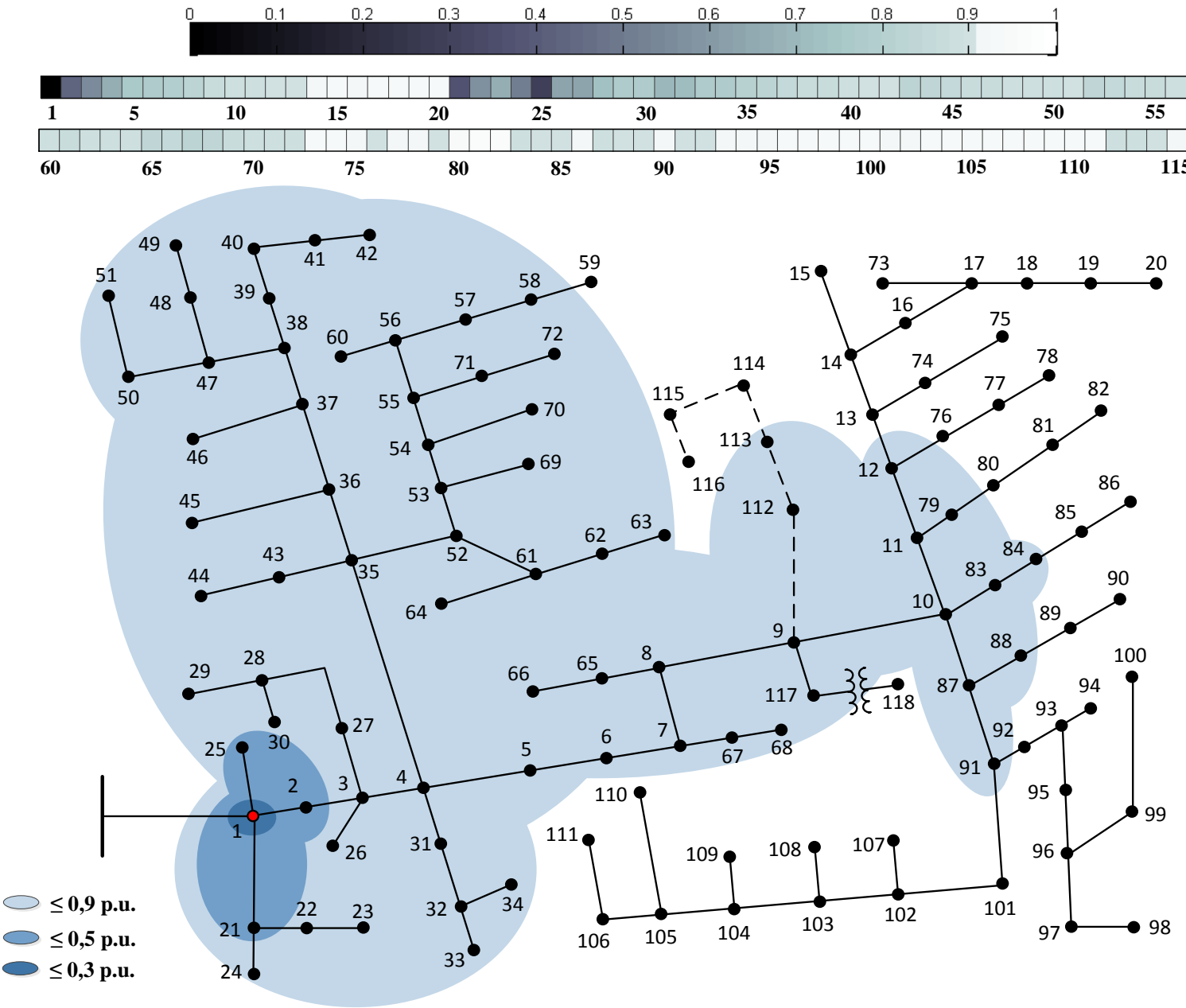


Neste cenário, sabendo-se que é uma prática usual das distribuidoras a instalação dos medidores na saída da subestação, observa-se que se o medidor de QEE estivesse instalado no nó 1, este não iria registrar a ocorrência de afundamentos de tensão caso ocorresse uma falta em qualquer nó fora da abrangência da área de vulnerabilidade delimitada.

Além das observações já colocadas, através das análises da vulnerabilidade do SD realizadas, e dispondo da curva de sensibilidade dos processos industriais, torna-se viável orientar as indústrias quanto à suportabilidade dos seus equipamentos frente aos afundamentos de tensão, e indicar o melhor local para a instalação de novos empreendimentos que apresentem em sua planta industrial equipamentos sensíveis que possam acarretar interrupções no processo industrial.

\subsection{Alocação Ótima de Medidores de QEE}

Como já mencionado nos capítulos anteriores, um monitoramento completo do SD é inviável devido ao custo elevado dos medidores e de sua implementação e manutenção. Logo, através da aplicação da metodologia descrita no capítulo 4 é possível determinar um número mínimo de medidores para o monitoramento das VTCDs.

Entretanto, para se obter um monitoramento eficaz e completo dos afundamentos de tensão no SD, é necessário ainda estabelecer os melhores locais nos quais os equipamentos de medição devem ser instalados, e definir um limiar de tensão para o qual se deseja que os medidores sejam sensibilizados.

$\mathrm{Na}$ literatura correlata consultada para esta pesquisa, normalmente, quando é determinado o número ótimo e a localização dos equipamentos para o monitoramento dos afundamentos da tensão, os autores reportam apenas as soluções obtidas para o limiar $\leq 0,9$ p.u.. Entretanto, quando este limiar é fixado, o número de afundamentos gravados pode ser excessivo e, consequentemente, exceder a capacidade de armazenamento do medidor. No outro extremo, se o limiar definido for muito baixo, o medidor não irá capturar um importante número de eventos. Portanto, um maior número de medidores é requerido para manter a observabilidade dos afundamentos de tensão.

Assim sendo, as soluções devem ser apresentadas de modo que possibilitem ao operador do sistema estabelecer o melhor arranjo de medidores de acordo com o número de equipamentos disponíveis, ou limites orçamentários para a aquisição dos mesmos. Portanto, neste trabalho, foi analisada a solução ótima de alocação de medidores para todos os limiares, compreendidos entre 0,1 e 0,9 p.u., que venham a caracterizar os afundamentos de tensão. 
De forma a determinar a melhor localização e o número mínimo de medidores para os sistemas testes do IEEE, foi utilizado o algoritmo BB, via a função bintprog do toolbox de otimização do software MATLAB ${ }^{\circledR}$.

Uma importante vantagem deste algoritmo é a garantia de convergência para a solução ótima global, e também a possibilidade de adicionar restrições práticas (dependentes do responsável pela operação de monitoramento) sobre quais nós, por exemplo, os medidores não devem ser instalados, quais já possuem medidores instalados e quais são candidatos prioritários à instalação. Estas restrições iniciais podem ser aplicadas sobre o vetor prioridade.

Desta forma, pode-se restringir a instalação do medidor em um determinado nó do SD estabelecendo, na posição específica do vetor prioridade correspondente a este nó, um valor superior às demais variáveis. Assim, se houver outra solução factível que não englobe a variável penalizada, o algoritmo fornecerá a solução ótima impedindo a instalação do medidor naquele nó.

Também pode ocorrer uma situação em que um nó já possui um medidor instalado e deseja-se priorizar a solução ótima para a alocação deste medidor. Neste caso, deverá ser associado um valor menor que as demais variáveis para a posição correspondente ao nó monitorado no vetor prioridade. Isto é válido também para uma situação que se deseje instalar o medidor em um nó específico do SD. Assim, se houver uma solução factível de minimização onde esta variável faça parte, garante-se que o algoritmo priorizará a instalação do medidor no nó especificado.

Neste trabalho, o objetivo é priorizar a instalação dos medidores nos nós mais vulneráveis aos afundamentos tensão, com o intuito de garantir a observabilidade máxima dos eventos no SD. Desta forma, para priorizar os nós com maior área de vulnerabilidade no processo de busca da solução ótima dos medidores, foi atribuído as posições relativas a estes nós um índice menor que nas demais variáveis do vetor prioridade.

Optou-se também, em apresentar os resultados de forma a maximizar a intersecção dos conjuntos de soluções para os diferentes limiares. Assim, caso seja necessário aumentar o número de medidores instalados para uma maior observabilidade, ou até mesmo para outras funções, como, por exemplo, uma localização mais precisa das faltas sobre o SD, há a possibilidade de acrescentar os medidores sem a necessidade de realocar os já instalados.

Assim sendo, torna-se viável maximizar a capacidade de monitoração deste distúrbio e se contrapor às dificuldades encontradas no registro histórico e atual do desempenho do sistema, que dificultam a definição e avaliação de indicadores específicos para este fenômeno que tanto afeta a QEE. 


\subsubsection{Alocação Ótima no SD de 13 Nós}

Como exposto na metodologia apresentada no capítulo 4, inicialmente, para cada matriz de afundamentos de tensão é necessário gerar uma MO para cada limiar de tensão préestabelecido. Em seguida, para analisar simultaneamente a ocorrência de qualquer tipo de curto-circuito é proposta a intersecção das MOs, utilizando um operador lógico AND (\&), conforme a formulação matemática exibida na subseção 4.1.2.

Posteriormente, para cada limiar de tensão é realizada a análise da vulnerabilidade simultânea para todos os tipos de curtos-circuitos passíveis de ocorrência, com a finalidade de obter a prioridade da instalação dos medidores que irá auxiliar na escolha entre as soluções a serem obtidas, de forma a priorizar a alocação dos medidores nos barramentos que possuírem maior observabilidade.

O gráfico de barras da Figura 71 ilustra a vulnerabilidade de todos os nós do SD de 13 nós quando analisados os limiares de tensão $(0,9 ; 0,5 ; 0,3$ e 0,1 p.u.). Já a Tabela 25 mostra a prioridade de instalação dos medidores conforme o limiar escolhido.

Figura 71 - Vulnerabilidade aos afundamentos de tensão do SD de 13 nós para os limiares $\leq 0,9$ p.u.; $\leq 0,5$ p.u.; $\leq 0,3$ p.u.; e $\leq 0,1$ p.u..

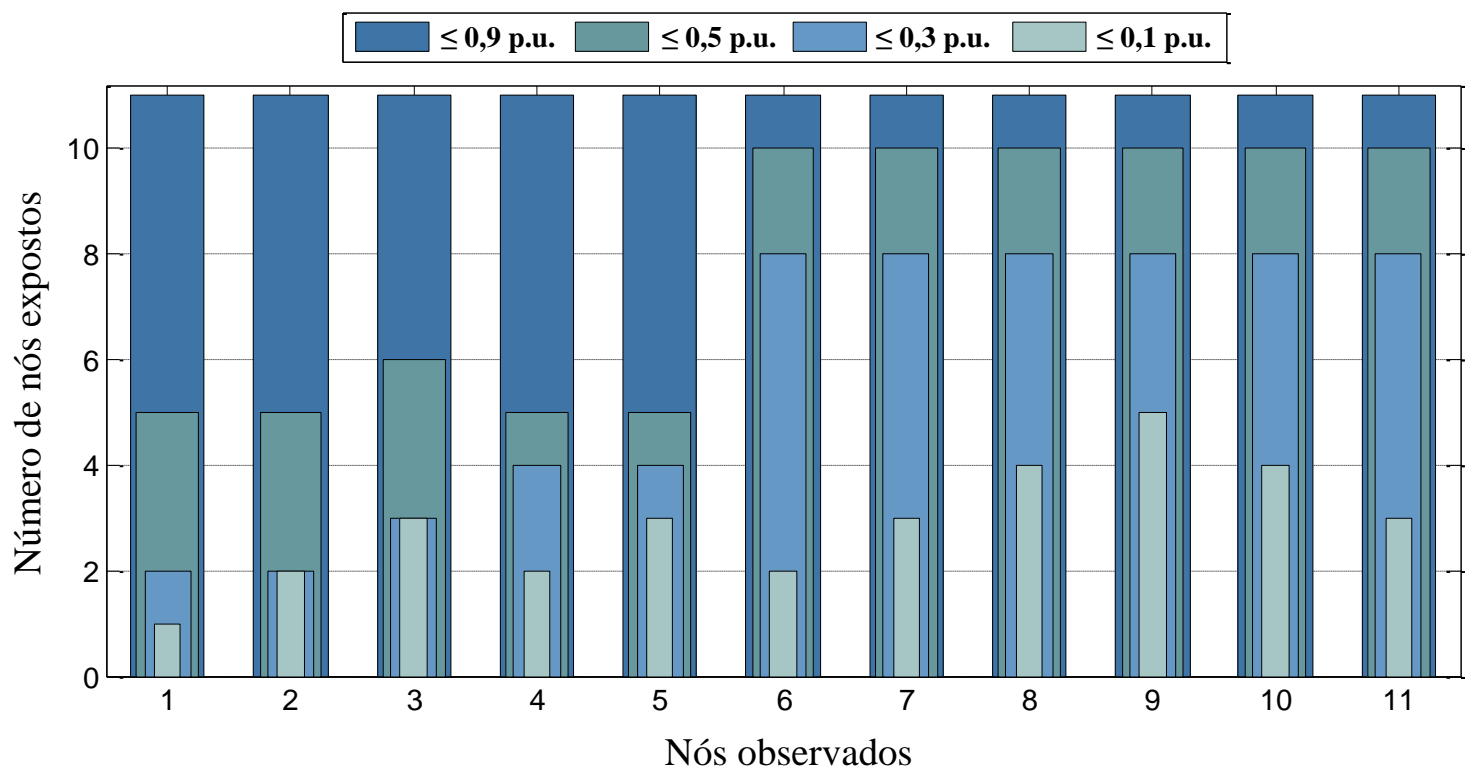

$\mathrm{Na}$ Figura 71, percebe-se que todos os nós estão igualmente vulneráveis aos afundamentos de tensão quando analisado o limiar $\leq 0,9$ p.u.. Assim, todos os nós têm a mesma prioridade de alocação dos medidores, conforme a Tabela 25. Para o limiar menor ou igual a 0,1 p.u., o nó mais vulnerável foi o nó 9 (nove), portanto, à posição específica deste nó 
foi atribuído um índice menor que aos demais elementos do vetor prioridade, e assim sucessivamente, como mostra a Tabela 25.

Tabela 25 - Prioridade de instalação dos medidores no SD de 13 nós para os limiares $\leq$ 0,9 p.u.; $\leq 0,5$ p.u.; $\leq 0,3$ p.u.; e $\leq 0,1$ p.u..

\begin{tabular}{|c|c|c|c|c|c|c|c|c|c|c|c|}
\hline Nós & (1) & (2) & (3) & (4) & (5) & (6) & (7) & (8) & (9) & (10) & (11) \\
\hline$P^{0,9}=$ & {$[1$} & 1 & 1 & 1 & 1 & 1 & 1 & 1 & 1 & 1 & $1]^{t}$ \\
\hline$P^{0,5}=$ & {$[3$} & 3 & 2 & 3 & 3 & 1 & 1 & 1 & 1 & 1 & $1]^{t}$ \\
\hline$P^{0,3}=$ & {$[4$} & 4 & 3 & 2 & 2 & 1 & 1 & 1 & 1 & 1 & $1]^{t}$ \\
\hline$P^{0,1}=$ & {$[5$} & 4 & 3 & 4 & 3 & 4 & 3 & 2 & 1 & 2 & $3]^{t}$ \\
\hline
\end{tabular}

A próxima etapa, antes da execução do algoritmo BB, é realizar a redução das MOs geradas para cada limiar de tensão. O propósito desta redução é diminuir a complexidade computacional e pré-determinar outras possíveis soluções sem que haja a necessidade de executar o algoritmo exaustivamente na busca de novas soluções.

Finalmente, o algoritmo BB é executado uma única vez para cada limiar de tensão $(\tau)$, compreendidos entre 0,1 e 0,9 p.u.. Na Tabela 26 é apresentada uma das possíveis soluções para cada limiar analisado no SD de 13 nós. Os resultados são exibidos seguindo a ordem prioritária de instalação dos medidores, da maior para a menor observabilidade dos afundamentos de tensão. Além disso, é informada ainda a dimensão da $\mathrm{MO}_{\text {Red }}$, o número total de soluções possíveis, o número de iterações e o tempo de simulação do software MATLAB ${ }^{\circledR}$, utilizando um microcomputador Dell XPS 8700 com processador Core I7 de 3,6 GHz e sistema operacional Windows 8.1, para cada limiar avaliado.

Tabela 26 - Resultado da alocação ótima no SD de 13 nós conforme a prioridade de instalação dos medidores.

\begin{tabular}{|c|c|c|c|c|c|c|}
\hline \hline $\begin{array}{c}\boldsymbol{\tau} \\
(\mathbf{p . u .})\end{array}$ & $\begin{array}{c}\text { Dimensão da } \\
\text { MO }_{\text {Red }}(\boldsymbol{m x n})\end{array}$ & $\begin{array}{c}\mathbf{N}^{\mathbf{o}} \text { de } \\
\text { medidores }\end{array}$ & $\begin{array}{c}\text { Nós para } \\
\text { alocação }\end{array}$ & $\begin{array}{c}\text { Número de } \\
\text { soluções }\end{array}$ & $\begin{array}{c}\text { Número de } \\
\text { iterações }\end{array}$ & $\begin{array}{c}\text { Tempo } \\
\text { simulação }\end{array}$ \\
\hline \hline $\mathbf{0 , 9}$ & $1 \times 11$ & 1 & $\{3\}$ & 11 & 1 & $0,2656 \mathrm{~s}$ \\
$\mathbf{0 , 8}$ & $2 \times 11$ & 1 & $\{3\}$ & 1 & 1 & $0,25 \mathrm{~s}$ \\
$\mathbf{0 , 7}$ & $4 \times 11$ & 3 & $\{9,3,5\}$ & 12 & 3 & $0,2344 \mathrm{~s}$ \\
$\mathbf{0 , 6}$ & $6 x 11$ & 3 & $\{9,3,5\}$ & 6 & 4 & $0,2344 \mathrm{~s}$ \\
$\mathbf{0 , 5}$ & $3 \times 11$ & 2 & $\{9,3\}$ & 6 & 2 & $0,2813 \mathrm{~s}$ \\
$\mathbf{0 , 4}$ & $4 x 11$ & 3 & $\{9,3,5\}$ & 12 & 3 & $0,2344 \mathrm{~s}$ \\
$\mathbf{0 , 3}$ & $4 x 11$ & 3 & $\{9,3,5\}$ & 12 & 3 & $0,2344 \mathrm{~s}$ \\
$\mathbf{0 , 2}$ & $7 x 11$ & 4 & $\{9,7,3,5\}$ & 6 & 5 & $0,25 \mathrm{~s}$ \\
$\mathbf{0 , 1}$ & $10 x 11$ & 5 & $\{9,3,5,7,11\}$ & 1 & 6 & $0,2813 \mathrm{~s}$ \\
\hline
\end{tabular}


Como já comentado, as características das faltas bifásicas FF diferem de todos os outros tipos de faltas, pois as tensões remanescentes registradas na ocorrência deste tipo de falta são maiores ou iguais a 0,5 p.u.. Assim, do limiar de 0,9 a 0,6 p.u., tem-se a observabilidade para todos os tipos de falta, à partir do limiar de 0,5 p.u., desconsideram-se as MOs decorrentes de curtos-circuitos FF. Logo, é requerido um maior número de medidores para o limiar de 0,6 p.u. do que para o limiar de 0,5 p.u., como evidenciado na Tabela 26.

Cabe comentar, que a escolha da solução para um dado limiar, não implica, necessariamente, que o medidor deva ser parametrizado (ajustado) com este limiar. Mesmo que na prática seja definido um limiar superior ao escolhido, a instalação de mais medidores é conveniente, pois assim a redundância das medidas será maior, e, consequentemente a confiabilidade da monitoração também irá aumentar.

Além disso, caso não houver recursos imediatos para a instalação simultânea de todos os medidores, conforme o conjunto de soluções apresentado na Tabela 26, basta seguir a ordem prioritária que foi definida pelo estudo da vulnerabilidade do SD. Desta forma, alocando-se os medidores sequencialmente, da esquerda para a direita, um número maior de eventos será monitorado, mesmo que a observabilidade dos afundamentos não seja completa.

\subsubsection{Alocação Ótima no SD de 34 Nós}

A fim de demonstrar a eficiência dos resultados obtidos através da metodologia apresentada no capítulo 4, serão comparados os resultados obtidos no sistema de 34 nós utilizando os métodos convencionais para a alocação ótima dos medidores e a metodologia proposta.

Para ambas as metodologias, o primeiro passo é obter a partir das seis matrizes de afundamento de tensão (Figura 43; Figura 44; Figura 47; Figura 48; Figura 50 e Figura 51) as MOs para cada limiar de tensão, totalizando, portanto, 54 MOs.

Nos métodos usualmente utilizados na literatura consultada, o algoritmo é executado para cada uma dessas 54 MOs, obtendo-se à cada execução, uma resposta diferente, em função das inúmeras soluções possíveis. Portanto, obter um arranjo único de medidores que contemple todos os tipos de falta torna-se uma tarefa árdua, sendo, na maioria das vezes, necessário executar o algoritmo exaustivamente para se obter uma resposta que seja compatível à todos os tipos de falta.

Para determinar a alocação pelo método convencional, foi definido o vetor prioridade utilizando os dados de vulnerabilidade da Figura 66. Assim, as posições de maior 
vulnerabilidade, relativas aos nós 27 e 28 , receberam um valor menor que as demais variáveis no vetor $P$. Sendo que, quanto menor o grau de vulnerabilidade frente aos afundamentos, maior foi o índice atribuído aos elementos do vetor $P$, como mostra a Figura 72.

Figura 72 - Vetor prioridade transposto para o SD de 34 nós.

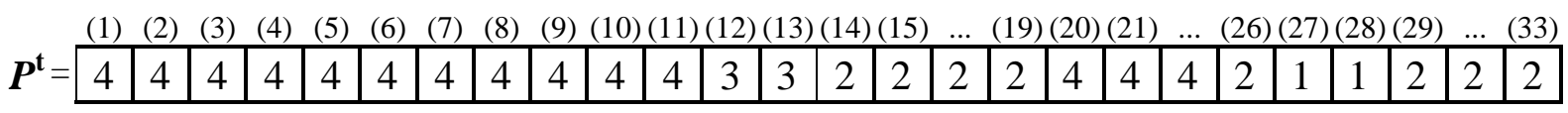

Após a penalização do vetor prioridade foi determinada para cada matriz de afundamento de tensão, o número ótimo de medidores para cada limiar de tensão, conforme representado na Tabela 27.

Tabela 27 - Número de medidores necessários para monitorar os diferentes tipos de falta para cada limiar analisado no SD de 34 nós.

\begin{tabular}{c|c|c|c|c|c|c|c|c|c}
\hline \hline \multirow{2}{*}{$\begin{array}{c}\text { Matrizes de } \\
\text { afundamentos }\end{array}$} & \multicolumn{10}{|c|}{$\begin{array}{c}0,9 \\
\text { p.u. }\end{array}$} & $\begin{array}{c}0,8 \\
\text { p.u. }\end{array}$ & $\begin{array}{c}0,7 \\
\text { p.u. }\end{array}$ & $\begin{array}{c}0,6 \\
\text { p.u. }\end{array}$ & $\begin{array}{c}0,5 \\
\text { p.u. }\end{array}$ & $\begin{array}{c}0,4 \\
\text { p.u. }\end{array}$ & $\begin{array}{c}0,3 \\
\text { p.u. }\end{array}$ & $\begin{array}{c}0,2 \\
\text { p.u. }\end{array}$ & $\begin{array}{c}0,1 \\
\text { p.u. }\end{array}$ \\
\hline \hline FFF & 1 & 1 & 1 & 1 & 1 & 1 & 2 & 2 & 5 \\
\hline FT $($ fase $A)$ & 1 & 1 & 1 & 1 & 1 & 1 & 1 & 2 & 3 \\
\hline FF (fase $B)$ & 1 & 1 & 1 & 1 & - & - & - & - & - \\
\hline FF ( fase $C)$ & 1 & 1 & 1 & 1 & - & - & - & - & - \\
\hline FFT $($ fase $B)$ & 1 & 1 & 1 & 1 & 1 & 1 & 1 & 2 & 3 \\
\hline FFT $($ fase $C$ ) & 1 & 1 & 1 & 1 & 1 & 1 & 2 & 2 & 5 \\
\hline
\end{tabular}

Em seguida, foi necessário determinar entre as possíveis soluções um arranjo único de equipamentos de medição para monitorar qualquer tipo de curto-circuito conforme o limiar desejado, sendo, muitas vezes, preciso penalizar o vetor $P$ para obter uma solução única para todos os tipos de falta conforme os resultados demonstrados na Tabela 28.

Tabela 28 - Local de instalação e número de medidores necessários para monitorar qualquer tipo de falta no SD de 34 nós, conforme o limiar desejado.

\begin{tabular}{|c|c|c|}
\hline \hline $\boldsymbol{\tau}$ (p.u.) & Nós de instalação & $\mathbf{N}^{\mathbf{o}}$ de medidores \\
\hline \hline $\mathbf{0 , 9}$ & $\{28\}$ & 1 \\
$\mathbf{0 , 8}$ & $\{28\}$ & 1 \\
$\mathbf{0 , 7}$ & $\{28\}$ & 1 \\
$\mathbf{0 , 6}$ & $\{28\}$ & 1 \\
$\mathbf{0 , 5}$ & $\{28\}$ & 1 \\
$\mathbf{0 , 4}$ & $\{28\}$ & 1 \\
$\mathbf{0 , 3}$ & $\{23,28\}$ & 2 \\
$\mathbf{0 , 2}$ & $\{23,28\}$ & 2 \\
$\mathbf{0 , 1}$ & $\{20,23,25,28,32\}$ & 5 \\
\hline
\end{tabular}


Utilizando a metodologia proposta neste trabalho, o algoritmo de otimização foi executado apenas uma vez, obtendo-se as respostas compatíveis para todos os tipos de falta, seguindo a ordem prioritária de instalação dos medidores, conforme os dados apresentados na Tabela 29.

Tabela 29 - Resultado da alocação ótima no SD de 34 nós, para monitorar qualquer tipo de falta, conforme a prioridade de instalação dos medidores.

\begin{tabular}{|c|c|c|c|c|c|c|}
\hline \hline $\begin{array}{c}\boldsymbol{\tau} \\
\text { (p.u.) }\end{array}$ & $\begin{array}{c}\text { Dimensão da } \\
\text { MO }_{\text {Red }} \text { (mxn) }\end{array}$ & $\begin{array}{c}\mathbf{N}^{\mathbf{0}} \text { de } \\
\text { medidores }\end{array}$ & Nós para alocação & $\begin{array}{c}\mathbf{N}^{\mathbf{0}} \text { de } \\
\text { soluções }\end{array}$ & $\begin{array}{c}\mathbf{N}^{\mathbf{0}} \text { de } \\
\text { iterações }\end{array}$ & $\begin{array}{c}\text { Tempo de } \\
\text { execução }\end{array}$ \\
\hline $\mathbf{0 , 9}$ & $3 \times 33$ & 1 & $\{28\}$ & 29 & 1 & $0,2344 \mathrm{~s}$ \\
$\mathbf{0 , 8}$ & $4 \times 33$ & 1 & $\{28\}$ & 16 & 1 & $0,25 \mathrm{~s}$ \\
$\mathbf{0 , 7}$ & $7 x 33$ & 1 & $\{28\}$ & 2 & 1 & $0,2344 \mathrm{~s}$ \\
$\mathbf{0 , 6}$ & $9 x 33$ & 1 & $\{28\}$ & 2 & 1 & $0,2344 \mathrm{~s}$ \\
$\mathbf{0 , 5}$ & $6 x 33$ & 1 & $\{28\}$ & 2 & 1 & $0,25 \mathrm{~s}$ \\
$\mathbf{0 , 4}$ & $8 \times 33$ & 1 & $\{28\}$ & 2 & 1 & $0,2344 \mathrm{~s}$ \\
$\mathbf{0 , 3}$ & $10 x 33$ & 2 & $\{28,23\}$ & 4 & 5 & $0,2344 \mathrm{~s}$ \\
$\mathbf{0 , 2}$ & $11 \times 33$ & 2 & $\{28,23\}$ & 4 & 5 & $0,25 \mathrm{~s}$ \\
$\mathbf{0 , 1}$ & $13 \times 33$ & 5 & $\{28,14,25,23,20\}$ & 48 & 10 & $0,25 \mathrm{~s}$ \\
\hline
\end{tabular}

Comparando as respostas obtidas pelo método convencional (Tabela 28) e pela metodologia proposta (Tabela 29), percebe-se que apenas houve divergência na resposta obtida para o limiar de 0,1 p.u.. Entretanto, há 48 possíveis soluções de instalação dos medidores para este limiar, sendo que a solução apresentada pode ser substituída por qualquer outra alocação que tenha a mesma observabilidade.

Assim, consultando o vetor de igualdade, podem ser obtidas as seguintes soluções: $S_{0,1}=\left\{x_{1}, x_{2}, x_{3}, x_{4}, x_{5}\right\}$, tal que $x_{1} \in X_{1}=\{27,28\}, x_{2} \in X_{2}=\{14,15,16,17,18,19,26,29$, $30,31,32,33\}, x_{3} \in X_{3}=\{25\}, x_{4} \in X_{4}=\{22,23\}$, e $x_{5} \in X_{5}=\{20\}$.

Portanto, a resposta apresentada na Tabela 28 faz parte do conjunto de soluções possíveis, comprovando-se a eficiência da metodologia proposta.

Desta forma, é possível obter várias soluções sem executar o algoritmo inúmeras vezes e sem a necessidade de exercer uma tarefa exaustiva para determinar um arranjo de medidores que observe qualquer situação de falta no SD.

\subsubsection{Alocação Ótima no SD de 37 Nós}

Para o SD de 37 nós as respostas ótimas estão sintetizadas na Tabela 30, indicando os nós onde os medidores devem ser instalados, bem como o número de medidores necessários 
para monitorar cada limiar de tensão. Da mesma forma como foram apresentados os resultados de alocação para os demais SDs, os nós para alocação dos medidores são informados conforme a maior observabilidade dos afundamentos. Assim a alocação pode ser realizada conforme o limiar de tensão desejado e os recursos disponíveis para aquisição dos medidores que a distribuidora de energia poderá disponibilizar.

Tabela 30 - Resultado da alocação ótima no SD de 37 nós conforme a prioridade de instalação dos medidores.

\begin{tabular}{|c|c|c|}
\hline \hline $\begin{array}{c}\boldsymbol{\tau} \\
\text { (p.u.) }\end{array}$ & $\begin{array}{c}\mathbf{N}^{\mathbf{0}} \text { de } \\
\text { medidores }\end{array}$ & Nós para alocação \\
\hline \hline $\mathbf{0 , 9}$ & 1 & $\{32\}$ \\
$\mathbf{0 , 8}$ & 2 & $\{32,23\}$ \\
$\mathbf{0 , 7}$ & 4 & $\{11,32,23,14\}$ \\
$\mathbf{0 , 6}$ & 7 & $\{11,34,32,23,29,19,14\}$ \\
$\mathbf{0 , 5}$ & 4 & $\{11,32,23,14\}$ \\
$\mathbf{0 , 4}$ & 5 & $\{11,34,32,23,29,29,21,19\}$ \\
$\mathbf{0 , 3}$ & 8 & $\{11,34,32,30,23,29,21,19,14,25\}$ \\
$\mathbf{0 , 2}$ & 10 & $\{11,34,31,32,30,28,23,29,21,19,14,25\}$ \\
$\mathbf{0 , 1}$ & 12 &
\end{tabular}

A Tabela 31 apresenta outras possíveis soluções para alocação dos medidores no SD de 37 nós para os limiares de 0,9;0,8;0,7;0,6 e 0,4 p.u., sendo notável que, para a maioria dos limiares de tensão não há outra opção que substitua a instalação do medidor no nó 32.

Tabela 31 - Outras possíveis soluções para alocação de medidores no SD de 37 nós para os limiares de 0,$9 ; 0,8 ; 0,7 ; 0,6$ e 0,4 p.u..

\begin{tabular}{|c|c|c|c|c|}
\hline \hline 0,9 p.u. & $\mathbf{0 , 8}$ p.u. & 0,7 p.u. & $\mathbf{0 , 6}$ p.u. & 0,4 p.u. \\
\hline$\{11\}$ & $\{32,17\}$ & $\{8,32,23,25\}$ & $\{10,34,32,23,26,19,14\}$ & $\{33,32,23,29,14\}$ \\
$\{34\}$ & $\{32,20\}$ & $\{9,32,22,14\}$ & $\{9,34,32,23,29,19,14\}$ & $\{34,32,22,27,25\}$ \\
$\{31\}$ & $\{32,21\}$ & $\{33,32,23,25\}$ & $\{11,34,32,22,29,19,14\}$ & $\{35,32,23,29,14\}$ \\
$\{28\}$ & $\{32,22\}$ & $\{10,32,24,14\}$ & $\{11,34,32,24,27,19,13\}$ & $\{33,32,23,29,25\}$ \\
$\{29\}$ & $\{32,24\}$ & $\{36,32,23,13\}$ & $\{12,34,32,23,29,19,14\}$ & $\{34,32,24,29,13\}$ \\
$\{30\}$ & - & $\{12,32,23,14\}$ & $\{9,34,32,22,28,19,25\}$ & $\{34,32,23,27,13\}$ \\
$\{12\}$ & - & $\{11,32,22,13\}$ & $\{36,34,32,23,29,19,14\}$ & $\{35,32,23,29,14\}$ \\
$\{36\}$ & - & $\{34,32,23,14\}$ & $\{11,34,32,23,26,19,14\}$ & $\{34,32,22,28,25\}$ \\
$\{9\}$ & - & $\{35,32,24,25\}$ & $\{12,34,32,24,29,19,25\}$ & $\{33,32,23,27,14\}$ \\
\hline
\end{tabular}

Na Tabela 32 são informados os números de possíveis soluções, a dimensão da $\mathrm{MO}_{\mathrm{Red}}$, o número de iterações e o tempo de simulação necessário para obter a solução de alocação para cada limiar no SD de 37 nós. 
Tabela 32 - Número de possíveis soluções, dimensão da $\mathrm{MO}_{\text {Red }}$ e número de iterações necessárias para obter a solução de alocação para cada limiar no SD de 37 nós.

\begin{tabular}{|c|c|c|c|c|}
\hline \hline $\begin{array}{c}\boldsymbol{\tau} \\
\text { (p.u.) }\end{array}$ & $\begin{array}{c}\text { Número de } \\
\text { soluções }\end{array}$ & $\begin{array}{c}\text { Dimensão da } \\
\text { MO }_{\text {Red }}(\boldsymbol{m} \boldsymbol{x} \boldsymbol{n})\end{array}$ & $\begin{array}{c}\text { Número de } \\
\text { iterações }\end{array}$ & $\begin{array}{c}\text { Tempo de } \\
\text { execução }\end{array}$ \\
\hline $\mathbf{0 , 9}$ & 21 & $3 \times 36$ & 1 & $0,2344 \mathrm{~s}$ \\
$\mathbf{0 , 8}$ & 6 & $9 \times 36$ & 4 & $0,2344 \mathrm{~s}$ \\
$\mathbf{0 , 7}$ & 81 & $13 \times 36$ & 10 & $0,2344 \mathrm{~s}$ \\
$\mathbf{0 , 6}$ & 180 & $18 \times 36$ & 13 & $0,2813 \mathrm{~s}$ \\
$\mathbf{0 , 5}$ & 81 & $14 \times 36$ & 11 & $0,25 \mathrm{~s}$ \\
$\mathbf{0 , 4}$ & 108 & $16 \times 36$ & 13 & $0,2344 \mathrm{~s}$ \\
$\mathbf{0 , 3}$ & 270 & $19 x 36$ & 14 & $0,2813 \mathrm{~s}$ \\
$\mathbf{0 , 2}$ & 24 & $26 x 36$ & 21 & $0,2344 \mathrm{~s}$ \\
$\mathbf{0 , 1}$ & 3 & $30 x 36$ & 24 & $0,2656 \mathrm{~s}$ \\
\hline
\end{tabular}

Considerando a resposta ótima obtida para o limiar de 0,5 p.u., $\{11,32,23,14\}$, constata-se pela Figura 73 que se os medidores estivessem instalados nestes nós e ocorresse um curto-circuito no nó 1 (coluna um), os 4 medidores instalados seriam sensibilizados pelo afundamento de tensão, criando assim uma redundância máxima sobre as variáveis em análise.

Figura 73 - Visualização gráfica da MO $_{\text {Red }}$ gerada para o SD de 37 nós quando fixado um limiar $\leq \mathbf{0 , 5}$ p.u..

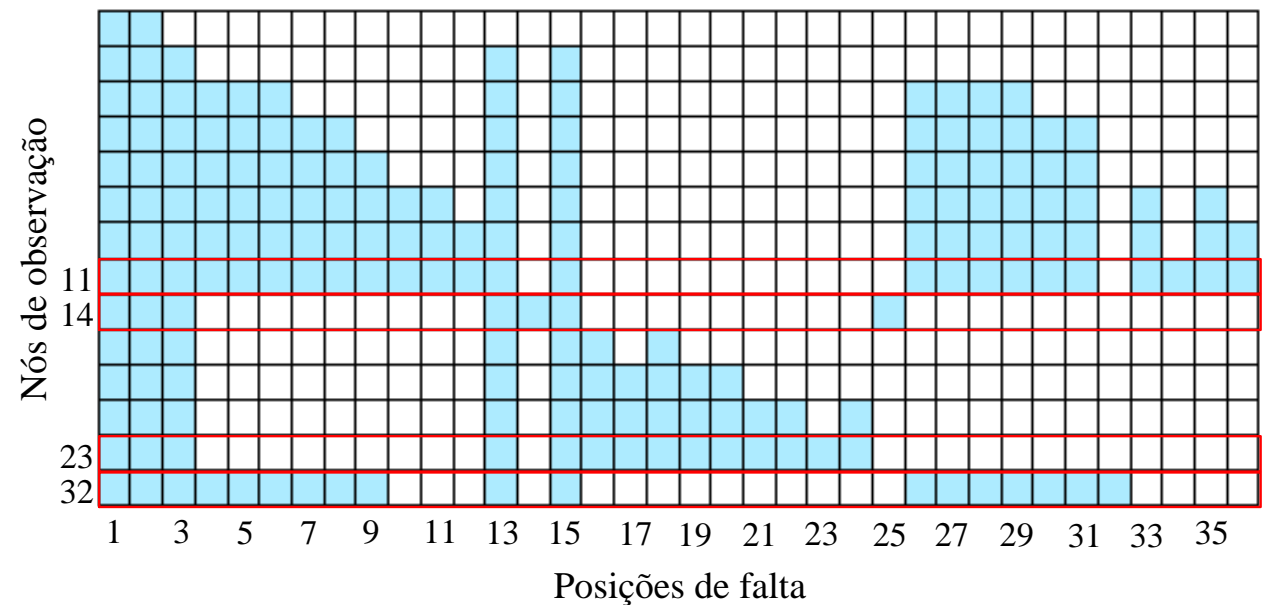

Vale a pena mencionar que certas redundâncias nas várias medidas realizadas são desejáveis, já que com isso ocorrerá um aumento na confiabilidade do sistema de monitoramento. Uma maneira direta de verificar a redundância entre as medidas é através do resultado do vetor de redundância, pois cada elemento deste vetor contabiliza o número de medidores capazes de monitorar o defeito correspondente a sua posição. Desta forma, para a $\mathrm{MO}_{\text {Red }}$ da Figura 73, têm-se as redundâncias para cada posição de falta conforme a Figura 74. 
Figura 74 - Redundância para cada nó do SD de 37 nós para a solução $\leq$ 0,5 p.u.

\begin{tabular}{|l|l|l|l|l|l|l|l|c|c|c|c|c|c|c|c|c|c|c|c|c|c|c|c|}
1 & 2 & 3 & 4 & $\ldots$ & 9 & 10 & 11 & 12 & 13 & 14 & 15 & 16 & $\ldots$ & 25 & 26 & $\ldots$ & 31 & 32 & $\ldots$ & 36 \\
\hline 4 & 4 & 4 & 2 & 2 & 2 & 1 & 1 & 1 & 4 & 1 & 4 & 1 & 1 & 1 & 2 & 2 & 2 & 1 & 1 & 1 \\
\hline
\end{tabular}

Ainda analisando a $\mathrm{MO}_{\text {Red }}$ da Figura 73, percebe-se que se o medidor for alocado no nó de observação 11 (linha 11), o mesmo poderá ser sensibilizado pela ocorrência de faltas em 24 nós do SD, o nó 14 é capaz de visualizar a ocorrência de faltas em 7 nós, o nó 23 visualiza a ocorrência de falta para 14 nós, e o nó 32 será sensibilizado pela ocorrência de qualquer tipo de falta em 18 nós do SD. Logo, comprova-se a prioridade sequencial de instalação dos medidores conforme apresentada na Tabela 30, viabilizando a instalação gradual dos equipamentos conforme a maior observabilidade dos eventos.

\subsubsection{Alocação Ótima no SD de 123 Nós}

Como nas bibliografias consultadas não foi possível estabelecer um consenso de qual limiar deve ser definido, na Tabela 33 são apresentadas as soluções ótimas de alocação no SD de 123 nós para todos os limiares inteiros, compreendidos entre 0,1 e 0,9 p.u., que caracterizam os afundamentos de tensão.

Tabela 33 - Resultado da alocação ótima no SD de 123 nós conforme a prioridade de instalação dos medidores.

\begin{tabular}{|c|c|c|}
\hline \hline $\begin{array}{c}\boldsymbol{\tau} \\
\text { (p.u.) }\end{array}$ & $\begin{array}{c}\mathbf{N}^{\mathbf{0}} \text { de } \\
\text { medidores }\end{array}$ & Nós para alocação \\
\hline \hline $\mathbf{0 , 9}$ & 1 & $\{118\}$ \\
$\mathbf{0 , 8}$ & 1 & $\{118\}$ \\
$\mathbf{0 , 7}$ & 6 & $\{81,116,118,41,29,23\}$ \\
$\mathbf{0 , 6}$ & 12 & $\{99,81,116,118,58,41,29,23\}$ \\
$\mathbf{0 , 5}$ & 4 & $\{105,99,15,81,116,118,58,41,62,33,29,23\}$ \\
$\mathbf{0 , 4}$ & 8 & $\{105,99,19,75,81,89,78,85,116,58,118,41,48,62,68$, \\
$\mathbf{0 , 3}$ & 12 & $44,33,29,23,24,25\}$ \\
$\mathbf{0 , 2}$ & 21 & $\{105,99,19,15,75,78,81,89,85,116,58,48,51,118,71,41$, \\
& & $62,65,70,46,68,69,45,33,34,44,29,30,23,26,24,25\}$ \\
$\mathbf{0 , 1}$ & 32 &
\end{tabular}

Caso haja a indisponibilidade, ou um maior custo associado à instalação do medidor em um determinado nó, para alocar os medidores conforme os arranjos apresentados na Tabela 33, há ainda a possibilidade de explorar o espaço de possíveis soluções avaliando o 
vetor de igualdade. Para exemplificar, temos que a solução fornecida para o limiar $\leq 0,7$ p.u. pode ser substituída por qualquer outra alocação que tenha a mesma observabilidade, ou seja, $S_{0,7}=\left\{x_{1}, x_{2}, x_{3}, x_{4}, x_{5}, x_{6}\right\}$, tal que $x_{1}$ apresenta três soluções possíveis $\in X_{1}=\{80,81,82\}, x_{2}$ apresenta quatro soluções possíveis $\in X_{2}=\{113,144,115,116\}$, $\mathrm{x}_{3}$ possui apenas uma solução $\in X_{3}=\{118\}, X_{4}$ apresenta trinta e quatro possíveis soluções $\in X_{4}=\{35,36$ a $64,69,70,71$, $72\}, \mathrm{x}_{5}$ possui quatro soluções $\in \mathrm{X}_{5}=\{27,28,29,30\}$ e $\mathrm{x}_{6}$ apresenta também quatro possíveis soluções para a instalação dos medidores $\in X_{6}=\{21,22,23,24\}$. Portanto, realizando a combinação de possíveis soluções para este limiar, obtém-se 6.528 possibilidades de instalação dos medidores, obtidas apenas com a análise do vetor igualdade.

Assim, como não é necessário executar o algoritmo exaustivamente para obter cada uma das soluções possíveis, o custo computacional torna-se bem menor, principalmente quando o número de soluções possíveis é elevado, como, por exemplo, para o limiar $\leq 0,2$ exibido na Tabela 34.

Tabela 34 - Número de possíveis soluções e o número de iterações necessárias para obter a solução ótima utilizando a $\mathrm{MO}_{\text {Res }}$ e a MO $\mathrm{Med}_{\text {Re }}$

\begin{tabular}{|c|c|c|c|c|}
\hline \hline \multirow{2}{*}{$\boldsymbol{\tau}$} & \multirow{2}{*}{$\begin{array}{c}\text { Número de } \\
\text { soluções }\end{array}$} & \multicolumn{2}{|c|}{ Número de iterações } & \multirow{2}{*}{$\begin{array}{c}\text { Dimensão da } \\
\text { MO }_{\text {Red }} \text { (mxn) }\end{array}$} \\
\cline { 3 - 4 } & M.u.) & MO $_{\text {Res }}$ & MO $_{\text {Red }}$ & \\
\hline $\mathbf{0 , 9}$ & 1 & 1 & 1 & $6 \times 118$ \\
$\mathbf{0 , 8}$ & 1 & 1 & 1 & $10 \times 118$ \\
$\mathbf{0 , 7}$ & 6.528 & 113 & 16 & $17 \times 118$ \\
$\mathbf{0 , 6}$ & 14.598 .144 & 117 & 33 & $34 \times 118$ \\
$\mathbf{0 , 5}$ & 204 & 113 & 14 & $15 \times 118$ \\
$\mathbf{0 , 4}$ & 362.880 & 113 & 22 & $24 \times 118$ \\
$\mathbf{0 , 3}$ & 45.619 .200 & 112 & 34 & $37 \times 118$ \\
$\mathbf{0 , 2}$ & 2.799 .360 .000 & 117 & 50 & $51 \times 118$ \\
$\mathbf{0 , 1}$ & 8.192 & 117 & 88 & $89 \times 118$ \\
\hline
\end{tabular}

Também é demonstrado na Tabela 34 a dimensão e a vantagem da utilização $\mathrm{MO}_{\text {red }}$ $(m \mathrm{x} n)$, pois quando comparada com a $\mathrm{MO}_{\text {res }}(n x n)$ a convergência do algoritmo é obtida em um menor número de iterações. Associado a isto, tem se que com o decréscimo da matriz binária, de $n$ para $m$ linhas, menos operações matemáticas são necessárias, como pode ser comprovado realizando-se a análise dimensional da função objetivo do problema conforme a equação (111).

$$
\min f(x)[m x m]=X[m x 1] \cdot P^{t}[1 x m]
$$


Além das vantagens já citadas de realizar o pré-processamento das matrizes binárias, na Tabela 35 é apresentada uma comparação do esforço computacional que seria necessário para se obter a solução ótima para cada $\mathrm{MO}$, e quando utilizado a $\mathrm{MO}_{\text {red }}$ para obter as soluções para qualquer tipo de falta, quando analisado o limiar $\leq 0,7$ p.u.. Pela metodologia convencional, seria necessário executar o algoritmo para cada MO, para, posteriormente, analisar uma única solução compatível para todos os tipos de falta. Ou seja, para cada limiar de tensão, o algoritmo teria que ser executado seis vezes. Pela metodologia proposta, basta executar o algoritmo uma única vez, pois todos os tipos de curtos-circuitos já foram condensados previamente na $\mathrm{MO}_{\text {res. }}$.

Assim, para se obter a mesma solução apresentada na última linha da Tabela 35, pela metodologia convencional seria necessário um maior tempo de execução do algoritmo, bem como o processamento das soluções obtidas para cada tipo de falta. Logo, para fornecer as soluções apresentadas na Tabela 33, seria necessário executar o algoritmo de otimização 54 vezes, o que acarretaria em um esforço computacional bem maior que o obtido.

Tabela 35 - Comparação dos resultados obtidos para cada MO e pela MO Red $_{\text {quando analisado o }}$ limiar $\leq \mathbf{0 , 7}$ p.u..

\begin{tabular}{|c|c|c|c|c|}
\hline MO & $\begin{array}{c}\text { Número de } \\
\text { medidores }\end{array}$ & Nós de alocação & $\begin{array}{c}\text { Número de } \\
\text { iterações }\end{array}$ & $\begin{array}{l}\text { Tempo de } \\
\text { execução (s) }\end{array}$ \\
\hline FFF & 2 & $\{35,118\}$ & 67 & 0,3432 \\
\hline FT $\quad($ fase $A)$ & 2 & $\{35,118\}$ & 67 & 0,3432 \\
\hline $\mathrm{FF} \quad($ fase $B)$ & 6 & $\{21,27,35,80,113,118\}$ & 113 & 0,3588 \\
\hline $\mathrm{FF} \quad$ (fase $C$ ) & 4 & $\{21,35,80,118\}$ & 113 & 0,3588 \\
\hline FFT (fase $B$ ) & 2 & $\{35,118\}$ & 67 & 0,3432 \\
\hline FFT (fase $C$ ) & 2 & $\{35,118\}$ & 67 & 0,3432 \\
\hline MO $_{\text {red }}$ & 6 & $\{21,27,35,80,113,118\}$ & 16 & 0,2964 \\
\hline
\end{tabular}

Portanto, apesar da estratégia apresentada ser relativamente simples, o esforço computacional para se obter múltiplas soluções e o tempo de execução do algoritmo é consideravelmente diminuído, principalmente para SD de grande porte. Além disso, a prioridade de instalação dos medidores possibilita a escolha do melhor arranjo de medidores que atenda aos limites orçamentários das distribuidoras de energia, evidenciando que os nós próximos às fontes geradoras não são locais apropriados para se obter a observabilidade máxima dos distúrbios, contrapondo-se à prática geralmente utilizada pelas distribuidoras de energia de instalar os equipamentos de medição na saída da subestação. 


\subsection{Testes e Validações da Metodologia Proposta via o Software ATP}

Com o objetivo de validar e comparar os resultados obtidos através da metodologia proposta por uma ferramenta computacional consolidada, implementou-se o SD IEEE 34-nós dispondo do software ATP via a interface gráfica do software ATPDraw.

A comparação dos resultados é motivada pela possibilidade de identificar se o método analítico proposto é adequado para a caracterização de VTCDs, e se mantém a estimação dos resultados dentro de limites aceitáveis, mesmo considerando a simplificação na modelagem dos componentes do sistema adotados para agilização dos procedimentos de cálculo e análises.

Para comparar os resultados, em cada situação de curto-circuito simulada em um nó do $\mathrm{SD}$, analisaram-se as magnitudes das tensões remanescentes em todos os outros nós do SD em análise, armazenando todas as tensões, obtidas através do valor RMS resultante dos registros gráficos das formas de onda geradas pelo programa, a fim de compará-los com as magnitudes das tensões resultantes pela aplicação do MPF.

Considerando que as linhas de distribuição raramente são transpostas, e objetivando a análise dos resultados com um sistema mais próximo possível do encontrado na prática, na implementação via o software ATP, considerou-se o sistema assimétrico e com cargas, justamente para comparar a diferença com os resultados obtidos através do MPF, que considera o sistema equilibrado e sem cargas. Destas comparações, foi observada uma divergência entre os resultados, sendo calculado o erro absoluto percentual para cada tipo de falta aplicada.

Sabendo-se que durante a ocorrência de um curto-circuito no SD há vários fatores que influenciam nas características e propagação das VTCDs, além das variáveis de influência já consideradas, como por exemplo, o tipo da falta e a localização da falta, houve ainda a necessidade de analisar o comportamento do SD frente a outras situações aleatórias, dentre as quais considerou-se a impedância de falta, a tensão de pré-falta, e a mudança dos perfis de carregamento do SD.

Diante de tantos fatores que influenciam o comportamento das VTCDs, foi ainda avaliado se o local indicado pela metodologia de alocação dos medidores de QEE se mantém propício para a visualização dos eventos, mesmo considerando as adversidades que possam ocorrer no SD. 


\subsubsection{Comparação dos Resultados Obtidos pelo MPF no SD de 34 Nós}

Ao simular o sistema do IEEE de 34 nós no software ATP via o ATPDraw, para cada situação de falta aplicada, foram realizadas 33 simulações de curtos-circuitos, uma em cada nó do SD. Para cada simulação, foram armazenados os valores RMS das tensões registradas em cada nó do sistema em análise, totalizando, para cada tipo de falta, 1.089 casos por fase.

No diagrama unifilar do SD de 34 nós (Figura 40) nota-se que os nós 20, 24, 25 e 33 estão conectados apenas na fase $B$ do SD. Já os nós 21, 22, 23 e 26 estão conectados na fase A. Pelo fato de existirem trechos monofásicos no SD de 34 nós em análise, há uma grande divergência na comparação dos resultados gerados pelo ATP com os fornecidos pelo MPF.

$\mathrm{Na}$ simulação das faltas FFF foram obtidas as tensões nas três fases do sistema e, posteriormente, foi realizada a agregação das fases, considerando o valor mínimo das tensões obtidas. A Figura 75 ilustra as comparações das tensões remanescentes registradas pelo MPF e pelo ATP durante a ocorrência de faltas FFF.

Figura 75 - Comparação das MTDFs geradas pelo MPF e ATP durante a ocorrência de faltas FFF no SD de 34 nós.
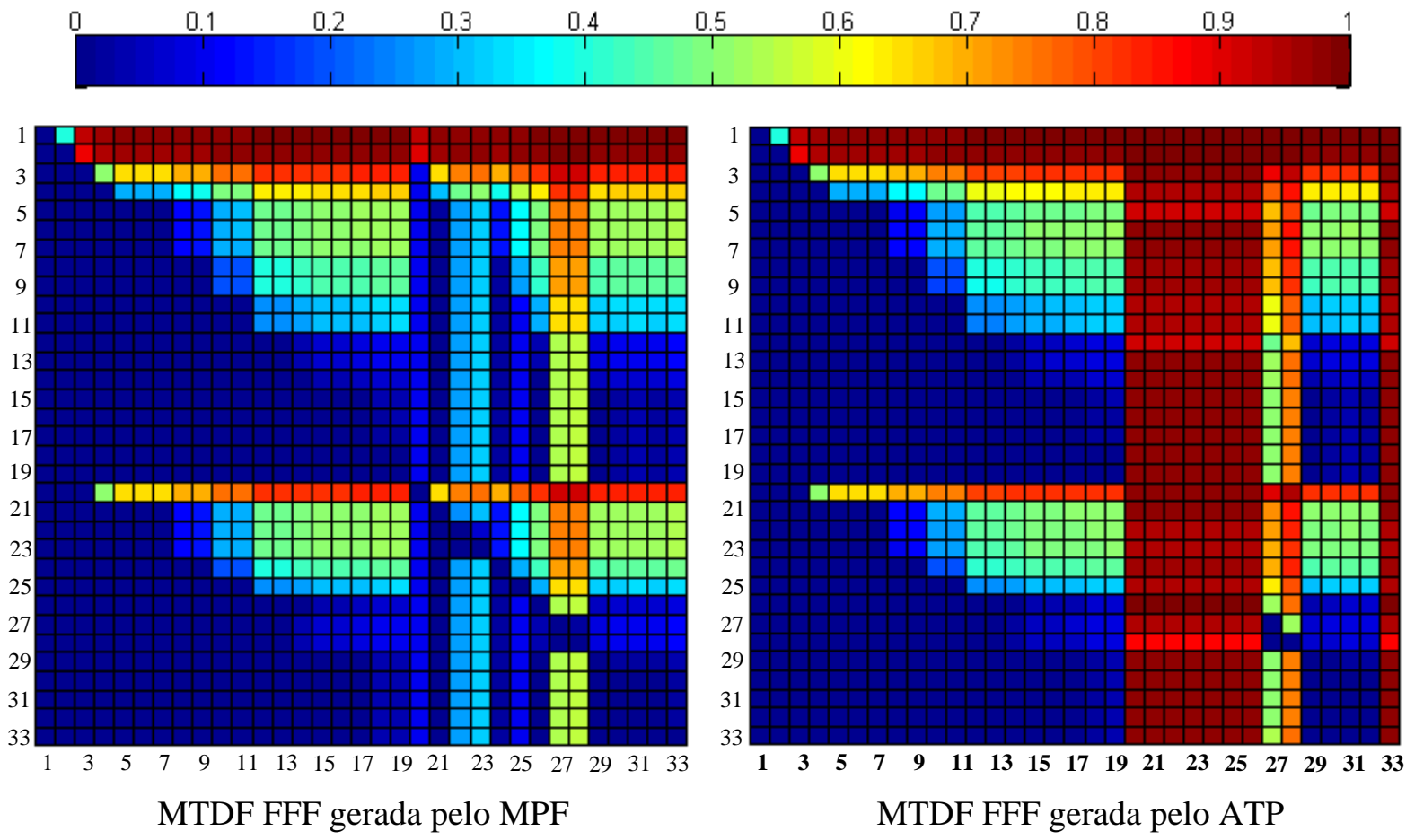

Como pode ser observado nas colunas da Figura 75, pela existência de trechos monofásicos, não é registrada pelo ATP a ocorrência da falta FFF nos nós de 20 a 26 e no nó 33. Portanto, a tensão nas colunas referentes a estes nós é a própria tensão de pré-falta no SD. 
Já pelo MPF pressupõe-se que o sistema é trifásico e, portanto, os resultados são fornecidos considerando as incidências das faltas FFF. Ainda analisando a Figura 75, observa-se que fora os trechos monofásicos há pouca discrepância na comparação das duas MTDFs, sendo as maiores divergências registradas durante o curto-circuito nos nós 27 e 28 (colunas 27 e 28) que estão localizados a jusante do transformador.

Para as faltas FT foram realizadas simulações nas três fases do SD, totalizando 3.267 casos analisados. Posteriormente, foram utilizados os valores das tensões remanescentes que apresentaram os casos mais críticos de afundamentos de tensão a fim de compará-los com o MPF. Assim, mesmo havendo trechos monofásicos correspondentes a apenas uma fase, através da agregação das fases, há a possibilidade de verificar o comportamento do sistema diante da incidência de faltas FT em qualquer fase do SD.

A Figura 76 ilustra as comparações entre a MTDF obtida pelo MPF, que considera as faltas FT aplicadas na fase $A$, idealizando o SD trifásico, e a MTDF gerada pelo ATP através da agregação das três fases. No nó 20 (coluna 20), da MTDF gerada pelo ATP, por exemplo, verifica-se que como este trecho possui apenas a fase $B$, a ocorrência de uma falta neste nó não irá afetar os nós $21,22,23$ e 26 que estão conectados à fase $A$ do SD. Fora estas considerações dos trechos monofásicos, novamente, a maior divergência ocorre na ocorrência de faltas no nó 28 , localizado logo após o transformador.

Figura 76 - Comparação das MTDFs geradas pelo MPF e ATP durante a ocorrência de faltas FT no SD de 34 nós.

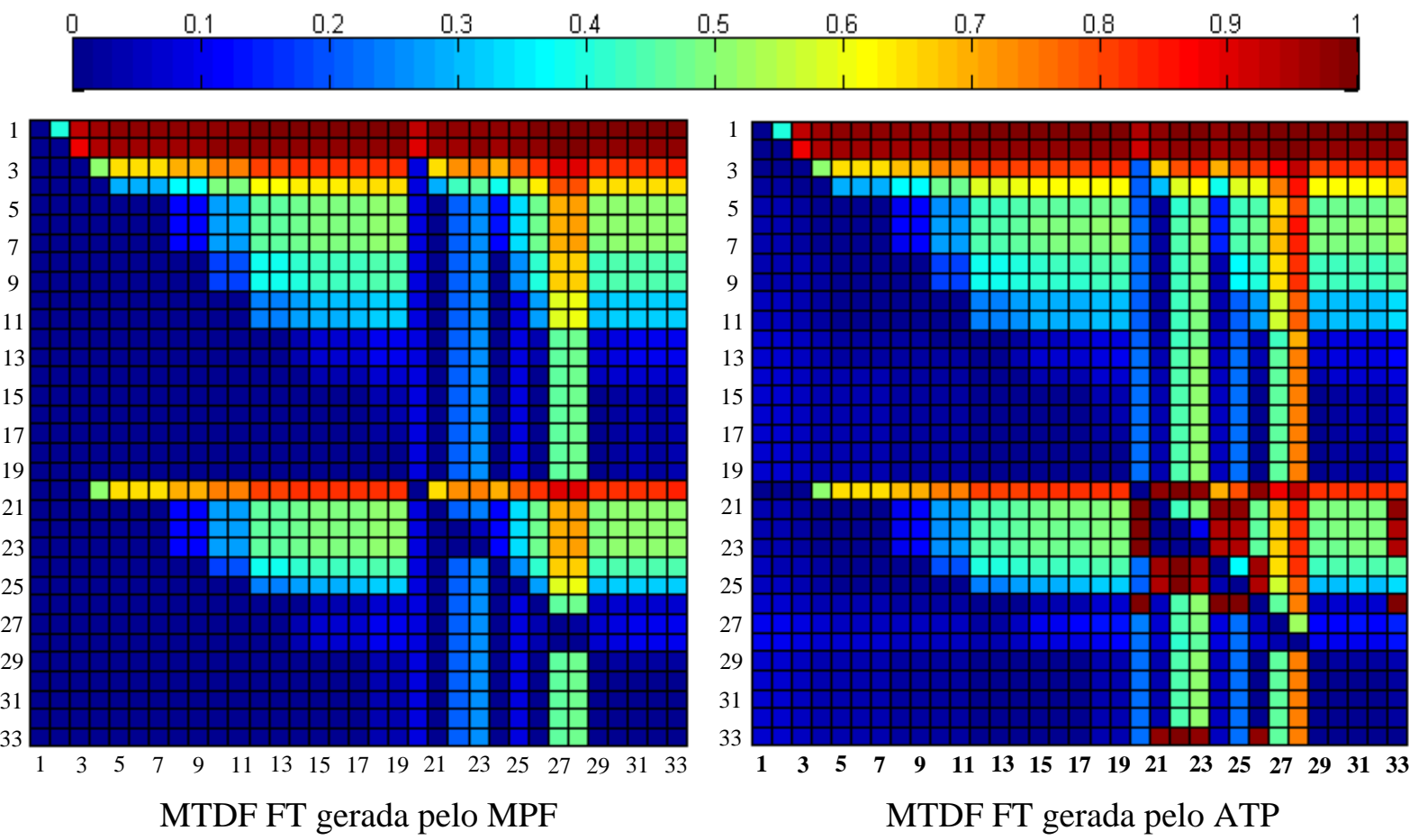


$\mathrm{Na}$ simulação das fases bifásicas, foram realizadas simulações no ATPDraw nas fases $A C, A B$ e $B C$, obtendo, duas MTDFs que caracterizam os afundamentos de tensão para cada situação de falta. Portanto, na ocorrência de faltas FF e FFT foram obtidas 6 (seis) MTDFs, totalizando 6.534 casos analisados. Em seguida foi realizada a agregação destas seis matrizes, considerando os casos mais severos dos afundamentos de tensão.

A Figura 77 ilustra as comparações obtidas durante a ocorrência de curtos-circuitos FF em todos os nós do SD. Já na Figura 78 são comparados os valores das tensões remanescentes obtidos na ocorrência de faltas FFT.

Figura 77 - Comparação das MTDFs geradas pelo MPF e ATP durante a ocorrência de faltas FF no SD de 34 nós.

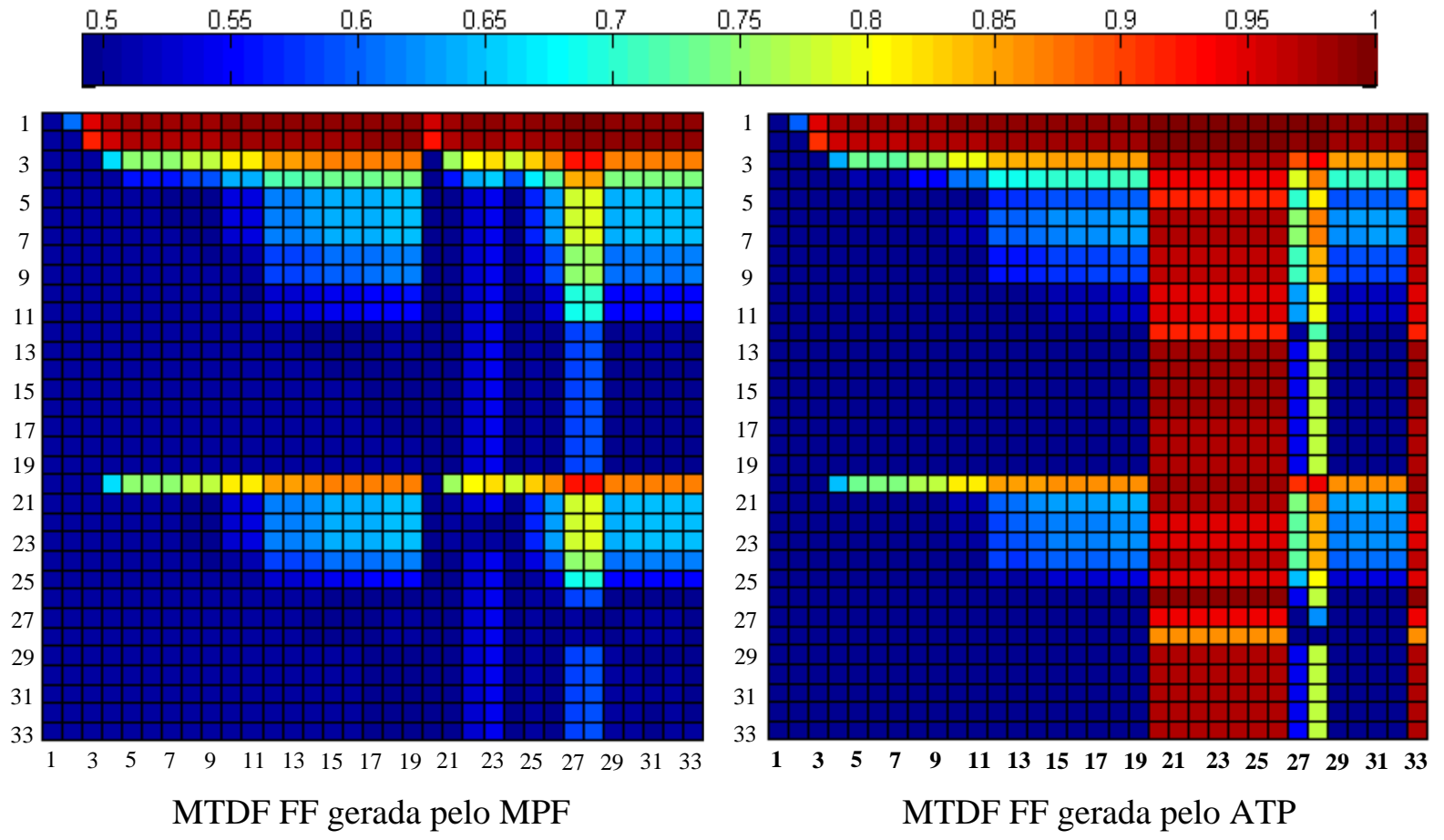

Na sequência, para cada tipo de falta foi calculado através da equação (111), o erro absoluto percentual, na qual $\mathrm{MPF}_{T k f}$ é a tensão remanescente registrada por meio do MPF no nó $k$ devido a uma falta no nó $f$. Já $\operatorname{ATP}_{T k f}$ é a tensão obtida pela simulação de curto-circuito no nó $k$ devido a uma falta no nó $f$ decorrente da simulação via o software ATP (ATPDraw).

$$
\operatorname{Erro}_{T k f}=\left(\left|M P F_{T k f}-A T P_{T k f}\right|\right) \times 100
$$

A Figura 79 sintetiza, para cada tipo de falta, o máximo erro absoluto percentual registrado para cada posição de falta. Por esta ilustração nota-se que, fora os trechos 
monofásicos (nós 20 à 26 e nó 33), o maior erro registrado foi no nó 28, localizado a jusante do transformador. Esta diferença pode estar intrínseca ao cálculo da impedância do transformador ao utilizar o MPF, sendo necessária uma análise mais aprofundada da influência do tipo de conexão dos transformadores no cálculo das tensões remanescentes.

Figura 78 - Comparação das MTDFs geradas pelo MPF e ATP durante a ocorrência de faltas FFT no SD de 34 nós.

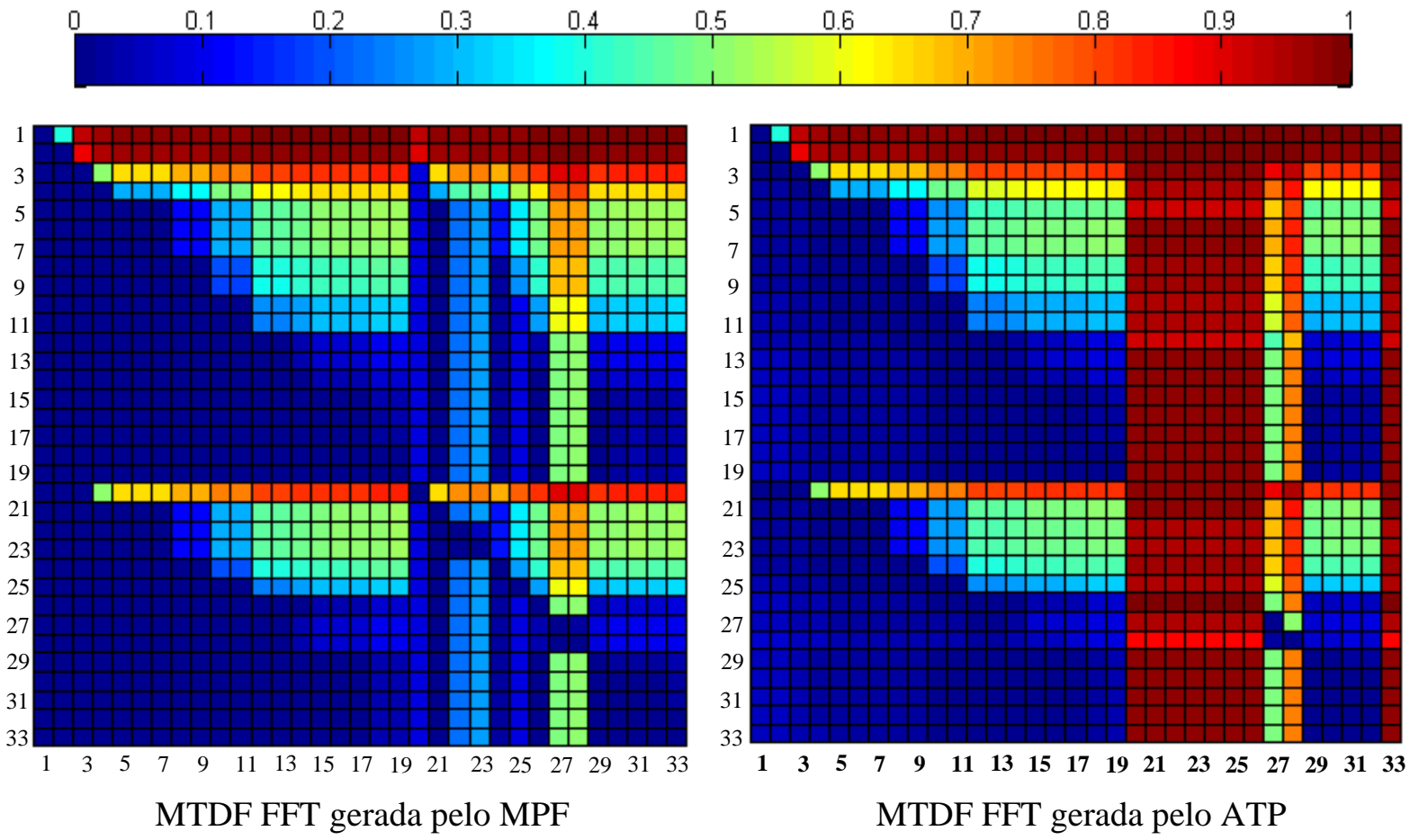

Figura 79 - Máximo erro absoluto registrado para cada posição de falta no SD de 34 nós.

Máximo erro absoluto (\%)

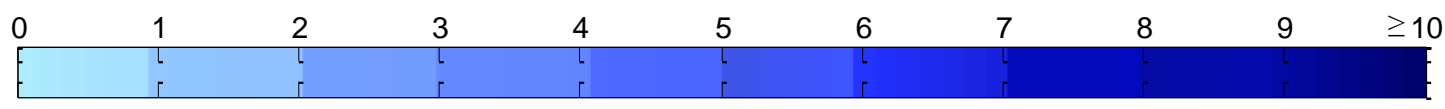

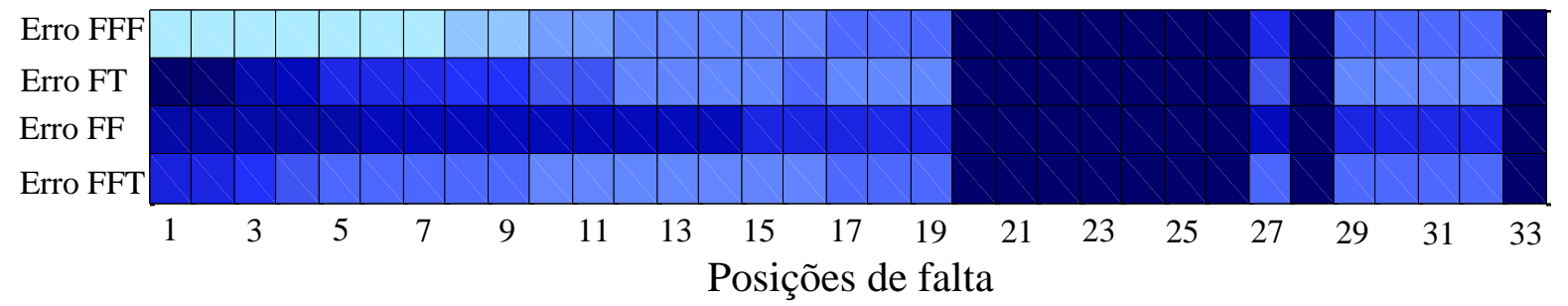

Durante a ocorrência de faltas FT percebe-se na Figura 79, que na incidência de uma falta no nó 1 (um), o máximo erro registrado foi 9,15\%. Comparando as tensões obtidas pelo MPF e pelo ATP (Figura 80), percebe-se que este erro está associado à tensão registrada no nó 28 durante a ocorrência da falta no nó 1 . Para os demais nós observados o erro registrado foi menor que $7 \%$. 
Figura 80 - Comparação entre as tensões remanescentes obtidas pelo MPF e ATP no SD de 34 nós durante a ocorrência de um curto-circuito FT no nó 1.

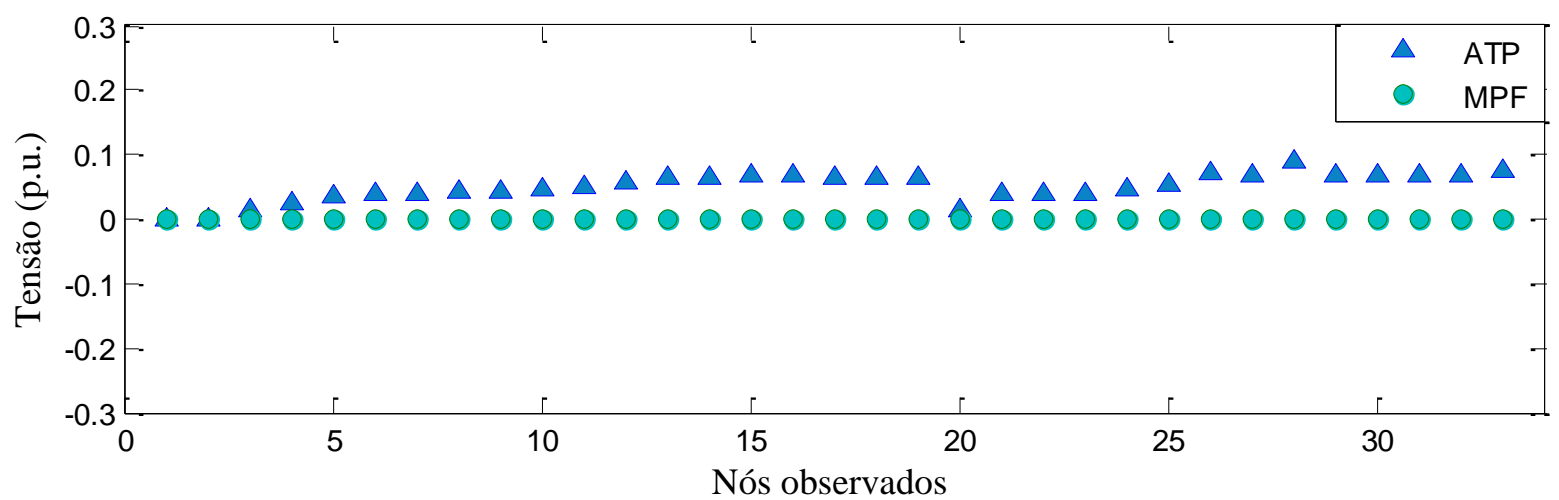

Para melhor quantificar e ilustrar o erro absoluto obtido com relação ao número total de casos analisados, a Figura 81 representa, em porcentagem, o número de casos analisados em função do erro absoluto percentual das magnitudes das tensões registradas para cada situação de curto-circuito simulado em todos os nós. Deste gráfico, constata-se que a maioria dos erros registrados foi menor que 6\%, sendo que, os erros maiores que $9 \%$ são relativos aos trechos monofásicos e aos nós localizados após o transformador.

Figura 81 - Percentual do erro absoluto registrado em relação ao número de casos analisados no SD de 34 nós.

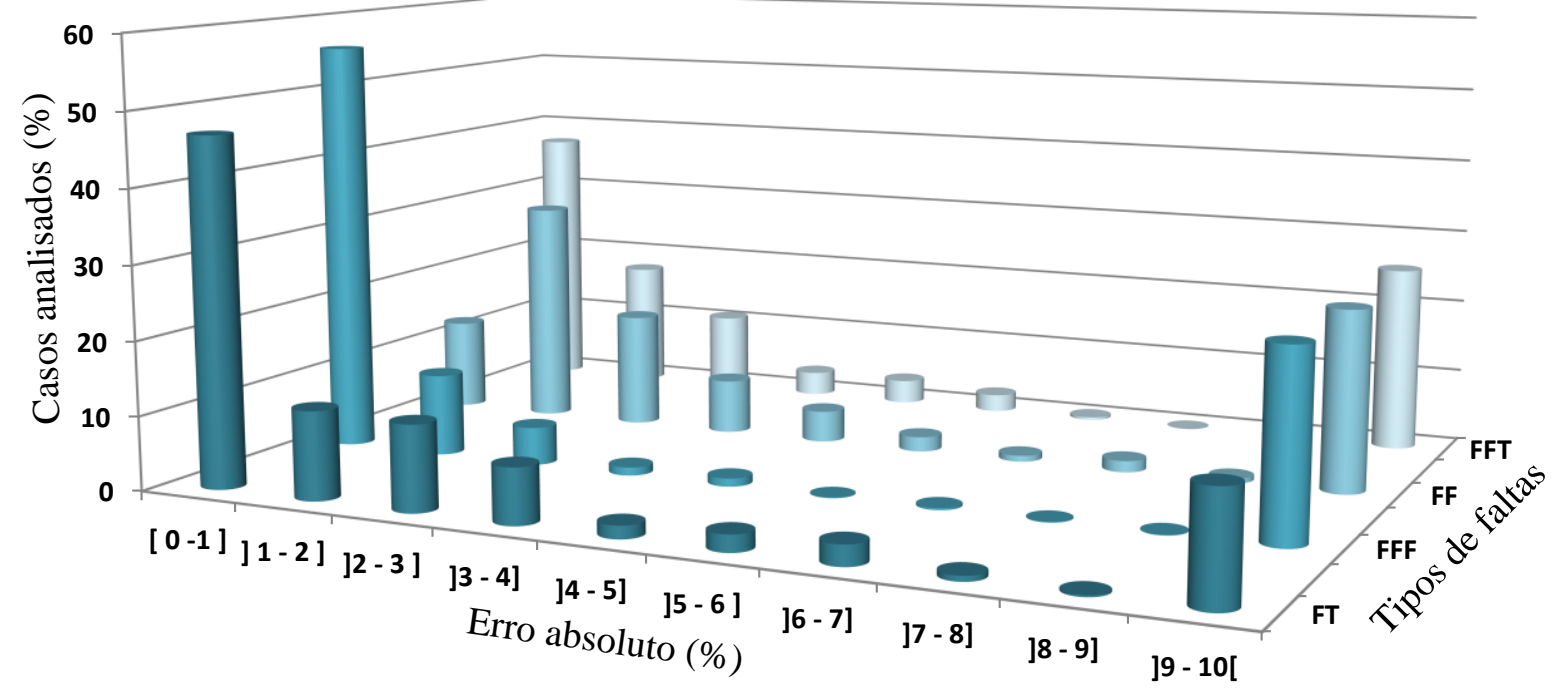

Cabe comentar, que já era esperada certa discrepância entre os resultados obtidos, pois na implementação utilizando o software ATP considerou-se o sistema assimétrico e com distinções na tensão de pré-falta devido ao carregamento do sistema. Já o MPF, utiliza-se componentes simétricas para facilitar os cálculos. Mesmo assim, o erro absoluto registrado manteve-se, na maioria dos casos analisados, inferior a 3\%, evidenciando que a simplificação no cálculo não compromete de forma significativa a precisão dos resultados. 


\subsubsection{Influência da Tensão de Pré-falta na Alocação Ótima de Medidores}

Geralmente, nos estudos de curto-circuito em SD adota-se a tensão de pré-falta igual a 1,0 p.u.. No entanto, esta premissa não é verdadeira, pois o perfil de tensão em regime permanente pode alterar ao longo do dia em função da curva de carga do sistema elétrico e, também, da disponibilidade de equipamentos destinados à regulação de tensão, como compensadores síncronos, banco de capacitores, reatores de linha, etc.

Devido às variações das tensões de pré-falta, durante a ocorrência dos curtos-circuitos, a propagação dos afundamentos de tensão pode se alterar. Então, surge a necessidade de avaliar a alocação ótima de medidores considerando diferentes valores da tensão de pré-falta.

Assim, inicialmente, foi analisada a alocação ótima de medidores para faltas FT considerando a tensão na subestação igual a 1 p.u.. Nestas condições, a tensão de pré-falta em cada fase para cada um dos nós do SD de 34 nós é mostrada na Tabela 36.

Tabela 36 - Tensões de pré-falta no SD de 34 nós, quando a tensão na subestação é igual a 1 p.u..

\begin{tabular}{|cccc|cccc|cccc|}
\hline \hline Nó & $\mathbf{V}_{\text {pref }} \boldsymbol{A}$ & $\mathbf{V}_{\text {pref }} \boldsymbol{B}$ & $\mathbf{V}_{\text {pref }} \boldsymbol{C}$ & $\mathbf{N o ́}$ & $\mathbf{V}_{\text {pref }} \boldsymbol{A}$ & $\mathbf{V}_{\text {pref }} \boldsymbol{B}$ & $\mathbf{V}_{\text {pref }} \boldsymbol{C}$ & Nó & $\mathbf{V}_{\text {pref }} \boldsymbol{A}$ & $\mathbf{V}_{\text {pref }} \boldsymbol{B}$ & $\mathbf{V}_{\text {pref }} \boldsymbol{C}$ \\
\hline $\mathbf{1}$ & 0,998 & 0,998 & 0,998 & $\mathbf{1 2}$ & 0,926 & 0,946 & 0,946 & $\mathbf{2 3}$ & 0,946 & 0,971 & 0,971 \\
\hline $\mathbf{2}$ & 0,996 & 0,991 & 0,997 & $\mathbf{1 3}$ & 0,986 & 0,946 & 0,946 & $\mathbf{2 4}$ & 0,963 & 0,949 & 0,949 \\
\hline $\mathbf{3}$ & 0,971 & 0,979 & 0,976 & $\mathbf{1 4}$ & 0,984 & 0,916 & 0,914 & $\mathbf{2 5}$ & 0,945 & 0,946 & 0,946 \\
\hline $\mathbf{4}$ & 0,941 & 0,959 & 0,950 & $\mathbf{1 5}$ & 0,983 & 0,981 & 1,001 & $\mathbf{2 6}$ & 0,985 & 0,963 & 0,963 \\
\hline $\mathbf{5}$ & 0,918 & 0,943 & 0,930 & $\mathbf{1 6}$ & 0,982 & 0,980 & 1,000 & $\mathbf{2 7}$ & 0,949 & 0,945 & 0,945 \\
\hline $\mathbf{6}$ & 0,973 & 0,973 & 0,975 & $\mathbf{1 7}$ & 0,982 & 0,977 & 0,996 & $\mathbf{2 8}$ & 0,864 & 0,985 & 0,985 \\
\hline $\mathbf{7}$ & 0,972 & 0,973 & 0,974 & $\mathbf{1 8}$ & 0,983 & 0,977 & 0,996 & $\mathbf{2 9}$ & 0,982 & 0,944 & 0,965 \\
\hline $\mathbf{8}$ & 0,965 & 0,963 & 0,965 & $\mathbf{1 9}$ & 0,983 & 0,976 & 0,995 & $\mathbf{3 0}$ & 0,982 & 0,869 & 0,878 \\
\hline $\mathbf{9}$ & 0,964 & 0,963 & 0,965 & $\mathbf{2 0}$ & 0,979 & 0,976 & 0,995 & $\mathbf{3 1}$ & 0,982 & 0,976 & 0,996 \\
\hline $\mathbf{1 0}$ & 0,950 & 0,998 & 0,998 & $\mathbf{2 1}$ & 0,971 & 0,976 & 0,996 & $\mathbf{3 2}$ & 0,982 & 0,976 & 0,996 \\
\hline $\mathbf{1 1}$ & 0,950 & 0,997 & 0,997 & $\mathbf{2 2}$ & 0,949 & 0,979 & 0,979 & $\mathbf{3 3}$ & 0,975 & 0,976 & 0,996 \\
\hline
\end{tabular}

Ressalta-se que o curto-circuito monofásico foi adotado uma vez que é o tipo de falta que tem a maior probabilidade de ocorrência em SDs aéreos, e também pela dificuldade em avaliar todos os tipos de faltas, em virtude do grande número de simulações que seriam necessárias. Portanto, foram aplicados curtos-circuitos monofásicos em todas as fases do SD e em seguida, registraram-se as tensões remanescentes durante a falta em todos os nós do sistema, obtendo-se três MTDFs. Na sequência, estas três MTDFs foram agrupadas em uma única matriz, considerando os casos mais críticos de afundamentos de tensão registrados em cada fase. 
Posteriormente, sabendo-se que em condições normais de operação, as distribuidoras de energia buscam suprir seus consumidores com tensões de operação dentro dos limites regulamentados $(0,95$ - 1,05 p.u.), foram refeitas as simulações, alterando as tensões de préfalta na subestação para 0,95 p.u. e, em seguida, para 1,05 p.u..

Para os três casos analisados, obtiveram-se as mesmas respostas do algoritmo de alocação ótima de medidores, indicando o local de instalação e o número de medidores necessário para monitorar a ocorrência de faltas monofásicas, conforme apresentadas na Tabela 37.

Tabela 37 - Resultados da alocação de medidores necessários para observar a ocorrência de faltas FT no SD de 34 nós, considerando diferentes tensões de pré-falta (0,95; 1 e 1,05 p.u.).

\begin{tabular}{|c|c|c|}
\hline \hline $\boldsymbol{\tau}$ (p.u.) & Nós de instalação & $\mathbf{N}^{\mathbf{o}}$ de medidores \\
\hline \hline $\mathbf{0 , 9}$ & $\{28\}$ & 1 \\
$\mathbf{0 , 8}$ & $\{28\}$ & 1 \\
$\mathbf{0 , 7}$ & $\{28\}$ & 1 \\
$\mathbf{0 , 6}$ & $\{28\}$ & 1 \\
$\mathbf{0 , 5}$ & $\{28\}$ & 1 \\
$\mathbf{0 , 4}$ & $\{23,28\}$ & 2 \\
$\mathbf{0 , 3}$ & $\{23,28\}$ & 2 \\
$\mathbf{0 , 2}$ & $\{23,28\}$ & 2 \\
$\mathbf{0 , 1}$ & $\{14,20,23,25,28\}$ & 5 \\
\hline
\end{tabular}

Comparando os resultados obtidos na Tabela 37 com a alocação determinada para qualquer tipo de falta (Tabela 29), percebe-se que houve divergência apenas para o limiar de 0,4 p.u.. Entretanto, caso fosse parametrizado no equipamento de medição um limiar maior que 0,4 p.u., ou até mesmo se os medidores estivessem instalados nos nós $\{23,28\}$, considerando uma maior redundância nas medições, a alteração das tensões de pré-falta não iriam interferir no registro dos afundamentos de tensão.

\subsubsection{Influência da Resistência de Falta na Alocação Ótima de Medidores}

Com relação à resistência de falta, tem-se que raramente os curtos-circuitos no sistema possuem resistência de falta nula (CABRAL, 2010). Portanto, desprezar a resistência de falta significa obter valores de afundamentos de tensão mais severos. Normalmente, a resistência de falta é constituída pela associação dos seguintes elementos (NOVAES, 2007): 
- Resistência do arco elétrico entre o condutor e a terra, para defeitos fase-terra;

- Resistência do arco entre dois ou mais condutores, para defeitos envolvendo fases;

- Resistência de contato devido à oxidação no local da falta; e

- Resistência do pé-de-torre, para defeitos englobando a terra.

Segundo relatado em Cabral (2010), os valores mais comuns de resistências de arco variam de $1 \Omega$ a $5 \Omega$, sendo que em SD aéreos os valores típicos de resistências de faltas para descargas atmosféricas estão entre $0 \Omega$ e $10 \Omega$. Faltas ocasionadas pela queda de estrutura resultam em resistências de falta entre $20 \Omega$ e $30 \Omega$. Já para defeitos provocados por árvores próximas aos condutores, a resistência de falta chega a atingir valores extremos em casos excepcionais de $55 \Omega$ a $70 \Omega$.

Para analisar a influência das resistências de falta na resposta à alocação ótima de medidores para as faltas monofásicas, foram adotadas as resistências de $0 \Omega, 15 \Omega, 25 \Omega \mathrm{e}$ $40 \Omega$. Para a resistência de $0 \Omega$, foram obtidas as mesmas respostas apresentadas na Tabela 37. Para as demais situações decorrentes do aumento da resistência de falta, apesar de o algoritmo ter sido executado para todos os limiares de tensão, os afundamentos de tensão não foram tão acentuados. Portanto, houve apenas soluções factíveis para os limiares de tensão de 0,9 e 0,8 p.u., indicando a instalação de um único medidor a ser instalado no nó $\{28\}$.

Além desta solução, na Tabela 38 são apresentadas outras possíveis soluções condizentes para as resistências de falta analisadas. Pelas soluções apresentadas, percebe-se que apesar de haver outras possibilidades para a instalação dos medidores, a melhor solução seria a instalação no nó $\{28\}$, localizado após o transformador abaixador de tensão. Pois, dependendo do limiar escolhido, não há outra solução possível que garanta a observabilidade dos afundamentos de tensão.

Tabela 38 - Outras soluções possíveis para a instalação dos medidores conforme a resistência de falta.

\begin{tabular}{|c|c|c|}
\hline \hline \multirow{2}{*}{$\boldsymbol{R}_{\text {falta }}$} & \multicolumn{2}{|c|}{ Número de soluções / Nós de instalação } \\
\cline { 2 - 3 } & $\mathbf{0 , 9}$ p.u. & $\mathbf{0 , 8}$ p.u. \\
\hline \hline $\mathbf{0} \boldsymbol{\Omega}$ & $22 /\{27\} \ldots\{32\},\{4\} \ldots\{19\}$ & $17 /\{27\} \ldots\{32\},\{10\} \ldots\{19\},\{5\}$ \\
$\mathbf{1 5} \boldsymbol{\Omega}$ & $20 /\{27\} \ldots\{32\},\{8\} \ldots\{19\},\{4\},\{5\}$ & $1 /\{28\}$ \\
$\mathbf{2 5} \boldsymbol{\Omega}$ & $6 /\{28\},\{27\},\{12\},\{11\},\{10\},\{5\}$ & $1 /\{28\}$ \\
$\mathbf{4 0} \boldsymbol{\Omega}$ & $3 /\{28\},\{27\},\{12\},\{5\}$ & $1 /\{28\}$ \\
\hline
\end{tabular}




\subsubsection{Influência dos Perfis de Carregamento na Alocação Ótima de Medidores}

Normalmente, os carregamentos dos SDs variam significativamente ao longo do dia, mas por falta de medidores instalados nos SDs direcionados a acompanhar o comportamento dinâmico e aleatório das cargas, é difícil a representação exata do carregamento dos SDs para a realização de estudos detalhados.

Portanto, serão avaliados três diferentes cenários de carga no SD de 34 nós, a fim de avaliar se o carregamento do sistema influenciará, ou não, de maneira direta nos resultados da alocação ótima de medidores de QEE obtidos pela metodologia proposta neste trabalho que considera o SD operando sem carga. Para isso, todas as cargas foram modeladas como impedância constante, as quais foram calculadas em função da potência e da tensão de operação fornecida em (DISTRIBUTION TEST FEEDERS, 2010).

$\mathrm{O}$ primeiro cenário, consiste no carregamento normal do $\mathrm{SD}$, sendo o mesmo fornecido pelo IEEE (DISTRIBUTION TEST FEEDERS, 2010). O segundo cenário, carga pesada, foi determinado ao aumentar em $20 \%$ a potência ativa e reativa de todas as cargas do sistema. Neste caso, o carregamento do sistema passou para aproximadamente 2,5 MVA. O terceiro cenário, carga leve, foi estabelecido ao diminuir em $20 \%$ a potência ativa e reativa de todas as cargas do sistema em relação ao sistema original. Neste caso, o carregamento do sistema passou para aproximadamente 1,65 MVA. Destaca-se que o tap dos reguladores de tensão e as potências nominais dos bancos de capacitores foram mantidos constantes para os três cenários apresentados.

A escolha de cenários extremos (carga pesada e carga leve) para as análises neste trabalho foi devido ao fato de que é tecnicamente difícil e inviável a representação de todas as combinações de carregamento do sistema. Desta forma, optou-se pela análise de tais condições extremas em conjunto com o cenário de carregamento normal.

A Figura 82 ilustra o perfil de tensão da fase $A$ dos três cenários avaliados para todos os nós do SD teste. Pela figura, pode-se observar que o cenário de carga leve é o que apresenta as maiores tensões de pré-falta, devido ao menor carregamento e, consequentemente, menores quedas de tensão ao longo do alimentador. De maneira complementar, por apresentar o maior carregamento, o cenário de carga pesada apresenta as menores tensões em regime permanente.

Para cada cenário foram simuladas faltas monofásicas nas três fases do SD, obtendo-se as soluções ótimas de alocação apresentadas na Tabela 39. 
Figura 82 - Perfil da tensão na fase $A$ do SD de 34 nós, para cada cenário de carga avaliado.

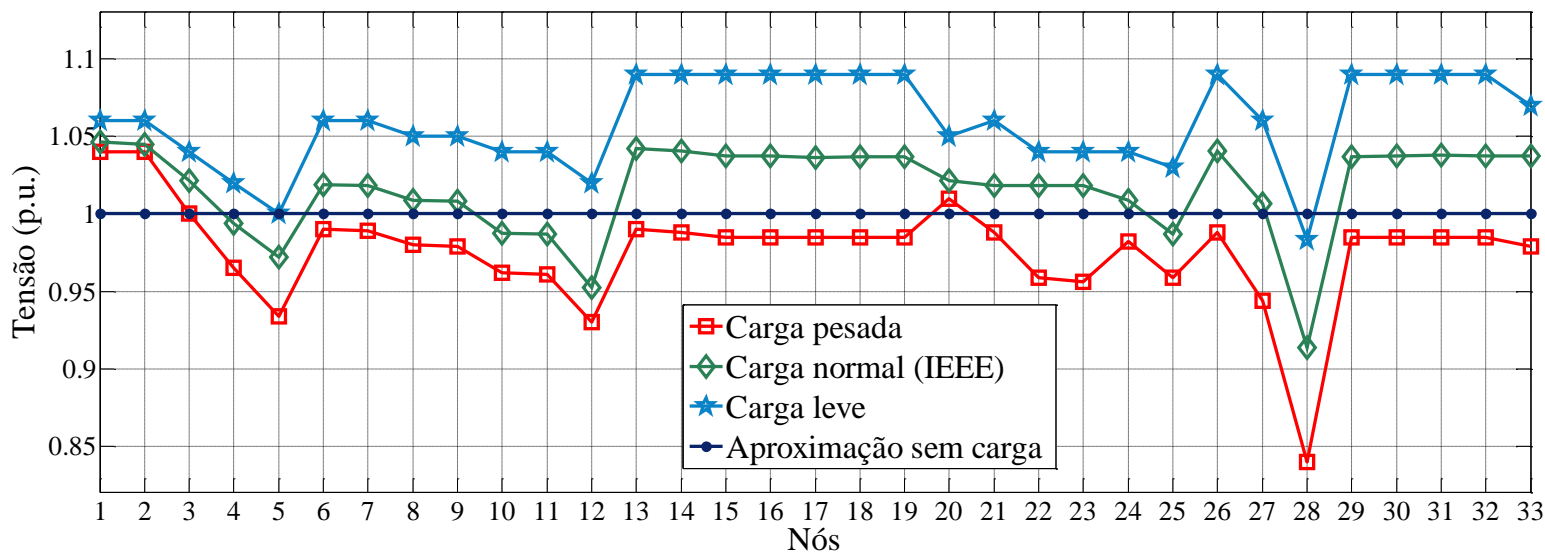

Tabela 39 - Soluções para monitorar faltas FT no SD de 34 nós, considerando diferentes perfis de carregamento.

\begin{tabular}{|c|c|c|c|}
\hline \hline \multirow{2}{\tau}{} & Carga leve & Carga normal IEEE & Carga pesada \\
\cline { 2 - 4 } (p.u.) & $\begin{array}{c}\mathbf{N}^{\mathbf{0}} \text { de medidores / Nós de } \\
\text { instalação }\end{array}$ & $\begin{array}{c}\mathbf{N}^{\mathbf{0}} \text { de medidores / Nós de } \\
\text { instalação }\end{array}$ & $\begin{array}{c}\mathbf{N}^{\mathbf{0}} \text { de medidores / Nós de } \\
\text { instalação }\end{array}$ \\
\hline \hline $\mathbf{0 , 9}$ & $1 /\{28\}$ & $1 /\{28\}$ & $1 /\{28\}$ \\
$\mathbf{0 , 8}$ & $1 /\{28\}$ & $1 /\{28\}$ & $1 /\{28\}$ \\
$\mathbf{0 , 7}$ & $1 /\{28\}$ & $1 /\{28\}$ & $1 /\{28\}$ \\
$\mathbf{0 , 6}$ & $1 /\{28\}$ & $1 /\{28\}$ & $1 /\{28\}$ \\
$\mathbf{0 , 5}$ & $1 /\{28\}$ & $1 /\{28\}$ & $1 /\{28\}$ \\
$\mathbf{0 , 4}$ & $2 /\{23,28\}$ & $2 /\{23,28\}$ & $1 /\{28\}$ \\
$\mathbf{0 , 3}$ & $2 /\{23,28\}$ & $2 /\{23,28\}$ & $2 /\{23,28\}$ \\
$\mathbf{0 , 2}$ & $2 /\{23,28\}$ & $2 /\{23,28\}$ & $2 /\{23,28\}$ \\
$\mathbf{0 , 1}$ & $5 /\{14,20,23,25,28\}$ & $5 /\{14,20,23,25,28\}$ & $5 /\{14,20,23,25,28\}$ \\
\hline
\end{tabular}

Na Tabela 39, observa-se que para o caso de carregamento pesado, considerando o limiar de 0,4 p.u., somente um medidor foi necessário para diagnosticar os afundamentos de tensão, enquanto que para os demais cenários são necessários dois medidores. Isto é justificável pelo fato deste cenário apresentar os menores valores de tensão de pré-falta (Figura 82), e, portanto, os afundamentos de tensão foram mais severos após a ocorrência da falta.

Comparando os resultados obtidos na Tabela 39 com a alocação proposta neste trabalho, que observa simultaneamente qualquer tipo de falta (Tabela 29), fica evidente que apenas um medidor instalado no barramento 28 seria suficiente para monitorar os afundamentos de tensão decorrentes de curtos-circuitos monofásicos, mesmo ocorrendo variações de carga. Sabendo-se que a confiabilidade do monitoramento sobre o SD pode 
aumentar conforme o número de medidores instalados, tem-se, ainda, a possibilidade de instalar outros medidores no SD conforme os resultados fornecidos para os limiares de 0,3 ; 0,2 e 0,1 p.u..

Estas comparações demonstram que, caso sejam desconsideradas as informações das cargas na modelagem do SD, muitas vezes por falta de informações precisas das mesmas, a eficácia do monitoramento não será afetada. 



\section{Capítulo 6}

\section{Considerações finais}

Tradicionalmente, grande parte das medições disponíveis nos SDs se encontram na saída da subestação de energia, não sendo monitoradas em tempo real as grandezas elétricas ao longo do alimentador. Neste sentido, muitos eventos que ocorrem nos alimentadores, e que deterioram a QEE entregue aos consumidores, não são monitorados, tampouco avaliados pelas distribuidoras de energia elétrica.

Uma vez que existem entraves na obtenção de informações precisas sobre a propagação das VTCDs, na situação atual da regulamentação referente à QEE não há limites definidos para estes distúrbios, nem mesmo um procedimento para estabelecimento desses limites. Desta forma, não é possível penalizar as distribuidoras e/ou os consumidores por situações que venham propagar tais distúrbios no SD com base nos indicativos estabelecidos no PRODIST. Nessa situação, não há nenhuma justificativa econômica regulatória para que as distribuidoras realizem ou mesmo busquem melhorias referentes a esse tema.

Neste contexto, para que possam ser estabelecidos índices de desempenho relativos a estes distúrbios é essencial que se obtenha um banco de dados (histórico) consistente que retrate a realidade da energia elétrica distribuída no Brasil.

Neste sentido, este trabalho de pesquisa teve como contribuição principal a definição de uma metodologia que propicia determinar os locais adequados para a instalação dos medidores de QEE de forma a obter informações representativas das VTCDs na ocorrência de qualquer tipo de curto-circuito no SD.

Conforme apresentado no trabalho, o MPF permitiu uma apurada análise das tensões remanescentes, ilustrando graficamente a influência e a propagação das VTCDs no SD como um todo, frente aos diferentes tipos de curtos-circuitos que o sistema possa vir ser submetido.

Através dos resultados obtidos pelo MPF, e uma vez pré-estabelecido um limiar de tensão, tornou-se também possível mapear as áreas de risco que equipamentos eletroeletrônicos sensíveis possam vir a ser submetidos, através da delimitação da área afetada e da área exposta ou de vulnerabilidade. 
Além do estudo destas áreas servir como um material alternativo e orientativo às indústrias conectadas ao SD quanto à tolerância dos seus equipamentos, bem como auxiliar na orientação para a instalação de consumidores com processos sensíveis, foi possível também estabelecer uma indicação dos pontos mais vulneráveis às VTCDs, sendo estes prioritários no processo de busca da solução ótima da alocação de medidores, de forma a maximizar a observabilidade dos distúrbios.

Após as obtenções das matrizes de afundamentos de tensão, foi proposta ainda, uma metodologia inovadora para a análise simultânea de diferentes tipos de faltas através da obtenção de uma matriz de observabilidade reduzida, para, posteriormente, determinar a alocação ótima dos medidores de QEE. A análise apresentada diminui o tempo de processamento e torna o processo da obtenção da solução ótima ágil e direto, pois menos execuções computacionais são necessárias para garantir a monitoração dos afundamentos de tensão para todos os tipos de curtos-circuitos.

Como ferramenta para a resolução do problema da alocação dos medidores de QEE foi utilizado um algoritmo BB. Os resultados obtidos permitiram observar que a instalação dos medidores em pontos estratégicos do SD possibilita a redução do número de equipamentos para a monitoração dos afundamentos de tensão, obtendo-se contudo, uma observabilidade máxima para os níveis de tensão desejados.

Pelos resultados obtidos, percebeu-se que os nós menos vulneráveis aos afundamentos de tensão são os que se encontram eletricamente próximos à subestação. Desta forma, as soluções ótimas obtidas não priorizam a alocação dos medidores para estes pontos. Contudo, vale relembrar que todos os SDs analisados nesta pesquisa possuem apenas um alimentador saindo da subestação. Sendo assim, para os SDs onde haja mais de um alimentador saindo da subestação, o estudo deverá ser inicialmente direcionado para se obter a matriz impedância de barra de sequência considerando todos os nós conectados à subestação. Após a obtenção da matriz impedância de barra para as três sequências, a formulação do MPF poderá ser utilizada como apresentada nesta pesquisa, sem modificações. Na sequência, o algoritmo de otimização poderá ser executado para se obter as respostas ótimas que definirão se a subestação será ou não um local indicado para observabilidade máxima dos afundamentos de tensão.

Como foram analisados diferentes limiares de tensão, foi possível demonstrar ainda que com a diminuição do limiar adotado, tem-se a opção da instalação de mais medidores, o que propiciaria uma maior redundância nas medidas. Assim, dependendo do número de equipamentos disponíveis pela distribuidora de energia, ou dos limites orçamentários para a aquisição dos mesmos, pode-se aumentar a observabilidade e a confiabilidade do SD e, 
consequentemente, a eficiência do sistema de monitoramento implementado.

Ainda, obtiveram-se diferentes soluções ótimas sem a necessidade de executar o algoritmo várias vezes, acarretando um menor esforço computacional. Além disso, da maneira como os resultados foram exibidos, tem-se a possibilidade de alocar os medidores de forma gradativa, instalando, inicialmente, os medidores nos nós que possuem a maior observabilidade dos eventos. Desta maneira, concede-se às distribuidoras de energia elétrica, um tempo compatível para implementação dos sistemas de monitoramento conforme os recursos disponíveis para aquisição e instalação dos equipamentos de medição.

Assim sendo, a metodologia desenvolvida neste trabalho permite orientar o planejamento do sistema de monitoramento do SD quanto à aquisição dos equipamentos de medição, de forma a obter um número mínimo de medidores que contemple a maior área de vulnerabilidade, onde um número maior de cargas estará suscetível ao distúrbio. Portanto, estando o medidor de QEE instalado no nó mais exposto aos afundamentos de tensão, melhor preparada estará a distribuidora responsável pelo SD para registrar e analisar todas as ocorrências das VTCDs.

Por fim a metodologia foi validada através do software ATP, onde se constatou a eficiência do método analítico frente à simplificação adotada nos procedimentos de cálculo. Concluiu-se também, através dos estudos da influência de diversos fatores que alteram a propagação dos afundamentos de tensão, que a alocação de medidores proposta manteve-se adequada mesmo considerando as adversidades que possam ocorrer no $\mathrm{SD}$, proporcionando, portanto, um monitoramento amplo e adequado das VTCDs.

\subsection{Sugestões para Trabalhos Futuros}

As sugestões propostas para continuidade da pesquisa são:

a) Analisar o efeito das conexões dos transformadores no cálculo dos afundamentos de tensão;

b) Criar uma interface gráfica para facilitar a obtenção e observação direta dos resultados.

c) Realizar o estudo da alocação para um SD real brasileiro;

d) Estimar os custos associados à instalação dos medidores;

e) Instalar os medidores de QEE conforme os resultados fornecidos pela metodologia proposta; 
f) Obter um banco de dados consistente, realizando medições pelo período mínimo de um ano;

g) Com base nos resultados de monitoração a serem obtidos, aprimorar ou criar indicadores de desempenho das VTCDs que possam ser utilizados para avaliar a qualidade do produto no âmbito da distribuição de energia elétrica no Brasil; e

h) Com a utilização da metodologia proposta também poderão ser desenvolvidos métodos para classificar e localizar as situações de falta passíveis de ocorrência sobre os SDs.

\subsection{Publicações}

Na sequência são listados os artigos, publicados ou aceitos, bem como os submetidos, para publicação em periódicos especializados no assunto e em eventos científicos.

\subsubsection{Publicações em Congressos Nacionais}

Kempner, T. R.; Oleskovicz, M.; Vieira Junior, J. C. M.. "Impactos Provocados pela Conexão de Geradores Distribuídos na Análise das Áreas de Propagação dos Afundamentos de Tensão em Sistemas de Distribuição”, X Conferência Brasileira sobre Qualidade da Energia Elétrica, Junho de 2013, Araxá-MG.

Kempner, T. R.; Oleskovicz, M.. "Monitoramento Otimizado de um Sistema de Distribuição Considerando a Propagação dos Afundamentos de Tensão Causados por Curtos-Circuitos", V Simpósio Brasileiro de Sistemas Elétricos, Foz do Iguaçu, PR, 22 a 25 de abril de 2014.

Kempner, T. R.; Mourinho, F. A.; Bottura, F. B.; Oleskovicz, M.; Vieira Junior, J. C. M.; Lima Filho, J. R. M.. "Monitoramento Otimizado de um Sistema de Distribuição Considerando a Alteração dos Perfis de Carregamento", VI Simpósio Brasileiro de Sistemas Elétricos, Natal, RN, 22 a 25 de maio de 2016.

\subsubsection{Publicações em Congressos Internacionais}

Kempner, T. R.; Oleskovicz, M.; Santos, A. Q.. "Optimal Allocation of Monitors by Analyzing the Vulnerability Area Against Voltage Sags", 16th International Conference on Harmonics and Quality Power (ICHQP). Bucharest, Romania, 25 - 28 de Maio 2014.

Kempner, T. R.; Santos, A. Q; Oleskovicz, M.. "Optimized Monitoring of Voltage Sags in Distribution Systems caused by Balanced and Unbalanced Short-Circuits", IEEE Power \& Energy Society General Meeting, Washington, 27 - 31 julho 2014. 


\subsubsection{Publicações em Periódicos}

Kempner, T. R.; Mourinho, F. A.; Bottura, F. B.; Oleskovicz, M.; Vieira Junior, J. C. M.; Lima Filho, J. R. M.. "Optimal Voltage Sags Monitoring Considering Different Loading Profiles in Distribution Systems". Aceito para publicação no Renewable Energy \& Power Quality Journal (RE\&PQJ) ISSN 2172-038.

\subsubsection{Demais Publicações}

Os seguintes trabalhos também foram desenvolvidos durante a realização desta tese de doutorado com a participação da autora e são indiretamente relacionados ou dependentes da metodologia de alocação ótima de medidores em SD.

Festa, A. V.; Kempner, T. R.; Oleskovicz, M.; Motter, D.; Coury, D. V.. “A Localização da Área Afetada e a Classificação de Faltas em Sistemas de Distribuição Utilizando RNA e Lógica Fuzzy", X Conferência Brasileira sobre Qualidade da Energia Elétrica, Junho de 2013, Araxá-MG.

Motter, D.; Festa, A. V; Oleskovicz, M.; Kempner, T. R.; Vieira Junior, J. C. M.; Coury, D. V.. "Uso de Redes Perceptron Multicamadas para Estimar a Distância de Ocorrência de Curtos-Circuitos em um Sistema de Distribuição", X Conferência Brasileira sobre Qualidade da Energia Elétrica, Junho de 2013, Araxá-MG.

Festa, A. V.; Motter, D.; Kempner, T. R.; Oleskovicz, M.; Vieira Junior, J. C. M.. “A Indicação da Área Afetada por Diferentes Tipos de Curtos-Circuitos em um Sistema de Distribuição pela Aplicação de Redes Neurais Artificiais", XI Simpósio Brasileiro de Automação Inteligente, Outubro de 2013, Fortaleza-CE.

Festa, A. V.; Kempner, T. R.; Oleskovicz, M.. "Diagnóstico de Faltas em um Sistema de Distribuição Subterrâneo Utilizando Redes Neurais Artificiais", $20^{\circ}$ Congresso Brasileiro de Automática, Setembro de 2014, Belo Horizonte - MG.

Festa, A. V.; Kempner, T. R.; Oleskovicz, M.. "Localização de Curtos-Circuitos a partir da Alocação Otimizada de Medidores em um Sistema de Distribuição Subterrâneo", VI Simpósio Brasileiro de Sistemas Elétricos, Natal, RN, 22 a 25 de maio de 2016.

Gomes, D. P. S.; Oleskovicz, M.; Kempner, T. R.; Lima Filho, J. R. M.. “A Generalized Coverage Matrix Method for Power Quality Monitor Allocation Utilizing Genetic Algorithm". Aceito para publicação no Renewable Energy \& Power Quality Journal (RE\&PQJ) ISSN 2172-038.

Gomes, D. P. S.; Oleskovicz, M.; Kempner, T. R.; Lima Filho, J. R. M.. “A Alocação de Monitores de Qualidade da Energia Elétrica através da aplicação de Algoritmos Genéticos via uma Matriz Híbrida de Cobertura", VI Simpósio Brasileiro de Sistemas Elétricos, Natal, RN, 22 a 25 de maio de 2016. 
Bertho, Jr., R., Kempner, T. R., Vieira Junior, J. C. M., Oleskovicz, M., Coury, D. V.. "Optimized Power Quality Monitor Placement Based on a Particle Swarm Optimization Algorithm". Submetido para a 17th International Conference on Harmonics and Quality Power (ICHQP). Belo Horizonte, MG, 16 a 19 de Outubro de 2016.

Pessoa, A. L. S.; Oleskovicz, M.; Festa, A. V.; Kempner, T. R.; Coury, D. V.. "A Localização de Faltas em um Sistema de Distribuição Utilizando Sistemas Neuro-Fuzzy". Submetido para o XXI Congresso Brasileiro de Automática (CBA). Vitória, ES, 03 a 07 de Outubro de 2016. 


\section{Referências Bibliográficas}

ALMEIDA, C. F. M.; KAGAN, N. Aplicação de Algoritmos Genéticos e Teoria dos Conjuntos Fuzzy no Dimensionamento de Sistemas de Monitoração para Redes de Transmissão de Energia Elétrica. Revista Controle \& Automação, v. 21, n. 4, julho 2010.

ALVES, M. F.; COSTA, J. G.; FONSECA, V. R. C. Impacto Econômico do Afundamento de Tensão na Indústria: Uma Metodologia Aplicada a Grandes Redes Elétricas. V SBQEE Seminário Brasileiro Sobre Qualidade da Energia Elétrica, Aracajú, SE, 2003. 483- 488.

ANDERSON, P. M. Analysis of Faulted Power Systems. New York: The Iowa University Press, 1973. 540 p. ISBN 978-0-7803-1145-9.

ANEEL. Procedimentos de Distribuição de Energia Elétrica no Sistema Elétrico Nacional - PRODIST: Módulo 8. Agência Nacional de Energia Elétrica. Resolução Normativa $n^{\circ} 664 / 2015$, p. 29-31. 2016.

AUnG, M. T.; MILANOVIC, J. V.; SIMMONS, P. A. Automated Comprehensive Assessment and Visualization of Voltage Sag Performance. Harmonics and Quality of Power, 11th International Conference on, p. 12-15, Sept. 2004.

BECKER, C. et al. Proposed Chapter 9 for Predicting Voltage Sags (Dips) in Revision to IEEE Std 493, the Gold Book. Industrial and Commercial Power Systems Technical Conference, p. 43-51, May 1993.

BOLlen, M. H. J. Understanding Power Quality Problems - Voltage Sags and Interruptions. New York: IEEE Press Series on Power Engineering, 1999. 672 p. ISBN 9780-7803-4713-7.

BOLLEN, M. H. J.; QADER, M. R.; ALLAN, R. N. Stochastical and Statistical Assessment of Voltage Dips. Tools and Techniques for Dealing with Uncertainty (Digest No. 1998/200), IEE Colloquium on, London, Jan. 1998.

BOLLEN, M. H. J.; SABIN, D. D.; THALlAM, R. S. Voltage-sag Indices - Recent Developments in IEEE PI564 Task Force. Quality and Security of Electric Power Delivery Systems, CIGRE/IEEE PES International Symposium, p. 34-41, Oct. 2003.

BROWN, H. E. Solution of Large Networks by Matrix Methods. New York: WileyInterscience, 1975. 320 p. ISBN 978-0-4718-0074-3. 
CABRAL, R. J. Análise Numérica de Curto Circuito Utilizando Componentes Simétricas e Componentes de Fases para Obter Índices de Afundamentos de Tensão. Dissertação de mestrado, Universidade Federal do Rio Grande do Sul. Porto Alegre, RS, p. 152, 2010.

CARPINELLI, G. et al. Complete Matrix Formulation of Fault-position Method for Voltagedip Characterisation. IET Generation, Transmission \& Distribution, v. 1, p. 56-64, Jan. 2007.

CARPINELLI, G. et al. Methods for Assessing the Robustness of Electrical Power Systems Against Voltage Dips. IEEE Transactions on Power Delivery, v. 24, p. 43-51, Jan. 2009.

CARVALHO FILHO, J. M. et al. Validation of Voltage Sag Simulation Tools: ATP and Short-Circuit Calculation Versus Field Measurements. IEEE Transactions on Power Delivery, v. 23, p. 1472 - 1480, July 2008.

CARVALHO, P. L. Uma Contribuição ao Estudo da Depressão de Tensão. Dissertação de mestrado, Universidade Federal de Itajubá. Itajubá, MG, p. 134, 1997.

CENELEC EN 50160. Voltage Characteristics of Electricity Supplied by Public Distribution Systems. European Committee for Electro Technical Standardization. 1999.

CIGRÉ. Power Quality Indices and Objectives. Joint Working Group Cigré 4.07/ Cired. , p. 96, 2004.

CONRAD, L. E.; BOLLEN, M. H. J. Voltage Sag Coordination for Reliable Plant Operation. IEEE Transactions on Industry Applications, v. 33, p. 1459-1464, Nov/Dec 1997.

CONRAD, L.; LITTLE, K.; GRIGG, C. Predicting and Preventing Problems Associated with Remote Fault-clearing Voltage Dips. IEEE Transactions on Industry Applications, v. 27, p. 167-172, Jan/Feb 1991.

CP No 005/2011. ANEEL - Agência Nacional de Energia Elétrica, 2011. Disponível em: <http://www.aneel.gov.br/aplicacoes/consulta_publica/detalhes_consulta.cfm?IdConsultaPubl ica=210>. Acesso em: Março 2016.

CP No 18/2014. ANEEL - Agência Nacional de Energia Elétrica, 2014. Disponível em: $<$ http://www.aneel.gov.br/aplicacoes/consulta_publica/detalhes_consulta.cfm?IdConsultaPubl ica=269>. Acesso em: Fevereiro 2016.

DISTRIBUTION TEST FEEDERS, 2010. Distribution System Analysis Subcommittee. IEEE PES Power \& Energy Society. Disponível em:

<Available: http://ewh.ieee.org/soc/pes/dsacom/testfeeders/index.html>. Acesso em: Março 2016.

DORR, D. S. et al. Interpreting Recent Power Quality Surveys to Define the Electrical Environment. IEEE Transactions on Industry Applications, v. 33, p. 1480-1487, Nov/Dec 1997. 
EPE. Consumo Nacional de Energia Elétrica na Rede por Classe: 1995-2015. Empresa de Pesquisa Elétrica, Ministério de Minas e Energia, Boletins de análise do mercado de energia, 2015. Disponível em:

$<$ http://www.epe.gov.br/Search/Results.aspx?k=Consumo\%20Nacional\%20de\%20Energia\%2 0El\%C3\%A9trica\%20na\%20Rede\%20por\%20Classe\&s=All\%20Sites>. Acesso em: Março 2016.

EPRI. Distribution System Power Quality Assessment: Phase II. Voltage Sag and Interruption Analysis. Electric Power Research Institute, Project Manager A. Sundaram, p. 5-7, 2003.

ESPINOSA-JUÁREZ, E.; HERNANDES, A.; OLGUIN, G. An Approach Based on Analytical Expressions for Optimal Location of Voltage Sags Monitors. IEEE Transactions on Power Delivery, v. 24, p. 2034-2042, Oct. 2009.

FORTESCUE, C. L. Method of Symmetrical Co-Ordinates Applied to the Solution of Polyphase Networks. AIEE Transactions, v. 37, p. 1027-1140, 1918.

GOSWAMI, A. K.; GUPTA, C. P.; SINGH, G. K. Area of Vulnerability for Prediction of Voltage Sags by an Analytical Method in Indian Distribution Systems. India Conference, INDICON, 2, p. 406-411, Dec. 2008.

HEINE, P. et al. A Method for Estimating the Frequency and Cost of Voltage Sags. IEEE Transactions on Power Systems, v. 17, p. 290-296, May 2002.

IEC 61000-2-1. Voltage Dips and Short Supply Interruptions. International Electrotechnical Commission. 1990.

IEC 61000-2-8. Voltage Dips and Short Interruptions on Public Electric Power Supply Systems with Statistical Measurement Results. International Electrotechnical Commission. 2002.

IEC 61000-4-30. Electromagnetic Compatibility (EMC) - Part 4-30: Testing and Measurement. International Electrotechnical Commission. 2003.

IEEE STD 1159. IEEE Recommended Practice for Monitoring Electric Power Quality. Institute of Electrical and Electronics Engineers. 1995.

IEEE STD 1346. IEEE Recommended Practice for Evaluating Electric Power System Compatibility With Electronic Process Equipment. Institute of Electrical and Electronics Engineers. New York. 1998.

IEEE STD 1564. Recommended Practice for the Establishment of Voltage Sag Indices. IEEE Voltage Quality Working Group. 2001.

IEEE STD 1564. IEEE Guide for Voltage Sag Indices. p. 1-59, 2014.

IEEE STD 446. IEEE Recommended Practice for Emergency and Standby Power Systems for Industrial and Commercial Applications. Institute of Electrical and Electronics Engineers. 1995. 
IEEE STD 493. IEEE Recomended Practice for the Design of Reliable Industrial and Commercial Power Systems. Institute of Electrical and Electronics Engineers. 1997.

INMET. Instituto Nacional de Meteorologia, 2016. Disponível em: $<$ http://www.inmet.gov.br/html/clima/graficos/plotGraf.php?chklist=2\%2C\&capita=saopaulo $\% 2$ Cportoalegre $\% 2 \mathrm{Cmanaus} \% 2 \mathrm{Cnatal} \% 2 \mathrm{C} \&$ peri $=99 \% 2 \mathrm{C} \&$ per6190=99\&precipitacao $=2 \& \mathrm{ma}$ naus $=28 \&$ natal $=29 \&$ portoalegre $=30 \&$ saopaulo $=37 \&$ Enviar $=$ Visualizar $>$. Acesso em: Março 2016.

ITI (CBEMA). Curve Application Note. Technical Committee 3 (TC3) of the Information Technology Industry Council. 2000. Disponível em:

<http://www.keysight.com/upload/cmc_upload/All/1.pdf?\&cc=BR\&lc=por>. Acesso em: Março 2016

KAGAN, N.; ROBBA, E. J.; SCHMIDT, H. P. Estimação de Indicadores de Qualidade da Energia Elétrica. Blucher, 2009. 240 p. ISBN 978-85-212-0487-9.

KAWAMURA, M. Tarefas em Uma Única Máquina com Data de Entrega Comum sob Penalidades de Adiantamento e Atraso. Dissertação de Mestrado, Escola Politécnica da Universidade de São Paulo. São Paulo, SP, p. 71, 2006.

KEMPNER, T. R. Robustez de um Sistema de Distribuição e a Alocação de Medidores de Qualidade da Energia Elétrica Frente aos Afundamentos de Tensão. Dissertação de mestrado, Universidade de São Paulo. São Carlos, SP, p. 135, 2012.

KERSTING, W. H. Radial DISTRIBUTION TEST FEEDERS, 2010. Power Engineering Society Winter Meeting, Columbus, p. 908-912, 2001.

KERSTING, W. H. Distribution System Modeling and Analysis. $2^{\mathrm{a}}$. ed. Florida, USA: Boca Raton, 2007. 421 p. ISBN 978-1-4398-5622-2.

KINDERMANN, G. Curto-Circuito. $1^{\circ}$. ed. Porto Alegre, RS: Editoração coordenada pelo próprio autor, 1992. ISBN 85-241-20368-X.

LAND, A. H.; DOIG, A. G. An Automatic Method of Solving Discrete Programming Problems. The Econometric Society, v. 28, p. 497-520, 1960.

LEBORGne, R. C. Uma contribuição à Caracterização da Sensibilidade de Processos Industriais Frente aos Afundamentos de Tensão. Dissertação de mestrado, Universidade Federal de Itajubá. Itajubá, MG, p. 163, 2003.

LUNA, E. K. Uma Contribuição ao Estudo de VTCDs Aplicado a Equipamentos Eletrônicos Alimentados por Conversor CA-CC. Dissertação de mestrado, Universidade Estadual de Campinas. Campinas, SP, p. 220, 2005.

MATHWORKS. Optimization ToolboxTM. User's Guide R2015b, 2015. Disponível em: <http://www.mathworks.com/help/pdf_doc/optim/optim_tb.pdf >. Acesso em: Fevereiro 2016. 
MCGRANAGHAN, M. F.; MUELLER, D. R.; SAMOTYJ, M. J. Voltage Sags in Industrial Systems. IEEE Transactions on Industry Applications, v. 29, p. 397-403, Mar./Apr. 1993.

NOVAES, E. G. C. Validação de Ferramentas de Simulação de Afundamentos de Tensão Através de Medições. Dissertação de Mestrado, Universidade Federal de Itajubá. Itajubá, MG, p. 152, 2007.

NRS 048-2. Electricity Supply - Quality of Supply, Part 2: Voltage Characteristics, Compatibility. Published in the Republic of South Africa by the South African Bureau of Standards. 2003. (ISBN 0-626-15179-1).

OLGUIN, G. Voltage Dip (Sag) Estimation in Power Systems Based on Stochastic Assessment and Optimal Monitoring. Thesis ( $\mathrm{PhD})$, Chalmers University of Technology. Göteborg, Sweeden, p. 193, 2005.

OLGUIN, G.; VUINOVICH, F.; BOLLEN, M. H. J. An Optimal Monitoring Program for Obtaining Voltage Sag System Indexes. IEEE Transactions on Power Systems, v. 21, p. 378-384, Feb. 2006.

OLIVEIRA, F. D. Monitoramento e Análise de Afundamentos Momentâneos de Tensão. Dissertação de mestrado, Universidade Federal de Minas Gerais. Belo Horizonte, MG, p. 107, 2015 .

OLIVEIRA, F. S. Programação Inteira Binária por Branch and Bound para Rebalanceamento de Linhas de Montagem em Ambiente de Mix de Modelos de Produtos: Um estudo de caso em uma empresa da indústria automobilística. Dissertação de mestrado em Gestão e Tecnologia Industrial, Faculdade Tecnologia SENAI CIMATEC. Salvador - BA, p. 108, 2011.

OLIVEIRA, J. C. Qualidade da Energia Elétrica - Uma visão da Área, 2000. Disponível em: <http://www.cck.com.br/artigos/palestras/Qualidade.pps>. Acesso em: Abril 2014.

ONS - OPERADOR NACIONAL DO SISTEMA ELÉTRICO. Indicadores de Qualidade de Energia Elétrica - Frequência e Tensão, Submódulo 25.6. Procedimentos de Rede. Brasil. 2010 .

QUAIA, S.; TOSATO, F. A Method for Analytical Voltage Sags Prediction. Power Tech Conference Proceedings, IEEE Bologna, p. 23-26, June 2003.

RAO, S. S. Engineering Optimization: Theory and Practice. $4^{\circ}$. ed. Hoboken, New Jersey: John Wiley \& Sons, 2009. ISBN 978-0-470-18352-6.

REIS, D. C. S. Um Algoritmo Branch and Bound para o Problema da Alocação Ótima de Monitores de Qualidade de Energia Elétrica em Redes de Transmissão. Dissertação de mestrado, Universidade Federal de Juiz de Fora. Juiz de Fora, MG, p. 119, 2007.

SEMI F47-0706. Specification for Semiconductor Processing Equipment Voltage Sag Immunity. Semiconductor Equipment and Material Institute. 2006. 
SILVA, J. M. Análise Comparativa de Resultados de Simulação de Afundamentos de Tensão Utilizando Programas de Curto-circuito e de Transitórios Eletromagnéticos. Dissertação de mestrado, Universidade Federal de Itajubá. Itajubá, MG, p. 215, 2004.

SOARES, R. Otimização de Layouts Industriais Utilizando Heurística SDPI no Treinamento de Redes Neurais MLP. Dissertação de Mestrado em Modelagem Matemática Computacional, Centro Federal de Educação Tecnológica. Belo Horizonte, MG, p. 92, 2006.

STEVEnSON JR, W. D. Elementos de Análise de Sistemas de Potência. 2º . ed. São Paulo: McGraw-Hill, 1986.

UNIPEDE. Guide to Quality of Electricity Supply for Industrial Applications, part 2, Voltage Dips and Short Interruptions. Paris. 1996.

WOLSEY, L. A. Integer Programming. New York: John Wiley \& Sons, 1998. ISBN 9780471283669. 


\section{Apêndice A - Consulta Pública ANEEL № 018/2014}

Na primeira versão do PRODIST aprovada em 2008, não foram estabelecidos limites para os fenômenos que afetam a QEE. Na época, devido à falta de conhecimento dos valores de medição dos fenômenos, considerou-se prudente estabelecer um programa de medição de duração mínima de 3 anos e que, somente após esse período, seriam estabelecidos os limites para os indicadores relativos a Desequilíbrio de Tensão, Harmônicos, Flutuação de Tensão e VTCDs.

Passados três anos, em 2011 foi aberta a consulta pública (CP N N $^{\circ} 005 / 2011,2011$ ) a fim de coletar subsídios para revisar o regulamento que trata da qualidade do produto. Como contribuição à consulta pública, a Associação Brasileira de Grandes Consumidores Industriais de Energia e de Consumidores Livres (ABRACE), relatou a insatisfação dos grandes consumidores industriais de energia com a qualidade do fornecimento de energia elétrica. Debateu-se ainda a definição de um protocolo de medição para cada fenômeno, para se estabelecer a obrigatoriedade de medições pelas distribuidoras, de forma a se obter uma base de dados consistente para a definição de responsabilidades entre os agentes.

A conclusão da consulta em 2011 foi que o assunto tratado era complexo e que havia necessidade de maior aprofundamento das discussões sobre o tema, não sendo definido um procedimento para medição das VTCDs, nem tampouco limites e penalidades para os distúrbios.

Diante da necessidade de aperfeiçoamento da Seção 8.1 do Módulo 8 do PRODIST para a regulamentação dos fenômenos de desequilíbrios de tensão, distorções harmônicas, flutuações de tensão e VTCDs, em 8/11/2013 foi assinado o contrato $n^{\circ}$ 179/2013-ANEEL com a Fundação de Apoio Universitário (FAU) para a prestação de serviços técnicos especializados de consultoria para dar suporte às ações da ANEEL na regulamentação dos fenômenos relacionados à qualidade do produto nas redes de distribuição de energia elétrica.

Os produtos elaborados pela consultoria geraram seis relatórios que constam na $\mathrm{CP} \mathrm{n}^{\mathrm{o}}$ 18/2014, instaurada em dezembro de 2014, abordando os seguintes temas:

Relatório 1 - Revisão bibliográfica atualizada do tema;

Relatório 2 - Definição dos indicadores para os fenômenos de desequilíbrios de tensão, harmônicos, flutuações de tensão e VTCDs; 
Relatório 3 - Definição do procedimento de medição para cada um dos fenômenos associados com a qualidade do produto;

Relatório 4 - Definição dos padrões de referência para os fenômenos de desequilíbrios de tensão, harmônicos, flutuações de tensão e VTCDs;

Relatório 5 - Definição dos procedimentos para acompanhamento da qualidade do produto na distribuição de energia elétrica; e

Relatório 6 - Proposições para o estabelecimento dos critérios mínimos para regulamentação dos padrões exigidos pelas distribuidoras quando da conexão de acessantes potencialmente perturbadores, ou de acessantes sensíveis a distúrbios na rede.

Com relação às VTCDs, no relatório 1 , foram analisadas as regulamentações e recomendações utilizadas no Canadá, em alguns países europeus (CENELEC) e também na África do Sul (NRS048). Na sequência, foi feito um levantamento sobre a proposição de indicadores e sistemas de medição para a avaliação dos distúrbios, sendo apresentados alguns relatórios finais de projetos de Pesquisa e Desenvolvimento $(\mathrm{P} \& \mathrm{D})$ regularizados pela ANEEL, e artigos técnico-científicos abordando aspectos relacionados ao monitoramento da QEE. As informações dos demais relatórios serão comentadas e discutidas na sequência.

\section{Definição de Indicadores e de Limites para as VTCDs}

O Relatório 2, da consulta pública $n^{\circ}$ 18/2014, teve como objetivo apresentar os conceitos gerais associados à definição dos indicadores, incluindo o aprimoramento ou inclusão de indicadores que possam ser utilizados para avaliação da qualidade do produto no âmbito da distribuição de energia elétrica no Brasil. Iniciando pela caracterização das VTCDs, o relatório destaca que os distúrbios podem ser interpretados através dos indicadores de desempenho que representem a amplitude, duração e frequência dos eventos, os quais estão expressos, respectivamente, em (112), (113) e (114).

$$
\begin{gathered}
V_{e}=\frac{V_{r e s}}{V_{r e f}} \cdot 100 \\
\Delta t_{e}=t_{f}-t_{i} \\
f_{e}=n
\end{gathered}
$$

Sendo:

$V_{e}$ - amplitude da VTCD, em \%; 
$V_{\text {res }}$ - tensão residual da VTCD;

$\mathrm{V}_{\text {ref }}$ - tensão de referência;

$\Delta t_{e}$ - duração da VTCD, em milissegundos;

$t_{f}-$ instante final da VTCD;

$t_{i}$ - instante inicial da VTCD;

$f_{e}-$ frequência de ocorrência das VTCDs; e

$n$ - quantidade de eventos de VTCDs registrados em um período de avaliação.

Para a estratificação dos parâmetros de amplitude e duração para contabilização das ocorrências de eventos de VTCDs, a sugestão da FAU é a subdivisão dos fenômenos conforme a Tabela 40, em consonância com a metodologia empregada pela norma NRS 048-2 (NRS 048-2, 2003), diferenciando-se apenas na subdivisão das células da tabela para contabilizar a ocorrência dos eventos.

Tabela 40 - Sugestão de metodologia para a estratificação dos parâmetros de amplitude e duração para contabilização dos eventos de VTCDs.

\begin{tabular}{|c|c|c|c|c|c|c|c|}
\hline \multirow[b]{2}{*}{$\begin{array}{c}\text { Amplitude } \\
\text { (p.u.) }\end{array}$} & \multicolumn{7}{|c|}{ Duração } \\
\hline & $\begin{array}{c}16,67-100 \\
\text { (ms) }\end{array}$ & $\begin{array}{c}100-300 \\
\text { (ms) }\end{array}$ & $\begin{array}{c}300-600 \\
\text { (ms) }\end{array}$ & {$[0,6-1](s)$} & {$[1-3](s)$} & {$[3 s-1 m i n]$} & {$[1-3](\min )$} \\
\hline $1,15-1,20$ & & & & & & & \\
\hline $1,10-1,15$ & & & & & & & \\
\hline $0,85-0,90$ & & & & & & & \\
\hline $0,80-0,85$ & & & & & & & \\
\hline $0,70-0,80$ & & & & & & & \\
\hline $0,60-0,70$ & & & & & & & \\
\hline $0,50-0,60$ & & & & & & & \\
\hline $0,40-0,50$ & & & & & & & \\
\hline $0,30-0,40$ & & & & & & & \\
\hline $0,20-0,30$ & & & & & & & \\
\hline $0,10-0,20$ & & & & & & & \\
\hline$<0,10$ & & & & & & & \\
\hline
\end{tabular}

Fonte: Adaptado de CP n⿳ 18/2014 (2014).

No relatório 2, é proposto ainda um agrupamento dos dados extraídos da Tabela 40, em nove categorias de sensibilidade (A à I), como mostra a Tabela 41, a qual também se baseia na NRS 048-2. Esta divisão tem por foco correlacionar a severidade do distúrbio manifestado com os níveis de sensibilidade dos diferentes equipamentos existentes nas unidades consumidoras. 
Fazendo uma análise comparativa entre a tabela apresentada na norma NRS 048-2 (Tabela 5), e a tabela proposta pela FAU (Tabela 41), percebem-se poucas diferenças, mantendo-se esta última conservadora na maioria das categorias, com algumas pequenas mudanças no intervalo de duração dos eventos e na faixa de amplitudes, listadas a seguir:

- Foram acrescidas quatro colunas, dividindo o intervalo de 1 ciclo - 600ms em três colunas, ao invés de duas colunas como consta na NRS 048-2;

- O intervalo de $600 m-3$ s foi dividido em duas colunas;

- Foram acrescidas duas colunas para registrar os eventos com duração de $3 \mathrm{~s}$ a $3 \mathrm{~min}$;

- Foram acrescidas duas categorias (H e I) para registrar as elevações de tensão;

- Na categoria B foi incluída a faixa de tensão de 0,7 a 0,8 p.u., alterando o intervalo de registro dos afundamentos de tensão para 1 ciclo - 100ms, em comparação com a categoria X1 da norma NRS 048-2;

- Na categoria C o intervalo de duração também foi alterado de 1 ciclo $-150 \mathrm{~ms}$, para 1 ciclo-100ms; e

- A área da categoria A foi reduzida em comparação com a NRS 048-2 (categoria Y), não entrando nesta categoria os eventos com tensão remanescentes inferiores a 0,8 p.u..

Tabela 41 - Proposta para caracterização das VTCDs.

\begin{tabular}{|c|c|c|c|c|c|c|c|}
\hline & \multicolumn{7}{|c|}{ Duração } \\
\hline $\begin{array}{c}\text { Amplitude } \\
\text { (p.u.) }\end{array}$ & $\begin{array}{c}16,67-100 \\
(\mathrm{~ms})\end{array}$ & $\begin{array}{c}100-300 \\
(\mathrm{~ms})\end{array}$ & $\begin{array}{c}300-600 \\
(\mathrm{~ms})\end{array}$ & {$[0,6-1](s)$} & {$[1-3](s)$} & [3s - 1min] & {$[1$ - 3] (min) } \\
\hline $1,15-1,20$ & \multirow{2}{*}{\multicolumn{3}{|c|}{ Categoria H }} & \multirow{2}{*}{\multicolumn{4}{|c|}{ Categoria I }} \\
\hline $1,10-1,15$ & & & & & & & \\
\hline $0,85-0,90$ & \multirow{2}{*}{\multicolumn{3}{|c|}{ Categoria A }} & & & & \\
\hline $0,80-0,85$ & & & & \multirow{2}{*}{\multicolumn{4}{|c|}{ Categoria G }} \\
\hline $0,70-0,80$ & \multirow{2}{*}{ Categoria B } & \multirow{4}{*}{\multicolumn{2}{|c|}{ Categoria D }} & & & & \\
\hline $0,60-0,70$ & & & & \multirow{7}{*}{\multicolumn{4}{|c|}{ Categoria F }} \\
\hline $0,50-0,60$ & Categoria C & & & & & & \\
\hline $0,40-0,50$ & Categutia & & & & & & \\
\hline $0,30-0,40$ & & \multirow{4}{*}{\multicolumn{2}{|c|}{ ategoria E }} & & & & \\
\hline $0,20-0,30$ & & & & & & & \\
\hline $0,10-0,20$ & & & & & & & \\
\hline$<0,10$ & & & & & & & \\
\hline
\end{tabular}

Fonte: Adaptado de CP n ${ }^{0}$ 18/2014 (2014).

Ressalta-se que como as ocorrências dos eventos são agrupadas em categorias, as alterações nas faixas de duração interferem muito pouco no registro dos eventos. 
Com relação ao limite de três minutos, proposto desde a primeira versão do PRODIST, na consulta pública $n^{\circ}$ 005/2011, a ABRACE já havia sugerido à ANEEL a adequação dos limites às reais condições em que os SDs estão inseridos atualmente. Inicialmente, este limite foi estabelecido com base no tempo de religamento manual dos SDs mais antigos. Como hoje, os religamentos da distribuição são realizados de maneira automática, não se justifica, portanto, um tempo tão longo de 3 minutos.

Uma vez estratificada a frequência de ocorrência dos eventos nas perspectivas categorias, a Consulta pública $\mathrm{n}^{\circ}$ 18/2014 propôs ainda, no relatório 2, uma inovação ao criar um indicador único, denominado Fator de Impacto (FI), que possibilita o acompanhamento das VTCDs nas redes de distribuição. A formulação aplicável ao FI é apresentada pela equação (115).

$$
F I=\frac{\sum_{i=A}^{I}\left(f_{e(i)} \cdot f_{p(i)}\right)}{F I_{\text {base }}} \quad i \in\{A ; B ; C ; \ldots I\}
$$

Sendo:

$f_{e(i)}$ - frequência de ocorrência dos eventos de VTCDs, apuradas por meio de medição apropriada, em um período de 30 dias consecutivos, para cada categoria de sensibilidade $i$;

$f p_{(i)}$ - fator de ponderação para cada categoria de sensibilidade $i$; e

$\mathrm{FI}_{\text {base }}$ - fator de impacto base, calculado considerando-se os fatores de ponderação e a frequência limite de ocorrência de VTCDs para cada categoria de sensibilidade $i$.

Para o cálculo do FI foram propostos, no relatório 4, valores limites em função das categorias estabelecidas, considerando o número máximo de eventos para a avaliação das VTCDs ao longo de 01 mês de medições. A Tabela 42 mostra os limites máximos dos eventos para Sistemas de Distribuição de Média Tensão (SDMTs), com tensões nominais maiores que $1 \mathrm{kV}$ e menores que $69 \mathrm{kV}$ (em vermelho), e para Sistemas de Distribuição de Alta Tensão (SDATs), com tensões nominais maiores que $69 \mathrm{kV}$ (em azul).

Além dos limites máximos estabelecidos, também foram propostos fatores de ponderação, grandezas estas diretamente correlacionadas com a relevância das VTCDs. A FAU relata que tais valores são consonantes com critérios empregados na NRS 048-2. Baseados nesta experiência, o trabalho de consultoria propôs os fatores de ponderação conforme a Tabela 43. Entretanto, não fica evidente, no relatório 4, ou mesmo na norma NRS 048-2, como estes valores foram calculados. Apenas subentende-se que o fator de ponderação é definido conforme a severidade dos eventos. 
Tabela 42 - Número máximo de ocorrências de VTCDs.

\begin{tabular}{|c|c|c|c|c|c|c|c|}
\hline & \multicolumn{5}{|c|}{ Duração } & & \\
\hline $\begin{array}{l}\text { Amplitude } \\
\text { (p.u.) }\end{array}$ & $\begin{array}{c}16,67-100 \\
\text { (ms) }\end{array}$ & $\begin{array}{c}100-300 \\
\text { (ms) }\end{array}$ & $\begin{array}{c}300-600 \\
(\mathrm{~ms})\end{array}$ & {$[0,6-1](s)$} & [1s - 3min] & & \\
\hline $1,15-1,20$ & & \multirow{2}{*}{\multicolumn{2}{|c|}{1}} & \multirow{2}{*}{\multicolumn{2}{|c|}{1}} & & \\
\hline $1,10-1,15$ & & & & & & $\square$ & Categoria A \\
\hline $0,85-0,90$ & \multirow{2}{*}{\multicolumn{3}{|c|}{ Sem limites }} & \multirow{3}{*}{4} & \multirow{3}{*}{1} & $\square$ & Categoria B \\
\hline $0,80-0,85$ & & & & & & $\square$ & Categoria C \\
\hline $0,70-0,80$ & \multirow{2}{*}{5} & \multirow{4}{*}{3} & \multirow{4}{*}{2} & & & $\square$ & Categoria D \\
\hline $0,60-0,70$ & & & & \multirow{7}{*}{1} & \multirow{7}{*}{1} & $\square$ & Categoria E \\
\hline $0,50-0,60$ & \multirow{2}{*}{4} & & & & & $\square$ & Categoria F \\
\hline $0,40-0,50$ & & & & & & & Categoria G \\
\hline $0,30-0,40$ & & \multirow{4}{*}{1} & & & & $\square$ & Categoria H \\
\hline $0,20-0,30$ & & & & & & $\square$ & Categoria I \\
\hline $0,10-0,20$ & & & & & & & \\
\hline$<0,10$ & & & & & & & \\
\hline
\end{tabular}

Fonte: Adaptado de CP n ${ }^{\circ}$ 18/2014 (2014).

Tabela 43 - Fator de ponderação para o cálculo do FI.

\begin{tabular}{|c|c|c|c|}
\hline \hline \multirow{2}{*}{ Categoria } & Fator de ponderação & \multicolumn{2}{|c|}{ Frequência de ocorrência máxima $\left(\boldsymbol{f}_{\boldsymbol{e}_{\_} \max }\right)$} \\
\cline { 3 - 4 } & $\boldsymbol{f} \boldsymbol{p})$ & SDMT & SDAT \\
\hline \hline A & 0 & - & - \\
\hline B & 0,04 & 5 & 3 \\
\hline C & 0,07 & 4 & 2 \\
\hline D & 0,15 & 3 & 1 \\
\hline E & 0,25 & 2 & 1 \\
\hline F & 0,36 & 1 & 1 \\
\hline G & 0,07 & 4 & 1 \\
\hline H & 0,02 & 1 & 1 \\
\hline I & 0,04 & 1 & $\mathbf{1 , 4 2}$ \\
\hline \multicolumn{2}{|c|}{ Fator de Impacto base $\left(\mathbf{F I}_{\text {base }}\right)$} & $\mathbf{2 , 1 3}$ & \\
\hline
\end{tabular}

Fonte: Adaptado de CP n ${ }^{\circ}$ 18/2014 (2014).

Para o cálculo do FI é definido ainda um Fator de Impacto base $\left(\mathrm{FI}_{\text {base }}\right)$, que é calculado a partir da quantidade máxima de eventos ocorridos e do fator de ponderação para uma determinada categoria, conforme apresentado em (116). Este fator seria, a princípio, considerado o limiar do indicador acima do qual os fenômenos se apresentariam acima dos níveis admissíveis, limitando, portanto, o FI em 1 p.u..

$$
F I_{\text {base }}=\sum_{i=A}^{I}\left(f_{e_{-} \max (i)} \cdot f_{p(i)}\right) \quad i \in\{A ; B ; C ; \ldots I\}
$$


Após a proposição do FI e dos limites máximos de ocorrência das VTCDs foi realizada uma análise de consistência para os limites propostos diante de campanhas de medição realizadas pelas distribuidoras nacionais Elektro e Escelsa. Os resultados dos cálculos do FI para cada categoria estão disponíveis no relatório 4 da nota técnica 105/2014 (CP No 005/2011, 2011).

Ao analisar a consistência dos limites propostos diante das medições encaminhadas pelas distribuidoras, a consultoria concluiu que a maioria das medições foi considerada adequada e em alguns casos os limites foram conservadores. Dos resultados apurados para o SDMT da distribuidora Elektro, considerando 138 pontos de medição, 95,65\% dos pontos monitorados apresentaram patamares inferiores ao limite de 1 p.u. proposto. Para o SDAT, 98,04\% dos 51 pontos monitorados apresentaram valores adequados para o FI. No SDMT da Escelsa, os resultados foram obtidos a partir de medições realizadas em 19 subestações, sendo que em todos os pontos monitorados os valores calculados para o FI foram menores que o limite proposto.

Em um estudo recente realizado por Oliveira (2015), foram realizadas medições no SD da Companhia Energética de Minas Gerais (CEMIG) por um período de 36 (trinta e seis) meses, compreendidos de abril/2011 a março/2014. O sistema de medição foi instalado no campus Pampulha da Universidade Federal de Minas Gerais (UFMG), onde foram registrados 297 (duzentos e noventa e sete) afundamentos de tensão no período monitorado. Utilizando os resultados de medição, no mês de dezembro de 2011, mês que apresentou o maior número de distúrbios, constatou-se que a CEMIG não atenderia aos limites propostos pela consulta pública. Para o mesmo período, o autor observou que os meses com mais eventos registrados foram os meses mais chuvosos na região metropolitana de Belo Horizonte, havendo, portanto, uma forte correlação entre o número de distúrbios registrados e os níveis de precipitação (OLIVEIRA, 2015).

Neste contexto, para o momento, considera-se mais importante o acompanhamento dos indicadores propostos para avaliar se um FI único mensal é indicado para todas as distribuidoras de energia. Considerando a diferença no nível de precipitação e sazonalidade anual de cada região, segundo os dados de precipitação acumulada (de 1961 a 1990) do Instituto Nacional de Meteorologia (INMET), seria imparcial penalizar igualmente as distribuidoras, pois em determinados meses a probabilidade de ocorrência de eventos em um determinado estado é bem discrepante dos demais. Tal situação pode ser ilustrada pela precipitação acumulada para quatro capitais brasileiras, conforme a Figura 83. 
Da mesma forma como foi criado um fator de ponderação dos níveis de sensibilidade para cada categoria, talvez uma solução seja incluir também um fator de ponderação de precipitação a ser incluído no cálculo do $\mathrm{FI}_{\text {base }}$ para cada estado brasileiro. Este fator seria calculado com base em dados climáticos, sendo que as informações poderiam ser obtidas no próprio site do Operador Nacional do Sistema (ONS), onde já existem dados de precipitação diária, semanal e mensal para o Brasil.

É evidente que esta é uma ideia preliminar, que necessita de muitas análises e maior aprofundamento sobre o tema. Contudo, é inegável a necessidade de distinção entre as regiões com maiores taxas de precipitação, visto que a probabilidade de ocorrências das VTCDs é bem maior, devido às descargas atmosféricas e ventos fortes, que podem ocasionar o contato direto entre cabos energizados ou contatos com árvores, entre outros fatores. Portanto, não se considera equitativa a atribuição de um índice global para todas as distribuidoras de energia, devendo ser atribuídas ao FI base às peculiaridades regionais.

Figura 83 - Precipitação acumulada (1961 a 1990).

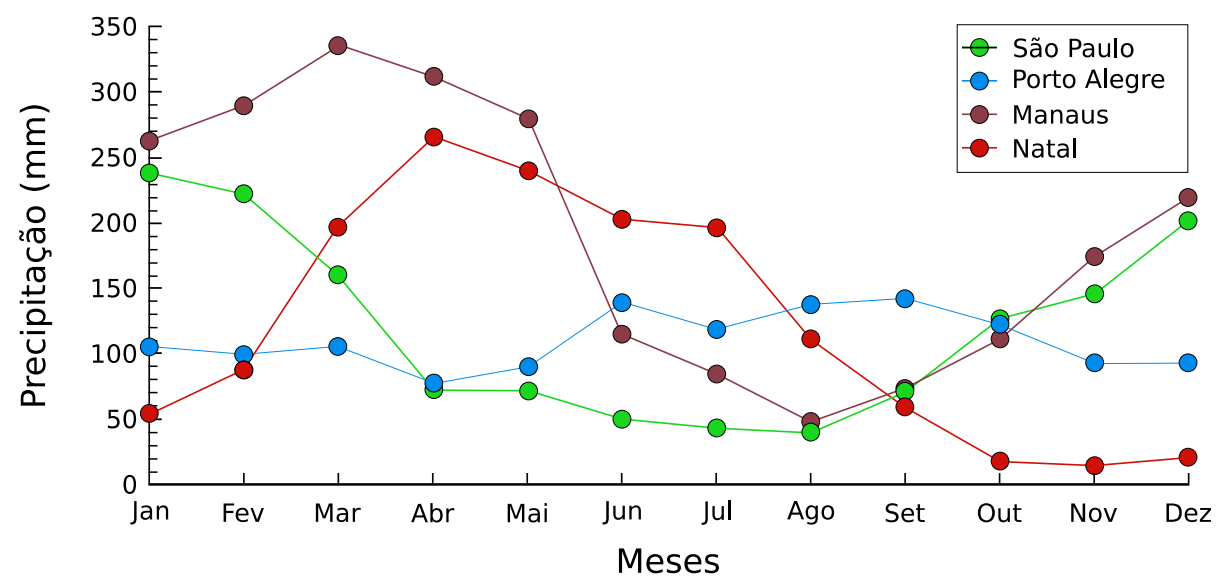

Fonte: Adaptado de INMET (2016).

Outro fator importante para a validação do índice proposto é o local de instalação do medidor, visto que se os medidores forem instalados nas subestações iriam registrar um número menor de eventos, como veremos no decorrer deste trabalho. Talvez por este motivo, ao analisar a consistência dos limites propostos, $100 \%$ dos pontos monitorados nas subestações pela distribuidora Escelsa apresentaram valores adequados.

Neste cenário, ressalta-se a necessidade de um estudo propenso a determinar os locais mais vulneráveis do SD de forma a instalar os medidores em pontos estratégicos para capturar o maior número possível de eventos, evidenciando os objetivos e contribuições deste trabalho. 


\section{Procedimentos para o Acompanhamento das VTCDs}

Para medições das VTCDs a nota técnica 105/2014 recomenda, no relatório 3, que sejam considerados os requisitos de medição definidos pela norma IEC 61000-4-30. Onde poderão ser utilizados instrumentos de medição classe A ou S. O princípio de medição da tensão eficaz para quantificação VTCDs estabelece que o valor da tensão deve ser calculado a cada $1 / 2$ ciclo, para medidores da classe $A$, ou a cada $1 / 2$ ciclo ou 1 ciclo, para medidores da classe S, sendo que o valor da tensão eficaz correspondente deve incluir, obrigatoriamente, as distorções harmônicas, assim como as inter-harmônicas de tensão. O valor calculado pode representar tensões de fase ou de linha.

A detecção e avaliação das VTCDs devem ser realizadas com base em uma porcentagem da tensão de referência (limiar de detecção), a qual pode ser fixa (definida pelo usuário), ou deslizante, calculada conforme a equação (117).

$$
V_{s r(n)}=0,9967 \cdot V_{s r(n-1)}+0,0033 \cdot V_{(12 R M S)}
$$

Sendo:

$V_{s r(n)}$ - valor calculado da tensão de referência;

$V_{s r(n-1)}$ - valor prévio da tensão de referência; e

$V(12 R M S)$ - valor da tensão eficaz média de 12 ciclos mais recente.

Conforme a consultoria, os limiares a serem utilizados para a detecção das VTCDs são de $85 \%$ ou $90 \%$ da tensão de referência, para o caso dos afundamentos momentâneos de tensão, e de $110 \%$ da tensão de referência para o caso das elevações momentâneas de tensão.

No relatório 5 da nota técnica 105/2014 (CP No 18/2014, 2014) constam três modalidades para a avaliação das VTCDs, a medição amostral, permanente e eventual (visando o atendimento às reclamações dos consumidores).

No caso das medições amostrais para quantificação das VTCDs, a consultoria propõe a avaliação do fenômeno em períodos consecutivos de 7 (sete) dias, visando uma uniformização com o período de medição já utilizado para avaliação das variações de tensão em regime permanente, assim como para os demais indicadores da qualidade do produto.

Para a realização de medições permanentes para o acompanhamento dos indicadores da qualidade do produto, verificam-se três possibilidades distintas a serem consideradas:

- Realização de uma campanha nacional de medições, abrangendo os indicadores da 
qualidade do produto em todas as distribuidoras do país;

- Instalação de medidores permanentes de QEE em pontos específicos do SD; e

- Realização de medições eventuais, visando o atendimento às reclamações dos consumidores.

Em relação à realização de uma campanha de medição nacional, devido aos custos associados serem bastante elevados, a consultoria sugere que em um primeiro momento, o acompanhamento dos indicadores seja realizado de forma a aproveitar, na medida do possível, as ações já realizadas pelas distribuidoras no atendimento à regulamentação atual.

Para a realização de medições permanentes deverão ser armazenadas a amplitude e duração das VTCDs, indicando a data e hora de início de cada evento, sendo recomendados dois critérios para a definição da quantidade e localização dos medidores no SD:

Critério 1 - Instalação de medidores (Classe S) nas barras de média e alta tensão de todas as subestações de distribuição com potência instalada igual ou superior a 25 MVA, assim como em todos os novos consumidores conectados ao SDAT; e

Critério 2 - Os consumidores atualmente conectados ao SDAT, ou ao SDMT, que desejarem a instalação dos medidores para acompanhamento da qualidade da tensão, deverão assumir os custos da instalação (equipamentos e mão-de-obra), sendo atribuição da distribuidora a definição dos critérios técnicos, dos equipamentos a serem utilizados, assim como da instalação dos equipamentos.

No caso das medições eventuais, em função da necessidade de uma caracterização do barramento de um consumidor em específico, a consultoria sugere aproveitar a mesma estrutura já existente para realização das medições amostrais de nível de tensão em regime permanente, considerando-se os mesmos critérios atualmente utilizados pelas distribuidoras, porém, substituindo-se os medidores de tensão por medidores de parâmetros da QEE .

Como os eventos das VTCDs são responsáveis pela quase totalidade das reclamações associadas à qualidade do produto, por parte dos consumidores conectados ao SDMT e ao SDAT, foram sugeridos alguns procedimentos de gestão das reclamações, visando a identificação, análise e ações corretivas (e respectivos prazos) para diminuição da incidência desses eventos nos SDs. As ações sugeridas são as seguintes:

1. Após o recebimento da reclamação, a distribuidora deverá instalar, em um prazo máximo de 15 dias consecutivos, contados da data da reclamação, medição digital junto ao ponto de conexão da unidade consumidora visando à caracterização do barramento em relação à incidência de VTCDs, o qual deverá permanecer instalado pelo período mínimo de 30 (trinta) dias consecutivos; 
2. A distribuidora deverá informar ao consumidor, com antecedência mínima de 5 (cinco) dias, a data e o horário da instalação do equipamento de medição, seu direito de acompanhar a instalação e o prazo de entrega do laudo técnico do resultado da medição, o qual deverá ser de 60 (sessenta) dias a partir da reclamação, informando o valor a ser cobrado pelo serviço, caso o resultado da medição não apresente FI superior ao limite estabelecido;

3. Os registros deverão ser organizados em arquivos individualizados, incluindo número de protocolo, datas da reclamação do consumidor e aviso da distribuidora ao reclamante sobre a realização da medição, que deverão estar disponibilizados, em meio magnético ou ótico, por um período mínimo de 5 (cinco) anos, para fins de fiscalização da ANEEL e consulta dos consumidores.

4. Após a retirada da medição, os resultados obtidos deverão ser analisados visando à elaboração de um relatório técnico, a ser fornecido à unidade consumidora, no prazo de 30 (trinta) dias consecutivos após o término da medição, o qual deverá conter as seguintes informações:

- Detalhamento dos eventos de VTCDs registrados conforme a Tabela 44;

- A estratificação dos eventos de VTCDs registrados conforme a Tabela 40;

- O FI para as VTCDs na barra monitorada. No caso de medições com duração superior a 30 dias, deverá ser calculado um FI para cada período inteiro de 30 dias de medição, sendo considerado o pior resultado;

- As ações a serem realizadas pela distribuidora, e respectivos prazos, visando à redução da frequência de ocorrência dos eventos com causas reincidentes originadas no SD; e

- Recomendações de ações a serem desenvolvidas por parte do consumidor, quando for o caso, visando à redução da sensibilidade das cargas ou proteções elétricas existentes.

Tabela 44 - Detalhamento das VTCDs registradas no período de monitoração.

\begin{tabular}{|c|c|c|c|c|c|c|}
\hline \hline Reg. & Data & Hora & $\begin{array}{c}\text { Amplitude da } \\
\text { VTCD em p.u. }\end{array}$ & $\begin{array}{c}\text { Duração do } \\
\text { evento (ms) }\end{array}$ & $\begin{array}{c}\text { Tipo do } \\
\text { evento }\end{array}$ & $\begin{array}{c}\text { Evento correspondente registrado } \\
\text { no relatório diário de operação }\end{array}$ \\
\hline \hline 1 & & & & & & \\
\hline 2 & & & & & & \\
\hline 3 & & & & & & \\
\hline 4 & & & & & & \\
\hline 5 & & & & & & \\
\hline 6 & & & & & & \\
\hline$\vdots$ & & & & & & \\
\hline
\end{tabular}

Fonte: Adaptado do relatório 5, nota técnica 105/2014, CP n ${ }^{\circ}$ 18/2014 (2014). 
Diante do exposto pela consultoria pública, desconsidera-se a opção associada com a realização de campanhas específicas de medição, em função, principalmente, dos custos adicionais envolvidos para instalação, retirada e gestão de medidores, assim como da necessidade de repetição da referida campanha de tempos em tempos, de forma a se ter um retrato sempre atualizado das reais condições do SD.

Portanto, mesmo que sejam aceitas as propostas para o aperfeiçoamento do PRODIST, não será possível obter índices de desempenho do SD, visto que no caso das medições amostrais, o período de monitoração de 7 dias, não é suficiente para caracterizar as VTCDs. Com relação às medições eventuais, que consideram o período de 30 dias de medição, consideram-se as mesmas, inicialmente, indicadas para atender às reclamações do consumidor, entretanto, apenas com este período de monitoração não se podem inferir índices de desempenho local do SD. Por este motivo, não se considera procedente atribuir encargos ao consumidor caso o resultado da medição não apresente FI superior ao limite estabelecido.

Em relação às campanhas de medições permanentes, com a instalação dos medidores nas subestações dos barramentos do SD com potência instalada igual ou superior a 25 MVA, consideram-se as mesmas muito importantes para que o setor elétrico possa oferecer maior visibilidade em relação a suas redes de distribuição. Entretanto, estas não serão suficientes para a validação dos índices propostos e tampouco para suprir a necessidade de desempenho dos consumidores industriais que necessitam de mais qualidade no fornecimento da energia elétrica, visto que as subestações são os locais com menor índice de registro dos eventos, como será enfatizado nos resultados deste trabalho.

Neste sentido, mesmo com a instalação de medidores permanentes, entende-se que o FI proposto será indicado apenas para fornecer índices de desempenho do local monitorado, sendo que para estendê-lo a âmbito de índice de desempenho do sistema é necessária a instalação de medidores em pontos estratégicos do SD.

\section{Contribuição à Consulta Pública no 18/2014}

Em dezembro de 2014, foi instaurada por meio de intercâmbio documental, a consulta pública $n^{\circ} 18 / 2014$. Nesta consulta pública, foi disponibilizada no dia 23/12/2014, a nota técnica nº 105/2014_SRD/ANEEL com vários pontos de discussão sobre os indicadores de qualidade do produto, definição de limites, instrumentação e metodologia de medição e questionamentos relativos ao acompanhamento dos indicadores. Sendo elaboradas as seguintes questões referentes às VTCDs: 
1. O indicador proposto para o acompanhamento das VTCDs está adequado ao objetivo da análise da qualidade na distribuição? Quais seriam as opções alternativas?

2. Os valores máximos de frequência de ocorrência para cada categoria de sensibilidade das VTCDs estão adequados?

3. Os fatores de ponderação do FI para cada categoria estão adequados?

4. As precisões propostas da leitura de cada fenômeno estão adequadas?

5. A padronização do arquivo de saída de dados dos medidores está adequada às necessidades das distribuidoras?

6. O critério da seleção das subestações com potência superior a 25MVA para a realização de medição permanente está adequado?

7. Devem ser estabelecidas penalidades quando da ultrapassagem dos limites? Se sim, como estabelecer os procedimentos para atribuir responsabilidades?

Finalizada a consulta pública, foram registradas 10 contribuições referentes aos questionamentos, encaminhadas por fabricantes, universidades, distribuidoras, associações representativas e outras entidades, as quais são listadas a seguir:

- AES Brasil;

- Associação Brasileira de Distribuidores de Energia Elétrica - ABRADEE;

- Associação Brasileira de Grandes Consumidores Industriais de Energia e de Consumidores Livres (ABRACE);

- Companhia Estadual de Distribuição de Energia Elétrica (CEEE-D);

- Eletrobrás - CEPEL;

- Grupo CPFL Energia;

- Grupo Energias do Brasil (EDP);

- Grupo de Qualidade da Energia Elétrica (GQEE) UNIFEI;

- Kron Instrumentos Elétricos; e

- Sociedade Brasileira de Qualidade da Energia Elétrica (SBQEE).

Com relação às três primeiras questões relacionadas ao FI proposto, aos valores máximos de frequência de ocorrência e sobre a adequabilidade dos fatores de ponderação do indicador FI definidos para cada categoria de sensibilidade, obtiveram-se as seguintes contribuições:

A AES Brasil afirma a necessidade da consideração de fatores regionais (os quais devem refletir as áreas predominantemente urbanas ou rurais, a densidade de unidades 
consumidoras, o perfil de carga, etc.), a definição dos pontos de medição e a sazonalidade climática para que o indicador não seja único para todo o setor elétrico. Também afirma a necessidade de validação das informações de definição dos indicadores, como o fator de ponderação, devendo ser testadas em uma base de dados consistente, proveniente de uma campanha de medição nacional, ou da implementação de processo gradual de instalação de medição em locais adequados. Com relação à adequação dos valores máximos propostos disse que não tem como chegar a uma conclusão pela ausência de uma base de dados consistente para validar tais valores para cada categoria, reforçando a necessidade de etapas anteriores à proposição do indicador. Acrescenta ainda que o número máximo de eventos foi baseado na norma sul-africana NRS 048-2, que estabelece um período de análise anual. Já os limites propostos são baseados em uma apuração mensal, demonstrando que existem fatos a serem apurados para o perfeito entendimento da proposta. A AES Brasil destaca ainda que não foi possível identificar a origem dos fatores de ponderação a partir dos anexos dispostos na nota técnica, e supõe uma relação direta com a norma sul-africana. A partir desta suposição, recomenda a aplicabilidade da proposta ao caso brasileiro.

A ABRADEE destacou que o estudo apresentado não é suficiente para representar fielmente as diferenças regionais, a sazonalidade, as áreas rural e urbana, o período climático, bem como as diferenças da propagação dos fenômenos nos diversos pontos do SD, afetando assim na correta representação do impacto deste fenômeno nos diferentes pontos da rede de distribuição. Afirmou não ser possível opinar quanto à adequabilidade dos valores propostos, uma vez que não há uma base de dados fidedigna do país, sendo que os valores foram validados com dados insuficientes, restritos a 02 distribuidoras do país. Também ressalta quanto a um maior esclarecimento a respeito da metodologia empregada para obter os valores de ponderação, máxima frequência dos eventos e a definição das categorias de sensibilidade. Complementa ainda, que o período de 30 dias é insuficiente para medir, quantificar, avaliar e representar a rede quanto à ocorrência de VTCDs, sendo necessárias medições permanentes deste fenômeno em todo o país a fim de obter uma base de dados mais concisa e representativa da realidade no Brasil, para então estruturar melhor este indicador.

A ABRACE mencionou que a metodologia elaborada para classificar as VTCDS em categorias de sensibilidade (A a I), e definir o FI como um indicador global para esses fenômenos está bem fundamentada, de fácil entendimento, e atende às expectativas da Associação. Contudo, destacou que os valores inicialmente propostos que criam o FI base e o limite máximo de eventos não refletem a qualidade do produto necessária à indústria, por considerar que o consumidor industrial poderá sofrer uma grande quantidade de 
desligamentos. Menciona ainda que não é possível a alteração dos fatores de ponderação de cada uma das categorias de sensibilidade em virtude da grande diversidade de cargas. Desta forma, sugere os seguintes pontos para aperfeiçoar a apuração do FI:

a) Adotar a medição permanente das VTCDs, incluindo-se, entretanto, a opção do consumidor de efetuar a instalação do medidor de QEE padronizado pela distribuidora;

b) Estipular períodos iniciais de testes e de adaptações, desde que limitados e não superiores a 180 dias, após os quais seria apurado o FI base de cada distribuidora; e

c) Substituir o limite único do FI de 1,0 p.u. por três novos limites, válidos para os períodos mensal ( 0,5 p.u.), trimestral ( 0,9 p.u.) e anual ( 1,7 p.u. $)$, visando criar números mais adequados para a realidade dos consumidores atendidos em alta tensão ( $\mathrm{Vn} \geq 69 \mathrm{kV})$.

Com relação à sugestão (c), a ABRACE propõe que uma mesma distribuidora seja representada por diferentes FIs bases, que seriam mais restritivos às regiões com maiores densidades de cargas industriais e mais permissivos às regiões menos industrializadas, com cargas predominantemente residenciais ou rurais.

A Eletrobrás- CEPEL julgou improcedente a definição de fatores de ponderação neste momento, devido os mesmos terem sido validados por dados obtidos de apenas duas distribuidoras (Elektro e Escelsa), ambas localizadas na região sudeste. Outro ponto de discordância foi com relação ao período de 30 dias para se contabilizar os fenômenos, esclarecendo que a frequência das VTCDs é dependente, sobretudo de condições climáticas como chuvas, ventos, queimadas e outros fatores que podem não ocorrer no intervalo de 30 dias proposto. Sugerindo, portanto, um período de medição de no mínimo 90 dias.

As distribuidoras da CPFL entendem que o indicador está adequado. No entanto, há a necessidade de maiores esclarecimentos quanto à metodologia adotada pela consultoria, que não evidencia a correlação entre o SD brasileiro com as curvas de sensibilidade de diferentes equipamentos a fim de estratificar as ocorrências das VTCDs, seu fator de ponderação e a sua frequência de ocorrência máxima. O Grupo CPFL diz não ser possível confirmar a adequação dos valores propostos uma vez que estes foram correlacionados com a norma sul-africana, não sendo possível verificar a aderência ao SD brasileiro. Afirma sua discordância em relação ao posicionamento da norma sul-africana quanto à impossibilidade de estabelecimento de limites, e que é necessária uma base de dados com medições realizadas por todas as distribuidoras do país, a fim de verificar a realidade de cada concessão. Por fim, sugerem 
medições que representem de forma adequada e fidedigna o sistema elétrico brasileiro, para que seja possível avaliar de forma mais eficaz a proposição de novos indicadores e os reais impactos deste fenômeno no SD, considerando as peculiaridades de cada região.

O grupo EDP questionou o período apresentado para estratificação da frequência de ocorrência dos eventos para o cálculo do FI, alegando que medições amostrais de 30 (trinta) dias possuem pouca, ou até mesmo, nenhuma relevância para o tratamento das VTCDs, uma vez que, para se atingir uma precisão de cerca de $90 \%$ com uma frequência de 1 (um) evento por dia, é necessário, no mínimo, 1(um) ano de medição. O grupo destacou a necessidade de avanços na definição dos limites máximos de frequência de ocorrência propostos, enfatizando que o limite máximo da categoria $\mathrm{F}$ não é realista, sugerindo, portanto, a alteração deste limite máximo para 3 (três) possíveis ocorrências. Também comentou que outro aspecto importante a ser considerado na definição de limites é a localização do ponto a ser medido, pois há distinção entre medições de eventos de VTCDs em pontos próximos às subestações de pontos distantes, propondo fatores de ponderação e/ou fator de impacto base diferentes para pontos de medição com características geoelétricas diferentes. Concluiu ainda que os estudos apresentados pela consultoria foram limitados, merecendo uma análise mais profunda que possibilite identificar como os fatores de ponderação se relacionam com a dinâmica geral de operação dos SDs.

O grupo de QEE da UNIFEI ressaltou que os afundamentos e elevações de tensão devem ser tratados separadamente, considerando que os efeitos destes dois distúrbios sobre os equipamentos dos consumidores são distintos, e que a frequência com que se observam as elevações de tensão é muito inferior à de afundamentos de tensão. Sugerindo, portanto, que os distúrbios continuem a ser tratados individualmente. Além disso, recomenda a inclusão dos eventos maiores que 1,2 p.u., já que estes eventos são os que causam danos mais severos aos equipamentos. Pela argumentação científica apresentada, o grupo de QEE julgou que o fator de ponderação proposto não é relevante, propondo o cálculo do fator de ponderação através do índice de severidade, utilizando a equação (9), de forma refletir efetivamente o real impacto dos eventos sobre as cargas sensíveis dos consumidores atendidos pelo SDMT e SDAT. Por fim, foi sugerido que o período mínimo de medição das VTCDs seja reavaliado, já que são eventos de natureza aleatória e sazonal, não sendo suficiente um mês de medição para se obter informações concretas.

Segundo a SBQEE, a metodologia é tecnicamente interessante, porém destaca a necessidade de aperfeiçoamento quanto ao período de avaliação, destacando que dados correspondentes a 7 (sete) dias, ou 30 (dias) de medição, não trarão nenhum subsidio 
consistente para a avaliação de desempenho das VTCDs, pois este tempo é insuficiente para considerar a sazonalidade climática, fator determinante quanto à incidência desses eventos. Neste sentido, é indicada a adequação do período de avaliação para 1 (um) ano, de forma a obter a comparação de desempenho entre meses do período seco com meses do período chuvoso. Por fim, a SBQEE não firma posição quanto aos valores máximos de frequência, afirmando ser necessário um período de acompanhamento dos dados a fim de verificar a consistência dos valores.

Com relação à instrumentação e metodologia de medição, abstrai-se das contribuições da AES Brasil, ABRADEE, Grupo CPFL e SBQEE, a concordância quanto à proposta da ANEEL referente ao questionamento 4. O grupo de QEE da UNIFEI ressalta que a detecção e a caracterização dos eventos de VTCDs deverão ser realizadas por meio de instrumentos de medição que considerem como parâmetro de referência uma tensão fixa, desconsiderando a possibilidade de utilizar uma tensão média deslizante, dado que a distribuidora deve cumprir o que foi estabelecido em contrato com o consumidor. O fabricante Kron diz que a precisão na duração dos VTCDs deveria ser diferente entre os instrumentos classe A e classe S, conforme cita a IEC 61000-4-30. Para a classe A, a Kron afirma que a precisão seria de 1 ciclo, para classe $\mathrm{S}$ de 2 ciclos, e que para o restante dos parâmetros a proposta estaria adequada.

Com relação à questão 5, a ABRADEE diz que a padronização do arquivo de saída de dados pelos fabricantes de medidores é necessária. Além disso, destaca ser fundamental a próatividade dos fabricantes destes equipamentos a fim de se alinharem e definirem um padrão de saída. As contribuições do Grupo AES Brasil e do Grupo CPFL relatam ser importante tal padronização, mas reiteram a necessidade de fomentar a discussão com os fornecedores de equipamentos e sistemas de medição, estimulando a livre concorrência a partir de um mercado bem definido e perene. Em complemento, o Grupo CPFL argumenta que, ao propor uma metodologia de apuração dos indicadores de qualidade diferente daquela que hoje é praticada pelo ONS, os medidores de qualidade deverão atender a dois protocolos distintos, sob a pena de não se lograr êxito na busca de um protocolo uniforme de saída de dados pelos fabricantes. Finalizando a contribuição a empresa Kron se mostrou favorável à padronização do arquivo.

Com relação a questão 6, a AES Brasil entende que o critério de seleção das subestações deve ser estabelecido pelas distribuidoras, visto que pode existir subestações com potência abaixo da estabelecida (25 MVA) com necessidade de monitoramento permanente da qualidade em função de especificidades geoelétricas.

A ABRADEE afirma que selecionar um critério único a ser aplicado a todas as 
distribuidoras não é o procedimento mais adequado, pois pode não resultar na representatividade das áreas de concessão, a depender das particularidades de cada sistema. Sugere que a distribuidora já inclua os medidores de QEE na implantação de uma nova subestação, e também estabeleça um cronograma para a implementação de medições permanentes em pontos fraqueados pelas distribuidoras, sendo as regiões representativas de suas concessões.

A ABRACE concorda com o critério proposto pela ANEEL, pois permite sinalizar medições de QEE em maiores densidades de cargas. Contudo, destaca que deve ser prevista a hipótese de o consumidor realizar a instalação da medição, senda esta aferida e reconhecida pela distribuidora.

A CEEE-D entende que deve ser especificado se os barramentos de transferência das subestações também serão pontos de medição. Também sugere esclarecimento se, a exemplo de uma subestação com potência maior ou igual a 25 MVA, composta por 2 transformadores de 12,5 MVA, também deveria ter medição nos barramentos desses transformadores, ou se seria aplicado somente aos transformadores com potência maior ou igual a 25 MVA.

A Eletrobrás-CEPEL acredita que faça mais sentido em um primeiro momento agregar estes instrumentos apenas nos barramentos de alta tensão ( $\mathrm{Vn} \geq 69 \mathrm{kV})$.

O grupo CPFL entende que um critério único não seja o mais adequado, pois não garante a escolha de pontos representativos, uma vez que não considera as particularidades regionais. Sugere que o processo de escolha das subestações, a serem realizadas medições permanentes, considere critérios técnicos que garantem a escolha de pontos representativos, com a necessidade do estabelecimento de um cronograma de instalação compatível com a capacidade de implementação das distribuidoras.

O grupo EDP mencionou que atualmente nem todas as subestações possuem monitoramento em todas as barras, dessa forma, entendem ser pertinente e importante a definição de um cronograma escalonado de modernização ao longo dos anos, de modo a se tornar possível o monitoramento em todas as barras das subestações de energia.

Por fim, a SBQEE afirma não estar de acordo com o critério de seleção das subestações, visto que no Brasil há pequenas localidades atendidas por subestações de pequeno porte. Menciona que não controlar este universo seria permanecer sem o conhecimento da QEE no SD, inviabilizando avaliações rápidas e uma gestão mais eficiente do sistema. Além disso, destaca que o custo de medição é irrisório se comparado aos benefícios da posse destas informações.

$\mathrm{Na}$ questão 7, questionou-se a respeito do estabelecimento de penalidades quando da 
ultrapassagem dos limites. Em caso positivo, perguntou-se como estabelecer procedimento para atribuir responsabilidades. A opinião da AES Brasil é que tais fenômenos devem ser tão somente, objeto de fiscalização pela ANEEL, com aplicação de multa apenas no caso de identificação de falta de diligencia nos processos de investigação e correção dos problemas identificados.

A ABRADEE entende que nesse momento não devem ser estabelecidas penalidades quando da ultrapassagem dos limites dos indicadores.

A ABRACE concorda que devem ser estabelecidas penalidades. Sugerindo que a partir do instante em que forem confrontadas as ocorrências de VTCDs com o FI de cada distribuidora, a empresa responsável teria um prazo para regularização, após o qual seria pertinente a aplicação de penalidades em caso de não cumprimento das ações de correção.

As distribuidoras do grupo CPFL entendem que ainda não se deve estabelecer qualquer tipo de penalidade, haja vista a significante proposta de avanço na regulamentação, a concorrência com outras atribuições recentemente delegadas às distribuidoras no que tange a manutenção dos níveis de tensão, os desafios técnicos e econômicos que as distribuidoras têm vivenciado diariamente e o vultoso investimento necessário para adequação ao regulamento proposto. Neste complexo contexto, sugere-se que a ANEEL concentre-se em prestar maiores esclarecimentos, evoluir e consolidar as metodologias que estão sendo propostas, incentivar a composição de uma base sólida e uniforme de medições da qualidade da energia para que possa avançar no sentido de se propor valores de referência para os indicadores quem venham a ser de fato definidos. Tão logo estas etapas tenham atingido certo grau de maturidade a ponto do regulamento estar aderente à realidade do SD e factível de ser cumprido, aí sim se entende que a Agência deva avançar no sentido de atribuir penalidades devido à ultrapassagem dos limites.

O grupo EDP destacou, que no cenário atual, não existe um histórico de medições padronizadas que possam embasar as penalidades tanto da parte da distribuidora, quanto do consumidor. Adicionalmente, menciona que é necessário identificar as responsabilidades de todos os agentes envolvidos (geração, transmissão, distribuição, usuários e fatores exógenos) para definir uma penalidade pecuniária.

Já o SBQEE diz que neste momento deve-se conhecer a realidade do sistema elétrico brasileiro, para que no futuro, possa-se pensar em um aprimoramento da legislação.

Pelas contribuições apresentadas é evidente a necessidade de etapas antecedentes para a determinação de novos indicadores. Para isso é essencial que se obtenha um banco de dados consistente que retrate a realidade da energia elétrica distribuída no Brasil, considerando as 
particularidades regionais, entre elas, a sazonalidade climática, áreas predominantemente urbanas ou rurais, bem como as diferenças da propagação dos fenômenos nos diversos pontos do SD.

Neste sentido, o primeiro fator a ser considerado é a definição de um critério de medição que estabeleça a implementação de um processo gradual de instalação dos medidores em locais adequados e representativos das VTCDs, concedendo desta maneira às distribuidoras, um tempo compatível para implementação dos sistemas de monitoramento.

Após um período de apuração de pelo menos um ano, conforme recomendam as normas internacionais consultadas, que permita ter uma base de dados consistente para apurar os índices, propõe-se, em um primeiro momento, obter fatores de ponderação compatíveis com a sensibilidade real dos equipamentos e, posteriormente, definir os valores máximos dos eventos, avaliando se a subdivisão das categorias é pertinente à realidade brasileira.

Como etapa final sugere-se que seja calculado um FI base para cada ponto monitorado, realizando uma análise posterior para verificar se há a possibilidade de estabelecer um FI base para cada distribuidora, de forma a inferir índices de desempenho do sistema e atribuir penalidades devido à ultrapassagem dos limites.

Diante do exposto, reforçam-se as contribuições deste trabalho, propenso em determinar os melhores locais de instalação de um número mínimo de medidores garantindo a máxima observabilidade dos eventos e estabelecer quais locais são prioritários para a instalação dos medidores, permitindo a instalação gradual dos equipamentos conforme a maior observabilidade dos eventos. 


\section{Apêndice B - Dados dos Alimentadores SD de 123-nós}

Tabela 45 - Dados dos alimentadores do SD IEEE 123-nós.

\begin{tabular}{|c|c|c|c|c|c|c|c|c|c|c|c|}
\hline Nó A & Nó B & $\begin{array}{c}\text { Compr. } \\
(\mathbf{m})\end{array}$ & Config. & Nó A & Nó B & $\begin{array}{c}\text { Compr. } \\
(\mathbf{m})\end{array}$ & Config. & Nó A & Nó $B$ & $\begin{array}{c}\text { Compr. } \\
(\mathbf{m})\end{array}$ & Config. \\
\hline 0 & 1 & 121,92 & 1 & 22 & 23 & 76,2 & 11 & 74 & 75 & 175,26 & 10 \\
\hline 1 & 25 & 53,34 & 10 & 27 & 28 & 129,54 & 9 & 76 & 77 & 99,06 & 11 \\
\hline 1 & 21 & 76,2 & 11 & 28 & 29 & 76,2 & 9 & 77 & 78 & 213,36 & 11 \\
\hline 1 & 2 & 91,44 & 1 & 28 & 30 & 76,2 & 9 & 79 & 80 & 167,64 & 3 \\
\hline 2 & 3 & 60,96 & 1 & 31 & 32 & 30,48 & 11 & 80 & 81 & 91,44 & 3 \\
\hline 3 & 26 & 68,58 & 10 & 32 & 33 & 114,3 & 11 & 81 & 82 & 243,84 & 3 \\
\hline 3 & 27 & 68,58 & 9 & 32 & 34 & 106,68 & 11 & 83 & 84 & 83,82 & 9 \\
\hline 3 & 4 & 91,44 & 1 & 35 & 43 & 76,2 & 9 & 84 & 85 & 99,06 & 9 \\
\hline 4 & 31 & 45,72 & 11 & 35 & 36 & 91,44 & 2 & 85 & 86 & 83,82 & 9 \\
\hline 4 & 35 & 251,46 & 2 & 35 & 52 & 114,3 & 4 & 87 & 88 & 83,82 & 11 \\
\hline 4 & 5 & 121,92 & 1 & 36 & 45 & 160,02 & 10 & 87 & 91 & 60,96 & 3 \\
\hline 5 & 6 & 60,96 & 1 & 36 & 37 & 76,2 & 2 & 88 & 89 & 106,68 & 11 \\
\hline 6 & 7 & 38,1 & 1 & 37 & 46 & 167,64 & 11 & 89 & 90 & 121,92 & 11 \\
\hline 7 & 67 & 83,82 & 1 & 37 & 38 & 83,82 & 2 & 91 & 92 & 121,92 & 6 \\
\hline 7 & 8 & 106,68 & 3 & 38 & 47 & 106,68 & 7 & 91 & 101 & 213,36 & 3 \\
\hline 8 & 65 & 76,2 & 10 & 38 & 39 & 60,96 & 2 & 92 & 93 & 30,48 & 6 \\
\hline 8 & 9 & 228,6 & 3 & 39 & 40 & 91,44 & 2 & 93 & 94 & 68,58 & 6 \\
\hline 9 & 117 & 167,64 & 5 & 40 & 41 & 106,68 & 2 & 93 & 95 & 144,78 & 6 \\
\hline 9 & 112 & 76,2 & 12 & 41 & 42 & 60,96 & 2 & 95 & 96 & 144,78 & 6 \\
\hline 9 & 10 & 106,68 & 6 & 43 & 44 & 99,06 & 9 & 96 & 97 & 76,2 & 6 \\
\hline 10 & 83 & 60,96 & 9 & 47 & 50 & 83,82 & 7 & 96 & 99 & 205,74 & 11 \\
\hline 10 & 87 & 83,82 & 3 & 47 & 48 & 68,58 & 11 & 97 & 98 & 76,2 & 6 \\
\hline 10 & 11 & 76,2 & 3 & 48 & 49 & 91,44 & 11 & 99 & 100 & 144,78 & 11 \\
\hline 11 & 79 & 83,82 & 3 & 50 & 51 & 152,4 & 9 & 101 & 102 & 137,16 & 6 \\
\hline 11 & 12 & 76,2 & 3 & 52 & 21 & 198,12 & 8 & 102 & 107 & 53,34 & 9 \\
\hline 12 & 76 & 68,58 & 11 & 52 & 53 & 76,2 & 1 & 102 & 103 & 83,82 & 6 \\
\hline 12 & 13 & 83,82 & 3 & 53 & 69 & 99,06 & 11 & 103 & 108 & 68,58 & 10 \\
\hline 13 & 74 & 68,58 & 10 & 53 & 54 & 76,2 & 1 & 103 & 104 & 68,58 & 6 \\
\hline 13 & 14 & 99,06 & 3 & 54 & 70 & 152,4 & 10 & 104 & 109 & 91,44 & 11 \\
\hline 14 & 16 & 137,16 & 9 & 54 & 55 & 60,96 & 1 & 104 & 105 & 68,58 & 6 \\
\hline 14 & 15 & 304,8 & 3 & 55 & 71 & 60,96 & 9 & 105 & 110 & 83,82 & 9 \\
\hline 16 & 17 & 91,44 & 9 & 55 & 56 & 76,2 & 1 & 105 & 106 & 91,44 & 6 \\
\hline 17 & 73 & 175,26 & 9 & 56 & 60 & 45,72 & 4 & 106 & 111 & 60,96 & 10 \\
\hline 17 & 18 & 38,1 & 9 & 56 & 57 & 76,2 & 4 & 112 & 113 & 53,34 & 12 \\
\hline 18 & 19 & 160,02 & 9 & 57 & 58 & 76,2 & 4 & 113 & 114 & 106,68 & 12 \\
\hline 19 & 20 & 99,06 & 9 & 58 & 59 & 76,2 & 4 & 114 & 115 & 129,54 & 12 \\
\hline 21 & 24 & 60,96 & 11 & 62 & 63 & 99,06 & 10 & 115 & 116 & 99,06 & 12 \\
\hline 21 & 22 & 99,06 & 11 & 65 & 66 & 76,2 & 10 & 117 & 118 & 0 & XFM-1 \\
\hline 21 & 64 & 91,44 & 9 & 67 & 68 & 83,82 & 1 & & & & \\
\hline 21 & 62 & 76,2 & 10 & 71 & 72 & 91,44 & 9 & & & & \\
\hline
\end{tabular}

Fonte: Adaptado de DISTRIBUTION TEST FEEDERS, 2010. 



\section{Apêndice C - Matrizes de Tensões Durante a Falta}

A seguir são apresentadas as MTDFs geradas para os SDs de 13, 37 e 123 nós. As MTDFs foram obtidas utilizando os dados apresentados na seção 5.1 e a formulação matemática apresentada no capítulo 3. Pela análise gráfica das figuras é possível perceber que quando comparadas as fases $B$ e $C$, os afundamentos e elevações de tensões foram mais severos na fase $C$ para os SDs de 13 e 37 nós, e mais severos na fase $B$ para o SD de 123 nós.

As amplitudes dos afundamentos e elevações de tensão serão mais brandas na ocorrência de faltas a jusante dos transformadores. Para o SD de 13 nós isso ocorre na incidência de faltas no nó 3, conforme o diagrama unifilar da Figura 39, para o SD de 37 nós no nó 32 (Figura 41), e para o sistema de 123 nós, os afundamentos e elevações serão menos severos na ocorrência de faltas no nó 118, localizado logo após o transformador (Figura 42).

Figura 84 - MTDF durante faltas FFF aplicadas no SD IEEE 13-nós.

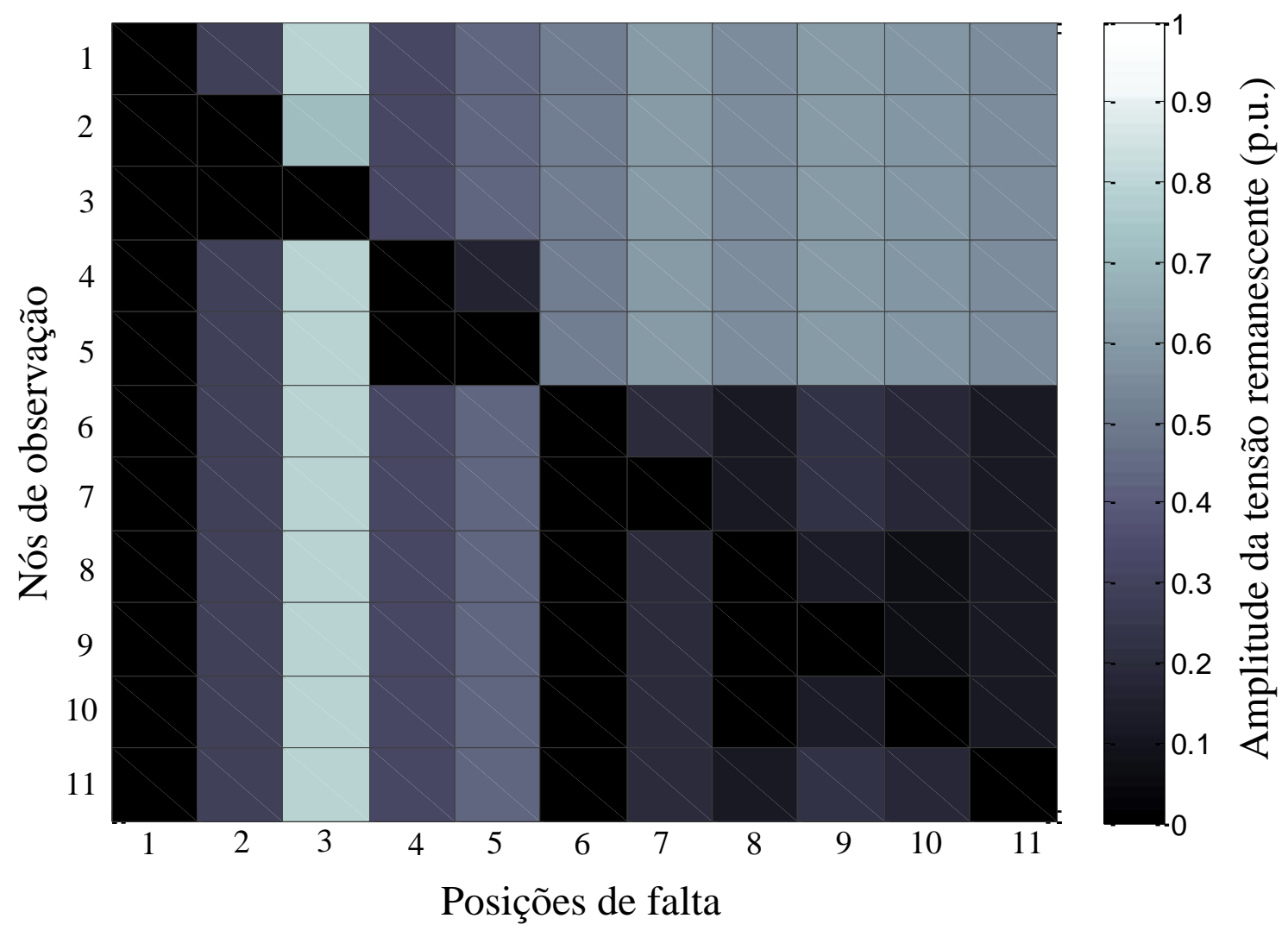


Figura 85 - MTDF (fase $A$ ) durante faltas FT aplicadas no IEEE 13-nós.

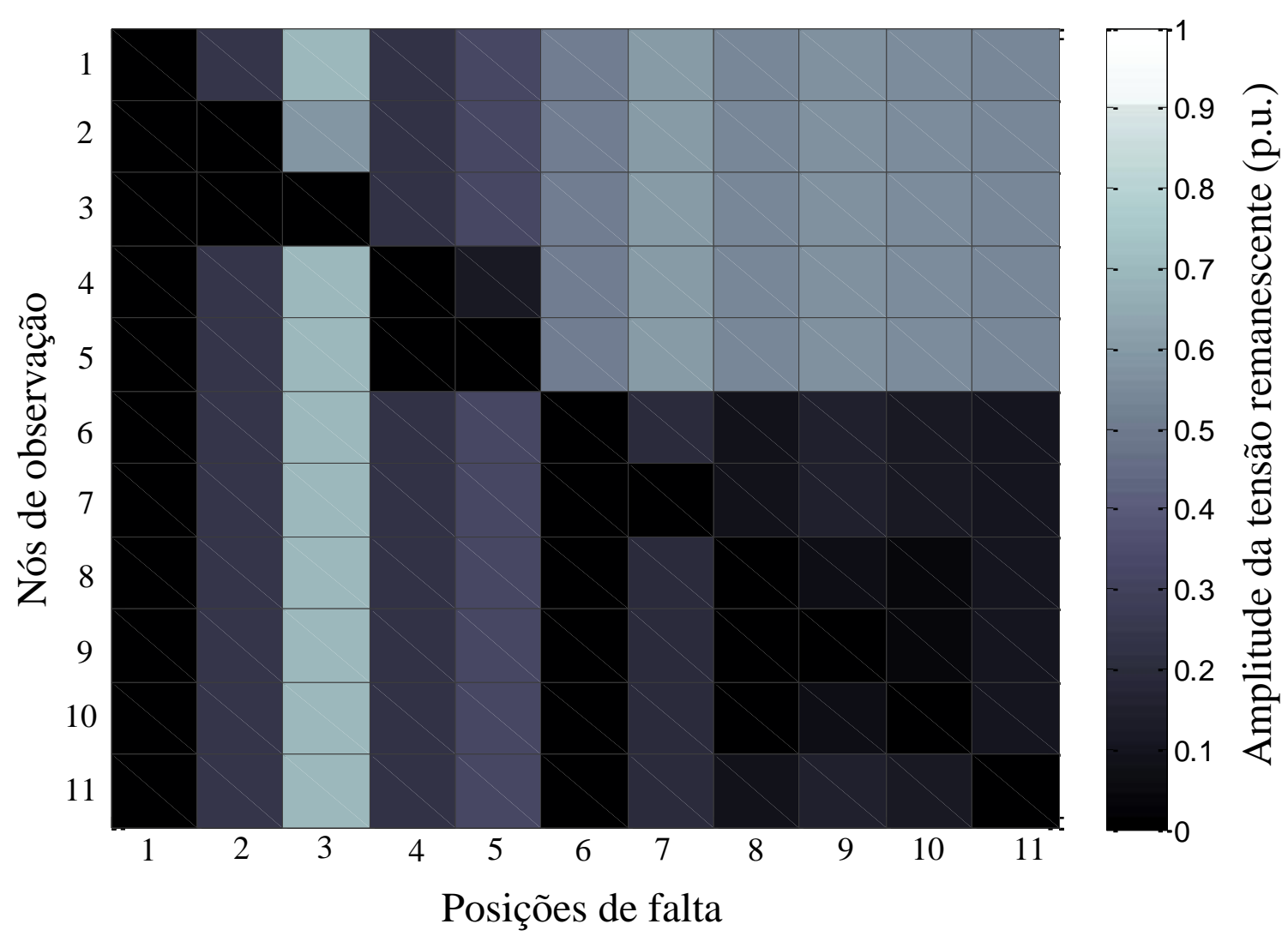

Figura 86 - MTDF (fase B) durante faltas FT aplicadas no SD IEEE 13-nós.

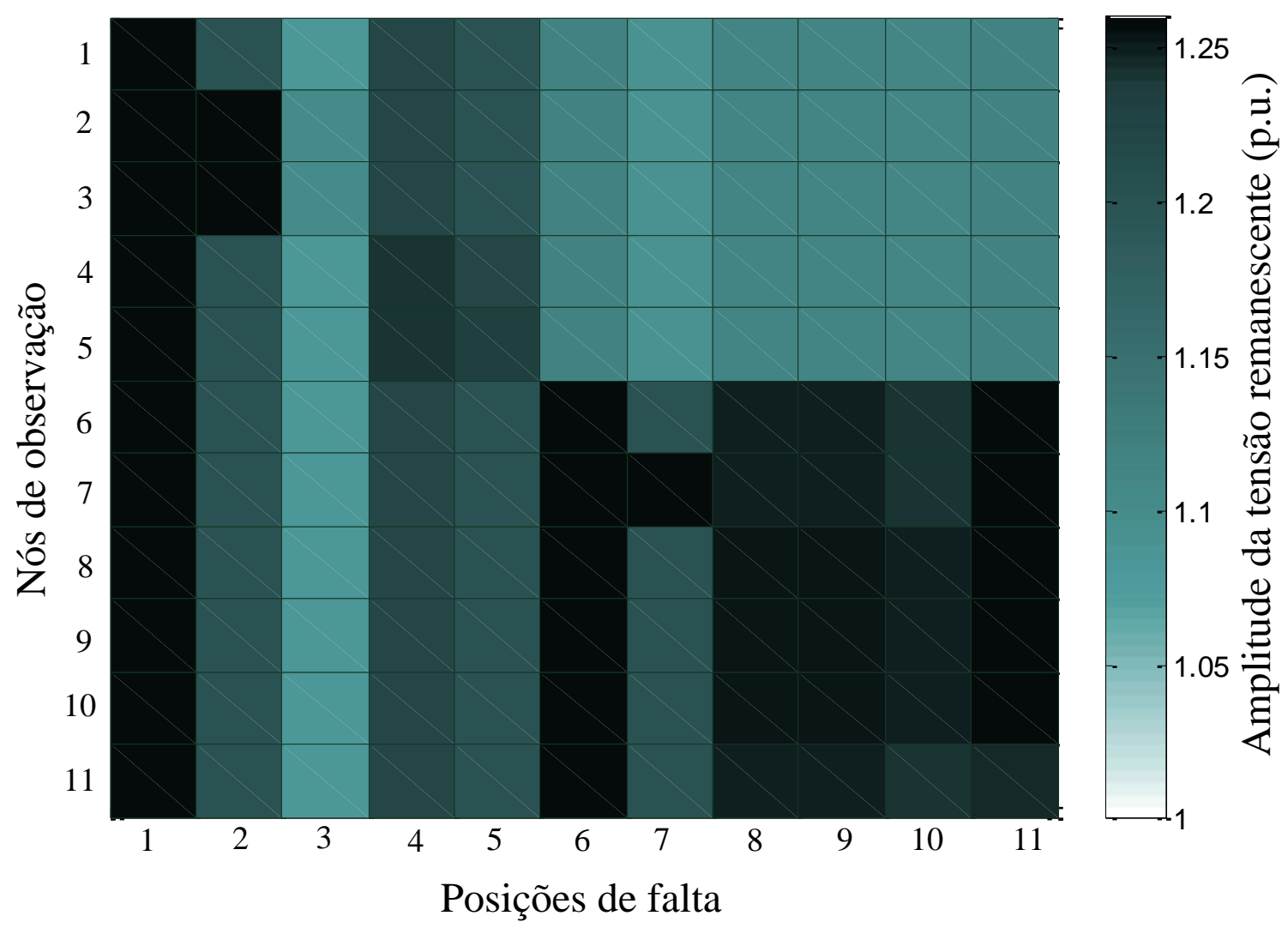


Figura 87 - MTDF (fase $C$ ) durante faltas FT aplicadas no SD IEEE 13-nós.

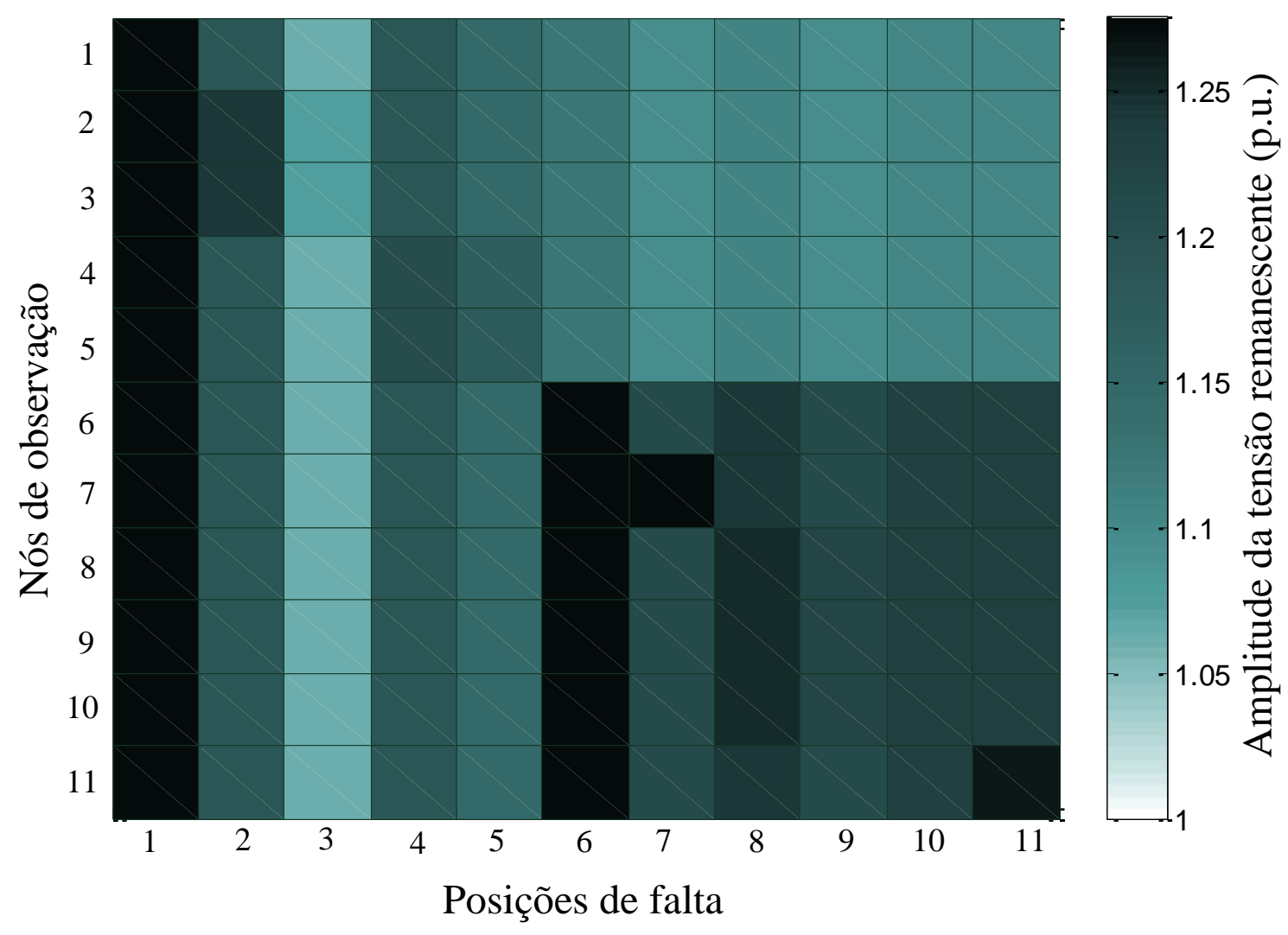

Figura 88 - MTDF (fase B) durante faltas FF aplicadas no SD IEEE 13-nós.

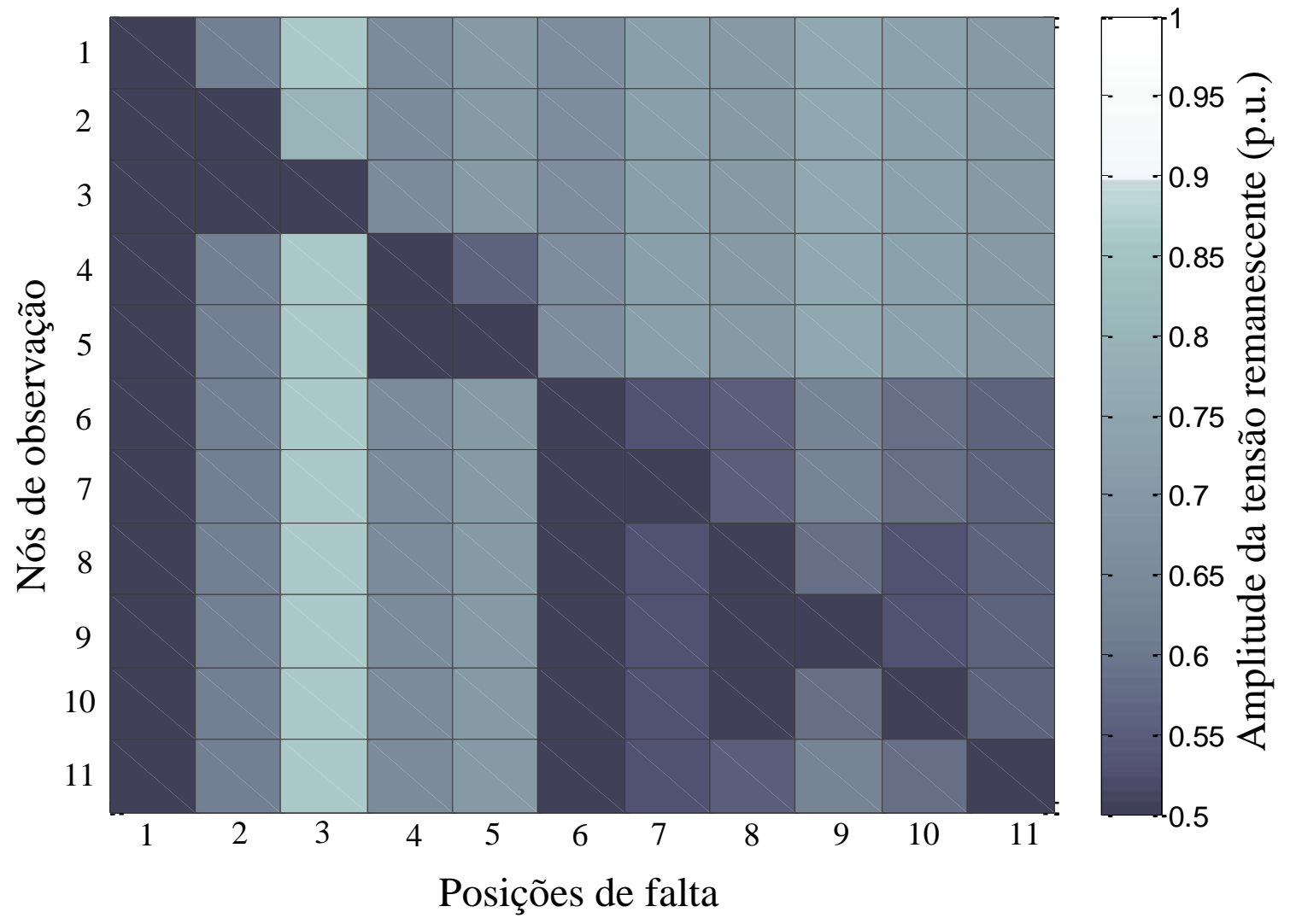


Figura 89 - MTDF (fase $C$ ) durante faltas FF aplicadas no SD IEEE 13-nós.

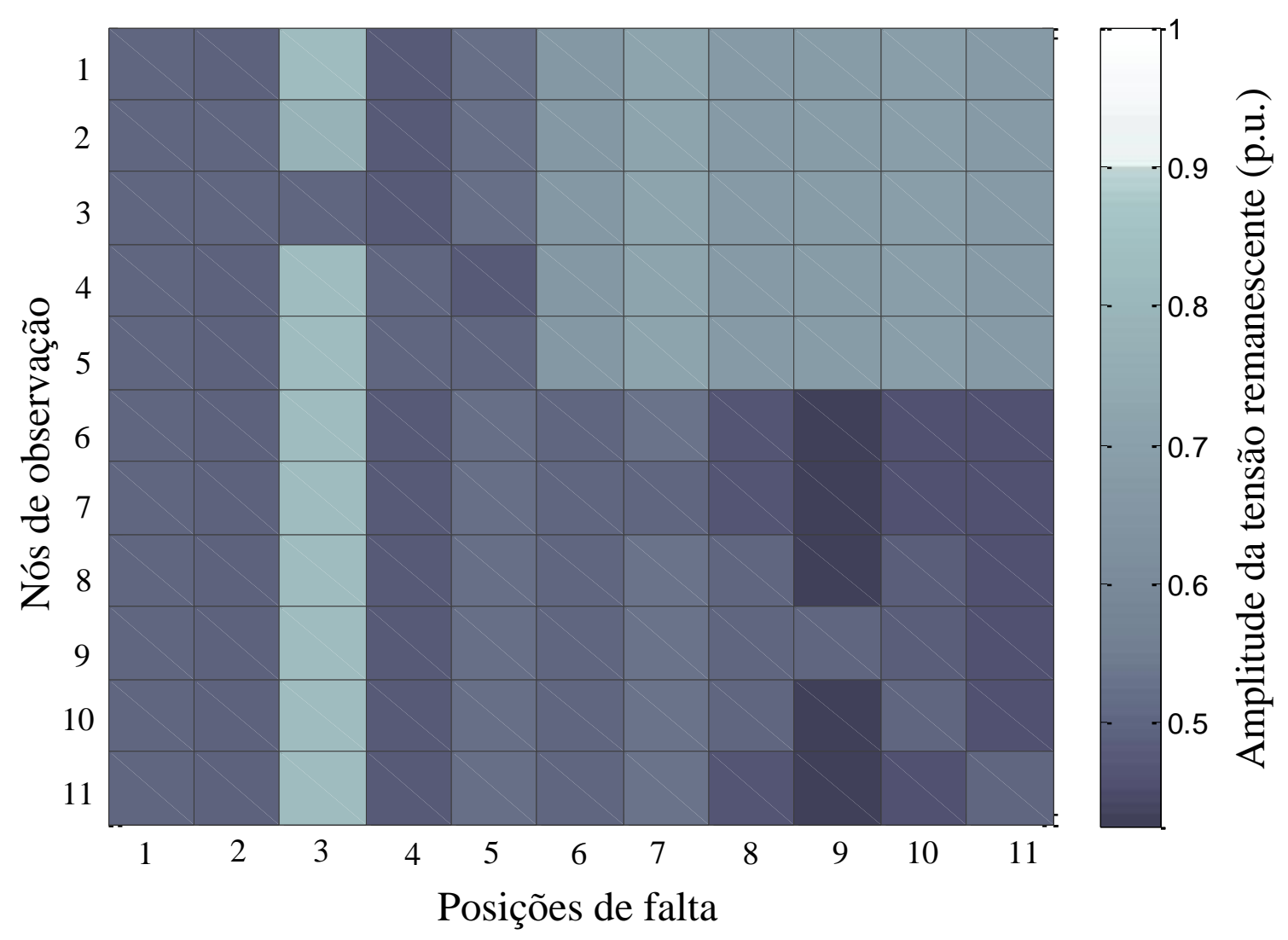

Figura 90 - MTDF (fase $A$ ) durante faltas FFT aplicadas no SD IEEE 13-nós.

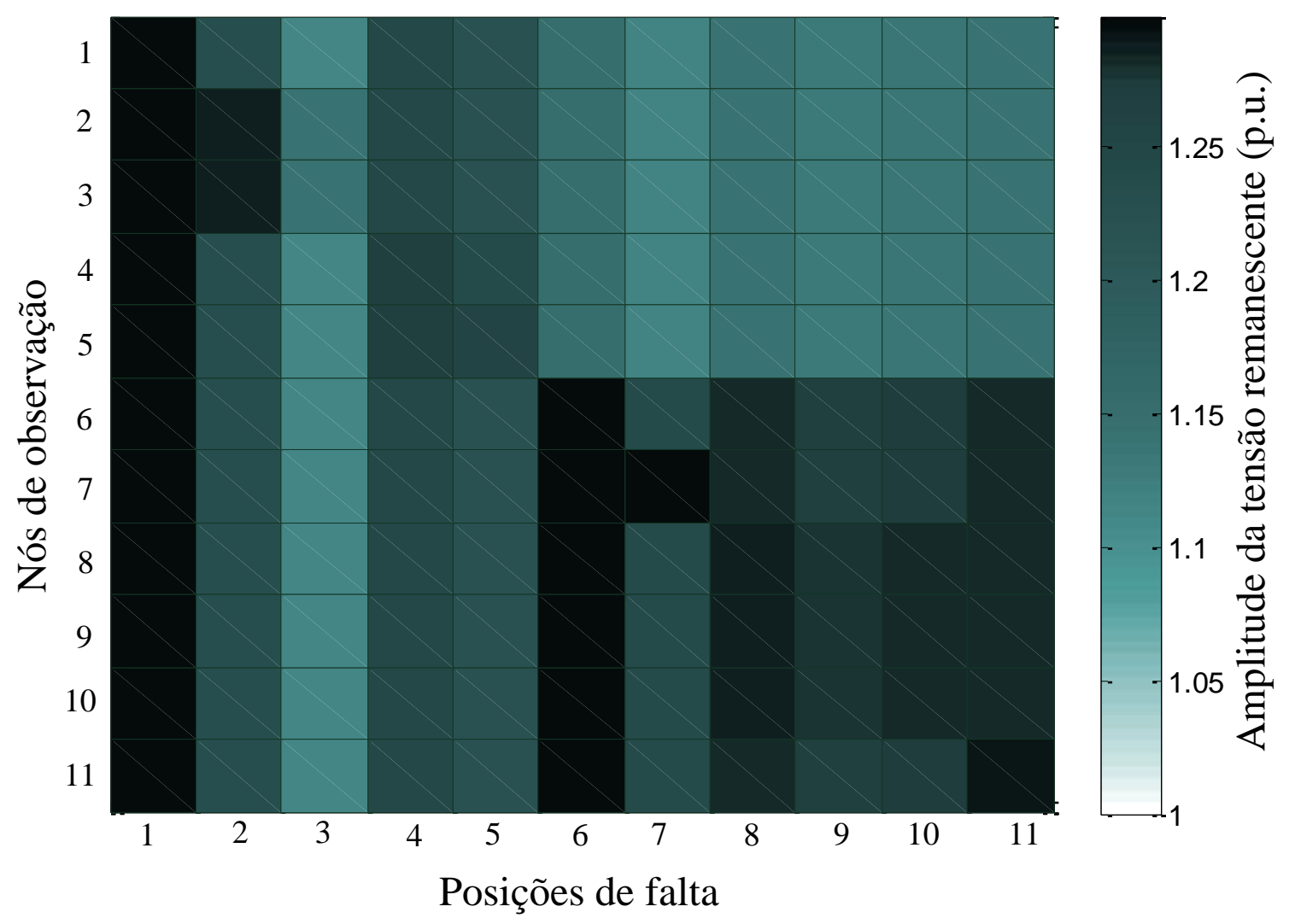


Figura 91 - MTDF (fase $B$ ) durante faltas FFT aplicadas no SD IEEE 13-nós.

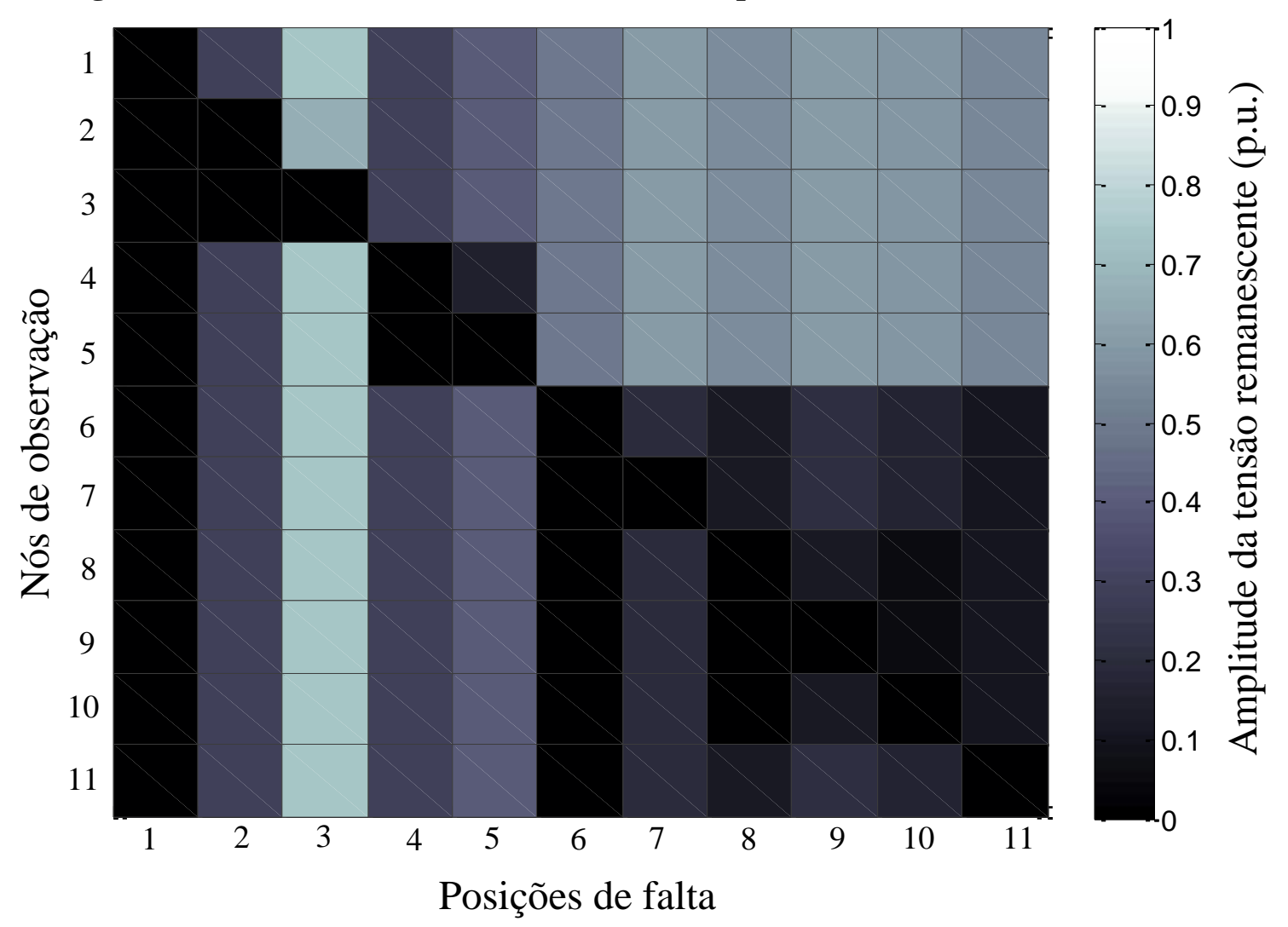

Figura 92 - MTDF (fase $C$ ) durante faltas FFT aplicadas no SD IEEE 13-nós.

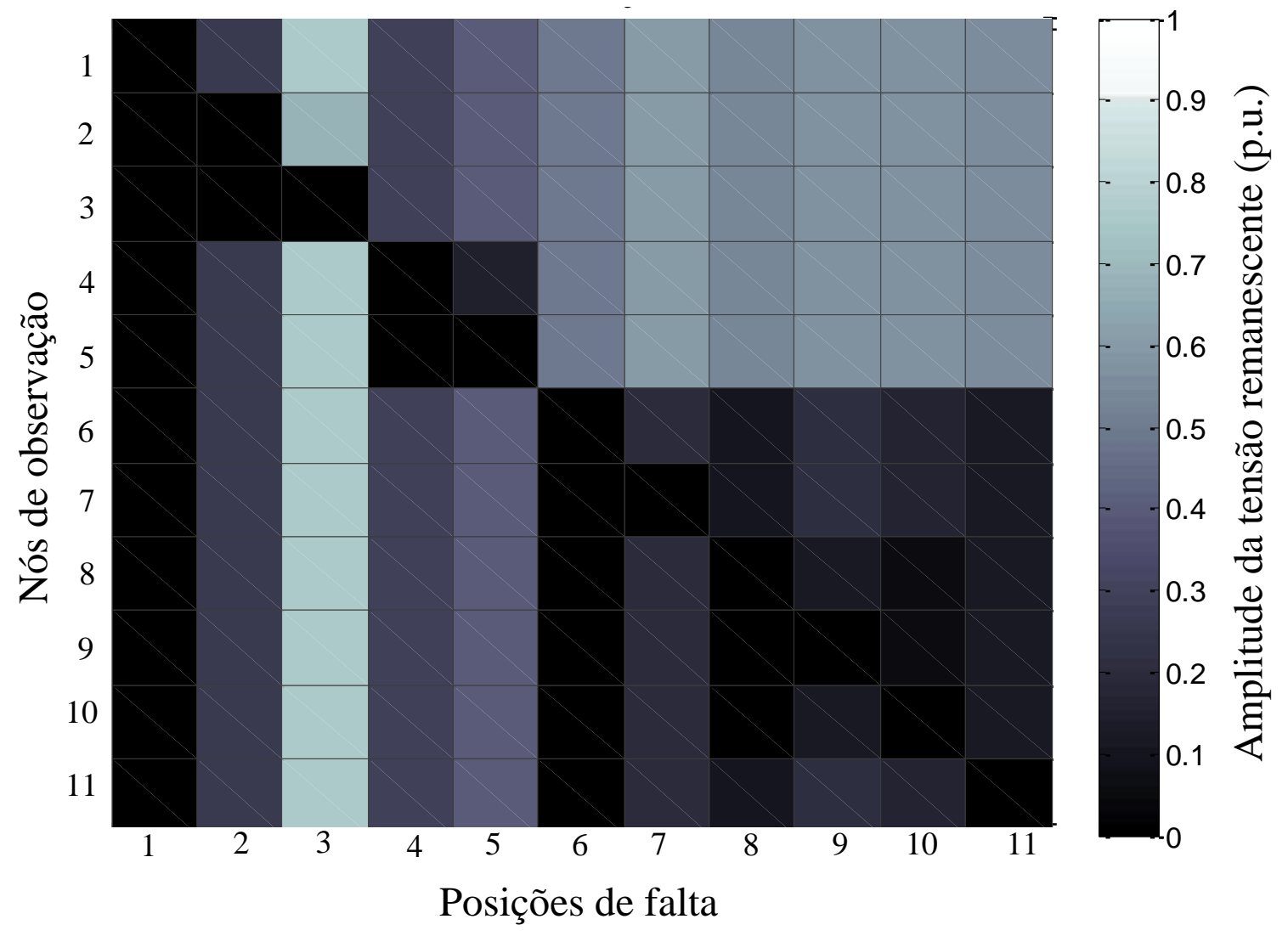


Figura 93 - MTDF durante faltas FFF aplicadas no SD IEEE 37-nós.

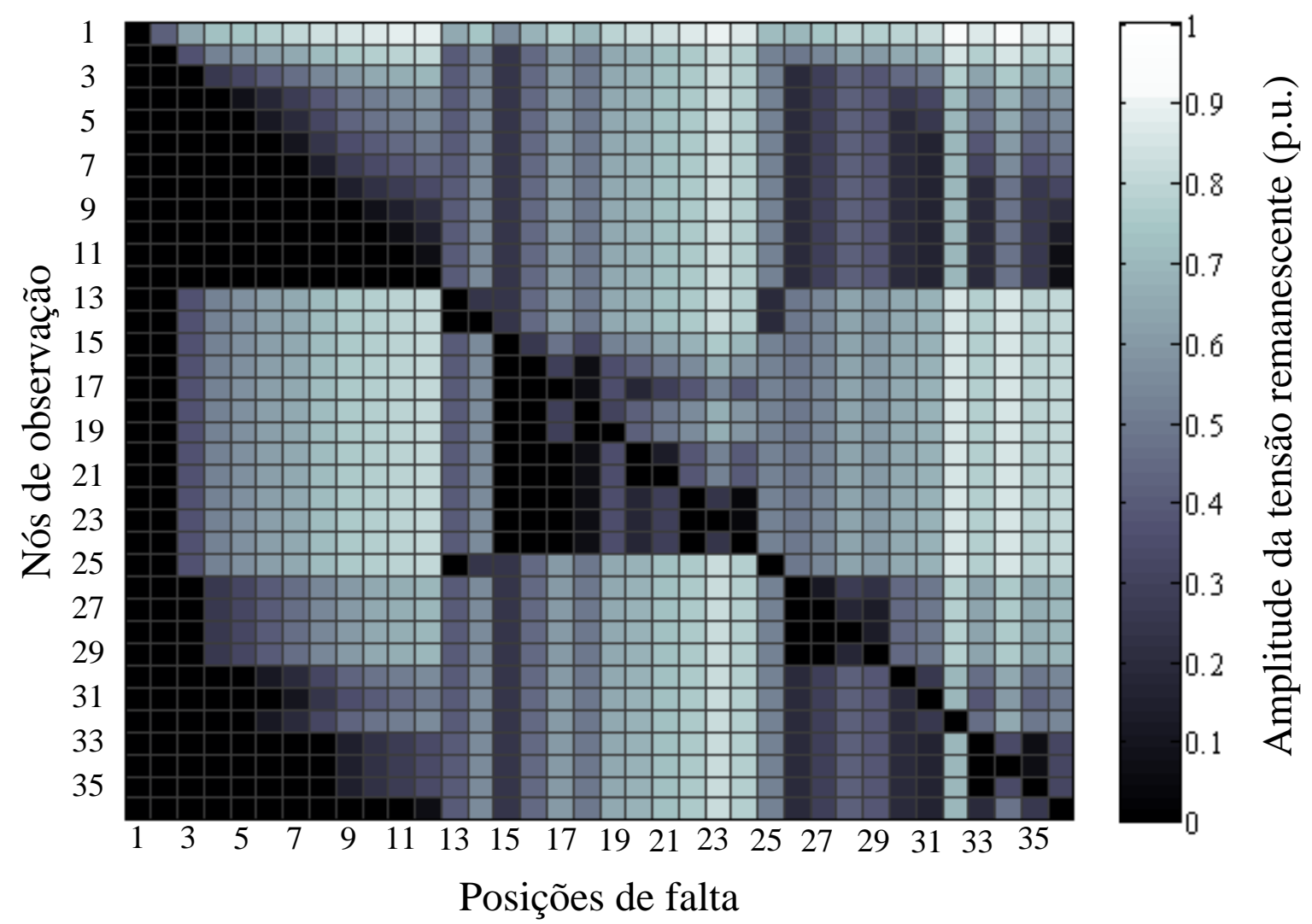

Figura 94 - MTDF (fase $A$ ) durante faltas FT aplicadas no SD IEEE 37-nós.

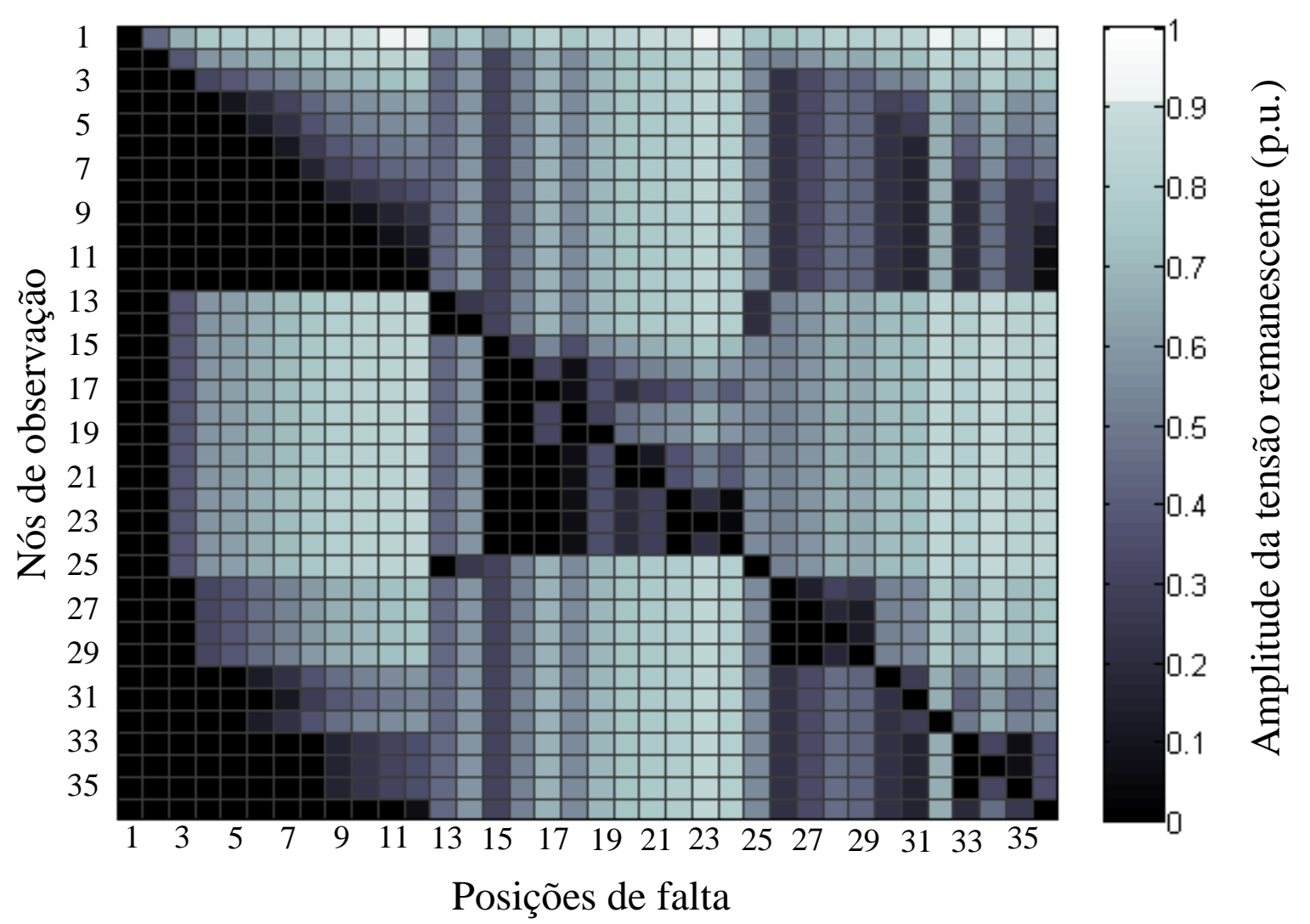


Figura 95 - MTDF (fase B) durante faltas FT aplicadas no SD IEEE 37-nós.

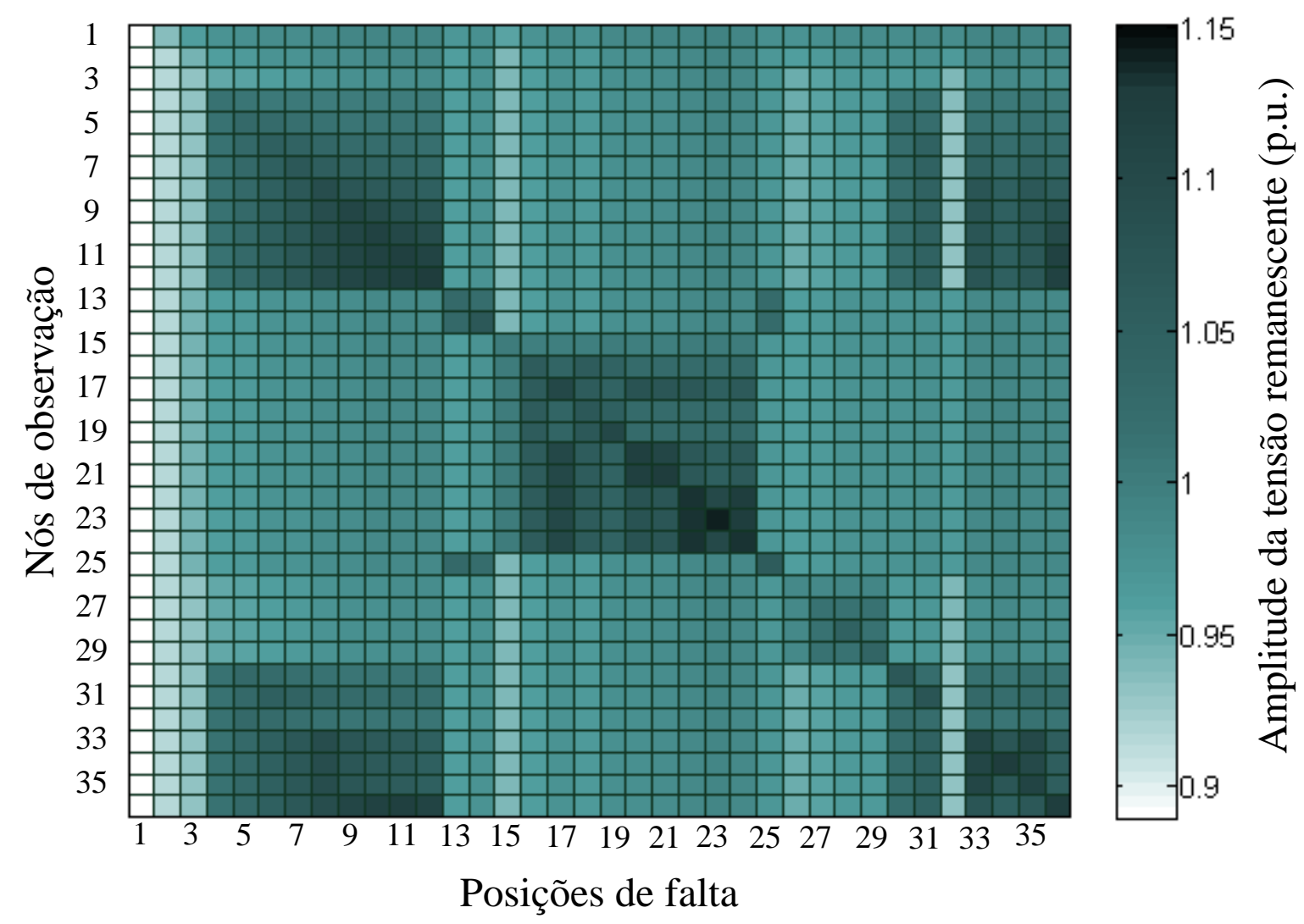

Figura 96 - MTDF (fase $C$ ) durante faltas FT aplicadas no SD IEEE 37-nós.

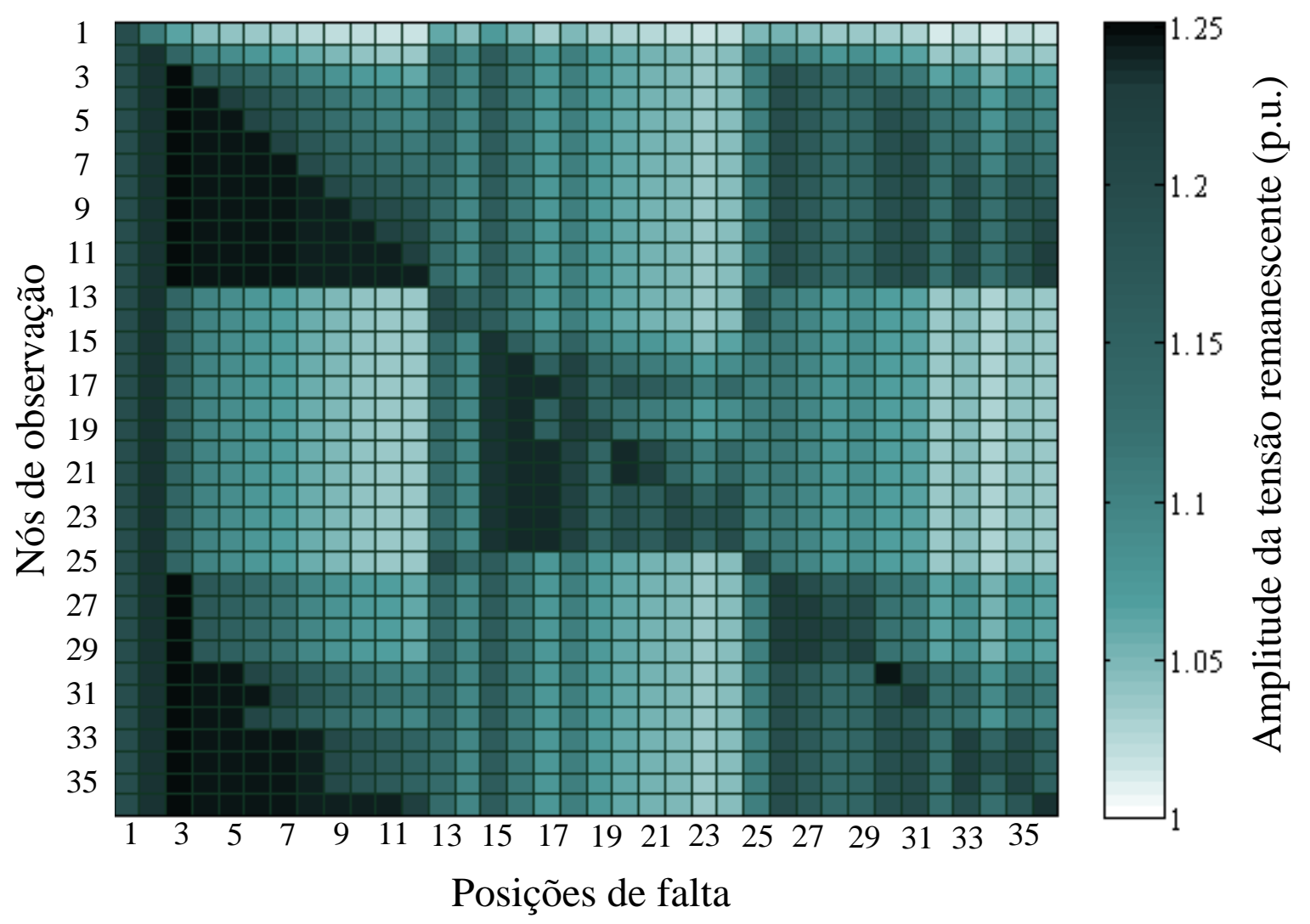


Figura 97 - MTDF (fase $B$ ) durante faltas FF aplicadas no SD IEEE 37-nós.

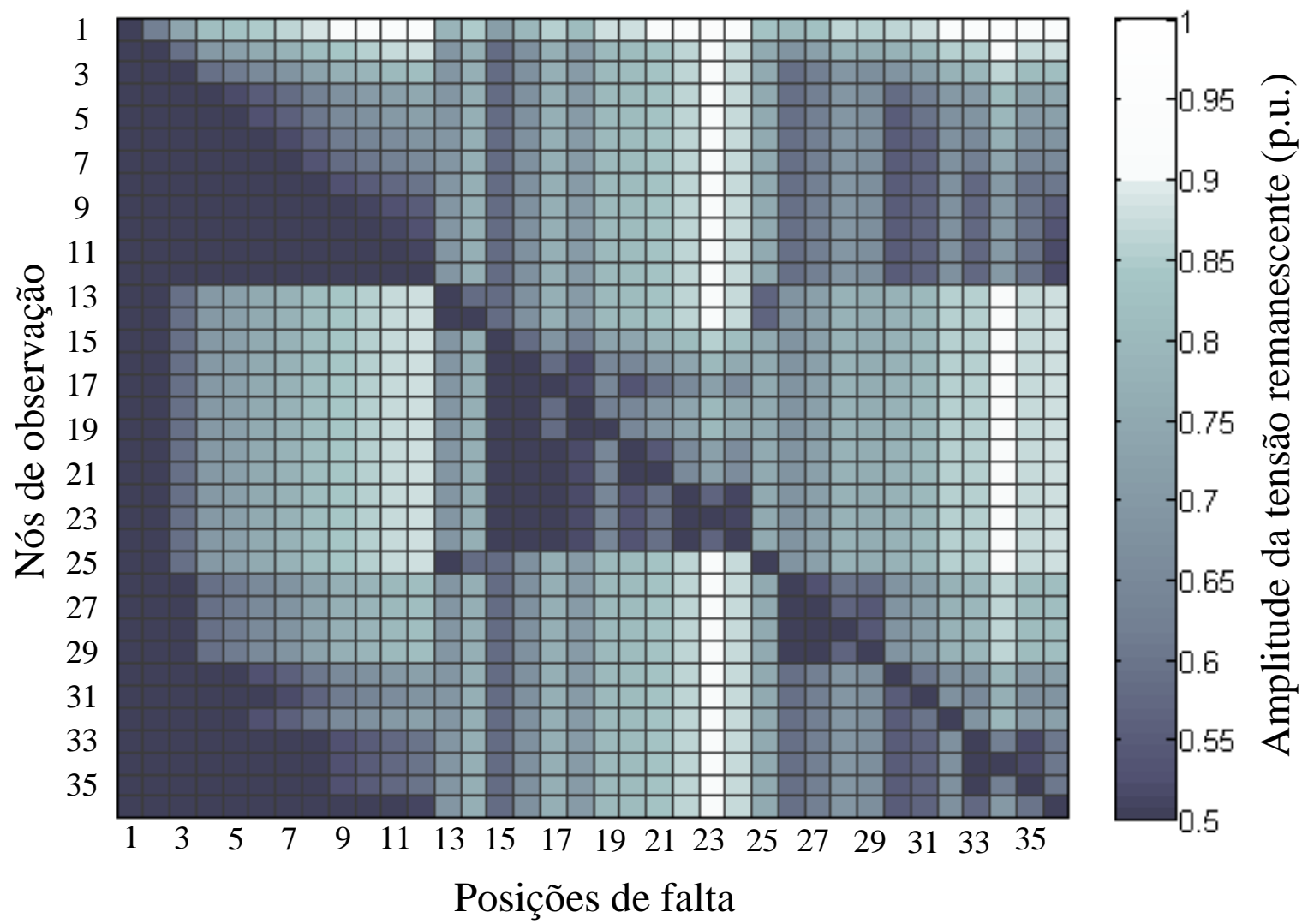

Figura 98 - MTDF (fase $C$ ) durante faltas FF aplicadas no SD IEEE 37-nós.

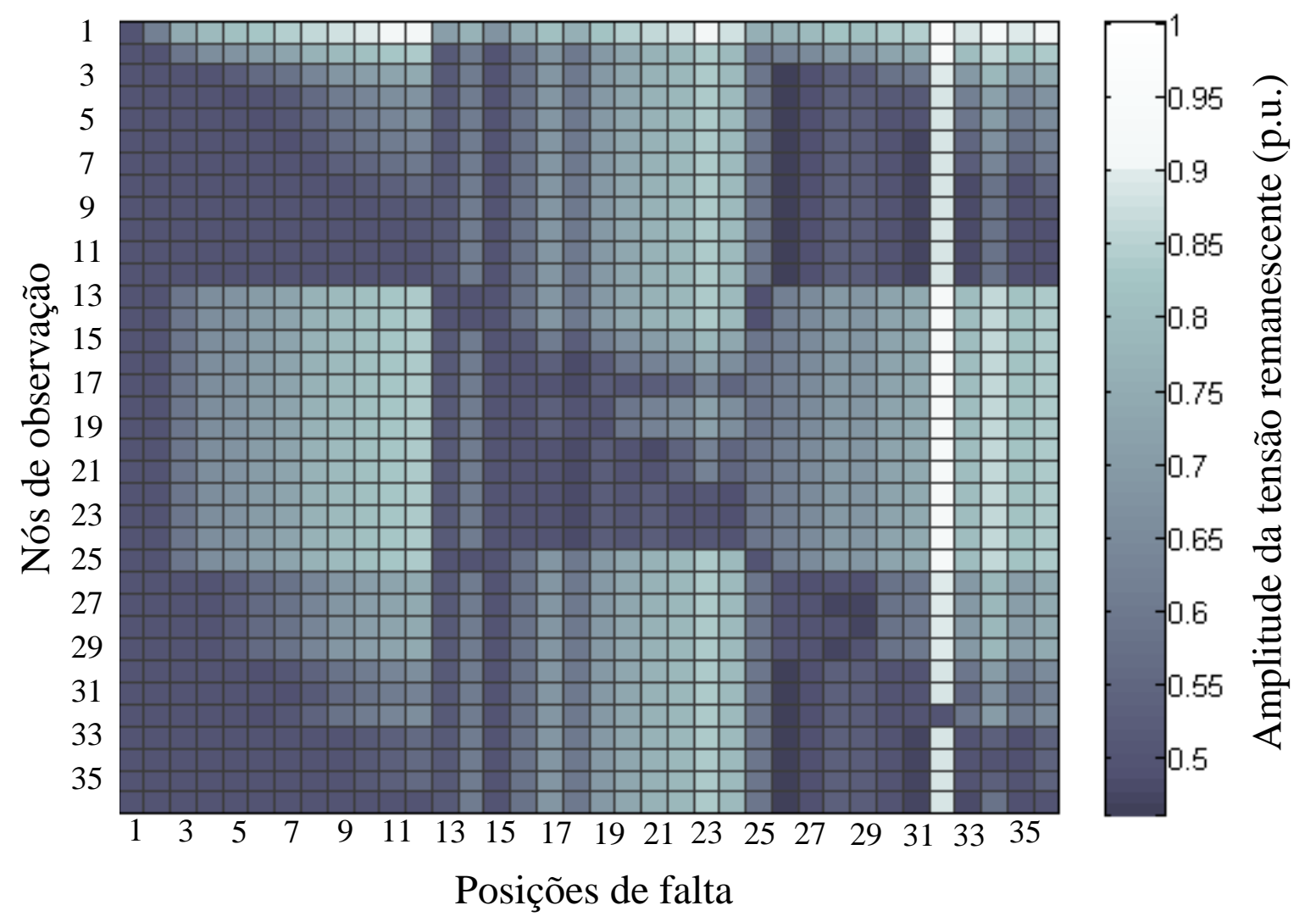


Figura 99 - MTDF (fase $A$ ) durante faltas FFT aplicadas no SD IEEE 37-nós.

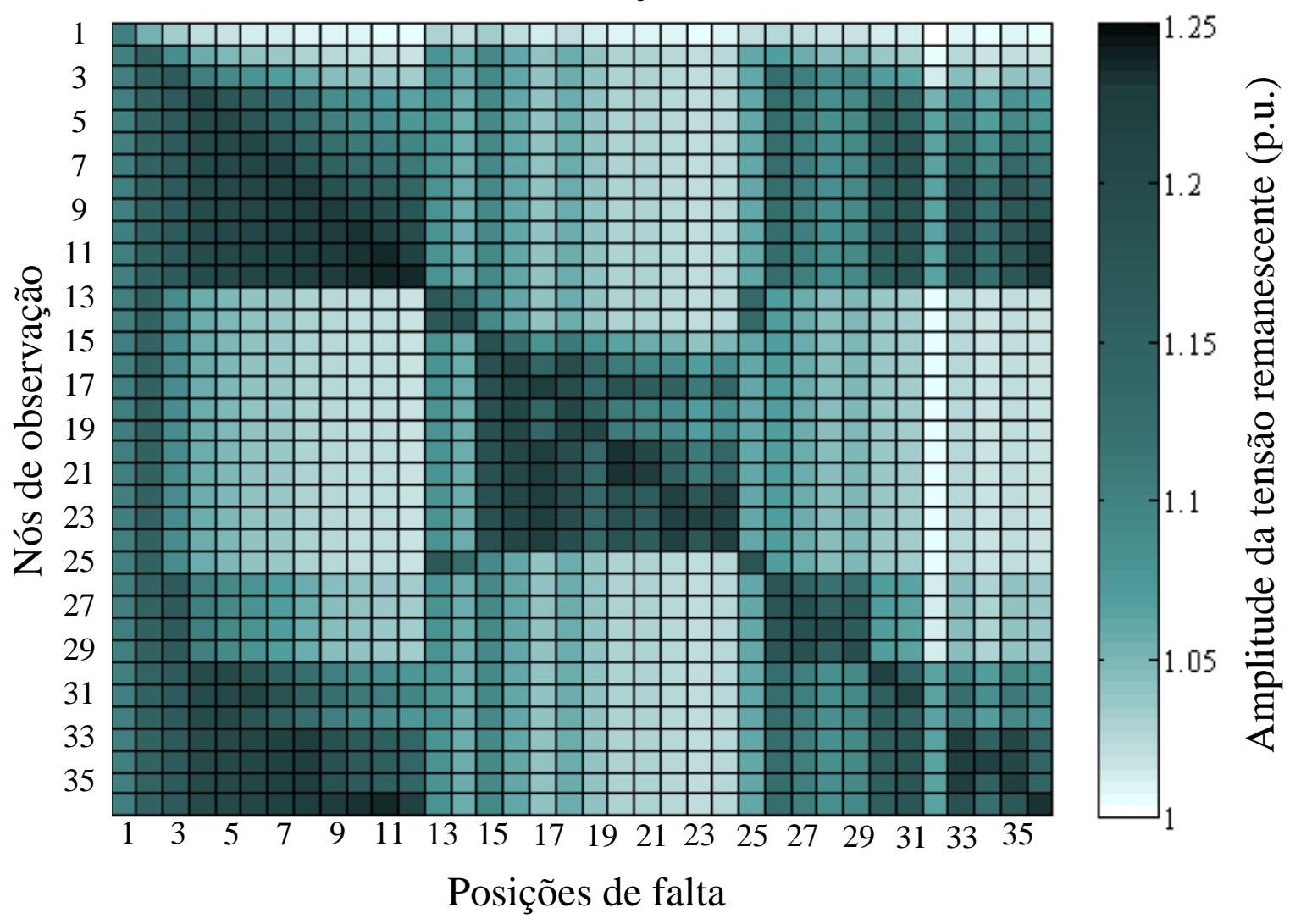

Figura 100 - MTDF (fase $B$ ) durante faltas FFT aplicadas no SD IEEE 37-nós.

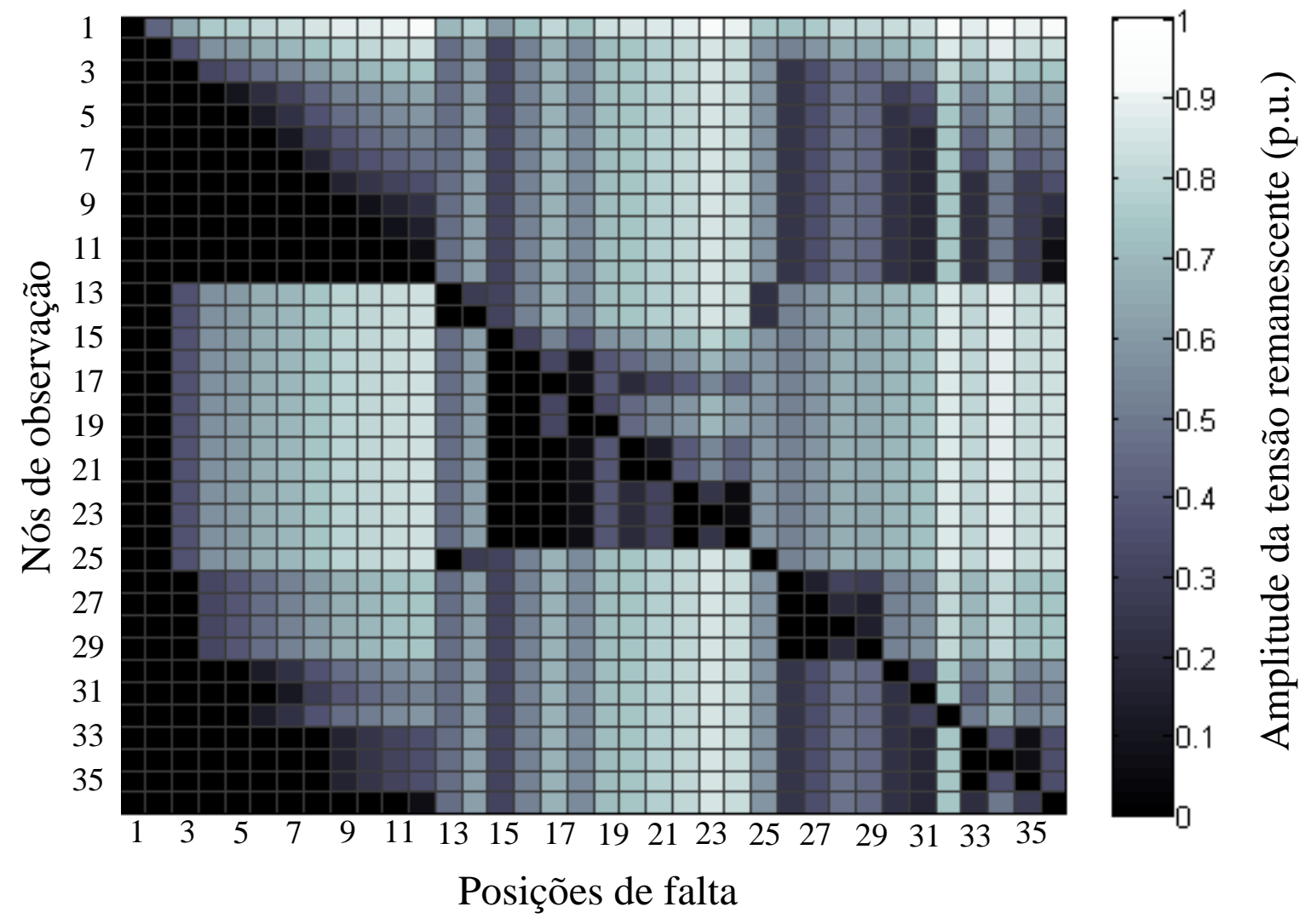


Figura 101 - MTDF (fase $C$ ) durante faltas FFT aplicadas no SD IEEE 37-nós.

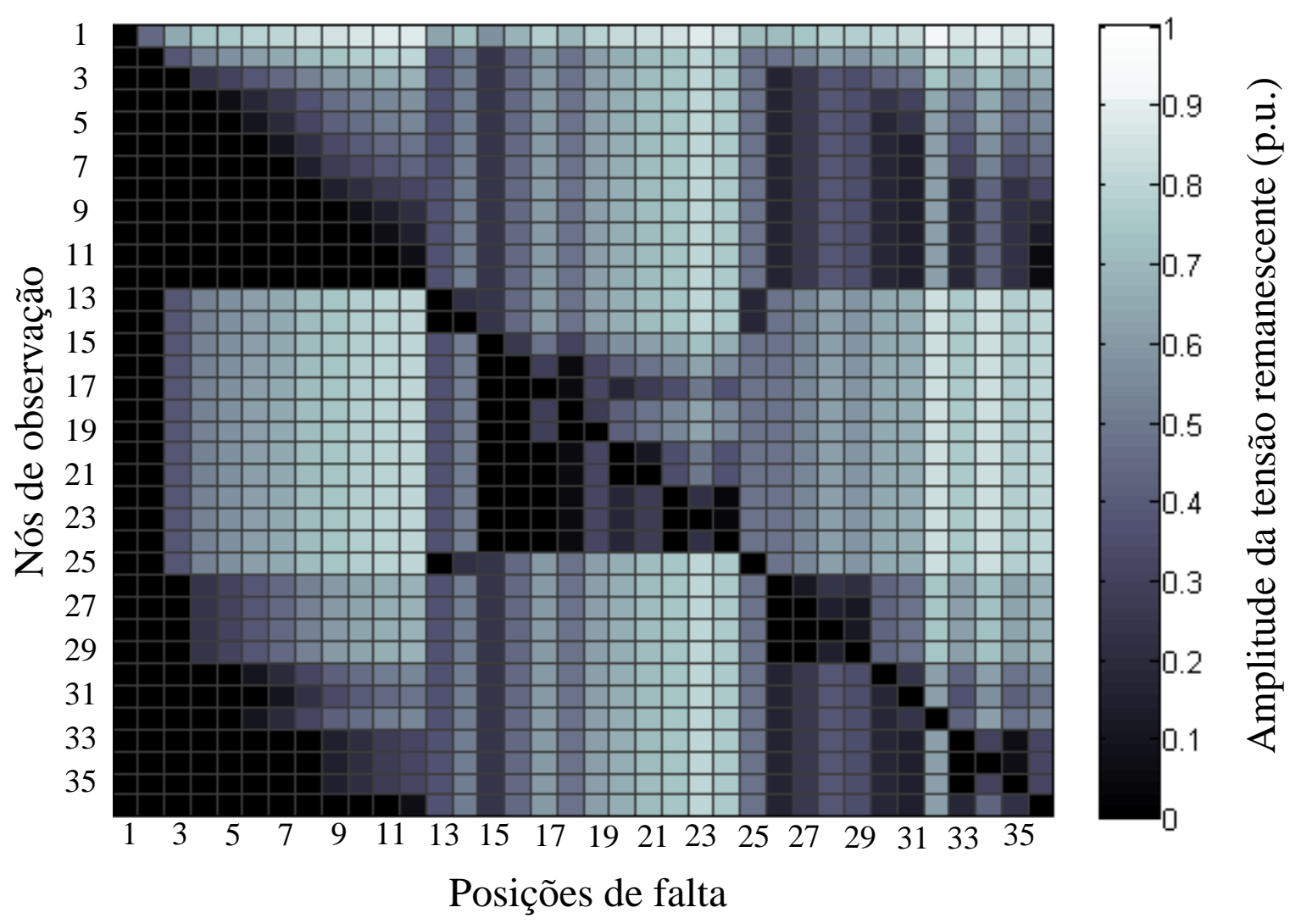


Figura 102 - MTDF durante faltas FFF aplicadas no SD IEEE 123 nós.

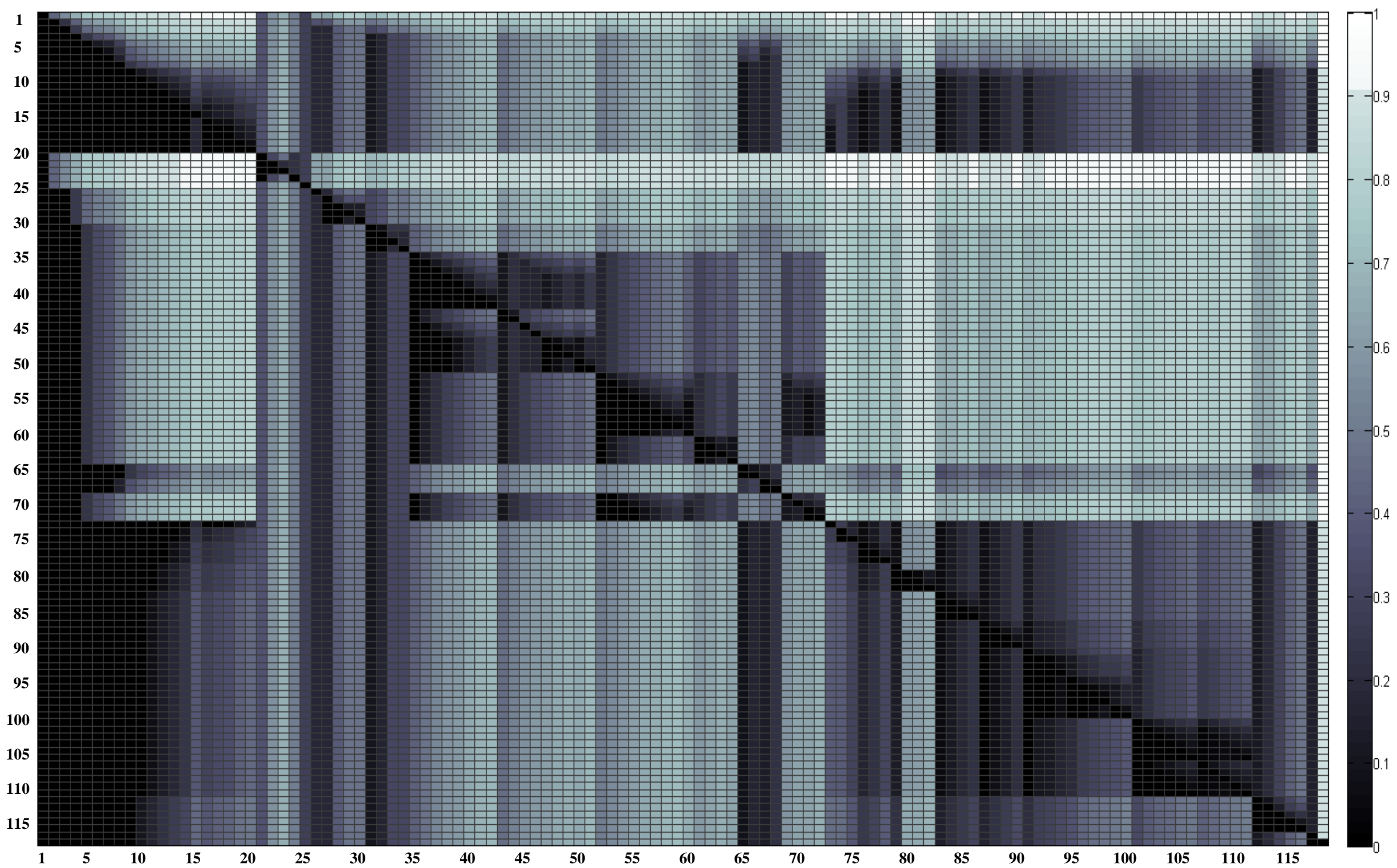


Figura 103 - MTDF (fase $A$ ) durante faltas FT aplicadas no SD IEEE 123-nós.

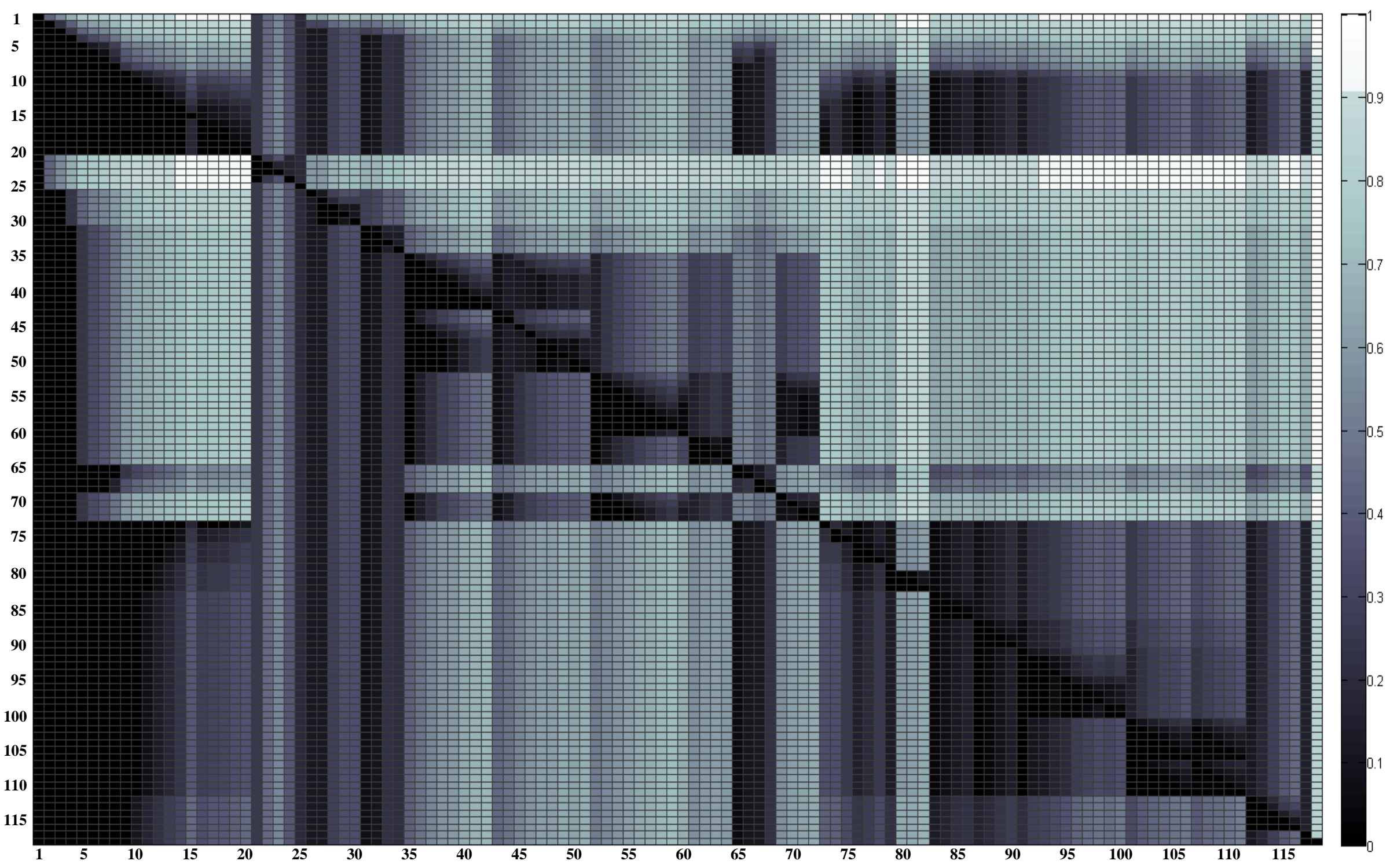


Figura 104 - MTDF (fase B) durante faltas FT aplicadas no SD IEEE 123-nós.

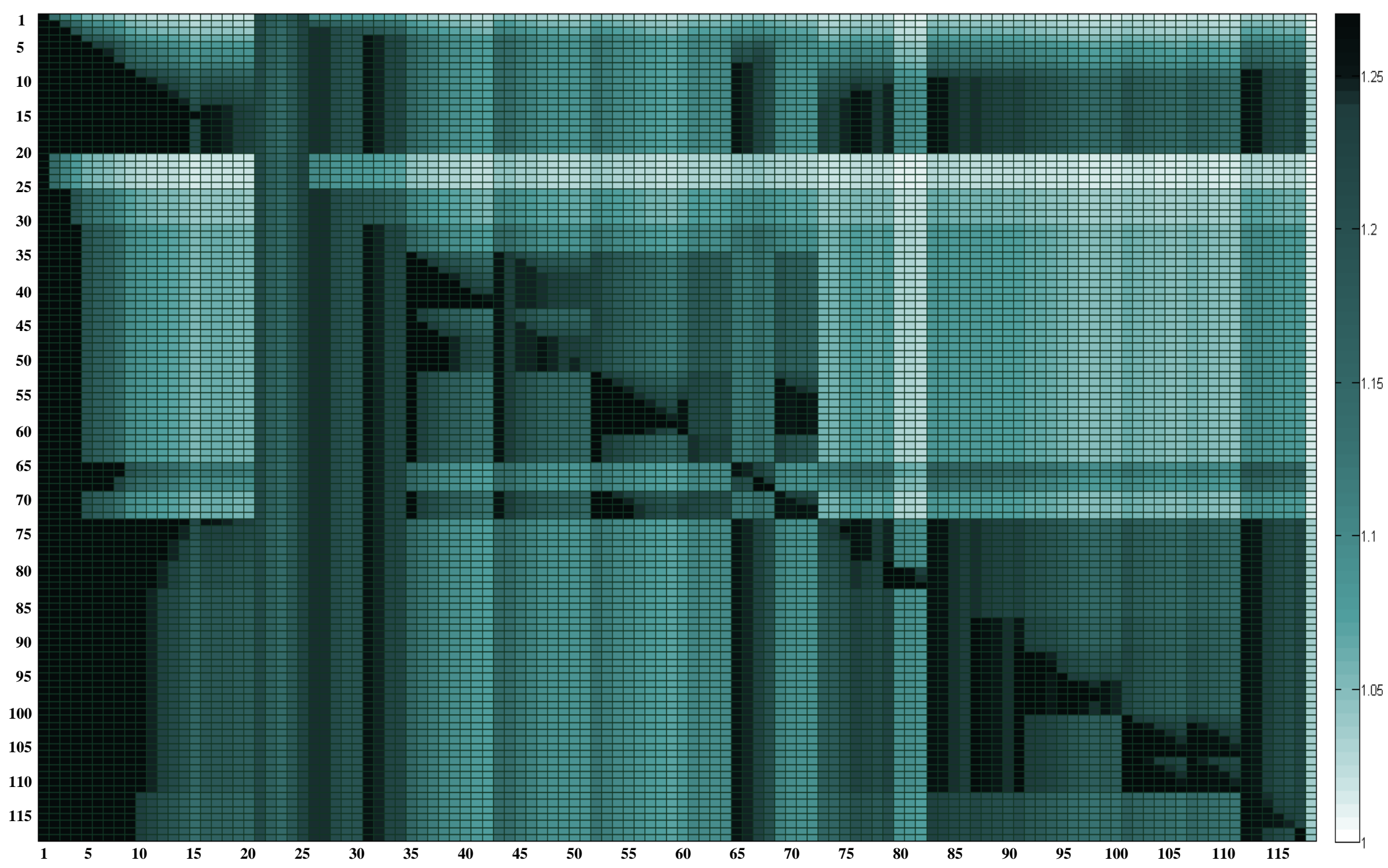


Figura 105 - MTDF (fase $C$ ) durante faltas FT aplicadas no SD IEEE 123-nós.

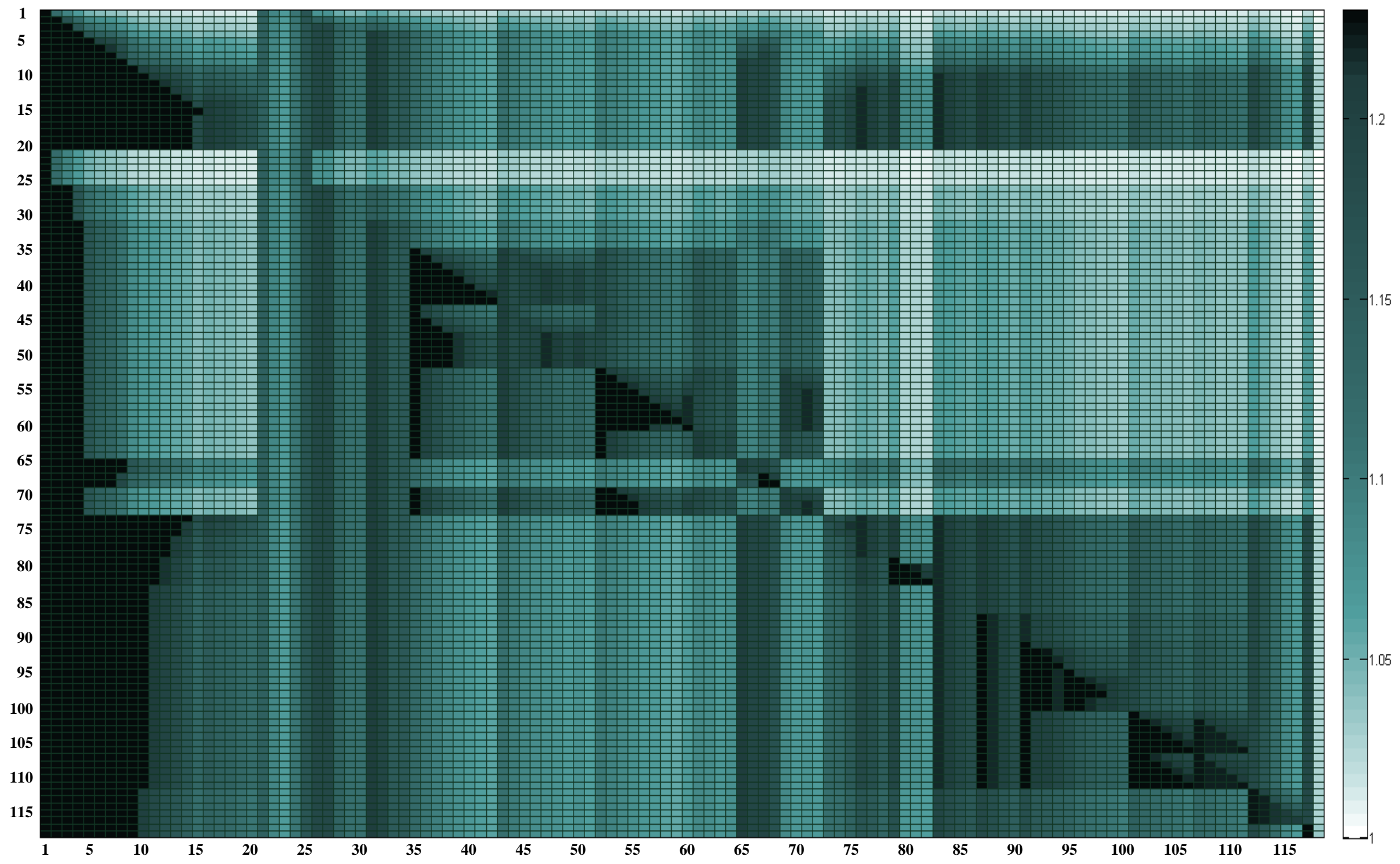


Figura 106 - MTDF (fase $B$ ) durante faltas FF aplicadas no SD IEEE 123-nós.

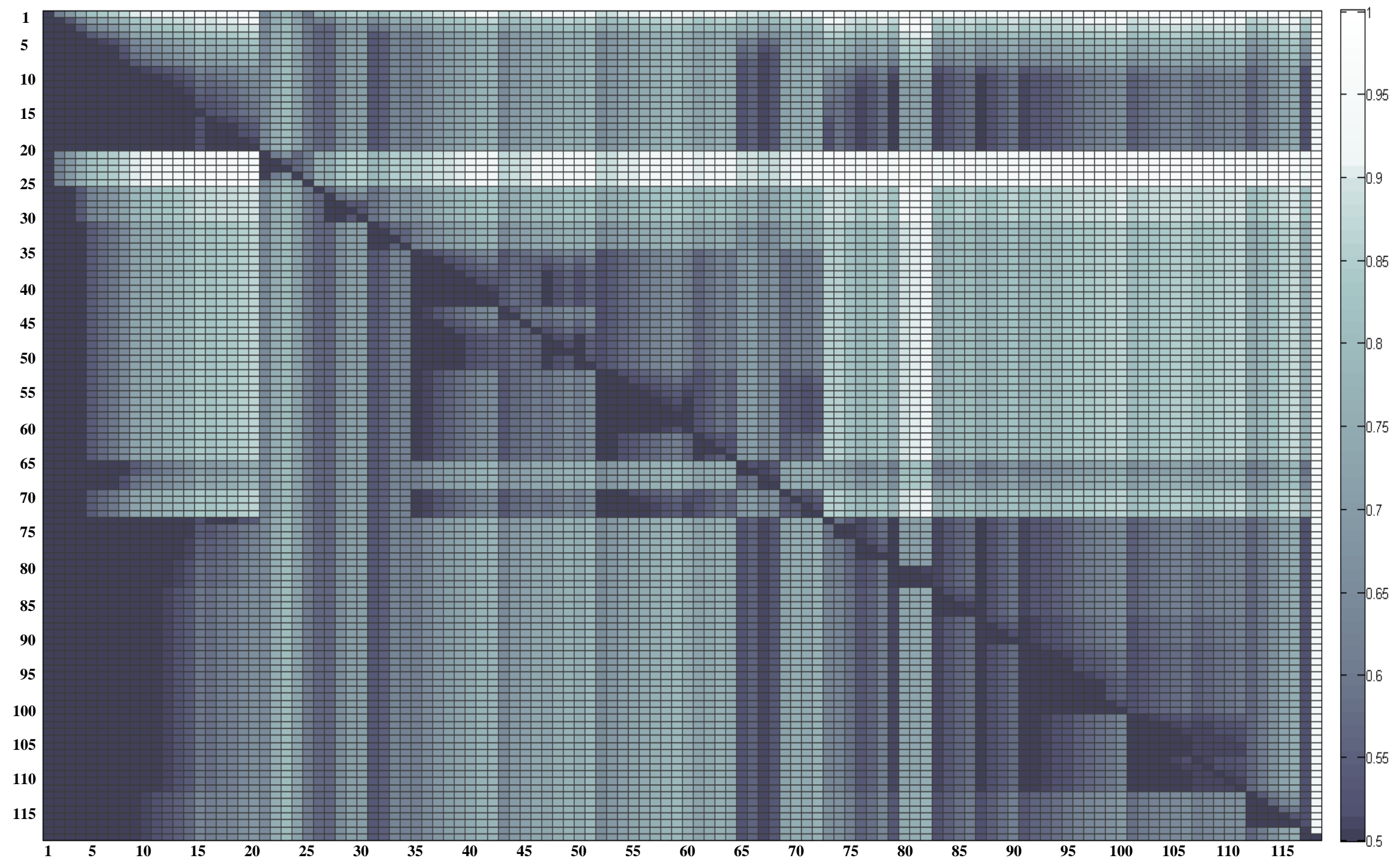


Figura 107 - MTDF (fase $C$ ) durante faltas FF aplicadas no SD IEEE 123-nós.

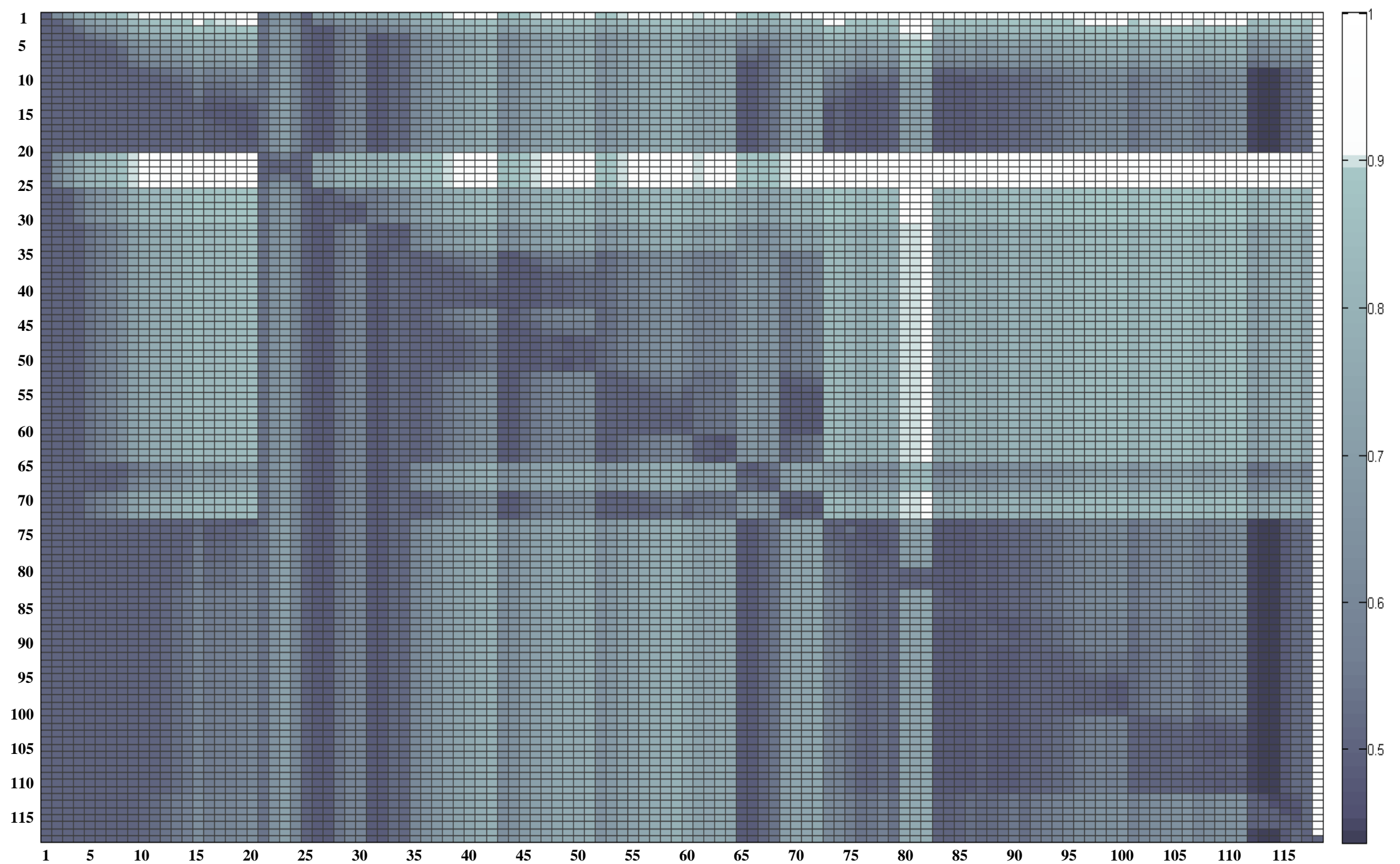


Figura 108 - MTDF (fase $A$ ) durante faltas FFT aplicadas no SD IEEE 123-nós.

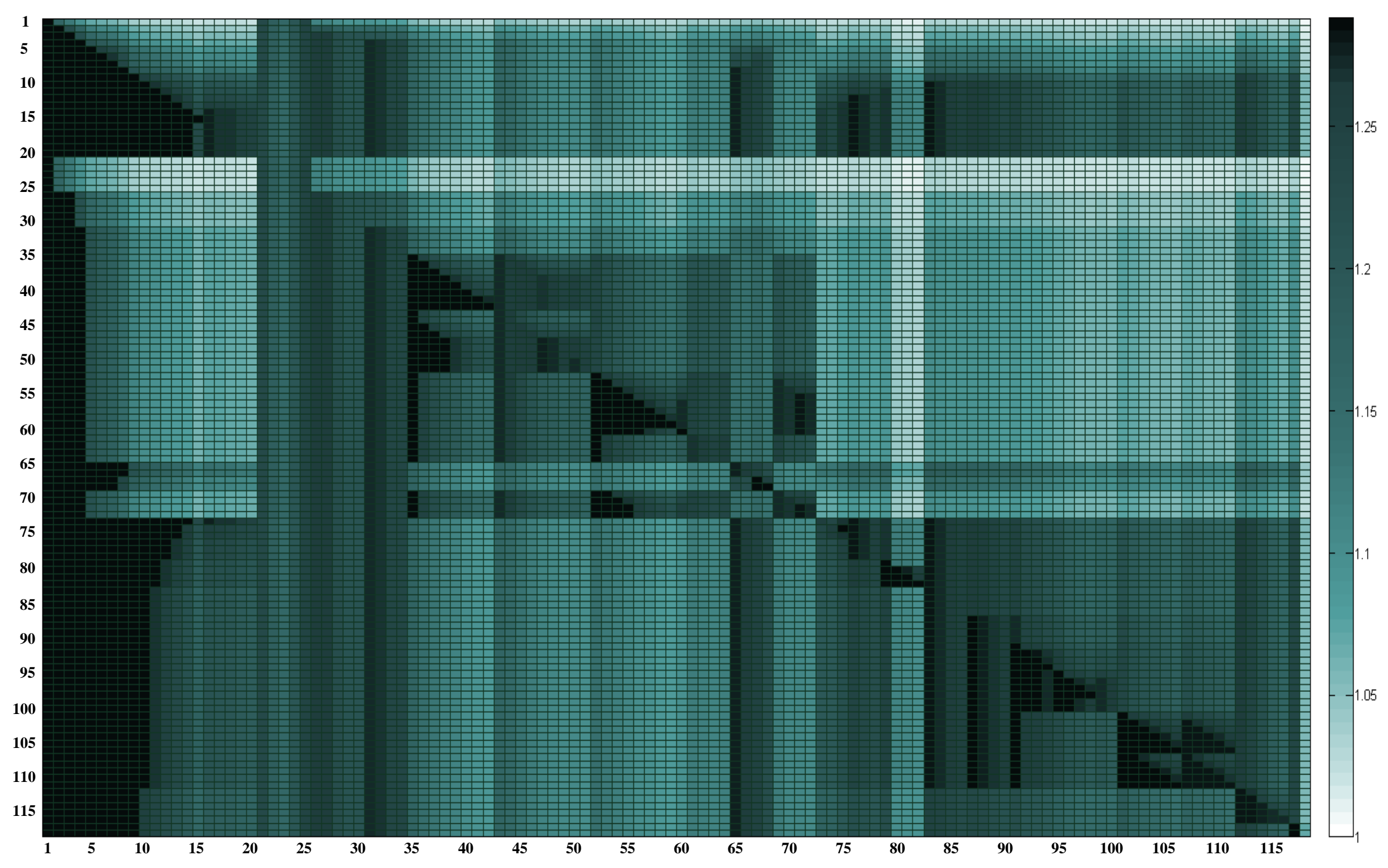


Figura 109 - MTDF (fase $B$ ) durante faltas FFT aplicadas no SD IEEE 123-nós.

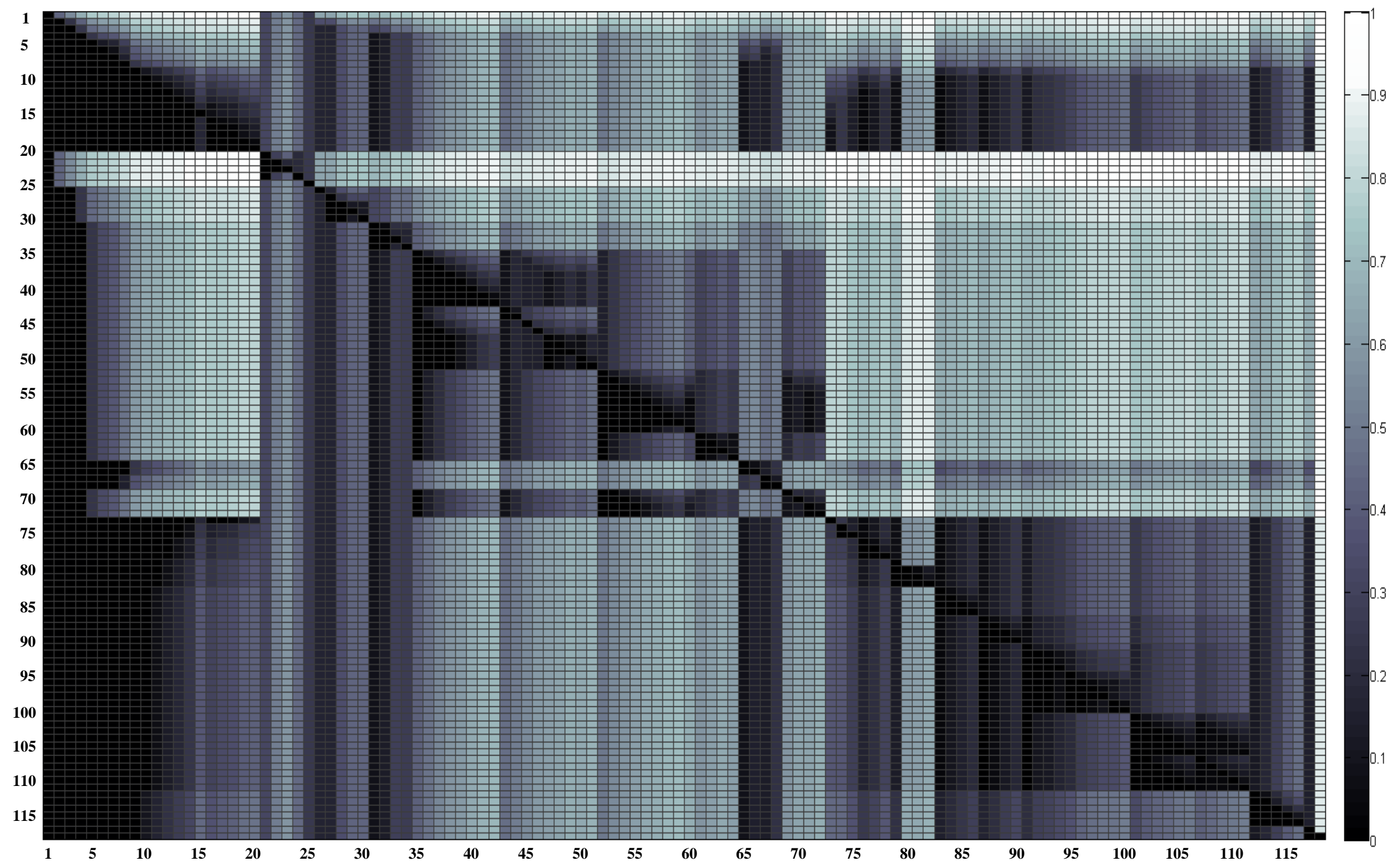


Figura 110 - MTDF (fase $C$ ) durante faltas FFT aplicadas no SD IEEE 123-nós.

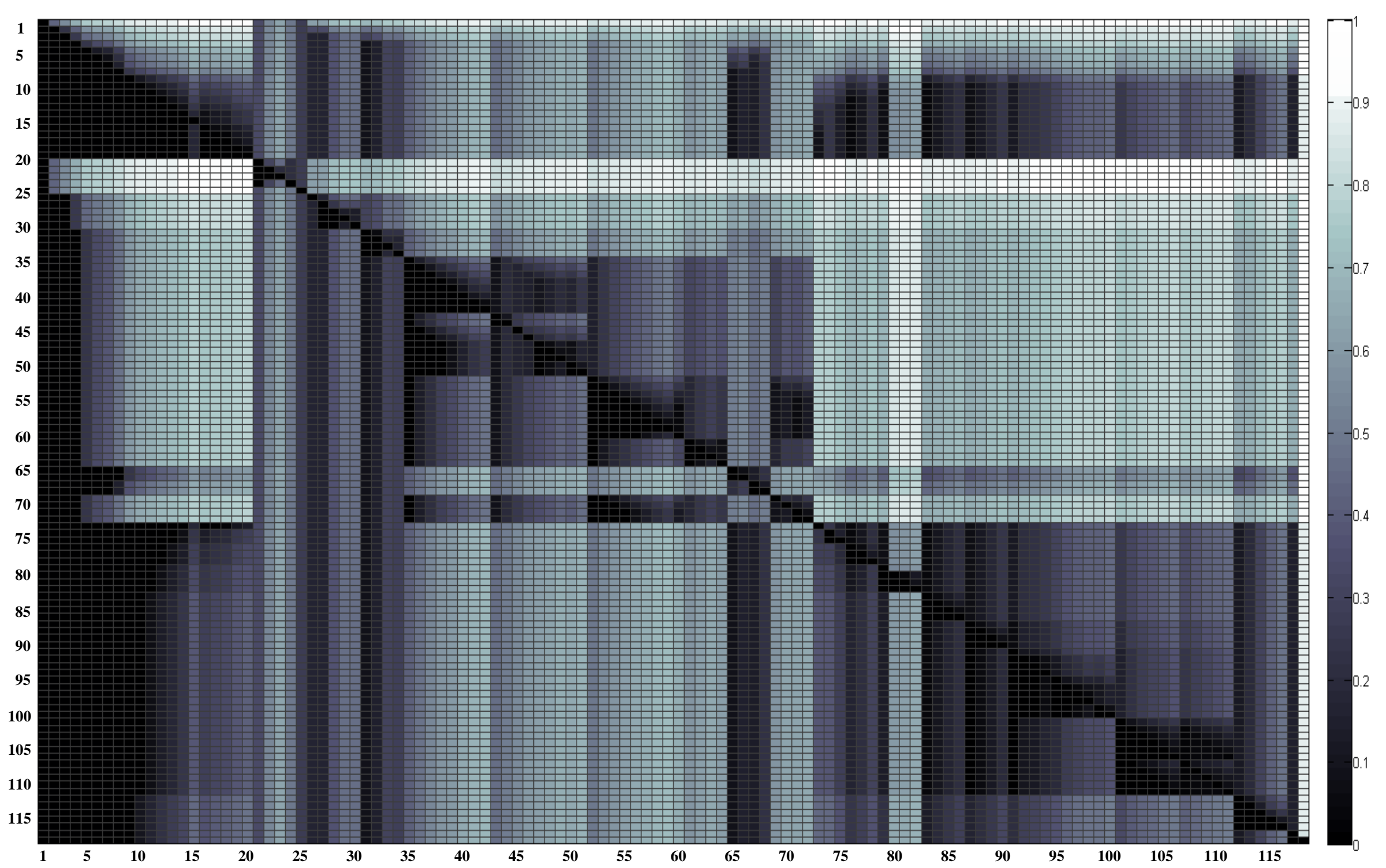

